\title{
ESTUDO DA INCORPORAC̄̃̃O DA ACESSIBILIDADE À ATIVIDADE NA ANÁLISE DA DEMANDA POR VIAGENS ENCADEADAS
}

\author{
Mateus Araújo e Silva
}

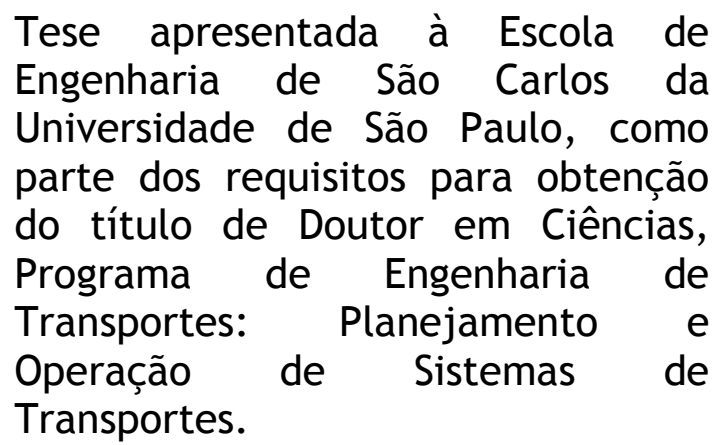

Orientador: Prof. Titular. Eiji Kawamoto

São Carlos

2011 
AUTORIZO A REPRODUÇÃO E DIVULGAÇÃO TOTAL OU PARCIAL DESTE TRABALHO, POR QUALQUER MEIO CONVENCIONAL OU ELETRÔNICO, PARA FINS DE ESTUDO E PESQUISA, DESDE QUE CITADA A FONTE.

Ficha catalográfica preparada pela Seção de Tratamento da Informação do Serviço de Biblioteca - EESC/USP

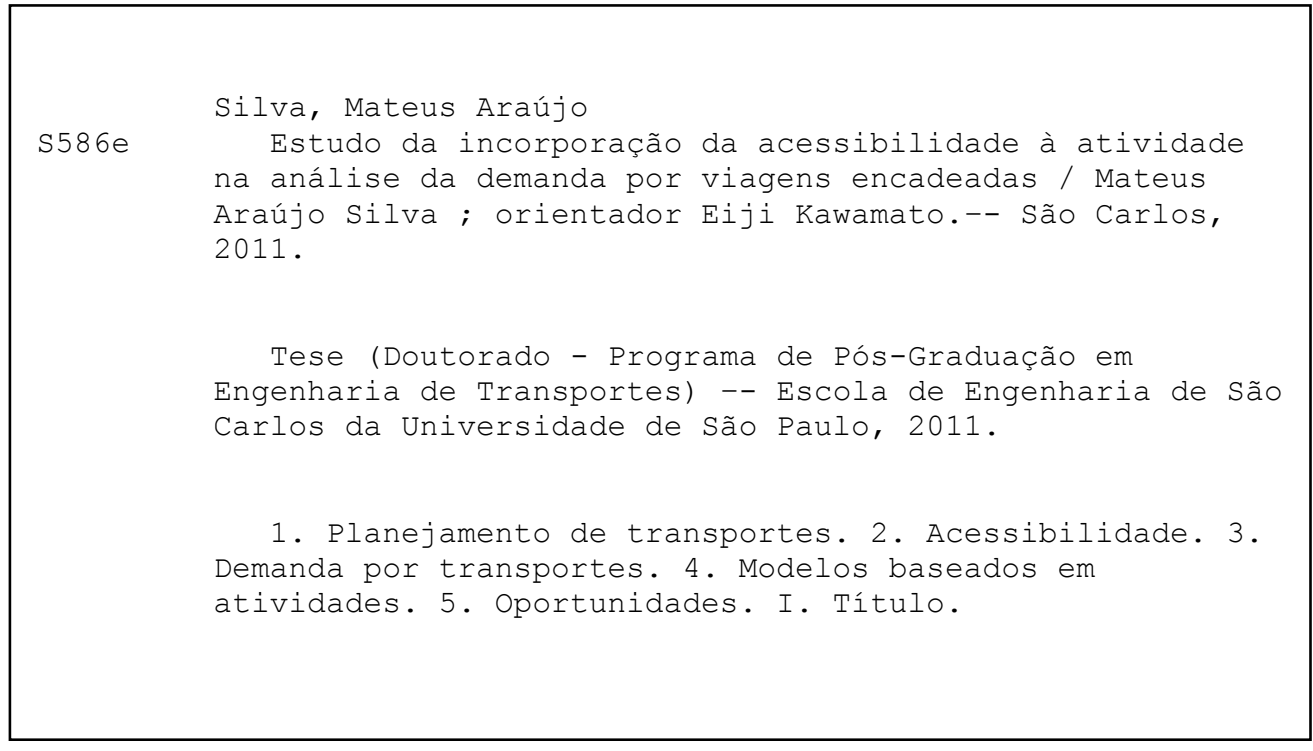




\section{FOLHA DE JULGAMENTO}

Candidato: Engenheiro MATEUS ARAÚJO E SILVA

Título da tese: "Estudo da incorporação da acessibilidade à atividade na análise da demanda por viagens encadeadas".

Data da defesa: $25 / 11 / 2011$ :

Comissão Julgadora:

Prof. Titular Eiji Kawamoto (Orientador)

(Escola de Engenharia de São Carlos/EESC)

Prof. Titular Antonio Clóvis Pinto Ferraz

(Escola de Engenharia de São Carlos/EESC)

Prof. Dr. José Aparecido Sorratini

(Universidade Federal de Uberlândia/UFU)

Prof ${ }^{a} \mathrm{r}^{\mathrm{a}}$. Suely da Penha Sanches

(Universidade Federal de São Carlos/UFSCar)

Prof. Dr. Pastor Willy Gonzales Taco

(Unibersidade de Brasília/UnB)

\section{Resultado:}

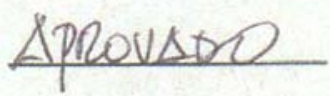

ATROVADO

Coordenador do Programa de Pós-Graduação em Engenharia de Transportes e Presidente da Comissão de Pós-Graduação:

Prof. Associado Paulo Cesar Lima Segantine 


\section{A Sofia, minha filha, a brisa que conduz a minha nau na imensidão azul.}

A minha esposa, Bruna, minha paixão linda.

Ao meu pai, Severiano, à minha mãe, Margarida, aos meus irmãos, Andréa, Rodrigo e Mariana, fontes de apoio incondicional e amor inesgotável.

Aos meus avós Firmino, Joana (in memorian), Severiano e Maria Amália (in memorian), exemplos de sabedoria, honestidade, luta, amor e sobretudo Fé.

O amor de vocês, minha família, é o maior bem que tenho na vida. 


\section{AGRADECIMENTOS ACKNOWLEDGMENTS}

A Universidade de São Paulo pelos sete anos de concessão de espaço físico, material e corpo docente para o desenvolvimento de meus estudos na Pós-Graduação.

Ao Governo Federal que, por intermédio do Conselho Nacional de Desenvolvimento Cientifico e Tecnológico - CNPq e da Coordenação de Aperfeiçoamento de Nível Superior CAPES, me laureou com bolsas de auxílio para desenvolvimento do Doutorado no Brasil e na Suiça.

Ao Governo do Estado de São Paulo que, por intermédio da Fundação de Amparo à Pesquisa do Estado de São Paulo, me laureou com bolsa de auxílio e recursos financeiros para o desenvolvimento do Doutorado.

A Universidade Federal de Uberlândia, especialmente ao Professor Carlos Faria pela concessão dos dados da Pesquisa Origem-Destino de Uberlândia do ano de 2002.

Ao Ministério da Educação e Ministério do Trabalho pela concessão dos dados sobre uso do solo da cidade de Uberlândia.

My special thanks go to Professor Kay W. Axhausen from the Swiss Federal Institute of Technology Zurcih - ETH, who provided his expertise and advice to my PhD Thesis. I was lucky enough to be part of his group at the IVT-ETH.

Special thanks go to Professor Jorgen Weibull from the Stockholm School of Economics, who provided two of his out-of print papers and for the pleasant meeting in Stockholm.

I am also in debt with Professor Bert van Wee from the Delft Technische Universitäte, Professor Kenneth Train from the University of California-Berkeley, Professor Laurence Lester from the Flinders University and Professor Michel Bierlaire from the École Polytechnique Fédérale de Lausanne.

Aos Professores: Edson Tadeu Bez da Universidade do Vale do Itajaí; Erivelton Guedes do Instituto de Pesquisas Econômicas Aplicadas; João Bosco Furtado Arruda da Universidade Federal do Ceará; e Orlando Strambi da Universidade de São Paulo, pelo auxílio na pesquisa.

A D. Soila Brilhante pelo apoio fundamental nesta pesquisa. 
Ao Senhor Neuton Karassawa pelas sugestões no início do desenvolvimento da pesquisa.

Aos funcionários da Universidade de São Paulo, em especial a Heloisa Morgado Belo (EESCSTT), Elizabeth Ortega (EESC-STT), Antônio Gigante (EESC-STT), Paulo Toyama (EESC-STT), Vicente Daló (EESC-STT), Beth Pilat (CCE) e Vagner Machado (CCE).

Ao Professor Antônio Ferraz, Antônio Nélson, Paulo Segantine e Ricardo Schaal da Universidade de São Paulo pelo apoio, conselhos e ensinamentos.

Ao Professor Wellington Correia de Figueiredo (in memorian) da Universidade Federal da Bahia pelos conselhos, ensinamentos na área de Engenharia de Transportes e amizade.

Ao amigo Antônio Carlos Dinato e sua família pela amizade e apoio ao longo deste trabalho.

Aos amigos Adalberto Faxina, Alex Suarez, Ana Furlan, Ana Larocca, Barbara Bezerra, Bruno Bertoncini, Cira Pitombo (Tutora!), Daniel Anijar, Danielle Andolfato, Carlos Prado, Cida Moraes, Dercio Terrabuio, Heliana Prado, Igor Baria, Jesner Ildefoson, Luis Miguel Klisky, Magaly Romão, Manuel Lucas, Marcus Seraphico, Mario Azevedo, Michael Saunders, Pablo Brilhante, Paulo Leite Filho, Peter Ebschner, Thaís Bocca e Vivian Bardini, pelo apoio.

My thanks go to my colleagues and workers from the Institut für Verkehrsplanung und Transportsysteme at the Swiss Federal Institute of Technology Zurich - ETH. Special thanks to Philipp Fröhlich, who provided his expertise and advice to my PhD Thesis.

Ao amigo Jorge Chueire (in memorian) pelo apoio e amizade.

To Rosemarie e Meinrad Lacher for your support and friendship!

Ao amigo de infância Antônio Quadros pelo apoio e amizade.

À Mazinha e lan Law pelo apoio e carinho.

Seu Faria, D. Nair, Júnior e Talita pelo apoio.

Aos demais amigos que sempre me acompanham meus sinceros agradecimentos! 
Não tenho nada a oferecer-vos senão sangue, trabalho, suor e lágrimas.

Winston Spencer Churchill

Londres

Casa dos Comuns

13 de maio de 1940 


\section{RESUMO}

SILVA, M. A. Estudo da incorporação da acessibilidade à atividade na análise da demanda por viagens encadeadas. 2011. 270 f. Tese (Doutorado) - Escola de Engenharia de São Carlos, Universidade de São Paulo, São Carlos, 2011.

O objetivo desta pesquisa é validar a hipótese de que a acessibilidade à oportunidades influencia o comportamento dos padrões de viagens desempenhados pelos indivíduos. Para realizar a verificação desta hipótese foi formulado um procedimento (um teste de hipótese) baseado em um estudo de caso realizado na cidade de Uberlândia, utilizando informações sobre: (i) as características dos deslocamentos dos indivíduos, suas características demográficas e de participação em atividades; (ii) informações sobre o sistema de transportes, e; (iii) informações sobre a distribuição espacial das atividades. Para atingir a finalidade proposta na tese, foram elaborados procedimentos que constituem no processo de verificação da hipótese nula, constituído pelas seguintes etapas: (i) tratamento dos dados; (ii) construção das variáveis (iii) proposta para avaliação da acessibilidade no contexto da formação dos padrões de viagens; (iv) escolha de técnicas de modelagem do comportamento individual referente às decisões sobre padrões de viagens; (v) seleção das técnicas estatísticas para avaliação da significância das variáveis e desempenho dos modelos; (vi) modelagem para simulação do comportamento individual em três níveis de decisão da programação diária de atividades, modo de viagem, destino da atividade primária e padrão de viagens, e; (vii) análise dos resultados obtidos e conclusão sobre a hipótese. Após a realização do experimento realizado com as informações da cidade de Uberlândia, concluiu-se que pela verificação realizada não há elementos para rejeitar a hipótese nula, ou seja, a acessibilidade a oportunidades influencia o comportamento dos padrões de viagens encadeadas desempenhados pelos indivíduos.

Palavras-chave: Planejamento de transportes. Acessibilidade. Demanda por transportes. Modelos baseados em atividades. Oportunidades. 


\begin{abstract}
SILVA, M. A. Incorporation of accessibility to opportunities on the activity-based travel demand analysis. 2011. $270 \mathrm{f}$. Thesis (Doctor's Dissertation) - Engineering School of São Carlos, University of São Paulo, São Carlos, 2006.

The main aim of this work is to submit to a validation test the hypothesis that the accessibility to opportunities influences individuals' trip chaining behavior. To perform the hypothesis test a procedure was developed on a study case in the city of Uberlandia, using data about: (i) characteristics of the individuals' trips, their demographic features and activity participation; (ii) transportation system information, and; (iii) information about the spatial distribution of activities. To achieve the purpose of the thesis, it was developed procedures which consist in the hypothesis test, made by the following stages: (i) data processing; (ii) setting of the variables; (iii) a proposal to evaluate the accessibility on the context of trip chaining patterns; (iv) choosing modeling techniques to represent individual behavior regarding to its decisions on trip chaining patterns; (v) selection of statistical techniques for measures of model and variable performance; (vi) modeling individual behavior on three decision levels of the daily activity schedule, mode choice, destination choice and trip chaining patterns, and; (vii) discussion of the results and conclusion about the hypothesis. The main conclusion is that the hypothesis cannot be rejected, i.e., accessibility to opportunities influences individuals' trip chaining behavior.
\end{abstract}

Keywords: Transportation Planning. Accessibility. Transportation Demand. Activity-based models. Opportunities. 


\section{SUMÁRIO}

Capítulo 1 - Introdução

1.0 Introdução

1.1 Abordagem de Atividades para Análise da Demanda por Viagens Urbanas

1.1.1 A Viagem é uma Demanda Derivada

1.1.2 A Cadeia de Viagens como Referencial para Análise

1.1.3 Restrições para Desempenho das Atividades

1.1.4 Ênfase no Domicilio como Unidade de Tomada de Decisão

1.1.5 Programação Diária de Atividades e Padrão de Viagens

1.2 Enfoque de Atividades e o Planejamento de Transportes

1.3 Contexto da Pesquisa: Incorporação da Acessibilidade à Atividade na Análise da Demanda por Viagens encadeadas

1.3.1 Acessibilidade

1.3.2 Relevância da Acessibilidade no Planejamento Urbano e de Transportes

1.3.3 Acessibilidade e o Comportamento Individual

1.3.4 Acessibilidade, Atividades e Análise da Demanda por Viagens Encadeadas

1.4 Ideia Diretriz

1.5 Justificativa

1.6 Síntese e Estrutura da Tese

Capítulo 2 - Revisão da Literatura

2.0 Introdução

2.1 Revisão das Medidas de Acessibilidade

2.2 Avaliação de Medidas de Acessibilidade em Estudos sobre Viagens Encadeadas

2.3 Seleção de Uma Medida de Acessibilidade

Capítulo 3 - Influência da Acessibilidade na Programação Diária de Atividades 
3.1.1 Definição do Estilo de Vida

3.1.2 Local do Domicilio $\quad 72$

3.1.3 Atividades Prioritárias $\quad 73$

3.1.4 Locais para Desempenho das Atividades Prioritárias 74

3.1.5 Locais Preferenciais para Desempenho de Outras Atividades 76

3.1.6 Alocação do Tempo: Duração da Atividade Prioritária e de Atividades Não 77 Prioritárias

3.1.7 Posse de Automóvel $\quad 79$

3.1.8 Definição das Atividades que serão Realizadas no Dia, Hierarquia entre as 81 Atividades e Sequência das Atividades

3.1.9 Restrições de Capacidade 83

3.1.10 Uso do Automóvel no Domicilio 83

3.2 Considerações Finais 86

Capítulo 4 - Delineamento do Método 91

4.1 Considerações Iniciais $\quad 91$

4.2 Tratamento dos Dados e Construção das Variáveis 95

4.2.1 Tratamento dos Dados 96

$\begin{array}{ll}\text { 4.2.2 Construção das Variáveis } & 104\end{array}$

4.3 Modelagem do Comportamento Individual $\quad 118$

$\begin{array}{ll}\text { 4.3.1 Modo de Viagem } & 121\end{array}$

$\begin{array}{ll}\text { 4.3.2 Destino da Atividade Primária } & 127\end{array}$

$\begin{array}{ll}\text { 4.3.3 Padrão de Atividades } & 143\end{array}$

4.4 Verificação da Hipótese Nula 150

4.4.1 Significância da Variável Medida de Acessibilidade nos Modelos 151

4.4.2 Verificação do Desempenho do Modelo 152

4.4.3 Verificação das Relações Encontradas no Modelo 152 
5.1 Considerações Iniciais

5.2 Município de Uberlândia

5.3.1 Base de Dados dos Indivíduos, Viagens e Atividades (Discretas e Encadeadas)

5.3.2 Base Espacial do Sistema de Transportes com a Distribuição das Atividades no Meio Urbano

5.4 Construção das Variáveis

5.4.1 Variáveis Independentes

5.4.2 Variáveis Dependentes

5.5 Considerações

5.5.1 Expansão dos Dados

5.5.2 Trabalho Informal

5.5.3 Georreferenciamento e Cálculo do Tempo de Viagem

Capítulo 6 - Resultados e Discussão

6.1 Considerações Iniciais

6.2 Modo de Viagem: Especificação do Modelo e Resultados

6.2.1 Modo de Viagem: Discussão dos Resultados

6.3 Destino da Atividade Primária: Especificação do Modelo e Resultados

6.3.1 Modelo de Oportunidades Intervenientes

6.3.2 Modelo de Oportunidades Intervenientes: Discussão dos Resultados

6.3.3 Modelo de Escolha Discreta

6.3.4 Modelo de Escolha Discreta: Discussão dos Resultados

6.3.5 Comparação entre o Modelo de Oportunidades e do Modelo de Escolha Discreta

6.4 Padrão de Viagens: Especificação do Modelo e Resultados 
7.1 Considerações Iniciais

7.2 Resultados Alcançados

7.3 Considerações sobre o Método Adotado

7.4 Caráter Científico do Trabalho

7.5 Recomendações a Trabalhos Futuros 


\section{Capítulo 1}

\section{Introdução}

[...] A principal característica da escrita científica é clareza. Um experimento científico de sucesso é o resultado de uma mente clara abordando um problema claro e produzindo conclusões claras. Idealmente, a clareza deve ser a característica de qualquer tipo de comunicação; no entanto, quando algo é dito pela primeira vez, a clareza é essencial [...]

Robert A. Day

\subsection{Introdução}

Este capítulo foi redigido com o proposito de:

- Delimitar e contextualizar o assunto abordado nesta tese;

- Identificar o problema central da tese e as razões de sua escolha;

- Propor uma (possível) solução para o problema, através da elaboração de uma hipótese;

- Apresentar a síntese do delineamento do experimento (teste de hipótese), e;

- Apresentar a estrutura dos capítulos que compõem esta tese.

Seguindo os propósitos mencionados, este capítulo inicia com a abordagem de viagens baseada em atividades para análise da demanda por viagens urbanas, descreve os 
seus fundamentos e destacando as vantagens de sua aplicação no planejamento de transportes.

O objetivo da seção sobre os fundamentos da abordagem de atividades é apresentar um texto sintético, uma vez que o propósito deste capítulo é introduzir elementos desta abordagem para a discussão de como relacionar a acessibilidade à análise das viagens encadeadas. Assim, a descrição dos princípios da abordagem para atividades apresentado na seção 1.2 é eminentemente teórica.

Dando continuidade ao processo de contextualização, na seção 1.3 é apresentado o estudo da acessibilidade dentro da abordagem de viagens baseada em atividades, sua importância no planejamento de transportes e no processo de investigação da demanda por transportes.

O propósito da seção 1.3 é discutir brevemente o conceito de acessibilidade, ressaltar a importância da acessibilidade dentro do planejamento de transportes, sua relevância dentro da análise de demanda por viagens encadeadas, e, principalmente, apresentar questões científicas pertinentes no estudo da acessibilidade e que serviram para o encadeamento lógico deste trabalho.

Baseado nas primeiras seções, na seção 1.4 é formalizado o problema central da tese, proposta uma solução através de uma hipótese (a acessibilidade a oportunidades influencia o comportamento dos padrões de viagens encadeadas desempenhados pelos indivíduos) e apresentado os objetivos (primários e secundários) deste trabalho. A hipótese é a estratégia utilizada nesta pesquisa para testar a condição de interferência entre a acessibilidade e o comportamento dos indivíduos referentes aos padrões de viagens.

Finalmente, na seção 1.5 é apresentada a justificativa desta pesquisa e na seção 1.6 é apresentada a síntese do experimento realizado para o teste de hipótese.

\subsection{Abordagem de Atividades para Análise da Demanda por Viagens Urbanas}

É crescente a discussão entre pesquisadores e planejadores em torno da abordagem de atividades para o estudo do comportamento de viagens urbanas (baseada no princípio de que a demanda por viagem é derivada da necessidade de participação em atividades fora do domicílio), em alternativa ao enfoque dado pelos modelos tradicionais de 
transportes ${ }^{1}$ que consideram as viagens discretas como objeto dentro da análise da demanda por transportes (SCHÖNFELDER; AXHAUSEN, 2009).

Esta abordagem tem conduzido ao que foi denominado por alguns pesquisadores, por exemplo, Kitamura (1997), Kuppam e Pendyala (2001), Pas (1997) e Jones et al. (1990), como uma mudança no paradigma nas pesquisas sobre comportamento dos viajantes, caracterizado pela mudança no foco da realização de viagens discretas para padrões de viagens encadeadas, dirigidas por decisões interdependentes, realizadas dentro do contexto domiciliar.

Ao relacionar estudos de demanda por viagens urbanas com o enfoque de atividades para análise do comportamento individual, podem ser citados como princípios da base teórica desta abordagem: (i) a viagem é uma demanda derivada; (ii) a cadeia de viagens como referencial para análise; (iii) restrições para desempenho das atividades; (iv) ênfase no domicílio como unidade de tomada de decisão; e; (v) programação diária de atividades e padrão de viagens.

\subsubsection{A viagem é uma Demanda Derivada}

A viagem é interpretada como uma demanda derivada de atividades realizadas fora do domicílio (BHAT; KOPPELMAN, 2000; ETTEMA, 1996; JONES et al., 1990). Apenas em raras circunstâncias a viagem é considerada como atividade principal (AXHAUSEN, 2000; MOKHTARIAN; SALOMON, 2001).

$\mathrm{Na}$ maioria dos casos a viagem não é uma demanda independente, ela advém da necessidade de participação em atividades que ocorrem em locais distintos. Como consequência as características das atividades influenciam o comportamento individual subjacente à viagem.

\subsubsection{A Cadeia de Viagens como Referencial para Análise}

Durante o processo de modelagem da demanda a cadeia de viagens é considerada como unidade básica da análise da demanda (DAVIDSON et al., 2007), ou seja, a viagem é considerada dentro do contexto do padrão de viagens que representa as decisões básicas da participação em atividades, suas prioridades e os locais de realização de cada atividade

\footnotetext{
${ }^{1}$ Um exemplo de modelo tradicional é o modelo de quatro etapas, compostos por quatro etapas distintas: 1) geração das viagens; 2) distribuição das viagens; 3) escolha modal; e 4) alocação das viagens (ORTÚZAR; WILLUMSEN, 2001).
} 
em uma configuração de viagens com episódios no domicílio, com implicância de interdependência entre eventos ao longo do dia.

\subsubsection{Restrições para Desempenho das Atividades}

São explicitamente consideradas nas análises e nos modelos informações sobre os indivíduos e o ambiente urbano, como: restrições temporais, espaciais, dependência de outros indivíduos para realização de atividades e capacidade de exercer as atividades (AXHAUSEN, 2000).

Atividades como compras, trabalho e estudo usualmente ocorrem em um número limitado de lugares que obedecem a um período de funcionamento. De outra forma, certas atividades, como compromissos sociais, submetem-se informalmente a um horário específico. Outras restrições são abordadas por Hägerstrand (1970):

- Restrições que dizem respeito à autoridade e que são institucionalmente impostas dentro de uma sociedade, como horário de funcionamento de serviços e regulamentações como restrições ao barulho;

- Restrição de dependência que é uma limitação imposta pela natureza ou pela tecnologia, e;

- Restrição de capacidade que significa que o indivíduo necessita da presença de outra pessoa ou algum outro recurso para conseguir realizar uma atividade.

Além disso, a necessidade de deslocamento para realização de várias atividades em locais distintos de acesso a serviços determina a quantidade necessária de viagens para ir a estes locais sob a imposição de outras restrições como disponibilidade de tempo, custo de viagem etc. Hägerstrand (1970) denomina esta restrição como prisma espaço-tempo. Pessoas se deslocam de um ponto a outro baseado na experiência do tempo e no custo que a pessoa percebe desse deslocamento.

A filosofia subjacente ao prisma espaço-tempo é a formação do conjunto de destinos que são acessíveis ao indivíduo através de uma estrutura prismática para representar o deslocamento associado a realização da atividade (graficamente expresso em duas dimensões) e o tempo disponível para realizar a viagem até o destino pelo sistema de transportes e exercer a atividade no destino (graficamente expresso na terceira dimensão). Na Figura 1.1 é apresentado um exemplo gráfico do prisma espaço-tempo. 
Outras restrições mencionadas na literatura referem-se as teorias subjacentes ao orçamento individual do tempo (ou uso do tempo) para programação das atividades e viagens (BHAT; KOPPELMAN, 1999).

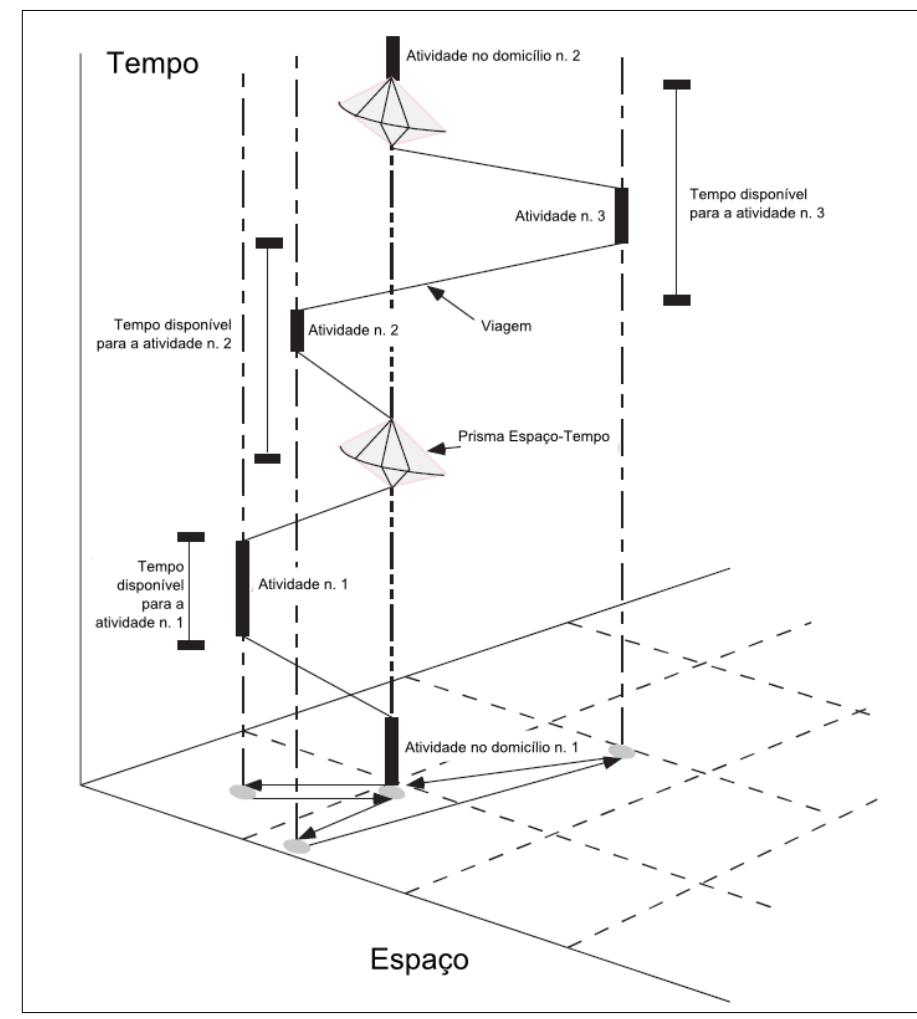

Figura 1.1 - Exemplo do padrão de atividades e cadeia de viagens de um indivíduo e o prisma espaço-tempo, adaptado de Hägerstrand (1970) e Recker, Chen, McNally (2001).

\subsection{4 Ênfase no Domicílio como Unidade de Tomada de Decisão}

As decisões individuais sobre as viagens são associadas ao contexto domiciliar, por exemplo, os papéis desempenhados no contexto familiar é uma variável descrita como relevante na análise de viagens baseadas em atividades (CHAPIN, 1974; TIMMERMANS; ZHANG, 2009);

O domicílio afeta as atividades do indivíduo e sua decisão de viagem. Normalmente, os indivíduos agem dentro de um contexto familiar, dividindo tarefas e compartilhando recursos com outros membros do domicílio. Algumas decisões tomadas no domicílio podem ser consideradas como uma unidade (a decisão do chefe de família pela participação em um curso de informática). 
A decisão de um indivíduo também pode ser influenciada pelos outros membros (a presença de crianças em idade de amamentação força a presença da mãe na residência). A composição do domicílio e a idade dos membros também afetam as decisões individuais e domiciliares. Estas condicionantes influenciam os padrões de atividades de cada indivíduo no domicílio.

\subsubsection{Programação Diária de Atividades e Padrão de Viagens}

A viagem deve ser considerada dentro do contexto do padrão de viagens que representa as decisões básicas da participação em atividades e suas prioridades e os locais de realização de cada atividade em uma configuração de viagens com episódios no domicílio, com implicância de interdependência entre eventos ao longo do dia. A abordagem de atividades considera viagens e atividades em uma sequência temporal, conforme esquema apresentado na Figura 1.2 (JONES et al., 1983).

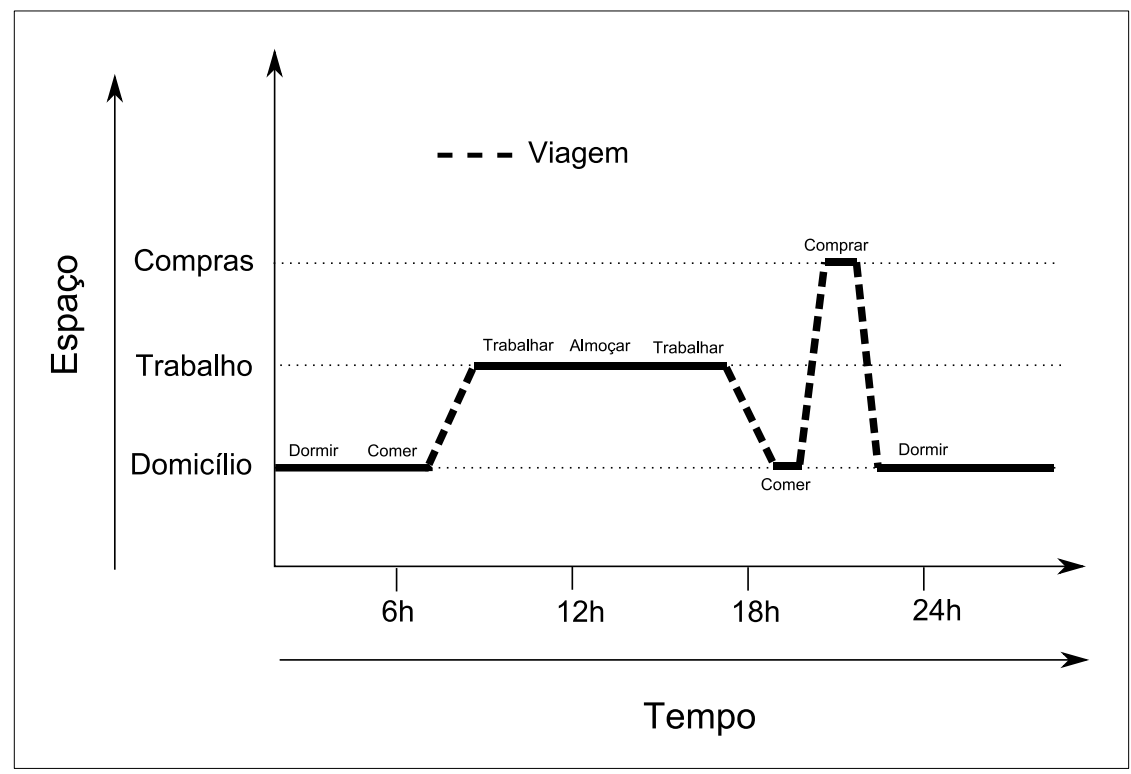

Figura 1.2 - Esquema da sequência de viagens e atividades, adaptado de Jones et al. (1983).

\subsection{Enfoque de Atividades e o Planejamento de Transportes}

Basicamente, o objetivo da aplicação do modelo de quatro etapas é a obtenção do contingente de viagens entre pares de origem e destino e como estes contingentes irão impactar na infraestrutura de transportes disponível. Segundo Owens (1995) e McNally e Rindt (2008), a filosofia de planejamento subjacente aos modelos de quatro etapas está associada à noção de prever e prover ${ }^{2}$, em que soluções para transportes são concentradas

\footnotetext{
${ }^{2}$ Refere-se a política para transportes em que as demandas são projetadas, igualadas com as necessidades de infraestrutura até o limite orçamentário dos poderes públicos. Esta filosofia tem na projeção dos volumes de
} 
na provisão da capacidade do sistema, ao invés de concentrar esforços no entendimento de como os indivíduos relacionam as suas decisões em relação às restrições do ambiente urbano.

Para Banister (2002), esta visão subestima os desafios enfrentados pelos planejadores que deve ser direcionado para melhoria da qualidade de vida dos indivíduos, em análises que incorporem a dinâmica entre transportes, comportamento individual e a distribuição das atividades no meio urbano, ao invés da preocupação com a oferta da capacidade do sistema.

Enquanto o ambiente institucional e recursos disponíveis deram suporte a prática de prever e prover, os modelos de quatro etapas eram ferramentas suficientes para análise da demanda. No entanto, mudanças quanto ao uso dos recursos públicos e a necessidade de implantação de uma agenda sustentável (durante a década de 1970, principalmente nos Estados Unidos da América) introduziram mudanças na política pública quanto ao planejamento urbano, abrindo espaço para emergência de novas abordagens para o tratamento da demanda por viagens.

Segundo McNally e Rindt (2008) teorias comportamentais, esquemas teóricos, métodos analíticos e estudos empíricos sobre o comportamento individual relacionado as viagens surgiram neste período envolvidos pelo ambiente de mudança no planejamento urbano.

$\mathrm{Na}$ busca por um tratamento mais próximo ao comportamento individual relacionada a transportes para análise da demanda por viagens, surge a proposta de investigação das viagens baseada na premissa que a demanda por viagens é derivada da necessidade de participação em atividades desempenhadas fora do domicílio. Apenas a atração da atividade no destino que gera a viagem, ou como descrito em Kanafani (1983, p. 1):

[...] a necessidade por transporte emerge da interação entre atividades econômicas e sociais difundidas no espaço. A diversidade destas atividades e a complexidade dos padrões de interação resultam em uma infinidade de determinantes para as necessidades de transporte. As razões para necessidades de deslocamentos das pessoas são infinitas; da indispensável busca por alimento e por agasalho ao exercício voluntário de deslocamento para lazer. Bens materiais são também transportados de um lugar a o outro por uma infinidade de motivos que emergem das necessidades de mercado $[\ldots]$.

tráfego sua principal razão (OWENS, 1995). Este modelo foi desenvolvido para avaliar o impacto de investimentos em infraestrutura de transportes para acomodar a demanda durante um período de rápido crescimento populacional e da atividade econômica do pós-guerra (MCNALLY; RINDT, 2008). 
As necessidades por atividades fora do domicílio, por sua vez, são ligadas a necessidades fisiológicas, culturais ou sociais dos indivíduos, que são traduzidas em uma série de atividades realizadas em horários e locais distintos.

A mudança de paradigma no âmbito da análise e modelagem de viagens levou à identificação de padrões comportamentais complexos, tornando a relação entre grupos de variáveis, formadas pelas: características individuais e dos domicílios; restrições espaciais; características das atividades (intensidade e distribuição no meio urbano) e; atributos do sistema de transportes com os padrões de viagens objetos de investigação da proposta de atividades para viagens urbanas.

Apesar dos ganhos da análise desagregada do comportamento individual relacionada a transportes efetuadas a partir dos modelos de atividades, em comparação aos modelos de quatro etapas, ainda há resistência por parte dos órgãos e profissionais de planejamento para aplicação dos modelos de atividades em termos práticos no planejamento de transportes (DAVIDSON et al., 2007).

A relativa complexidade dos modelos de atividades, maior demanda por dados, o tempo despendido para elaboração dos procedimentos para implementação do modelo e, consequentemente, o custo associado para o desenvolvimento do modelo de atividades em regiões metropolitanas (superior ao custo associado a um modelo de quatro etapas) são alvos de críticas com inúmeras questões a serem exploradas no contexto da análise de viagens baseada em atividades. (DAVIDSON et al., 2007).

De forma simples, estas questões podem ser relacionadas à teoria, ao processo de modelagem (algoritmo empregado na modelagem dos processos decisórios) e ao processo de coleta dos dados (detalhe das informações necessárias para o delineamento do modelo).

Apesar da relativa importância do processo de modelagem, coleta de dados para análise das viagens baseadas em atividades e a elaboração dos modelos, muito das considerações finais das pesquisas sobre abordagem de atividades são relacionadas ao campo teórico, podendo-se evidenciar como as mais importantes:

- A complexidade dos modelos de atividades e o grande número de interações entre as componentes do modelo tornam delicada a tarefa de análise de sensibilidade de fatores e de distinção entre um resultado ser referente ao comportamento ou a falha no processo de modelagem (DAVIDSON et al., 2007; SCHÖNFELDER; AXHAUSEN, 2009); 
- Falta de consenso entre os pesquisadores da área sobre os critérios empregados durante o processo de modelagem para obtenção de valores estatisticamente representativos para os parâmetros das variáveis que descrevem o comportamento individual relacionado aos padrões de viagens (COOL; MOONS; WETS, 2010; DAVIDSON et al., 2007);

- Investigação da interação entre membros dos domicílios nos níveis decisórios sobre a formação dos padrões de atividades e cadeias de viagens (ARENTZE; TIMMERMANS, 2009; FERDOUS et al., 2010);

- Dificuldade em reproduzir o verdadeiro conjunto de alternativas (por exemplo, alternativas de destinos de viagens) visíveis ao indivíduo durante o processo de modelagem das decisões relacionadas às viagens. (HANNES; JANSSENS, 2009);

- Programação diária das atividades e cadeias de viagens nos finais de semana (BULIUNG; ROORDA; REMMEL, 2008);

- Prazos em que as decisões ocorrem (curto, médio ou longo prazo) e seus reflexos no comportamento individual (ROORDA; RUIZ, 2008);

- Variabilidade do tempo de viagem e da duração das atividades (ETTEMA, TIMMERMANS, $2007^{3}$, ZHOU; GOLLEDGE, 2007);

- Percepção individual do tempo, viagem e duração da atividade, e custo, da viagem, e do benefício da atividade (DAVIDSON et al., 2007);

- Inclusão da competição pelas atividades entre indivíduos e competição das atividades pelos indivíduos (BERNARDIN; KOPPELMAN; BOYCE, 2009);

- Uso adequado de medidas de acessibilidade que represente (nos modelos de atividade) a facilidade de acesso dos indivíduos a locais para execução das atividades (BRADLEY; BOWMAN, 1998; DAVIDSON et al., 2007; DONG et al., 2006; GEURS; VAN WEE, 2004 ${ }^{4}$; HSU; HSIEH, 2004; RECKER; CHEN; MCNALLY, 2001; ANG, 1996);

\footnotetext{
${ }^{3}$ Acessibilidade associada a atividades.

${ }^{4}$ Trata-se de uma revisão das medidas de acessibilidade indicando que as futuras pesquisas devem incorporar a acessibilidade na análise de viagens urbanas com base nas atividades.
} 
Contudo, a abordagem de atividades para análise da demanda por viagens permite aos planejadores uma melhor compreensão de como os indivíduos relacionam as suas decisões em relação às suas características e restrições do ambiente urbano, gerando expectativas de que as medidas desenvolvidas sob esta abordagem tenham eficiência superior para melhoria da qualidade do sistema urbano e da vida da população em contraste as medidas elaboradas a partir da noção de prover e prever.

As principais vantagens do processo de modelagem da abordagem de atividades (em comparação ao modelo de quatro etapas) para planejamento de transportes são:

- Geração das viagens: geração dos padrões de atividades e cadeias de viagens, distinção entre atividades primárias e secundárias;

- Distribuição das viagens: escolha dos destinos das viagens por propósito, distinção entre viagens com origem domiciliar e não domiciliar aos destinos;

- Escolha modal: modelagem dos modos das cadeias de viagem simultaneamente ${ }^{5}$;

- Alocação: micro-simulação das cadeias de viagens individuais. Análise do impacto das condições do sistema de transportes (condições operacionais do sistema) na formação dos padrões de atividades e cadeias de viagens.

Sobre a aplicação dos modelos de atividades no planejamento de transportes, Davidson et al. (2007, p. 478) descreve assim:

[...] Os modelos de atividades são capazes de lidar com questões críticas do planejamento e políticas, por exemplo, implantação de estacionamentos, cobrança de pedágios, tarifação sobre congestionamento, análise de provisão de infraestruturas para transporte de massa, análise da qualidade do ar, simulação de cenários com diferentes conjunturas demográficas e simulação no longo prazo de cenários com diminuição da carga horária de trabalho. Estes modelos já demonstraram sua capacidade de lidar com questões críticas de planejamento como análise de equidade social em planos de longo prazo para transportes, apoiar decisões em estudos de viabilidade para melhorias em rodovias e no transporte coletivo e na elaboração de planos diretores. Os novos modelos são capazes de satisfazer as necessidades existentes para planejamento de transportes, para formulação de políticas públicas, superando as capacidades dos modelos de quatro etapas para esta funcionalidade [...].

\footnotetext{
${ }^{5}$ Há situações em que não há alteração do modo na cadeia de viagens, ou baixa frequência relativa de modos distintos na cadeia de viagens, Cirillo e Axhausen (2002). Para esta situação, o procedimento na abordagem de viagens baseada em atividades distingue do enfoque do modelo de quatro etapas pela natureza desagregada do processo de modelagem.
} 
Vários casos de sucesso de aplicação dos modelos de atividades são reportados na literatura, por exemplo, New York Best Practices Model (NYMTC, 2010; VOSHA; CHIAO, 2008), Portland METRO (BOWMAN, 1998), Stockholm Model (ALGERS et al., 1995), The San Francisco Chained Activity Modeling Process (SFCTA, 2010), demonstrando que o conceito de viagens baseadas em atividades pode ser utilizado em termos práticos no planejamento de transportes.

\subsection{Contexto da Pesquisa: Incorporação da Acessibilidade à Atividade na Análise da Demanda por Viagens Encadeadas}

O delineamento da confluência entre os temas acessibilidade, atividades e análise da demanda por viagens encadeadas é apresentado em três subseções. Na próxima subseção é realizada uma breve discussão sobre o conceito de acessibilidade, e em seguida é descrito a importância da acessibilidade dentro do planejamento urbano e de transportes.

$\mathrm{Na}$ subseção seguinte é descrito como a acessibilidade se relaciona com vários aspectos do comportamento humano para, finalmente, apresentar a confluência entre os temas acessibilidade, atividades e análise da demanda por viagens encadeadas.

\subsubsection{Acessibilidade}

Em função da disciplina em que o termo é aplicado, a acessibilidade pode ser definida de diversas formas ${ }^{6}$. Em estudos de transportes e planejamento urbano (incluindo estudos da geografia) o termo acessibilidade é empregado na explicação da variação espacial entre fenômenos, por exemplo, na geografia urbana, acessibilidade tem sido aplicada em análises de crescimento das cidades.

\footnotetext{
6 Segundo o Dicionário contemporâneo da língua portuguesa Caldas Aulete (AULETE; VALENTE, 2011) o termo acessibilidade significa:

1 Caráter ou condição daquilo ou daquele que é acessível;

2 Restr. Possibilidade de aproximação; característica de um local a que se pode chegar com maior ou menor facilidade: 0 porto de Santos tem/permite/dá boa acessibilidade aos navios cargueiros;

3 Caráter ou condição da pessoa com quem é fácil relacionar-se ou interagir, que é cooperativa ou atenciosa: político de boa acessibilidade;

4 Possibilidade ou facilidade de se obter, utilizar, adquirir: acessibilidade dos serviços públicos: acessibilidade dos resultados da pesquisa;

5 Qualidade de um texto, material informativo, programas e aplicativos de informática, obra artística etc. de ser, às vezes por meios especialmente desenvolvidos, acessível a qualquer pessoa, qualquer que seja sua capacitação, ou seja, mesmo para pessoas que tenham dificuldade ou impossibilidade de ver, locomover-se, ler ou interpretar textos, usar teclado ou mouse, falar ou compreender a língua na qual o material é expresso, poder usar mãos, olhos, ouvidos etc. (como na situação de estar conduzindo veículo, ou em ambientes escuros ou barulhentos), dispor de equipamento ou programas compatíveis etc.
} 
O conceito de acessibilidade tem sido encontrado com frequência em estudos relacionados a planejamento urbano e de transpores. Podem ser citadas como definições, por exemplo, acessibilidade definida por Hansen (1959) como o potencial de oportunidades para interação; acessibilidade definida como características inerentes, ou desvantagem, para se alcançar um destino (INGRAM, 1971), e; acessibilidade definida por Weibull (1980) como uma propriedade das configurações das oportunidades para interação espacial.

Os conceitos empregados para definição do termo acessibilidade, em geral, a descrevem de forma ampla, sem a menção do indivíduo ou grupo de indivíduos em sua definição. Sobre esta questão, uma abordagem diferenciada é proposta por Hanson (1995) que sugere a subdivisão do conceito da acessibilidade em função da forma como ela é estudada ${ }^{7}$ : acessibilidade de lugar (a facilidade com que certos lugares podem ser atingidos); e acessibilidade de pessoas (a facilidade com que uma pessoa ou grupo de pessoas podem atingir certos locais de atividades).

No planejamento urbano em função do escopo de estudo da acessibilidade é apropriado a distinção da acessibilidade em termos de lugar, por exemplo, quando o estudo da acessibilidade envolve análise da localização de residências, localização industrial e de negócios, e de pessoas, por exemplo, quando o estudo da acessibilidade envolve análise de equidade urbana: cidadãos de um determinado bairro têm acesso às oportunidades de emprego quanto os residentes de outros bairros?

No entanto, no contexto da análise da demanda por viagens, a acessibilidade de pessoas (a partir deste momento será mencionado apenas acessibilidade) é particularmente importante, uma vez que o indivíduo é o agente da viagem.

Neste contexto, a explicação da acessibilidade como variação espacial entre fenômenos pode ser interpretada com o potencial que um indivíduo, em um dado local, possui para tomar parte em uma atividade particular ou uma série de atividades utilizado o sistema de transportes, ou como descrito por Davidson (1995), traduzido por Raia Jr. (2000 p. 17):

[...] a facilidade com que cada pessoa, em um dado ponto, pode ter acesso, via sistema de transportes (qualquer que seja o modo ou subsistema de transporte), a todos os outros lugares em uma área definida, levando em consideração as variações de atratividade e o custo percebido para atingi-los $[\ldots]$

\footnotetext{
${ }^{7}$ Relação de consequência adicionada pelo autor deste trabalho.
} 
Extrapolando a semântica e sob a ótica em que está sendo apresentada, pode ser afirmado que acessibilidade está mais associada à busca de capacidade para atingir destinos desejados, do que propriamente pelo movimento em $\mathrm{si}^{8}$.

A acessibilidade torna possível o acesso dos indivíduos aos locais de empregos, lazer, estudo, equipamentos públicos etc. e é função tanto do uso do solo quanto das características do sistema de transportes (RAIA Jr. et al., 1997).

Dentro de um contexto amplo, acessibilidade se refere à facilidade de movimento entre lugares. Na medida em que o custo da viagem decresce (em termos de custo generalizado da viagem) entre dois locais, cresce a acessibilidade (desde que mantida constante a atratividade do local). A propensão de interação entre dois lugares cresce na medida em que o custo de movimentação entre eles diminui (desde que a oferta das atividades não seja superada pela demanda). Consequentemente, a estrutura e capacidade da rede de transportes afeta o nível de acessibilidade dentro de uma determinada área.

A acessibilidade também inclui o conceito de atratividade, ou seja, as oportunidades ou atratividades localizadas em um dado lugar. Assim, a facilidade de movimentação entre lugares, tanto quanto a atratividade desses lugares é relacionada na acessibilidade.

Segundo Raia Jr. (2000) o conceito básico subjacente na relação entre uso do solo e transportes é a acessibilidade. As características do sistema de transportes determinam a acessibilidade, ou a facilidade de deslocamento entre um lugar e outro. A acessibilidade, por sua vez, afeta a localização de atividades, consequentemente, a distribuição espacial das atividades. A distribuição das oportunidades afeta os padrões de atividades diárias, que, por outro lado, resultam em padrões de viagens. Os padrões individuais de viagens, quando agregados, geram carregamentos na rede de transportes que afetam o sistema de transportes.

Uma vez que foi elaborado um conjunto de ideais sobre a acessibilidade, o passo seguinte, seguindo o desenvolvimento lógico de estudos da área, é a fase de construção de um indicador para quantificar a acessibilidade, motivados por várias questões científicas, por exemplo:

- Como mensurar a acessibilidade?

\footnotetext{
${ }^{8}$ Esta é uma das razões que distingue o conceito de acessibilidade de mobilidade.
} 
- Se a acessibilidade é assumida como a facilidade com que cada pessoa, em um dado ponto, pode ter acesso as oportunidades, via sistema de transportes, levando em consideração as variações de atratividade e o custo percebido para atingi-los, quais dimensões do sistema de transportes devem ser envolvidos na mensuração da acessibilidade?

No Capítulo 2 são discutidos alguns indicadores de acessibilidade encontrados na literatura, bem como a apresentação de uma classificação baseada em como a acessibilidade considera a oportunidade.

\subsubsection{Relevância da Acessibilidade no Planejamento Urbano e de Transportes}

A vantagem de se incluir o conceito de acessibilidade no planejamento de transporte e uso do solo permite o reconhecimento da interação do sistema de transporte com o uso do solo. A acessibilidade considera o efeito da impedância de viagem na participação do indivíduo nas atividades, ao mesmo tempo em que considera que a viagem é uma demanda derivada da necessidade dos indivíduos de participação em atividades (JONES; 1981).

Considerando a dinâmica urbana com uma distribuição qualquer de domicílios e atividades qualquer com um sistema de transportes apresentado determinadas características, o nível de acessibilidade disponibilizado distribuição espacial das atividades e domicílio/sistema de transporte não somente afeta diretamente o acesso físico de pessoas às facilidades urbanas, portanto a qualidade de vida da população, mas também outros efeitos indiretos consideráveis (RAIA Jr., 2000).

No tocante à equidade social, Bosco (1995) menciona a desvantagem do acesso à locais de emprego por grupos de indivíduos de baixa renda em cidades de países em desenvolvimento. Estas desvantagens são causadas pelo custo da habitação nestas cidades em regiões onde ocorre a concentração de emprego na cidade, que leva grupos de indivíduos de baixa renda a habitarem em subúrbios com oferta e a qualidade do sistema de transportes inadequada.

Segundo Bosco (1995) a consequência destes fatores aos indivíduos de baixa renda e moradores do subúrbio é o elevado custo generalizado das viagens (custo monetário e tempo) aos locais de emprego, o que resulta em diversas implicações, por exemplo: (i) restrição a locais de empregos; (ii) comprometimento do orçamento doméstico; (iii) menor tempo para lazer e descanso durante os dias de trabalho, e; (iv) impossibilidade de participar em outras atividades (demanda reprimida). 
As condições de acessibilidade desfavoráveis para locais de trabalho para indivíduos de baixa renda em cidades de países em desenvolvimento são, provavelmente, uma consequiência de um processo histórico em que a dinâmica do desenvolvimento urbano foi/é moldada por especulações no mercado imobiliário, associadas a políticas públicas de planejmaneto urbano que não contemplaram a equidade social.

Neste contexto Farrington (2007) destaca a importância da acessibilidade na formulação de políticas públicas para melhoria de vida das classes de baixa renda: "a pobreza pode ser vista duplamente como um fator que contribui para níveis baixos de acessibilidade e como consequencia de um baixo acesso", Farrington (2007, p. 320).

Outra área de aplicação de estudos de acessibilidade é a provisão de serviços de utilidade pública, como hospitais, postos de saúde, parques e escolas. Estudos nesta linha de pesquisa avaliam se o acesso para um serviço social em particular é socialmente equânime ou discriminatório, e analisam as áreas em que o acesso a este serviço é deficitário.

Além dos temas mencionados, em estudos de planejamento urbano e de transportes são encontradas na análise da acessibilidade em: avaliação da estrutura urbana; localização residencial; localização industrial, comércio e negócios; valorização de imóveis; expansão de redes de transportes; investimentos em transportes etc. Estes temas ressaltam a importância da acessibilidade no planejamento urbano e de transportes.

\subsubsection{Acessibilidade e o Comportamento Individual}

Alguns estudos demonstram a influência da acessibilidade no comportamento individual, relacionados diretamente ou indiretamente às decisões sobre viagens. Segundo Jones (1981), a acessibilidade afeta as taxa de viagens, o comprimento das viagens, posse de automóvel e localização residencial. 


\section{$\underline{\text { Taxa de viagens }}$}

Em seu trabalho Jones (1981) ressalta que evidências na literatura sugerem que as taxas de viagens (taxas de viagens por modos e propósitos das viagens) sofrem variação devido à acessibilidade. Os trabalhos citados são:

- Organisation for Economic Co-operation and Development (1977): quando a acessibilidade para compras e negócio cresce, a taxa geral para essas atividades aumenta, número de viagens a pé aumenta, o número de viagens por transporte público cai e o número de viagens por automóvel inicialmente cresce para depois declinar para o nível original;

- Doubleday (1981): número de viagens de mulheres com motivos de trabalho e compras cresceu na medida em que a acessibilidade para essas atividades também aumentou;

- Koenig (1978): correlação entre taxas de viagens com propósitos distintos de trabalho de pessoas não empregadas e suas acessibilidades com centros de comércio e serviços;

- Vickerman (1974): a acessibilidade para facilidades de compras e lazer afeta o número de viagens feitas para essas intenções, e;

- Hillman e Whalley (1977): a frequência no uso de facilidades de esportes diminui rapidamente com a distância e as distâncias percorridas pelos usuários de facilidades de esportes dependem das características dos usuários (idade, automóvel e modo utilizado).

\section{Comprimento das viagens}

Em uma pesquisa realizada na Austrália, Black (1976) concluiu que para propósitos distintos de trabalho (escola, compras, lazer, saúde, etc.), os indivíduos tendem a realizar mais viagens e próximas a seus domicílios, quando a sua acessibilidade aumenta. Para as viagens com propósito trabalho a dinâmica difere, mas a acessibilidade interfere no comprimento das viagens para a escolha dos locais de trabalho (próximos a residência).

\section{Posse de automóvel}

Dunphy (1973) encontrou correlação entre acessibilidade para emprego por transporte público e número de pessoas que tem carro próprio. Shindler e Ferrari (1967) obtiveram uma correlação entre propriedade de automóveis e a relação acessibilidade de emprego por transporte público e acessibilidade de emprego por transporte privado. Bates 
et al. (1978) desenvolveu um modelo para previsão de posse de automóvel em que acessibilidade a empregos foi uma das variáveis explicativas.

\section{Localização residencial}

Segundo Jones (1981), há uma tendência de atribuir um peso relevante a acessibilidade ao local de trabalho ou ao centro da cidade na escolha da localização residencial. Ainda segundo este autor, a acessibilidade influencia de forma diferenciada em função da renda: indivíduos de renda alta são propensos a realizar compensações de bons níveis de acessibilidade em troca de outros fatores para escolha do local da residência, por exemplo, redução de poluição sonora (CATANESE, 1971; STEGMAN, 1969).

\subsubsection{Acessibilidade, Atividades e Análise da Demanda por Viagens Encadeadas}

Um pressuposto básico na modelagem da geração das cadeias de viagens na abordagem de atividades é a demanda por viagens ser derivada da demanda por atividades fora do domicílio, ou seja, a necessidade por atividades gera demandas por viagens.

Sob este enfoque é aceitável propor que a taxa de produção das viagens é relacionada com a intensidade da necessidade por atividades (sujeita a um amplo conjunto de fatores), pela intensidade das atividades (oferta), distribuição espacial das atividades e como os indivíduos percebem, a partir do domicílio, a facilidade de acesso a destinos potenciais para engajamento nas atividades.

Particularmente, quanto a facilidade de acesso, ou acessibilidade, vários estudos na análise de demanda por atividades já apresentaram evidências de sua influência na elasticidade da demanda (KIM; THILL, 2005).

Em políticas públicas é comum o uso da taxa de geração de viagens para avaliação das medidas a serem tomadas, pela possibilidade de capturar a percepção da coletividade (ou pelo menos dos usuários do sistema de transportes) a variações no custo generalizado da viagem (GOODWIN, 1992).

Como o custo generalizado é formando pelo custo da oportunidade do tempo (e/ou distância, primeiras aproximações de medidas de acessibilidade) e o gasto monetário para realização da viagem, as características do sistema de transportes (não somente aqueles relacionados ao custo monetário) tem o potencial de influenciar nas taxas de geração das viagens. 
Assim, em locais onde o aumento da acessibilidade é promovido (por exemplo, redução do tempo de viagem) a expectativa é que um maior número de atividades seja programado e cadeias com maior número de viagens (indução da demanda) e/ou viagens com trechos mais longos em distância sejam realizadas.

No sentido inverso, quando há redução da acessibilidade (por exemplo, aumento do tempo de viagem) as viagens vão demandar um maior consumo do tempo na programação diária dos indivíduos e a expectativa é uma redução da participação em atividades e viagens na programação diária de atividades.

Por causa da elasticidade e da indução da demanda, a variação no custo generalizado do sistema de transportes implica em variação na propensão em realização de viagens a destinos potenciais para engajamento em atividades.

Segundo Neuberger (1971), Thill e Kim (2005) e Williams (1976) estudos na área de teoria econômica já concluíram que a acessibilidade influencia a propensão dos indivíduos no engajamento de atividades, consequentemente, na realização de viagens encadeadas. Ainda segundo os autores a acessibilidade é crucial na modelagem da demanda por transportes.

Foi a proposta do prisma espaço-tempo de Hägerstrand (1970), um dos princípios da abordagem de atividades para investigação das viagens urbanas, que ofereceu o potencial necessário para a integração entre modelos de demanda por viagens baseadas em atividades e a acessibilidade, associando componentes espaciais e temporais (restrições) nas decisões individuais referentes a formação dos padrões de atividades e cadeias de viagens.

Adaptações e aplicações da teoria de espaço-tempo no desenvolvimento de modelos de atividades associados a medidas de acessibilidade são apresentados, por exemplo, Ettema e Timmermans (2007), Kwan (1998, 2008), Miller (1999), e Recker, Chen e McNally (2001).

Alternativas para incorporação da acessibilidade as atividades no meio urbano no processo de modelagem de viagens urbanas baseadas em atividades vem sendo exploradas, a exemplo, das propostas de Bradley e Bowman (1999) e Dong et al. (2006), que integram conceitos da abordagem microeconômica proposta para a medida da acessibilidade (BEMAKIVA; LERMAN, 1979) à estrutura de modelagem das viagens urbanas baseadas em atividades. 


\subsection{Ideia Diretriz}

Segundo Beaud (1996), a ideia diretriz deve responder aos problemas propostos e subentender o conjunto do movimento do projeto. 0 problema proposto no trabalho é:

- Como a acessibilidade a oportunidades influencia o comportamento relacionado às viagens encadeadas?

Para responder a este problema, formula-se a hipótese nula que será submetida a um teste de verificação para confirmá-la ou refutá-la:

- Acessibilidade a oportunidades influencia o comportamento dos padrões de viagens encadeadas desempenhados pelos indivíduos.

Desta forma, ficam caracterizados os objetivos do trabalho. 0 objetivo primário desta pesquisa é:

- Investigar como a acessibilidade influencia o acesso das pessoas na realização de atividades fora do domicílio, afetando assim a forma como os indivíduos programam suas atividades e o comportamento dos padrões de encadeamento de viagens no meio urbano.

Os objetivos secundários, não menos importante, são:

- Selecionar uma medida de acessibilidade que reflita a facilidade de acesso do sistema de transportes a destinos potenciais para realização de atividades;

- Propor uma estrutura para representação das decisões individuais relacionadas a programação diária de atividade e dentro desta estrutura desenvolver uma proposta para análise da acessibilidade nas decisões sobre a programação diária de atividades;

- Elaborar um conjunto de variáveis a ser utilizado na análise da demanda por viagens encadeadas e que represente informações sobre características socioeconômicas dos indivíduos; dos domicílios; participações individuais em atividades realizadas fora do domicílio; intensidade e distribuição geográficas das atividades no meio urbano; características dos padrões de mobilidade, e; características de acesso da população às atividades; 
- Propor um processo para modelagem do comportamento individual relacionado às decisões na programação diária de atividades para interação entre variáveis independentes que representam as decisões na programação e variáveis independentes que representam os atributos considerados na formação das decisões, incluindo a acessibilidade;

- Testar a significância das variáveis propostas e o desempenho dos modelos, e;

- Elaborar a conclusão sobre a hipótese nula.

\subsection{Justificativa}

Parte das atividades que indivíduos desempenham durante o dia são realizadas fora do domicilio, levando a uma sequência de atividades programadas fora do domicílio, ou seja, uma cadeia de viagens.

O estudo desta cadeia de viagens, do ponto de vista analítico, é uma mudança no foco de entendimento da realização de viagens discretas para padrões de viagens encadeadas, dirigidas por decisões interdependentes, realizadas dentro do contexto domiciliar.

A natureza da abordagem de viagens encadeadas implica em maiores exigências em termos de dados e maior complexidade na análise. As vantagens oferecidas, em particular a habilidade de superar as limitações dos modelos convencionais, são de grande importância para o planejamento de transportes, prevalecendo sobre as desvantagens.

O estudo do comportamento relacionado a viagens em termos de cadeias de viagens depende, dentre uma série de fatores, das características da zona da residência, das distintas origens e destinos da cadeia de viagens e da maneira que são proporcionados os meios para o deslocamento.

Desta forma, o comportamento de viagem pode ser determinado não apenas por localizações residenciais, mas também através da localização dos centros de atividades e das características do sistema de transportes, que é uma forma de promover a acessibilidade a estas atividades. 
A análise do encadeamento de viagens possibilita uma melhor compreensão da diversidade de padrões de atividades e viagens realizados pelos indivíduos. A inclusão de variáveis relacionadas à acessibilidade vem enriquecer a análise, baseando-se no fato de que as viagens realizadas pelos indivíduos são afetadas pelos acessos as atividades.

Assim, este trabalho busca maior fundamentação no que se refere à investigação da escolha de padrões de viagens ao considerar a programação diária dos indivíduos em termos de necessidades, características individuais, das vizinhanças, sequência de deslocamentos, distribuição das atividades e características do sistema de transportes.

A principal justificativa deste trabalho seria aprimorar este tipo de estudo, que remanesce atualmente no campo investigativo e exploratório, para que futuramente possam ser utilizados modelos mais precisos que representem adequadamente a forma como os indivíduos se comportam e organizam seus respectivos itinerários de viagens.

Ressalta-se que este trabalho é mais um estudo, de uma série iniciada em 2000, pertencente à linha de pesquisa na Escola de Engenharia de São Carlos (EESC) da Universidade de São Paulo (USP) que tem por base o desenvolvimento de pesquisas com contribuições ao entendimento da demanda por viagens urbanas.

Juntamente com os trabalhos de Ichikawa (2002), Ichikawa et al (2002), Pitombo (2003), Sousa (2004), Pitombo et al (2004), Aguiar (2005), Pitombo e Kawamoto (2005), Silva (2006), Pitombo e Kawamoto (2006), Silva e Kawamoto (2006) e Pitombo (2007) este trabalho integra a linha de pesquisa da EESC-USP que propõe a abordagem de atividades para o estudo do comportamento de viagens urbanas.

A incorporação de características do sistema de transportes por meio de indicadores individuais de acessibilidade, na análise das relações entre variáveis independentes e padrões de viagens, integra o objetivo atual da linha de pesquisa, que é analisar a influência das condições socioeconômicas dos viajantes, do uso e ocupação do solo e do sistema de transportes no comportamento individual referente ao encadeamento de viagens. 


\subsection{Síntese e Estrutura da Tese}

O objetivo global desta tese é avaliar como a acessibilidade influencia o acesso das pessoas na realização de atividades fora do domicílio, afetando assim a forma como os indivíduos programam suas atividades e o comportamento dos padrões de encadeamento de viagens no meio urbano.

Para atingir esta finalidade, é proposto o esquema da Figura 1.3 para desenvolvimento da tese. A primeira etapa consiste na motivação para realização da pesquisa: contexto da pesquisa, definição do problema central da tese, ideia diretriz, justificativa para realização do estudo e estrutura para desenvolvimento do estudo. Esta etapa é estruturada neste capítulo.

A segunda etapa do trabalho, apresentada nos Capítulo 2 e Capítulo 3, corresponde à elaboração do corpo conceitual do desenvolvimento da tese, com uma revisão sobre as propostas para medidas de acessibilidade e a apresentação do desenvolvimento da ideia para incorporação da acessibilidade ao estudo do comportamento dos indivíduos, relacionada aos padrões viagens.

No Capítulo 4 é apresentado o delineamento das etapas que constituem o processo de verificação da hipótese nula, com o tratamento dos dados, construção das variáveis e escolha das técnicas de modelagem do comportamento individual referente às decisões sobre padrões de atividades e de viagens e seleção das técnicas estatísticas para avaliação da significância das variáveis e desempenho dos modelos.

No Capítulo 5 é apresentada a etapa de preparação do experimento, com descrição da cidade estudo de caso. Para realização do experimento foi selecionada a cidade de Uberlândia, em função das características da cidade e da factibilidade deste experimento a partir das informações disponíveis.

A aplicação do experimento é apresentada no Capítulo 6 com a apresentação dos resultados obtidos através dos modelos propostos associados e sua discussão com a conclusão sobre a hipótese nula. As considerações sobre os procedimentos desenvolvidos e recomendações para os trabalhos futuros são apresentadas no Capítulo 7. 
Capítulo 1 - Introdução

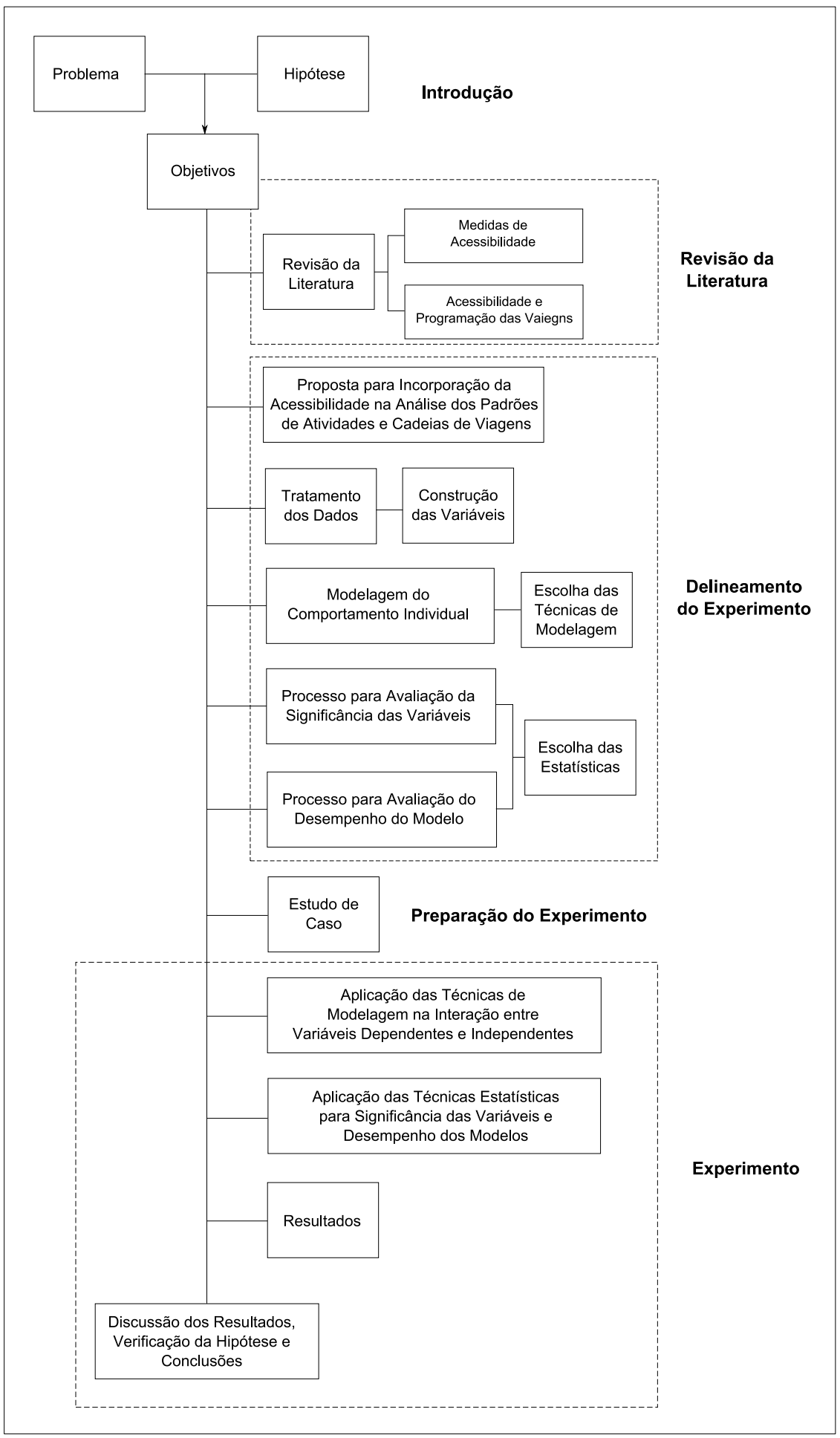

Figura 1.3 - Fases de desenvolvimento da tese. 


\section{Capítulo 2}

\section{Revisão da Literatura}

[...] A referência é uma forma de o leitor conseguir a prova factual do que se está falando no texto lido. Com ela, o leitor pode obter o texto referido e avaliá-lo, para conferir se concorda com esse texto. Afinal, ele foi citado para fundamentar alguma coisa importante. [...]

Gilson Volpato

\subsection{Introdução}

Com o propósito de dar continuidade ao contexto teórico deste trabalho, iniciado no capítulo anterior, e baseado em um dos objetivos secundários de selecionar uma medida de acessibilidade este capítulo apresenta:

- Uma revisão das principais medidas de acessibilidade com discussão das vantagens e desvantagens de sua utilização (seção 2.1);

- Uma revisão de como a acessibilidade foi abordada em estudos de demanda por transportes sob o enfoque de atividades (seção 2.2), e;

- Seleção de uma medida de acessibilidade (seção 2.3). 


\subsection{Revisão das Medidas de Acessibilidade}

Há na diversidade dos estudos da acessibilidade um enfoque quanto a identificação de elementos nas abordagens elaboradas para categorização da acessibilidade em classes de características semelhantes.

Para Lee e Goulias (1997), as formulações das medidas de acessibilidade podem ser classificadas em: (i) simples medidas de separação; (ii) medidas do tipo gravitacional; e (iii) medidas isocrônicas.

Raia Jr. (2000) sugere a classificação em: (i) indicadores do tipo atributo de redes; (ii) indicadores do tipo separação espacial; (iii) indicadores do tipo quantidade de viagens; (iv) indicadores do tipo oferta do sistema de transporte; ( $v$ ) indicadores que usam dados agregados que combinam aspectos de transportes e uso do solo; e (vi) indicadores que usam dados desagregados que combinam aspectos de transportes e uso do solo.

Em função de como a acessibilidade é medida Geurs e Van Wee (2004) propõem a classificação das medidas de acessibilidade em: (i) medidas de infraestrutura; (ii) medidas baseadas no local; (iii) medidas de acessibilidade baseadas no indivíduo, e; (iv) medidas baseadas na utilidade.

Em uma recente revisão sobre medidas de acessibilidade, Curtis e Scheurer (2010) propõem a classificação das medidas de acessibilidade em: (i) medidas de separação espacial; (ii) medidas de contorno; (iii) medidas gravitacionais; (iv) medidas de competição; (v) medidas de tempo-espaço; (vi) medidas baseadas na utilidade, e; (vii) medidas de rede.

A diversidade de abordagens para representação da acessibilidade em termos de indicadores e as diferentes classificações propostas sugerem que não há consenso quanto a classificação das medidas de acessibilidade. Entretanto, baseado na teoria subjacente a construção da medida, principalmente em função de como as oportunidades e características do sistema de transportes são considerados na medida, neste trabalho é adotada uma classificação com a acessibilidade agrupada em seis categorias: (i) medida de acessibilidade baseada no desempenho operacional ou capacidade da infraestrutura de transportes; (ii) medida de acessibilidade de um local a outro; (iii) medida de acessibilidade a oportunidades; (iv) medida de acessibilidade baseada no modelo entrópico; (v) medida de acessibilidade baseada na teoria do prisma espaço-tempo, e; (vi) medida de acessibilidade baseada na utilidade máxima esperada. 
(i) Medida de Acessibilidade Baseada no Desempenho Operacional ou na Capacidade da $\underline{\text { Infraestrutura de Transportes }}$

Este agrupamento engloba as medidas que expressam a acessibilidade em termos de desempenho ou oferta do sistema de transportes. Vários indicadores são utilizados para descrever o funcionamento do sistema de transportes, por exemplo, nível de congestionamento, velocidade no percurso, oferta de assentos no transporte coletivo etc.

Estes indicadores são utilizados em avaliação de projetos de transportes, como parte de implantação de políticas públicas. No plano diretor de transportes da Holanda foi utilizada a velocidade média das viagens para avaliação de projetos (AVV, 2000), os projetos de transportes foram avaliados no plano diretor de transportes da Inglaterra utilizando níveis de congestionamento e tempo perdido em congestionamento como medidas de acessibilidade (DETR, 2000).

No plano diretor da região metropolitana do Rio de Janeiro (RIO DE JANEIRO, 2005) são considerados como indicadores de acessibilidade o aumento da oferta de transporte coletivo e de capacidade das vias urbanas. Outros exemplos de medidas desta categoria são apresentados em Bruton (1979), Januário e Campos (1996), Akinyemi (1998), Magalhães et al (2004).

Entre as principais vantagens desta medida estão a sua operacionalização, facilidade de obtenção dos dados e facilidade de interpretação dos resultados. Entretanto, esta medida falha no aspecto teórico por não possuir associação entre o sistema de transporte, oportunidades, e a percepção individual no contexto da medida.

Sob o contexto da demanda, espera-se que esta categoria de acessibilidade tenha relação com a escolha do modo de viagem, por exemplo, supõe-se que a relação entre a propensão de escolha do modo coletivo é não decrescente com a oferta deste modo, ao passo que, a propensão para o modo individual motorizado seja não crescente com o nível de congestionamento.

Contudo, quando a análise é realizada para a escolha do destino para realização da atividade, acredita-se que não há estabelecimento desta classe de acessibilidade com a escolha dos destinos das viagens, ou relação direta de causa de consequência com as oportunidades, por exemplo, se velocidade média das viagens para uma determinada região 
sofrer um aumento, qual o impacto resultante no número de viagens, ou na distribuição das oportunidades?

Espera-se que, no longo prazo, o aumento da oferta de transportes para uma determinada região possa impulsionar o desenvolvimento nesta região, ou a não expansão da oferta possa limitar o desenvolvimento do uso do solo, no entanto, a medida falha em não apresentar esta interação (entre sistema de transporte e oportunidades) de forma direta, sendo necessário a utilização de outras abordagens para realizar esta análise.

(ii) Medida de Acessibilidade de um Local a Outro

A formulação mais difundida desta categoria é baseada na proposta de Ingram (1971) que propõe duas formulações para quantificar a acessibilidade: acessibilidade relativa e acessibilidade integral:

- Acessibilidade relativa: o grau que dois lugares, ou pontos, na superfície são conectados.

$$
A_{i j}^{\text {Relativa }}=d_{i j}
$$

- Acessibilidade integral: o grau de interseção com todos os pontos dentro dos limites espaciais.

$$
A_{i}^{\text {Integral }}=\frac{\sum_{j=1}^{n} d_{i j}}{n}
$$

Em que, $A_{i j}^{\text {Relativa }}$ é a acessibilidade relativa, $A_{i}^{\text {Integral }}$ é a acessibilidade integral e $d_{i j}$ é a distância euclidiana entre a origem $i$ e o destino $j$.

Esta categoria de medida apresenta como vantagem a simplicidade de interpretação e cálculo, como desvantagem é apontada a ausência de interação com as oportunidades e não considerar vários aspectos do comportamento individual em relação as escolhas de viagens, por exemplo, como a distância afeta os diferente grupos de indivíduos.

Ingram (1971) destaca que o efeito de separação entre dois pontos pode ser interpretado de diversas formas, e sob esta ótica a distância na rede viária, tempo de viagem, custo da viagem, custo generalizado da viagem podem ser aplicados para interpretação da 
separação. Entretanto, para Ingram (1971), apesar de diferentes todas as formas de impedimento a viagem são de alguma forma relacionadas com a distância euclidiana.

A afirmação de Ingram pode não ser aplicável em uma diversidade de situações. 0 impedimento (ou desutilidade) de uma viagem pode ser medido de várias formas e cada forma é sujeita uma série de outras considerações.

A maneira mais simples de separação de um local a outro é através da distância euclidiana, no entanto, raramente é possível viajar em linha reta entre uma origem e um destino no meio urbano. Desta forma, a distância euclidiana pode levar a uma estimativa diferente da real distância percorrida.

Outra maneira de utilizar a distância é a proposta do uso da distância na rede viária (ou distância viajada) que considera a menor distância percorrida na rede viária (incluindo os sentidos das vias e as redes dos diferentes modos de transportes) entre uma origem e um destino.

Entretanto, uma dúvida que emerge é se a distância mais curta na rede viária permite o deslocamento mais rápido entre uma origem e destino. Usuários de automóvel são propensos a evitar vias onde há congestionamento, enquanto usuários do transporte coletivo podem optar pela utilização de modos mais rápidos (por exemplo, o metrô) ou ainda, realizarem integração entre modos coletivos para minimizar o tempo de viagem, mesmo que a transferência incorra em aumento da distância.

Para pedestres e ciclistas, por outro lado, a distância euclidiana possui vantagens que se sobrepõe a distância na rede viária. Estes usuários são propensos a utilizarem atalhos (espaços abertos em edifícios, passarelas, travessia de terrenos etc.) que são, comumente, não representados em mapas, mas possuem uma influência na distância da viagem.

Curtis e Scheurer (2010) ressaltam que parte dos problemas que envolvem o uso da distância pode ser resolvida com o emprego do tempo de viagem. Para pedestres, ciclis$\operatorname{tas}^{9}$, condutores de veículos e usuários do transporte coletivo, o tempo de viagem, em geral, representa o principal fator na escolha da rota e um dos elementos considerados para escolha dos destinos para desempenho das atividades.

O custo da viagem (custo desembolsado na viagem e o custo generalizado) é outro indicador de impedimento da viagem e pode ser medido de diversas formas. A forma mais

\footnotetext{
${ }^{9}$ Para pedestres e ciclistas o tempo de viagem pode ser influenciado por condições operacionais, como presença de semaforização para travessia de vias e controle de velocidade das vias para automóveis.
} 
simples é considerar apenas o custo desembolsado na viagem, como tarifa do transporte coletivo, ou custo da queima do combustível no modo individual motorizado.

Neste contexto, pedestres e ciclistas são, em geral, considerados "usuários sem custo", apesar do custo para estes modos poderem ser medido em termos de queima de calorias (medida de equivalência metabólica) e o correspondente em custo de alimentação (pedestre) e o custo de aquisição e manutenção da bicicleta (ciclistas). O custo de aquisição e manutenção do veículo também pode ser considerado no cálculo do custo da viagem para os proprietários de automóveis.

Retomando o foco da discussão da acessibilidade para a ótica da demanda, acredita-se que o principal aspecto ${ }^{10}$ da relação entre demanda por viagens e acessibilidade é compreender como os indivíduos se comportam quando defrontados com um conjunto de oportunidades (escolha do destino), ou como mencionado por Kwan et al. (2003, p. 130) “o principal ponto dos estudos de acessibilidade é um entendimento das respostas comportamentais para a separação espacial entre locais de oferta e locais de demanda" e por Bates (2008, p.14) "separação espacial é a essência da demanda por transportes, e a maioria dos modelos visam reconhecer a distribuição espacial das viagens explicitamente".

Os modelos de interação espacial realizam estimação dos fluxos de viagens entre origens e destinos, simulando o comportamento individual em situações de decisões sobre a escolha dos destinos das viagens. Estes modelos consideram a separação espacial entre origens e destinos e a distribuição das oportunidades.

Segundo Kwan et al. (2003) avanços em relação a esta categoria vem sendo realizado, particularmente no desenvolvimento de métodos que associam medidas de separação e modelos de interação espacial: “Há muitas questões científicas não respondidas associadas ao uso de modelos de interação espacial no contexto da acessibilidade”, Kwan et al. (2003, p.132).

Ainda segundo Kwan et al. (2003), o principal desafio para este tipo de abordagem recai em incorporar o comportamento do individual na operacionalização das medidas e no processo de modelagem, por exemplo, tem-se por premissa na maioria dos modelos de interação espacial que os indivíduos viajam para destinos mais próximos para realização das atividades. Contudo, esta situação pode não representar a realidade com que o indivíduo se depara. No caso em que há competição pela oferta da atividade, o posto no local

\footnotetext{
${ }^{10}$ É apresentado em seções subsequentes que a acessibilidade afeta outros níves de decisão na programação diária de atividades, não apenas na decisão sobre a escolha de destinos.
} 
mais próximo para realização da atividade pode estar ocupado, o que leva o indivíduo buscar o segundo lugar mais próximo para realização da atividade e, assim, sucessivamente até o indivíduo encontrar uma posição disponível para realização da atividade.

(iii) Medida de Acessibilidade a Oportunidades

\section{Medida de Linha de Contorno}

Expressa a acessibilidade em termos de oportunidades que pode ser alcançada dentro de uma distância determinada, tempo de viagem, ou custo generalizado:

$$
A_{i}=\sum_{j} W_{j} \cdot f\left(c_{i j}\right)
$$

Em que, $W_{j}$, representa as oportunidades (número de postos de emprego, número de lojas, etc) na zona $j$ e $f\left(c_{i j}\right)$ é a medida de impedância entre $i$ e $j$, com $f\left(c_{i j}\right)=1$ se $c_{i j} \leq C$ (completamente acessível) e $f\left(c_{i j}\right)=0$ se $c_{i j}>C$ (não é acessível), em que $C$ é o limite determinado.

Esta medida indica que a acessibilidade é não decrescente com o aumento da distância, ou tempo de viagem, um maior número de oportunidades pode ser alcançado. Graficamente esta medida pode ser representada pela Figura 2.1.

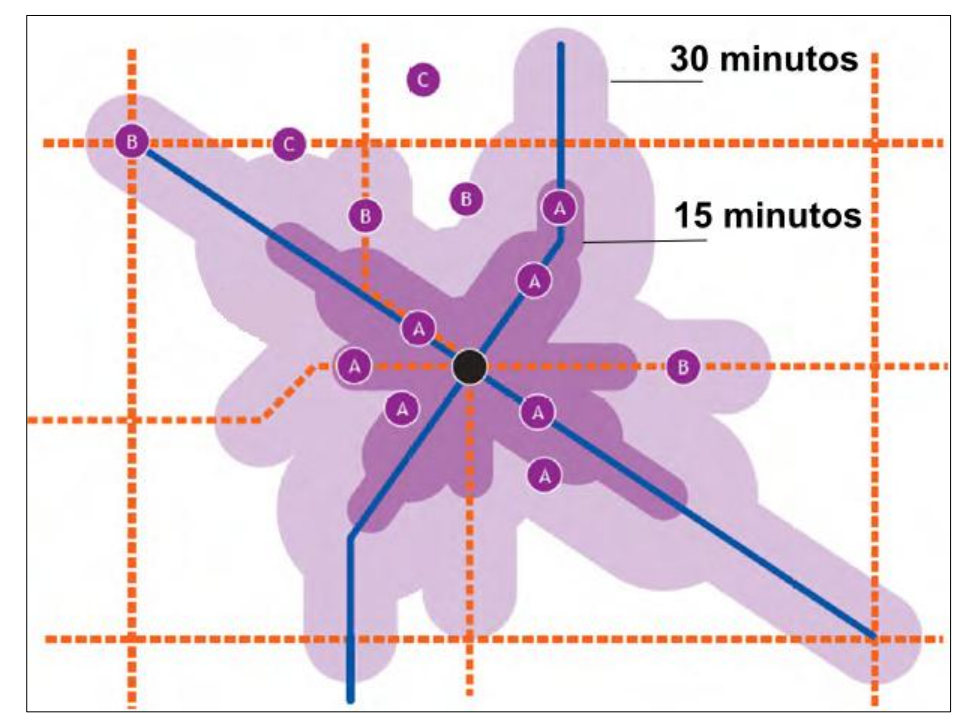

Figura 2.1 - Medida de linha de contorno: oportunidades (indicados pelos círculos em lilás) são classificadas segundo o tempo de viagem a partir da zona de origem (indicado pelo círculo em preto ao centro da figura): $\mathrm{A}=$ até 15 minutos; $\mathrm{B}=$ acima de 15 minutos e até 30 minutos, e; $\mathrm{C}=$ acima de 30 minutos (CURTIS; SCHEURER, 2010, p. 62). 
Tradicionalmente, estudos com aplicação desta categoria de acessibilidade são realizados adotando-se um valor para a desutildiade e calculando-se o total de oportunidades a partir de uma zona de origem. Entretanto, vários estudos realizam o inverso: fixam um número de oportunidades desejado e calcula-se a desutilidade necessária (distância, ou tempo) para se atingir os destinos necessários para o número de oportunidades pretendido.

As vantagens das medidas de linha de contorno são relacionadas a operacionalização (coleta de dados e cálculo) e facilidade de interpretação. Apesar de associar o sistema de transporte a distribuição das atividades, a medida falha em não representar a interação entre os dois, por exemplo, se o tempo de viagem para uma região sofrer um acréscimo o que ocorre com as oportunidades nesta região.

Outras desvantagens em relação a esta medida são: (a) o uso da medida implica que todas as oportunidades são igualmente desejáveis e disponíveis a todos os indivíduos na zona de origem; (b) A medida implica que o custo para atingir duas oportunidades distintas na área delimitada pela linha de contorno seja igual, por exemplo, o custo para se atingir uma oportunidade próxima a origem é o mesmo para se atingir uma oportunidade próximo a fronteira da linha de contorno; (c) Se todas as oportunidades delimitadas por um custo qualquer são disponíveis, implica que não há competição pelas oportunidades; (d) Ausência de um procedimento para determinar o critério de escolha do limite da linha, e; (e) assume-se que todos os indivíduos da zona possuam disponibilidade para viajar a distância, tempo, ou custo determinado pela linha de contorno adotado.

\section{Medida Potencial}

A abordagem desta categoria é agregar as oportunidades disponíveis, ponderada por uma função de resistência (impedância) para atingir estas oportunidades. A formulação inicial para esta categoria de medida foi desenvolvida por Hansen (1959), que propôs que a acessibilidade pode ser representado por:

$$
A_{i}=\sum_{j} W_{j} \cdot d_{i j}^{\alpha}
$$

Em que, $W_{j}$ representa as oportunidades (número de postos de emprego, número de lojas, etc) na zona $j, d_{i j}$ é a distância entre $i$ e $j$ e $\alpha$ é o expoente que descreve o efeito da distância entre as zonas. 
A função potência para representação da impedância da viagem é baseada na Lei Gravitacional de Newton, mas alternativas a forma da impedância da viagem são apresentados, por exemplo, função exponencial, gaussiana e logística.

Semelhante a medida de um local a outro e de linha de contorno alternativas para representação da impedância da viagem são apresentados, substituindo a distância euclidiana pela distância na rede viária, tempo de viagem, custo monetário e custo generalizado. De forma geral, a Equação 4 pode ser reescrita como:

$$
A_{i}=\sum_{j} W_{j} \cdot f\left(c_{i j}\right)
$$

Em que, $f\left(c_{i j}\right)$ é o custo generalizado entre $i$ e $j$.

Quanto a escolha da função de resistência à viagem, a função potência ou exponencial para representação da resistência à viagem sugere uma forte sensibilidade para variações curtas do custo generalizado da viagem (distância, tempo, custo monetário, etc). Do ponto de vista comportamental, uma forte sensibilidade a pequenas variações pode não ser realista.

Para Fotheringham (1982), a função potência é mais adequada para descrição da percepção de viagens interurbanas, ao passo que a função exponencial é mais apropriada para descrição da percepção de viagens intra-urbanas. Para Ingram (1971) a função Gaussiana é mais apropriada para descrição de fenômenos urbanos, enquanto para Hilbert e Verroen (1993) a função logística representa melhor a percepção das viagens em função da sua forma ("S").

A principal vantagem desta classe de medida corresponde ao seu fácil entendimento e o efeito combinado das oportunidades com a medida de resistência à viagem (a acessibilidade é não crescente com o aumento da resistência à viagem e não decrescente com o aumento da oportunidade).

Para Geurs e Van Wee (2004) esta medida é particularmente importante para análise do nível de acesso a serviços sociais e empregos para diferentes grupos de indivíduos (a função de desutilidade da viagem pode ser calibrada para diferentes grupos de indivíduos).

Apesar de largamente empregada no planejamento urbano esta medida possui desvantagens. Para diversos pesquisadores (BRÖCKER, 1989; FROST; SPENCER, 1995; GEUS; 
VAN ECK, 2001; GEUS; VAN WEE, 2004) as oportunidades na zona de origem consistem em um problema de superestimação da medida de acessibilidade, principalmente para zonas de grande área e de alta concentração de oportunidades.

Uma vez que as oportunidades na zona são representadas pelo seu centroide, e como o centroide da origem é o ponto de partida para o acúmulo das oportunidades, uma interpretação na medida é assumir valor da oportunidade na zona em seu valor absoluto no cálculo da acessibilidade interna. Esta interpretação leva a dois problemas: uma superestimação da acessibilidade no local de origem; e falha em assumir que não há custo associado para atingir as oportunidades na zona de origem.

Outra interpretação para o cálculo da medida dentro da zona de origem é considerar que as oportunidades são distribuídas homogeneamente, ou seja, que as oportunidades são contínuas dentro da zona e adotar um valor médio para impedância.

Entretanto, ao assumir que as oportunidades são contínuas, na zona de origem, deve-se assumir que as oportunidades nas zonas de destinos também são contínuas, o que implica um detalhamento do cálculo das impedâncias nas zonas de destino e uma ponderação com as oportunidades.

Outra desvantagem desta classe é a consideração de que todas as oportunidades são igualmente desejáveis e disponíveis, além do indicador desconsiderar a demanda pelas oportunidades (competição pelas oportunidades). Segundo Shen (1998) e Geurs e Van Eck (2001) a ausência da competição na medida induz a resultados discrepantes para a acessibilidade.

Se a medida potencial de acessibilidade é utilizada para avaliar cenários alternativos, utilizando a média das acessibilidades individuais, resultados insatisfatórios podem ser encontrados. Geurs e Van Eck (2001) apresentam um exemplo.

Duas zonas adjacentes “A" e “B” (sendo que a área de "A" é muito maior do que a área de “B”) possuem o número de habitantes e oportunidades (empregos) conforme apresentado na Tabela 2.1.

Tabela 2.1 - Situação de Referência: habitantes e oportunidades das zonas hipotéticas

\begin{tabular}{ccc}
\hline Zona & Habitantes & Oportunidades \\
\hline $\mathrm{A}$ & 10.000 & 10.000 \\
\hline $\mathrm{B}$ & 1.000 & 10 \\
\hline
\end{tabular}


A zona "A" apresenta um equilíbrio entre o número de empregos e o número de habitantes, enquanto a zona "B" apresenta um desequilíbrio entre a oferta e a demanda. Supondo que a o valor da desutilidade da viagem dentro da zona seja 1,0 e entre zonas seja 0,1 , os respectivos valores da acessibilidade da zona $A$, zona $B$ e a acessibilidade média são: acessibilidade potencial em "A" = 10.000; acessibilidade potencial em "B" = 10 e acessibilidade média $=9.092^{11}$.

No cenário 1 são adicionados 1.000 empregos a zona "A", e no cenário 2 , são adicionados 1.000 empregos a zona “B”, conforme apresentado nas Tabelas 2.2 e 2.3.

Tabela 2.2 - Cenário 1: habitantes e oportunidades das zonas hipotéticas

\begin{tabular}{ccc}
\hline Zona & Habitantes & Oportunidades \\
\hline A & 10.000 & 11.000 \\
\hline B & 1.000 & 10 \\
\hline
\end{tabular}

Tabela 2.3 - Cenário 2: habitantes e oportunidades das zonas hipotéticas

\begin{tabular}{ccc}
\hline Zona & Habitantes & Oportunidades \\
\hline A & 10.000 & 10.000 \\
\hline B & 1.000 & 1.010 \\
\hline
\end{tabular}

Recalculando os valores das acessibilidades, obtem-se os valores da Tabela 2.4.

Tabela 2.4 - Valores da acessibilidade potencial.

\begin{tabular}{cccc}
\hline Cenário & Acessibilidade em “A” & Acessibilidade em “ $B$ ” & Acessibilidade Média \\
\hline Referência & 10.000 & 10 & 9.092 \\
\hline 1 & 11.000 & 10 & 10.001 \\
\hline 2 & 10.000 & 1.010 & 9.183 \\
\hline
\end{tabular}

Claramente, os valores da Tabela 2.4 indicam que o cenário 1 possui a melhor condição de acessibilidade (média) do que o cenário 2. Contudo, observa-se no cenário 2 um equilíbrio entre a oferta e a demanda dentro das zonas, em contraste com o desequilibrio encontrado no cenário 1 em que os indivíoduos de $\mathrm{B}$ devem ir a $\mathrm{A}$ em busca de emprego, esta situação não é representada em termos de acessibilidade média. Este resultado insatisfatório é gerado pelo grande número de habitantes na zona “A" em relação a zona "B".

\section{Medidas que Consideram a Competição}

Baseados nas tradicionais medidas de acessibilidade a oportunidades, alguns estudos tentaram reproduzir na formulação da medida a situação em que o equilíbrio entre a

\footnotetext{
${ }^{11}$ Para simplificação foi omitida a unidade da medida
} 
oferta e a demanda foi superado pela realidade, por exemplo, trabalhadores competem entre si pela vaga de trabalho e firmas competem entre si pelos trabalhadores. Contribuições nesta linha são as abordagens propostas por Weibull (1976) - medida relativa considerando a competição - e Van Wee et al. (2001) - medida potencial considerando a competição.

\section{Medida Relativa Considerando a Competição}

Weibull (1976) propôs um indicador para a acessibilidade incluindo a competição no mercado de trabalho através da razão entre as oportunidades e a demanda (dentro de limites espaciais estabelecidos por uma distância ou tempo de viagem dado):

$$
A_{i}=\frac{\sum_{j=1}^{n} f\left(d_{i j}\right) W_{j}}{\sum_{k=1}^{n} f^{\prime}\left(d_{k j}\right) \cdot h_{k}}
$$

Em que, $A_{i}$ é a acessibilidade da zona $i, f\left(d_{i j}\right)$ é a distância (ou tempo) de viagem entre a zona i e a zona $j, W_{j}$ representa a oportunidade (número de empregos) na zona $j, f^{\prime}\left(d_{k j}\right)$ é a distância (ou tempo) de viagem entre $k$ e $j$ e $h_{k}$ é o número de trabalhadores na zona $k$ (zonas que podem ser alcançadas dentro dos limites espaciais dado uma distância, tempo de viagem, ou custo generalizado), sendo $f\left(d_{i j}\right)$ e $f^{\prime}\left(d_{k j}\right)=1$ se $d_{i j} \leq D$ (completamente acessível) e $f\left(d_{i j}\right)$ e $f^{\prime}\left(d_{k j}\right)=0$ se $d_{i j}>D$ (não é acessível), em que $D$ é o limite determinado.

Interpretando a medida observa-se que o numerador da Equação (6) representa a medida de linha de contorno e expressa as oportunidades que podem ser alcançadas dentro de uma distância determinada, tempo de viagem, ou custo generalizado, enquanto o denominador da medida representa a quantidade de indivíduos que podem alcançar as mesmas oportunidades dentro do mesmo limite imposto de desutilidade para atingir as oportunidades.

Graficamente, a medida pode ser representa pelo diagrama da Figura 2.2. A partir da origem localizada no ponto “ $O$ ” e definido uma distância (dij), tempo de viagem (Tij) ou custo (Cij), alcançam-se os pontos "P1" a "P5" onde estão localizadas as oportunidades "W1" a "W5". A partir de cada ponto ("P1" a "P5") abrange-se uma região delimitada pela mesma desutilidade adotada em " $\mathrm{O}$ ", e calcula-se a demanda pelas oportunidades. 


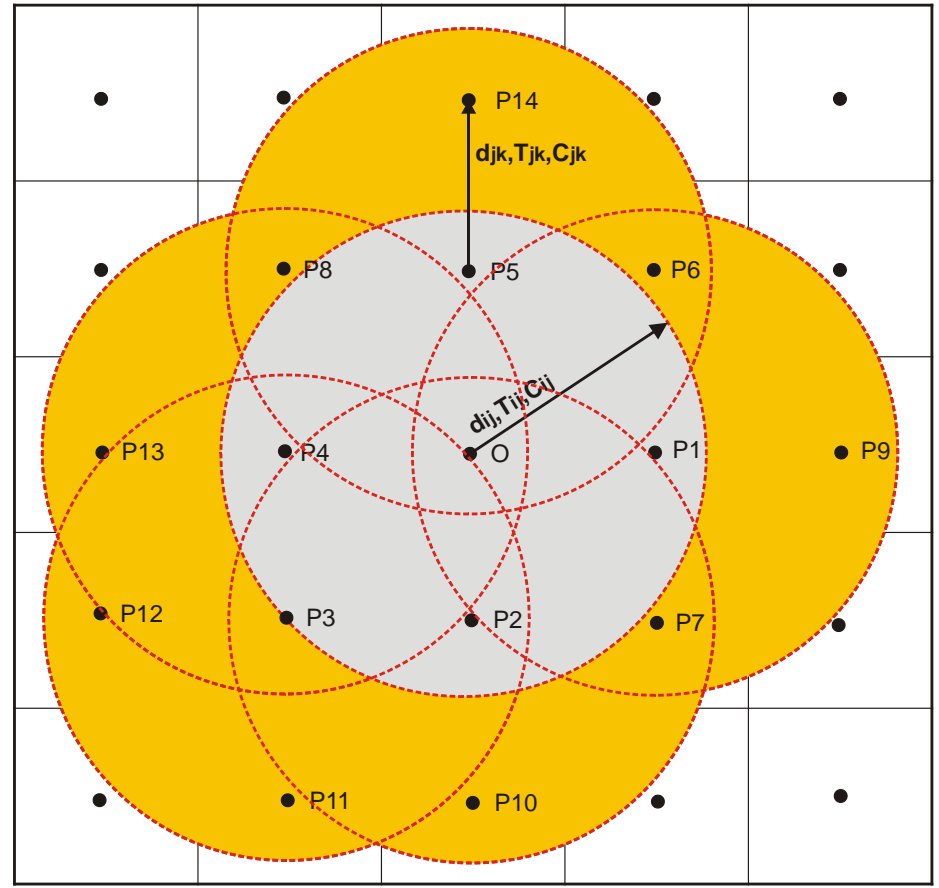

Figura 2.2 - Diagrama demonstrando a interpretação da competição pelas oportunidades na medida de acessibilidade proposta por Weibull (1976)

A medida é adimensional e reflete o grau de disponibilidade das oportunidades em função de valores de desutilidade. Um valor de acessibilidade superior a unidade $(A i>1)$ implica em um baixo nível de competição de emprego (as oportunidades de emprego são maiores que a demanda) e um valor inferior a unidade ( $\mathrm{A} i<1)$ implica um elevado nível de competição.

A proposta de Weibull (1976) foi aplicada para avaliação da acessibilidade a emprego na região de Estocolmo (Suécia) por automóvel e transporte coletivo. Foram simulados dois cenários futuros (para o ano 2000), ambos com projeções de crescimento das oportunidades de emprego e trabalhadores de $0.6 \%$ ao ano.

A distinção entre os cenários refere-se às distribuições de emprego e habitantes no meio urbano: no primeiro cenário (alternativa 1), foi proposto a distribuição do adicional de empregos na região central de Estocolmo, e o adicional de habitantes nos subúrbios; enquanto no segundo cenário (alternativa 2) foi distribuído o adicional de empregos no subúrbio e o adicional de trabalhadores de forma homogênea na cidade.

A análise dos cenários é apresentada de forma gráfica na Figura 2.3 com os valores da medida de acessibilidade no eixo das ordenadas ( $\mathrm{y}$ ) e o percentual de área residencial urbana abaixo de cada correspondente da medida de acessibilidade no eixo das abscissas $(\mathrm{x})$. 


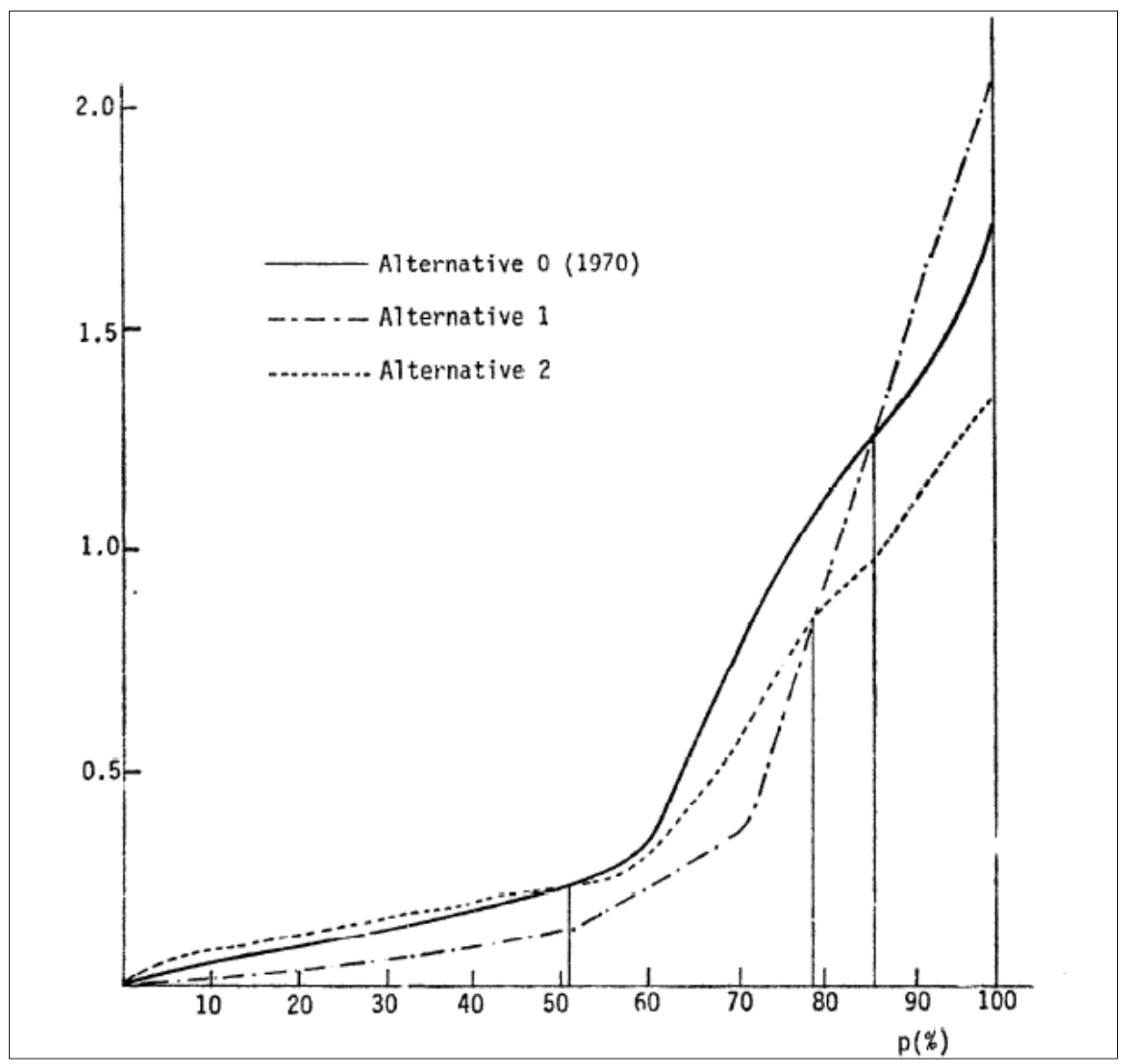

Figura 2.3 - Acessibilidade a empregos em alternativas as mudanças estruturais na região de Estocolmo para o ano de 2000, medido a partir da Equação 6. Valores percentuais da medida de acessibilidade distribuídos na região residencial urbana, Weibull (1976, p.376)

Analisando o resultado do gráfico da Figura 2.3, no global, a alternativa 2 apresenta um melhor nível de acessibilidade ao emprego, o que de fato era o esperado em função da distribuição do adicional do emprego ter sido distribuído no subúrbio, uma região que já tinha baixos níveis de acesso a emprego em 1970.

A abordagem de Weibull (1976) é de fácil interpretação e aplicação, entretanto possui algumas desvantagens. A medida implica que o custo para atingir duas oportunidades distintas na área delimitada pela linha de contorno seja igual, por exemplo, o custo para se atingir uma oportunidade próxima a origem é o mesmo para se atingir uma oportunidade próximo a fronteira da linha de contorno, enquanto espera-se que a acessibilidade seja não crescente com o aumento da impedância da viagem e, de forma semelhante, que a propensão do indivíduo é não crescente com o aumento da impedância.

Quanto ao tratamento da competição há alguns problemas teóricos envolvidos. A medida supõe que todos os indivíduos das zonas concorrentes são igualmente competidores das zonas de origem pelas oportunidades e que possuem disponibilidade para viajar a dis- 
tância, tempo, ou custo determinado pela linha de contorno adotado, quando em realidade, a propensão do indivíduo é não crescente com a impedância.

Outro problema relacionado a competição está na forma de tratamento. Isolando o termo de competição $\left(\mathrm{W}_{\mathrm{j}} / \mathrm{h}_{\mathrm{k}}\right)$, este indicador reflete apenas a competição entre duas regiões, sem considerar o efeito das zonas ao redor. Introduções na modificação do zoneamento podem alterar consideravelmente os valores da competição. Além do mais, não há evidência empírica no estudo que comprove que a competição no mercado de trabalho seja dada pela razão entre vagas de empregos e trabalhadores.

Mattsson e Weibull (1981) realizaram outro estudo sobre acessibilidade e oportunidades de emprego e constataram que a seleção da oportunidade e competição pelas oportunidades é formada por um conjunto mais abrangente de fatores (por exemplo, qualificações de quem busca o emprego, decisão do empregador, tamanho do mercado de trabalho) do que a simples razão das oportunidades pela demanda.

Fortheringham (1983) e Van Wee et al. (2001) destacam que além da competição de indivíduos pelas oportunidades, há competição entre oportunidades, ou seja, competição das oportunidades pelos indivíduos (firmas competindo por trabalhadores).

Entende-se que o número de empregos, sem segmentação, é uma simplificação do modelo, entretanto, estudos demonstram que a elasticidade da demanda em relação a escolha dos locais de trabalho varia em função da renda do trabalhador, situação familiar (chefe de família, filho etc), propriedade do domicílio (próprio ou alugado) e outros fatores.

\section{Medida Potencial Considerando a Competição}

Outra abordagem proposta é desenvolvida em Van Wee et al. (2001):

$$
\begin{gathered}
A_{i\left(t \leq t_{\max }\right)}=A_{i\left(t \leq t_{\max }\right)}^{0} \cdot e_{i\left(t \leq t_{\max }\right)} \\
A_{i\left(t \leq t_{\max }\right)}^{0}=\sum_{j=1}^{j=n} \frac{W_{j}}{t_{i j}^{\alpha}}
\end{gathered}
$$




$$
\begin{gathered}
e_{i\left(t \leq t_{\text {max }}\right)}=\frac{\sum_{k=1}^{k=n}\left(\frac{\frac{W_{k}}{L_{f k}} \times L_{f k}}{t_{j k}^{\alpha}}\right)}{\sum_{k=1}^{k=n}\left(\frac{L_{f k}}{t_{j k}^{\alpha}}\right)} \\
A_{\text {obs }_{i(T \leq T \text { Tax })}}=\sum_{j=1}^{j=n}\left(\frac{W_{j}}{t_{i j}^{\alpha}} \times \frac{\sum_{k=1}^{k=n}\left(\frac{W_{k}}{t_{j k}^{\alpha}}\right)}{\sum_{k=1}^{k=n}\left(\frac{L_{f k}}{t_{j k}^{\alpha}}\right)}\right)
\end{gathered}
$$

Em que $A_{J o b s_{i(T \leq T \max )}}$ é a acessibilidade medida para um tempo $(t)$ inferior ao tempo máximo $\left(t_{\max }\right)$ incluindo a competição, $A_{i\left(t \leq t_{\max }\right)}^{0}$ é a acessibilidade medida para um tempo $(t)$ inferior ao tempo máximo $\left(t_{\max }\right)$ sem a inclusão da competição , $e_{i\left(t \leq t_{\max }\right)}$ é o fator de competição para um tempo $(t)$ inferior ao tempo máximo $\left(t_{\max }\right)$, $i$ é a origem, $j$ são os destinos alcançados a partir de i dentro do intervalo de tempo $(t)$ inferior ao tempo máximo $\left(t_{\max }\right)$, $k$ são as zonas geradoras de competidores englobadas pelo tempo máximo a partir de $j, W_{j}$ e $W_{k}$ é a oportunidade em $j$ e em $k$, respectivamente, $L_{f k}$ é o número de trabalhadores em $k$.

A medida de acessibilidade é descrita como o produto entre uma medida potencial (número de oportunidades alcançadas nas zonas “j” a partir da zona de origem $\mathrm{i}$, ponderadas pela resistência para atingí-las) por um fator de competição (que é representado pela razão entre oportunidades que podem ser atendidas por uma demanda de trabalhadores nas zonas "k" a partir da zona "j" e o número de trabalhadores nas zonas "k" a partir da zona “ $\mathrm{j} " 12$ ).

A principal contribuição desta medida ao estudo da acessibilidade é a proposta de quantificação da influência da competição (espera-se que na forma de redução das oportunidades que podem ser alcançadas pelos indivíduos), utilizando como referência a medida potencial, largamente utilizado no planejamento urbano. Em um estudo de caso na Holanda os autores concluíram que há uma variação de até $10 \%$ no valor da medida quando o efeito da competição é incluído.

Como já foi discutido neste capítulo as vantagens e desvantagens da medida potencial, nesta seção serão analisadas apenas aspectos relacionados ao fator de competição. 0

\footnotetext{
${ }^{12}$ Para início das contagens das oportunidades que são percebidas pelos competidores e para o cálculo dos competidores considera-se a zona $j$.
} 
primeiro ponto a ser discutido é a representação da competição. Não há evidência empírica de que a melhor forma de representação da competição no mercado de trabalho seja dada por uma razão entre oportunidades e trabalhadores. Os autores não apresentam embasamento teórico que justifique o uso da razão e/ou argumentos que refutem outras formas de representação, por exemplo, a forma aditiva.

Ainda que seja aceito a razão como forma plausível para representação da competição, não há controle sobre as propensões individuais em relação às oportunidades, na Figura 2.4 é ilustrado um exemplo.

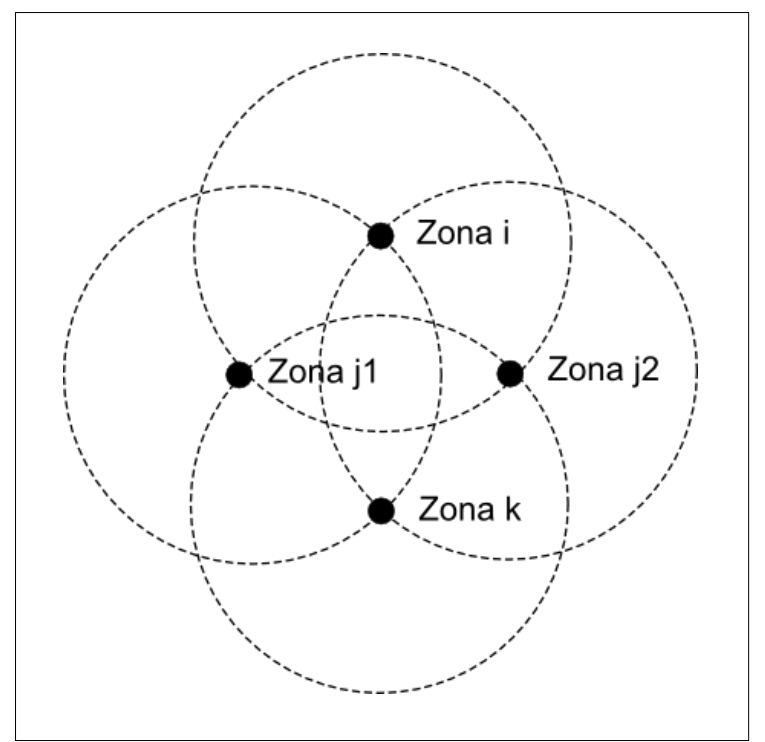

Figura 2.4 - Diagrama demonstrando as impedâncias para atingir as zonas com oportunidades e zonas com competidores pelas oportunidades na medida de acessibilidade proposta por Van Wee et al. (2001).

No esquema da Figua 2.4 a zona "k" possui um indivíduo e zero oportunidade, as zonas “j1" e "j2" são equidistantes de “k”, com impedância de viagem igual 1, oportunidade igual a 1 e sem competidor. Isoladamente, a competição para a zona "j1" e “j2" será igual a $1^{13}$ que é o indivíduo da zona "k".

Como a medida faz uso de limites de impedância para seleção das zonas competidoras, adotando o limite de impedância igual a 1, e o cálculo da acessibilidade a partir da origem “i” distante de “j1" e “j2" com impedância igual a 1 e distante da zona "k" com impedância igual a 2, tem-se uma situação para o cálculo da medida com 2 oportunidades e dois competidores (um na zona "i", e um competidor para a zona "j1" que é o mesmo para a zona "j2"), entretanto o modelo considera que há existência de quatro competidores distintos.

\footnotetext{
${ }^{13} \mathrm{O}$ modelo assume que todas as oportunidades são igualmente desejáveis.
} 


\section{(iv) Medida Baseada no Modelo Entrópico}

São medidas associadas aos parâmetros de calibração dos modelos de distribuição de viagens ou associadas à teoria subjacente aos modelos. Wilson (1967) denominou o fator de balanceamento do total de viagens produzidos na zona $i$ como uma medida de acessibilidade:

$$
\begin{aligned}
& T_{i j}=A^{\prime}{ }_{i} \cdot O_{i} \cdot B_{j} \cdot D_{j} \cdot e^{-\beta \cdot c_{i j}} \\
& A_{i}{ }^{\prime}=\left(\sum_{j} B_{j} \cdot D_{j} \cdot e^{-\beta \cdot c_{i j}}\right)^{-1} \\
& B_{j}=\left(\sum_{i} A_{i} \cdot O_{i} \cdot e^{-\beta \cdot c_{i j}}\right)^{-1} \\
& A=\frac{1}{A^{\prime}{ }_{i}}=\sum_{j} B_{j} \cdot D_{j} \cdot e^{-\beta \cdot c_{i j}}
\end{aligned}
$$

Em que $T_{i j}$ representa o número de viagens entre a zona $i$ e a zona $j, O_{i}$ o número de viagens produzidas em $i, D_{j}$, o número de viagens atraídas por $j, c_{i j}$ representa o custo da viagem entre $i$ e $j, A_{i}^{\prime}$ representa o parâmetro de calibração para a zona $i, B_{j}$ representa o parâmetro de calibração para a zona $j$ e $\beta$ a medida de resistência a viagem. Para Thomas (1977) a acessibilidade do destino $j$ pode ser expressa pelo parâmetro $B_{j}$, Equação 13 , do modelo gravitacional de Wilson (1967).

As medidas gravitacionais são calculadas a partir de um modelo de distribuição de viagens largamente difundido, no entanto, os resultados das medidas refletem mais aspectos de otimização do processo de calibração do que a interação entre diversos atores (uso do solo e transportes) no valor da acessibilidade.

Fortheringham (1983) propôs a inclusão uma variável de competição (refletindo a competição entre destinos) ao modelo gravitacional para iteração de viagens. A proposta inclui os modelos de interação espacial com restrição na origem e com dupla restrição (origem e destino).

Com restrição na origem:

$$
T_{i j}=Z_{i} O_{i} W_{j} A_{i j}^{\delta_{i}} d_{i j}^{\beta_{i}}
$$




$$
\begin{aligned}
& Z_{i}=\left(\sum_{j=1}^{n} W_{j} A_{i j}^{\delta_{i}} d_{i j}^{\beta_{i}}\right)^{-1} \\
& A_{i j}=\sum_{\substack{k=1 \\
k \neq i, k \neq j)}}^{n} W_{k} d_{j k}^{\sigma_{i}}
\end{aligned}
$$

Duplamente restrito (origem e destino):

$$
\begin{gathered}
T_{i j}=Z_{i} O_{i} B_{j} D_{j} A_{i j}^{\delta_{i}} d_{i j}^{\beta_{i}} \\
Z_{i}=\left(\sum_{j=1}^{w} B_{j} D_{j} A_{i j}^{\delta_{i}} d_{i j}^{\beta_{i}}\right)^{-1} \\
B_{j}=\left(\sum_{i=1}^{m} Z_{i} O_{i} A_{i j}^{\delta_{i}} d_{i j}^{\beta_{i}}\right)^{-1} \\
A_{i j}=\sum_{\substack{k=1 \\
k \neq i, k \neq j)}}^{l} W_{k} d_{j k}^{\sigma_{i}}
\end{gathered}
$$

Em que $T_{i j}$ representa o número de viagens entre a zona $i$ e a zona $j, O_{i}$ o número de viagens produzidas em $i, D_{j}$, o número de viagens atraídas por $j, A_{i j}$ representa a acessibilidade do destino $j$ para todos os outros destinos disponíveis para a origem $i$ (também chamado de acessibilidade inversa) $d_{i j}$, $d_{j k}$ representam o custo da viagem entre $i$ e $j$ e entre $k$ e $j, Z_{i}$ representa o parâmetro de calibração para a zona $i, B_{j}$ representa o parâmetro de calibração para a zona $j, W_{j}$ e $W_{k}$ representam respectivamente a oportunidade da zona $j$ e da zona $k, \sigma_{i}$ reflete a importância da distância na percepção da acessibilidade, $\beta_{i}$ reflete a impedância à viagem entre $i$ e $j$ e $\delta_{i}$ reflete a influência da acessibilidade $A_{i j}$.

Se a origem também é considerada como um destino de oportunidade, a Equação 21 pode ser reescrita:

$$
A_{i j} \approx \sum_{\substack{k=1 \\ k=1, k \neq j)}}^{m} W_{k} d_{k j}^{\sigma_{i}}
$$

Assumindo $\sigma_{i}$ igual a todas as origens:

$$
A_{i j} \approx A_{j}=\sum_{\substack{k=1 \\ k=1, k \neq j)}}^{m} W_{k} d_{k j}^{\sigma}
$$


A concepção de acessibilidade proposta por Fortheringham (1983) expressa a competição através da proximidade espacial entre o destino na zona “j” com outros destinos (zona “k”), quando se espera que o efeito da competição ocorra a partir da origem (o efeito da separação para os indivíduos localizados na zona de origem “i” e as zonas "k").

Além do mais, a medida proposta por Fortheringham (1983) não considera explicitamente o efeito da competição entre indivíduos pelas oportunidades. Alguns pesquisadores (THOMAS, 1977; GEURS E VAN WEE, 2004) sugerem que implicitamente o efeito da competição é explicado pelo parâmetro das zonas de destino $(\mathrm{Bj})$, uma vez que este parâmetro é calculado para assegurar o equilíbrio para as viagens com destino na zona "j".

Esta afirmação só teria validade se as oportunidades na zona “j” fossem iguais ao total de viagens destinadas a zona "j". Para o caso em que há mais oportunidades na zona “j” do que viagens destinadas, o parâmetro reflete apenas aspectos de otimização do processo de calibração.

\section{(v) Medidas Baseadas na Teoria do Prisma Espaço-Tempo}

São medidas individuais de acessibilidade desenvolvidas a partir da teoria do prisma espaço-tempo de Hägerstrand (1970). Estas medidas refletem a potencialidade de áreas de oportunidades que podem ser alcançadas pelas restrições de tempo.

Uma abordagem é a proposta de Miller (1999) que apresenta três formas diferentes (devido à operação binária adotada para cada forma) de medidas de acessibilidade dentro da teoria do prisma espaço-tempo baseado em uma função utilidade em que a premissa é que o indivíduo não pode deixar um local "i” engajar-se numa oportunidade em "j" se as restrições de tempo não permitirem. Miller (1999) propõe que a função utilidade seja especificada da seguinte forma:

$$
U_{i j}\left(W_{j}, T_{k}, t_{k}\right)=W_{j}^{\alpha} \cdot T_{j}^{\beta} \cdot e^{-\mu \cdot t_{j}}
$$

Em que $\mu$ representa o parâmetro de calibração para o tempo de viagem entre $i$ e $j, W_{j}$ a oportunidade em $j, \alpha$ representa o parâmetro de calibração para a oportunidade em $j, T_{j} 0$ tempo disponível para realização da atividade, $\beta$ representa o parâmetro de calibração para o tempo disponível para realização da atividade e $t_{j}$ o tempo de viagem entre $i$ e $j$. 
A função utilidades especificada na Equação (24) postula um processo não compensatório no sistema de decisão, envolvendo a oportunidade, o tempo disponível para participação na atividade e o tempo requerido de viagem para atingir o destino onde se encontra a oportunidade. Se a oportunidade for zero, ou o tempo necessário para realizar a atividade for nulo, a função retorna o valor zero para a utilidade $(\alpha, \beta$ e $\mu$ são maiores que zero).

Para Miller (1999) a acessibilidade (com abordagem do prisma espaço-tempo) pode ser interpretada de três maneiras. A primeira forma é interpretada como uma avaliação do benefício do prisma-espaço tempo, baseada no conceito de trocas de custos e benefícios. A idéia básica é que a medida acessibilidade é um indicador que expresse os benefícios oriundos do sistema de transporte e de uso do solo. Esta definição é idêntica a proposta de utilidade máxima esperada (que será vista a seguir). Sob esta interpretação é expressa por:

$$
A_{i}=\frac{1}{\mu} \cdot \ln \sum_{j=1}^{m} e^{W_{j}^{\alpha} \cdot T_{j}^{\beta} \cdot e^{-\mu \cdot t_{j}}}
$$

A segunda forma trata a acessibilidade como benefício relativo de um local e os demais dentro da cobertura espacial. Sob esta interpretação é expressa por:

$$
\begin{gathered}
A_{2}=\sum_{j=1}^{m} b_{k} \\
b_{k}=\left\{\begin{array}{c}
0 \text { se } a_{k}=0 \text { ou } T_{k} \leq 0 \\
e\left[\begin{array}{l}
{\left[\frac{\alpha}{\mu} \cdot \ln a_{k}+\frac{\beta}{\mu} \cdot \ln T_{k}-t_{k}\right)}
\end{array}\right]
\end{array}\right.
\end{gathered}
$$

A terceira e última forma apresentada por Miller (1999) também considera a acessibilidade como um benefício, mas como um máximo benefício que pode ser alcançado dentro do prisma espaço-tempo

$$
A_{3}=\max _{k}\left[b_{k}\right]
$$

Estudos recentes de acessibilidade apontam cada vez mais para o desenvolvimento de medidas baseadas no prisma espaço-tempo, pela vantagem da perspectiva individual e sensibilidade quanto a mudanças nas componentes. 
Uma falha teórica refere-se a não inclusão da competição pelas oportunidades. Assume-se que pela cobertura espacial do prisma o indivíduo tem total disponibilidade pelas oportunidades, o que não é realístico.

Entretanto, a maior desvantagem apontada na literatura relativa a esta medida refere-se a exigência quanto a dados que só são possíveis através de diários de atividades, operacionalização complexa e necessidade de desenvolvimento de algoritmos específicos para cada estudo de caso.

(vi) Medidas Baseadas na Utilidade Máxima Esperada

As medidas enquadradas nesta categoria interpretam a acessibilidade como o resultado de um processo em que o indivíduo maximiza a sua escolha em um conjunto de alternativas, Ben-Akiva e Lerman (1979). Nesta abordagem a medida de acessibilidade é desagregada (individual) e há interação entre as componentes de transportes, uso do solo, temporal e individual.

Usualmente as medidas são derivadas de um modelo logit para a escolha do destino ou modelo logit hierárquico para um modelo combinado de modo e destino. A Equação 29 expressa a medida de acessibilidade para um modelo multinomial logit (MNL)

$$
A_{n}=E_{i \in C_{n}}\left(\max U_{i n}\right)=\frac{1}{\mu} \cdot \ln \sum_{i \in C_{n}} e^{\mu \cdot V_{i n}}
$$

Em que $V_{\text {in }}$ é a componente sistemática da função utilidade $U_{\text {in }}$ para um indivíduo $n$ escolhendo a alternativa $i$ de um conjunto de alternativas $C_{n}$

Alguns estudos sobre acessibilidade (NEUBURGER, 1971; WILLIAMS, 1976; GEURS; VAN ECK, 2001; GEURS; VAN WEE, 2004) associam a variação da medida de acessibilidade baseada em modelos de escolha discreta ao excedente do consumidor da teoria microeconômica.

Esta relação é utilizada para avaliação dos benefícios de um sistema de transportes, mas, segundo McFadden (2001) e Jara Díaz (2007), esta relação só é possível se a porção da utilidade relacionada a renda assumir a forma linear, ou quando não há efeito das variações na renda (renda individual, ou familiar), ou quando os efeitos sobre a renda (renda 
individual, ou familiar) devido a mudanças de políticas para o transporte são pequenas que a correção linear da renda é suficiente.

As medidas baseadas na utilidade máxima esperada são oriundas de modelos que refletem preferências individuais relacionadas as escolhas de transportes, além da possibilidade de se obter uma medida do benefício econômico de suas escolhas de transportes. No entanto, esta medida só é interpretada com auxílio de parâmetros, além da relativa complexidade de obtenção de dados e cálculo.

Outra desvantagem relacionada a medida baseada na utilidade máxima esperada está relacionada a premissa de que o indivíduo é o único responsável pela sua escolha, principalmente quando a escolha envolve o local de trabalho. Para a situação de um mercado de trabalho competitivo, em geral, está premissa não é válida e o indivíduo é compelido a escolher emprego onde existe trabalho disponível (há oferta e o empregador resolveu contratá-lo).

Além do mais, a formação do conjunto de destinos disponíveis é outra fonte de erros. Muitas aplicações consideram que todas as oportunidades (consequentemente os destinos das viagens) estão disponíveis aos indivíduos e fazem parte do cálculo da acessibilidade. Quando, para vários casos, nem todas as oportunidades no meio urbano (ainda que pertinentes ao desejo do indivíduo em se engajar na atividade) se encontram disponíveis.

Desenvolvimento do modelo de escolha discreta para escolhas de destino sob restrições tem sido divulgados na literatura, um exemplo, é Palma, Picard e Waddel (2007) que desenvolveram um modelo de escolha de destino para a situação de desequilíbrio entre a oferta e a demanda.

Entretanto, o desenvolvimento da competição em modelos de escolha discreta ocorre no estágio do cálculo da probabilidade o que sugere uma limitação da utilidade máxima esperada em considerar o efeito da competição na função utilidade. 


\subsection{Avaliação de Medidas de Acessibilidade em Estudos sobre Viagens Encadeadas}

Nesta seção são descritos e avaliados os resultados de estudos que procuraram estabelecer relações entre acessibilidade e o comportamento dos indivíduos frente aos padrões de viagens.

O objetivo é descrever como a acessibilidade foi concebida e incluída na análise do comportamento individual (por exemplo, conceito de acessibilidade, índice utilizado para representação da facilidade de acesso) e extrair elementos, ou boas práticas, que possam ser incorporados na elaboração da proposta em pauta na tese. Ressalta-se que nesta seção são apresentados apenas os estudos que trataram do efeito da acessibilidade em modelos de atividades.

Há estudos que relacionam atributos do sistema de transportes em modelos de atividades, mas não consideraram o efeito destes atributos no comportamento individual em relação a participação em atividades e formação das cadeias de viagens como influência da acessibilidade. Por esta razão, trabalhos desta natureza não foram descritos nesta seção.

Os trabalhos são apresentados de forma sucinta e classificados conforme a forma abordada para estudo da acessibilidade na análise do comportamento individual referente aos padrões de viagens em: (i) conjunto de rotas alternativas; (ii) parâmetro para otimização da programação diária de atividades; (iii) atributo para escolha do destino, e; (iv) produto final do padrão de viagens. Estes grupos são detalhados de forma sucinta nas próximas seções.

\section{(i) Acessibilidade como um Conjunto de Rotas Alternativas}

Lenntorp (1976, 1978) baseado na abordagem de Hägerstrand (1970) desenvolveu o modelo de atividades PESASP (Program for Evaluating the Set of Alternative Sample Paths). Na estrutura de modelagem da programação de atividades o PESASP gera um conjunto de possíveis rotas alternativas a partir da origem para se atingir os locais para desempenho das atividades, segundo o tipo de atividade, restrições de espaço e tempo, modos de transportes e as cadeias de viagens e Leentorp (1976) denomina este conjunto de rotas como acessibilidade individual. 
(ii) Acessibilidade como Parâmetro para Otimização da Programação Diária de Ativida$\underline{\text { des }}$

Recker, Chen e McNally (2001), incorporando o conceito do prisma espaço-tempo e outros fundamentos da abordagem de atividades para interpretação das viagens, analisaram o potencial em termos de economia de tempo de viagem que cada indivíduo poderia obter pela otimização da programação diária de atividades sob restrições de espaço-tempo impostas pelas atividades, características individuais e a oferta do sistema de transportes.

Nesta abordagem a acessibilidade é considerada como tempo de viagem e a otimização é baseada na reestruturação dos prismas individuais com o rearranjo das cadeias de viagens. O potencial em termos de tempo de viagem, ou como os autores denominaram "ganho de acessibilidade", é transferido para o tempo disponível para realização das atividades dentro e fora do domicílio.

(iii) Acessibilidade como Atributo para Escolha do Destino

Hsieh e Hsu (2004) utilizando os conceitos do prisma espaço-tempo (tempo de viagem, duração da atividade e disponibilidade de tempo) formularam uma proposta de acessibilidade associada a teoria de atividades em que a decisão para engajamento em uma atividade em particular (ou conjunto de atividades) em um local específico (ou vários destinos) e viagem (ou cadeia de viagens) é baseado na premissa de que o indivíduo escolherá entre as alternativas de atividades e de viagens aquela que maximizará a sua acessibilidade (menor consumo de tempo) dado as restrições de tempo e espaço.

Em outro estudo, sob a perspectiva da acessibilidade como atributo para escolha do destino, Naess (2006) considerou a acessibilidade (representado pela distância euclidiana) para escolha dos locais de desempenho das atividades (escolha dos destinos de viagem) como parte da análise do comportamento dos indivíduos referentes às viagens.

(iv) Acessibilidade como Produto Final do Padrão de Viagens

Bradley e Bowman (1998) analisaram os efeitos da acessibilidade no comportamento individual adaptando a proposta de Ben-Akiva e Lerman (1978) para o cálculo da acessibilidade em um modelo de atividades. No modelo de atividades proposto por Bradley e Bowman (1998) a medida baseada na utilidade máxima esperada das escolhas dos modos utili- 
zados e dos destinos das viagens (acessibilidade) foi utilizada como atributo para simulação das escolhas dos padrões de viagens.

Para construção de uma medida de acessibilidade baseadas em atividades ( $A B A$ activity-based accessibility), Dong et al. (2006) adaptaram o conceito desenvolvido por Ben-Akiva e Lerman (1979) ao contexto de atividades definindo a acessibilidade como a utilidade máxima esperada do processo de escolha em um conjunto de alternativas de padrões de viagens. Sob esta ótica toda a estrutura de decisão é considerada para cálculo da acessibilidade.

\section{Avaliação das propostas}

Iniciando a avaliação das propostas que procuraram estabelecer relações entre acessibilidade e o comportamento dos indivíduos frente aos padrões de viagens, a proposta de medida de acessibilidade de Lenntorp (1976) recai no principal problema identificado para as medidas de acessibilidade baseadas no prisma espaço tempo: exigência quanto aos dados para construção da medida.

A acessibilidade obtida por Dong et al. (2006), através da utilidade máxima esperada para um conjunto de escolhas, é atribuída a funções utilidades que avaliam atributos além daqueles relacionados às condições de acesso promovida pelo sistema de transportes às atividades. Apesar de evidente, através dos parâmetros nas funções de utilidade a contribuição do sistema de transportes, não há referência do peso de atributos do sistema de transportes ou da atividade na composição da medida de acessibilidade.

As demais propostas consideram a acessibilidade como atributo para avaliação das escolhas de destino da viagem, simulando o comportamento individual para este nível decisório. Dentro da estrutura destas propostas a acessibilidade atua como um dos fatores (RECKER; CHEN; MCNALLY, 2001), ou fator (HSIEH; HSU, 2004; NAESS, 2006) para escolha do destino da viagem.

Em geral, na complexidade que envolve a modelagem da escolha do destino das atividades, admite-se que o individuo durante o processo de escolha seja influenciado principalmente pelos atributos do destino, localização das atividades antecessoras e subseqüentes, atributos dos destinos competitivos e a acessibilidade oferecida pelos diversos modos de transportes. 
Independentemente do grau de complexidade que envolve este processo, principalmente referente a escolha do local para engajamento na atividade trabalho que condicionada por um conjunto mais amplo de fatores, que não delegadas a decisões do individuo, é plausível que decisões referentes a destinos estejam ligadas como os indivíduos percebem o acesso às atividades.

Entretanto, a premissa de que a acessibilidade seja o único atributo para escolha do destino, como sugere Hsieh e Hsu (2004) e Naess (2006), só é possível num contexto em que preferências individuais pelas atividades e padrões de distribuição da atividade no meio urbano são indiferentes no comportamento individual.

Outro aspecto analisado foi o método apresentado para incorporação da acessibilidade na análise dos padrões de viagens. De forma geral, as fases de desenvolvimento dos métodos apresentados pelos estudos podem ser descritas como: (i) conceito de acessibilidade e um índice para sua representação; (ii) proposição de um esquema conceitual para interpretação de decisões individuais relacionada aos padrões de viagens; (iii) premissa sobre em que etapa na programação dos padrões de viagens a acessibilidade é considerada; e (iv) hipótese sobre o processo de modelagem das decisões individuais com a inclusão da acessibilidade.

\subsection{Seleção de Uma Medida de Acessibilidade}

A idéia básica para representação da acessibilidade é um índice que reflita a condição de acesso pelo sistema de transportes que é percebida ${ }^{14}$ pelos indivíduos ao programar suas decisões para realização de atividades.

Da análise das abordagens para representação da acessibilidade através de índices, apresentada no início deste Capítulo, as medidas de separação espacial se destacam entre as demais propostas pela facilidade de interpretação, requisito quanto a dados, cálculo do índice e pelo seu potencial de utilização em modelos de demanda por transportes, particularmente em modelos de atividades através da proposta do prisma espaço-tempo de Hägerstrand (1970).

Restava à própria natureza deste projeto científico de caráter exploratório e investigativo, explorar entre as medidas de separação espacial a mais adequada aos requisitos conceituais propostos pela pesquisa.

\footnotetext{
${ }^{14}$ Grifo proposital
} 
Ressalta-se que não é intenção deste trabalho apresentar o melhor índice de acessibilidade a ser utilizada em estudos de demanda por transportes, na medida em que não há consenso entre pesquisadores e planejadores sobre qual a melhor forma de representação da acessibilidade (CURTIS; SCHEURER, 2010).

Como argumentado por Kwan (1998), cada proposta para mensurar a acessibilidade captura apenas uma parte do que a acessibilidade representa. Segundo Thill e Kim (2005), diferentes medidas de acessibilidade são complementares entre si, fornecendo uma descrição (plural) de como os indivíduos se comportam em relação a distribuição espacial das atividades aos destinos de viagem e as características do sistema de transportes (configurações da rede e modos disponíveis).

De acordo com o exposto acima, um dos propósitos deste capítulo é selecionar uma medida de acessibilidade que seja coerente com a concepção de viagens baseadas em atividades e que possa ser utilizado para analisar aspectos referentes as condições de acesso as atividades no comportamento individual referente aos padrões de viagens.

Entre as alternativas analisadas para a medida de separação espacial (distância euclidiana, distância viária e tempo de viagem) o tempo de viagem é o índice escolhido para representar a facilidade que é percebida pelos indivíduos para alcançar qualquer atividade no espaço urbano utilizando o sistema de transportes.

Trata-se de uma forma de representação da acessibilidade largamente utilizado na literatura de transporte. Em demanda por viagens encadeadas o tempo de viagem é considerado como medida de acessibilidade no processo de modelagem em Recker, Chen e McNally $(2001)^{15}$ e de forma indireta nos trabalhos de Bradley e Bowman (1998), Hsieh e Hsu (2004) e Dong et al. (2006) ${ }^{16}$. Esta medida apresenta algumas vantagens em relação as medidas de distância que podem ser descritas como:

- Reflete a facilidade de acesso entre locais de interesse do sistema de transportes e não relativa a posição espacial entre pontos. Embora a distância seja largamente utilizada como medida de acessibilidade, este índice não reflete as características da infraestrutura do sistema como hierarquia entre vias (arterial, coletora, local) e seus diferentes limites de velocidades permitidas, não só as velocidades legais, mas também os limites condicionados pela qualidade de sua manutenção;

\footnotetext{
${ }^{15} \mathrm{O}$ tempo de viagem é considerado como medida de acessibilidade.

${ }^{16}$ Nestes trabalhos o tempo de viagem não é utilizado em si como medida de acessibilidade, mas faz parte do cálculo do índice.
} 
- É um instrumento para avaliação das condições de acesso entre os modos de transportes do sistema (por exemplo, a pé, bicicleta, motorizado individual e coletivo). A distância não captura as diferenças da facilidade de acesso entre os modos, exceto os casos em que os modos possuem redes viárias distintas;

- Captura as condições operacionais do sistema: congestionamento (aumento do tempo de viagem), intensidade da oferta do transporte público (em geral, a alta oferta do transporte coletivo incide em menor tempo de espera) e os efeitos da hora pico;

- Esta medida tem a capacidade de capturar a variação da facilidade de acesso entre pares de origem e destino de distância equivalente. A proximidade entre dois pontos pode não refletir as condições de acesso onde, por exemplo, a escolha da rota incide em regiões onde há conflitos de tráfego;

- O tempo de viagem tem o potencial de representar características individuais, por exemplo, pessoas que utilizam o automóvel para se deslocarem possuem uma melhor condição de acesso aos locais de atividade, do que as pessoas que utilizam o transporte coletivo e que estão sujeitas as restrições do serviço prestado;

- Através de modelos microeconômicos é possível estimar o custo da oportunidade do tempo de viagem, ou disposição do indivíduo desembolsar a mais para obter redução no tempo de viagem em um modo particular de transportes.

Antes de prosseguir com o detalhamento das demais dimensões da proposta para incorporação da acessibilidade no estudo do comportamento dos indivíduos relacionada aos padrões de viagens, há algumas questões conceituais sobre as medidas de separação espacial para acessibilidade que foram apresentadas na seção 2.1 e que precisam ser discutidas.

- Georreferenciamento da base de informações espaciais: ao invés de dados agregados por áreas geográficas, por exemplo, zonas de tráfego, os dados espaciais são baseados nos endereços das origens e destinos das viagens, e;

- Desagregação do tempo de viagem: cálculo do tempo de viagem (medida de acessibilidade) para cada indivíduo e por modo disponível no sistema de transportes.

Pela proposta do cálculo de tempo de viagem por modo de viagem ficam adicionadas algumas características desta medida para a acessibilidade, por exemplo: 
- A melhoria em um modo particular de transportes não deve alterar a acessibilidade para o indivíduo (ou grupo de indivíduos) com capacidade ou habilidade insuficiente para utilização deste modo para realização da atividade.

- A acessibilidade baseada em informações espaciais desagregadas (no nível do endereço) oferece a capacidade de realização de análises individuais; relação da medida com a componente individual, e; de dados necessários.

A abordagem de associação para as relações entre as componentes de uso do solo e temporal com a acessibilidade pode ser viabilizada pela análise da cobertura espacial dos locais de atividades englobadas por prismas individuais de espaço-tempo.

Assim, os locais de atividades não englobados pelo prisma não seriam considerados para cômputo do tempo de viagem e por esta proposta ficam atendidos os critérios da relação da medida com a componente de uso do solo e a componente temporal.

A incorporação da competição na medida de separação espacial pode ser associada a cobertura prismática dos locais em que a chance de desempenho da atividade é garantida. Contudo, a inserção dos locais em que a atividade pode ser desempenhada depende da disponibilidade da garantia de que o indivíduo pode desempenhar a atividade no local na base de dados.

No capítulo sobre o delineamento do experimento é proposto uma forma de inserir a competição pelas oportunidades pela proposição de um modelo de interação espacial que considera implicitamente a competição pelas oportunidades. 


\section{Capítulo 3}

\section{Influência da Acessibilidade na Programação Diária de Atividades}

[...] Existem três verdades: a sua, a minha e a verdadeira. [...]

Autor Desconhecido

\subsection{Introdução}

Com o propósito de dar continuidade ao contexto teórico deste trabalho e baseado no objetivo secundário de desenvolver uma proposta para análise da acessibilidade nas decisões sobre a programação diária de atividades, este capítulo apresenta uma proposta para avaliação da acessibilidade ao estudo do comportamento individual relacionado às cadeias de viagens. 


\subsection{Proposta para Avaliação da Acessibilidade na Programação Diária de Atividades}

A análise de viagens urbanas baseada na participação dos indivíduos em atividades realizadas fora do domicilio é uma tentativa de lidar com a complexidade das demandas diárias por atividades e suas decisões de participação.

$\mathrm{Na}$ estrutura analítica do processo de investigação do comportamento individual a viagem é considerada como resultado de um processo individual de decisões que ocorre em estágios distintos da programação de atividades. De forma simples, uma vez que o mecanismo cognitivo é complexo, os estágios que estas decisões ocorrem referem-se às dimensões e horizontes destas decisões.

As dimensões podem ser relacionadas, por exemplo: ao propósito da atividade; escolha do local para desempenho da atividade; escolha do modo de transportes para acessar as atividades; sequência das atividades; quantidade de pessoas que desempenham a atividade em conjunto; horário para realização das atividades; duração das atividades; importância relativa entre as atividades, e; decisão de quem usará o automóvel no domicílio. Segundo Axhausen (1995) e Gärlinget al. (1998), os horizontes das decisões ocorrem em três níveis: no longo prazo, no médio prazo e no curto prazo ${ }^{17}$.

Segundo Miller (2005), as decisões de longo prazo são decisões chaves que influenciam o contexto espacial de membros do domicílio ou habilidades de realização de viagens que incluem o local do domicílio, o local da atividade prioritária e decisão pela compra do automóvel, enquanto as decisões no médio ${ }^{18}$ e curto prazo são aquelas que são realizadas em prazos mais curtos ou diariamente, como participação em atividades e escolha do modo de viagem.

Ainda segundo o autor, as decisões no médio e curto prazo envolvem um conjunto inflexível de recursos e restrições (por exemplo, o trabalho presente, o local do domicílio atual, o presente número de automóveis no domicílio), enquanto as decisões no longo prazo atuam na modificação dos recursos e das restrições (por exemplo, a compra ou venda do carro, a mudança de emprego, a mudança de residência).

\footnotetext{
17 Alguns autores, por exemplo, Miller (2005) e Gärlinget et al. (1998) consideram apenas dois horizontes de decisão: longo e curto prazo. No entanto, algumas decisões como participação em atividades, restrições de capacidade e uso do automóvel no domicílio, podem ocorrer em horizontes mais extensos, o que caracterizaria uma decisão no médio prazo.

${ }^{18}$ Inclusão da decisão no médio prazo a exposição da ideia de Miller (2005) pelo autor deste trabalho.
} 
Sem direcionar o enfoque da questão a mecanismos cognitivos subjacentes ao processo de tomada de decisão do ser humano, assume-se que as dimensões e horizontes das decisões para a programação das atividades possa ser seguido pelo diagrama adaptado de Axhausen (1995), Davidson et al. (2007) e Gärling et al. (1998) apresentado na Figura 3.1.

Ressalta-se que a proposição do diagrama da Figura 3.1 não tem por finalidade sintetizar a base teórica do processo de elaboração das decisões individuais, ou seja, o mecanismo cognitivo. A sua principal funcionalidade é a proposição de um esquema para investigação da acessibilidade no contexto da demanda por viagens baseadas em atividades.

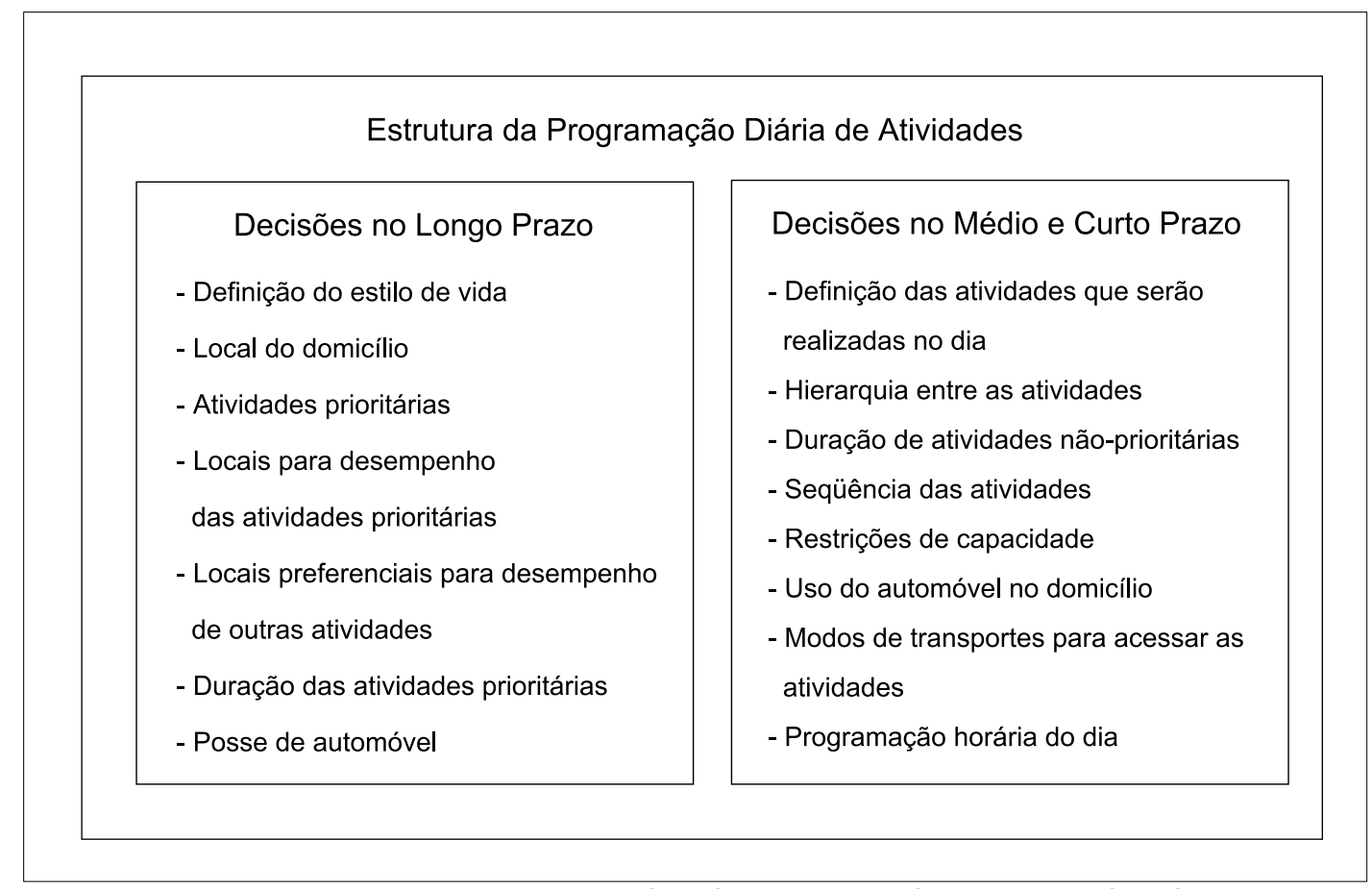

Figura 3.1 - Esquema para representação das dimensões e horizontes das decisões.

A apresentação das decisões e das dimensões em fatores separados e ordenados pode transmitir uma ideia de sequência e objetividade nas decisões, entretanto, em termos práticos esta sequência e objetividade raramente existem (CULLEN; GODSON, 1975).

Em geral, o processo de decisão na programação diária de atividades é governado pelas atividades prioritárias e dada a dinâmica da vida dos indivíduos, ou como descrito em Miller (2005) o estresse causado por situações, adaptações em busca de um melhor bem-estar geram uma reprogramação nas decisões no longo prazo que é propagado às decisões no médio e curto prazos.

A estrutura da Figura 3.1, ainda que sucinta para apresentação da complexidade que é o processo de tomada de decisão individual em relação a formação do padrão de 
viagens, apresenta os elementos necessários a serem explorados na análise de demanda por viagens encadeadas e, particularmente, apresenta as dimensões em que a influência da acessibilidade pode ser avaliada.

Baseado na premissa de que a acessibilidade influencia o comportamento individual dentro do processo de tomada de decisão relacionada a programação diária das atividades é delineado nesta seção a influência da acessibilidade nas dimensões deste processo baseado em estudos na literatura sobre modelos de atividades e na interpretação do autor sobre o tema.

O objetivo do desenvolvimento desta fase é fornecer subsídios a formulação do processo de inclusão da acessibilidade no processo de modelagem do comportamento individual relacionado aos padrões de viagens para verificação da hipótese nula da pesquisa: acessibilidade a oportunidades influencia o comportamento dos padrões de viagens encadeadas desempenhados pelos indivíduos.

\subsubsection{Definição do Estilo de Vida}

Segundo Bowman (1998), em geral, o estilo de vida é definido como associação de três históricos biográficos:

- Um conjunto de atributos individuais e familiares, estabelecidos como resultados dos eventos que ocorrem na vida;

- O acúmulo gradual de hábitos e preferências que determinam as necessidades e;

- Preferências por atividades e os recursos disponíveis para a sua satisfação.

O estilo de vida inclui: a estrutura familiar (como o adulto solteiro, decisão em ter filhos); situação no domicílio (como assalariado de renda principal no domicílio); atividades prioritárias (trabalho e/ou estudo); compromissos e hábitos (absoluta devoção ao trabalho, passatempos, recreação e participação em organizações religiosas ou sociais); e as capacidades pessoais e financeiras (tais como riqueza, qualificação profissional e deficiência física).

A abordagem de atividades para entendimento das viagens sugere que a precisão da modelagem do comportamento individual em relação aos padrões de atividade e cadeias de viagens está relacionada com a representação do estilo de vida. 
Segundo Bowman (1998) as decisões relacionadas ao estilo de vida subentendem todo o processo da programação diária de atividades. Definem os indivíduos, suas preferências, necessidades de atividades, enquanto as codições financeiras e as capacidades pessoais determinam os recursos disponíveis para sua satisfação.

Apesar de não ter empregado explicitamente o termo estilo de vida, Becker (1965) desenvolveu uma teoria sobre a alocação do tempo entre diferentes atividades. 0 ponto central desta teoria de raízes econômicas é a premissa de que membros do domicílio são produtores e consumidores: eles alocam o tempo (recurso que eles dispõem) com base em benefícios que podem ser obtidos no exercício da atividade sujeitos ao principio da minimização de custos da teoria microeconômica de maximização da utilidade.

No modelo de Becker, a renda (ou salário) é uma variável determinada pelo produto das horas que o indivíduo decide trabalhar pela remuneração paga por hora trabalhada. Como a função utilidade depende do consumo (de tempo), para o indivíduo aumentar a renda é necessário que ele adicione mais tempo à atividade trabalho, entretanto, quanto mais tempo é consumido no trabalho, menos tempo é alocado às atividades de lazer. Becker utilizou esta relação entre tempo dedicado ao trabalho e tempo dedicado as atividades de lazer como um diferencial em seu modelo.

Transferindo a perspectiva de Becker (1965) para o contexto do estilo de vida dos indivíduos, é plausível que o tempo (incluindo o de viagem) afete o estilo de vidas dos indivíduos (quanto mais tempo dedicado ao trabalho, maior será a renda, no entanto, menor será o tempo dedicado a atividades de lazer) e que o individuo busque um equilíbrio entre o benefício do tempo alocado ao trabalho com o benefício do tempo alocado a atividades de lazer.

Seguindo a linha de pensamento da valoração do tempo e sua alocação nas atividades, Train e McFadden (1978) desenvolveram um procedimento para examinar as escolhas dos modos de transportes para o trabalho baseado em uma função utilidade que expressa o processo de trocas entre capital e o tempo de lazer:

$$
\begin{gathered}
U=(1-\beta) \cdot \ln G+\beta \ln L \\
G=V+w \cdot W-c \\
L=T-W-t
\end{gathered}
$$


Em que $G$ é o capital, $L$ é o tempo de lazer, $V$ é a renda provida por outras fontes, $w$ é a taxa de salário dada em termos do valor monetário recebido por hora, $W$ é o número de horas trabalhadas, $c$ é o custo total do deslocamento para o trabalho (ida e volta), $T$ é o tempo total disponível e $t$ o tempo total do deslocamento para o trabalho (ida e volta). 0 parâmetro $\beta$ reflete a preferência do indivíduo (trabalhador) entre o capital e o lazer, um valor alto para $\beta$ implica uma grande preferência para o lazer em relação ao capital.

\subsubsection{Local do Domicílio}

O local do domicilio, em geral ${ }^{19}$, é considerado no processo de tomada de decisão sobre a programação diária de atividades como a origem e destino final das cadeias de viagens derivadas da necessidade de participação em atividades distribuídas no meio urbano.

Segundo Roorda, Carrasco e Miller (2009) a localização do domicílio é diretamente relacionado com o nível de acessibilidade de membros do domicílio às atividades no meio urbano. Por exemplo, a mudança de residência de um local provido de fácil acesso ao sistema de transportes coletivo para uma área no subúrbio com baixa disponibilidade de oferta do transporte público pode afetar a acessibilidade de membros do domicílio às atividades, resultando em viagens mais longas (distância e/ou tempo de viagem) para o desempenho de atividades.

Embora prevaleça na investigação da seleção da localização da residência a noção de que os indivíduos associam as escolhas dos locais dos domicílios ao problema do custo para realização de deslocamentos a polos de atividades (MCFADDEN, 1977; PALMA; PICARD; WADDELL, 2007), estudos demonstraram que o efeito da acessibilidade nas decisões sobre a escolha da localização da residência pode ser ofuscada por outros atributos, por exemplo, atributos do bairro (área verde, ganho de status social, segurança, etc.), renda familiar e tamanho da família (STEGMAN, 1969; WEISBROD; BEN-AKIVA; LERMAN, 1980), ou o efeito da acessibilidade ser menor que o esperado (KNIGHT; TRYGG, 1977; MTC, 1977).

\footnotetext{
${ }^{19}$ A programação diária de atividades considera um dia típico (dia útil) de atividades e viagens, considerando a origem de toda a programação no domicílio. Há exceção a esta regra, por exemplo, os casos em que as atividades ultrapassam a duração de um dia (jornadas de trabalho que incluem pernoite no local de trabalho, ou decisão de estender a atividade de lazer).
} 


\subsubsection{Atividades Prioritárias}

A prioridade das atividades é considerada como uma dimensão importante na programação diária de atividades, em particular como fator determinante na sequência da estrutura de decisão para elaboração de atividades e cadeias de viagens (DOHERTY et al., 2001).

O indivíduo, em função de seus atributos, estabelece uma ordem de prioridade entre as possíveis alternativas de atividades que serão realizadas no dia. Para Cullen e Godson (1975) os fatores que contribuem na avaliação das prioridades das atividades estão relacionados a:

- Importância da atividade, medido em termos financeiros, estratégicos e físicos;

- A presença de outros participantes nas atividades e suas características (relação com o indivíduo, frequencia de contato);

- A ordem em que as atividades foram planejadas, o planejamento das atividades resulta em atividades que foram pensadas com prioridade e;

- Idiossincrasias para algumas atividades.

Esta ordem, prioridade entre atividades, pode ser alterada ao longo do tempo em resposta às diferentes situações (AXHAUSEN; GÄRLING; 1992; DOHERTY et al., 2001).

A decisão quanto à atividade primária é sempre de longo prazo, enquanto as demais ocorrem em prazos diferentes. Em geral, atividades como trabalho e estudo são consideradas como atividades prioritárias e incluídas em primeiro plano na programação diária. Não foram encontrados na revisão da literatura indícios que confirmem a relação da acessibilidade na escolha do tipo de atividade prioritária. 


\subsubsection{Locais para Desempenho das Atividades Prioritárias}

A literatura sobre a escolha do local para desempenho das atividades (comportamento espacial) abrange várias disciplinas da ciência e contribuições a este tema são encontradas em estudos sobre o comportamento espacial e estudos sobre a modelagem do comportamento espacial (BEKHOR; PRASHER, 2008; GOLLEDGE; GÄRLING, 2004).

Nesta subseção é discutida uma abordagem para estudo do comportamento individual relacionado ao processo de decisão em relação ao local para desempenho das atividades para análise da influência da acessibilidade neste nível do processo de decisão. A discussão do processo de modelagem do comportamento espacial é descrita nasegunda etapa deste método (modelagem do comportamento individual).

$\mathrm{Na}$ análise da demanda por transportes os estudos sobre o comportamento espacial são caracterizados pelo desenvolvimento de métodos para descrição do processo de percepção do indivíduo sobre a realidade e como esta estrutura pode ser associada às decisões sobre escolha dos locais para realização de atividades e deslocamentos na programação diária de atividades.

Em geral, a premissa básica para desenvolvimento dos métodos para descrição da percepção do indivíduo sobre a estrutura espacial urbana é de que as decisões sobre escolha dos locais para realização de atividades e deslocamentos na programação diária de atividades são apoiadas em um conjunto de informações ${ }^{20}$ que em sua diversidade incluem, segundo Golledge e Gärling (2004), inferências da experiência do indivíduo no ambiente urbano.

$\mathrm{Na}$ visão destes autores, quando as pessoas envelhecem e ocorre o desenvolvimento psicológico e intelectual, os indivíduos acumularam informações sobre os ambientes e suas restrições (culturais, sociais, econômicas, políticas, jurídicas etc.) que limitaram (e limitam) a liberdade de escolha e a liberdade de movimento, além de desenvolverem diferentes níveis de habilidades para reconhecimento do ambiente.

Utilizando uma perspectiva das ciências humanas e biológicas para análise da complexidade que envolve o comportamento individual e a percepção sobre a estrutura espacial urbana, O’Keefe e Nadel (1978) sugerem que as informações que são percebidas pelos indivíduos sobre a estrutura geográfica do meio urbano é armazenada em um mapa cognitivo localizado no hipocampo.

${ }^{20} \mathrm{O}$ conjunto de informações utilizadas sobre as decisões dos locais de atividades é mais abrangente, relaciona características individuais, dos domicílios, características de mobilidade, restrições pessoais e de capacidade, etc. 
Uma vez que a informação é coletada, ela é codificada e armazenada na memória de longo prazo ${ }^{21}$ dos indivíduos. A partir das informações coletadas cada indivíduo elabora um mapa cognitivo que representa as atividades, suas características e condições de acesso a elas (GOLLEDGE; GÄRLING, 2004; HANNES; JANSSENS; WETS, 2008; KITAMURA, 2004; WESTON; HANDY, 2004).

Apesar do termo, os mapas cognitivos são codificações que podem não corresponder ao formato cartográfico, uma vez que o processo de formação da memória e da inferência perceptiva do intelecto humano da realidade é complexo e distinto. Cada indivíduo, à sua maneira, armazena e processa as informações.

No entanto, como sugerido por Kuipers (1978), presume-se que, quando confrontados com uma tarefa que envolva o deslocamento no meio urbano, os indivíduos dentro da sua capacidade congnitiva são capazes de transferir as informações codificadas (oriundas de experiências prévias) na memória de longo prazo para a memória instantânea ${ }^{22}$ e, potencialmente, organizá-las em um formato cartográfico, ou outra forma para descrição da estrutura espacial que apoiem suas decisões.

A essência da relação dos mapas cognitivos e a programação diária de atividades é a noção de que indivíduos definem o prisma espacial para realização de suas atividades e viagens baseados na experiência adquirida no meio urbano.

O mapa sugere a distribuição espacial das atividades, sendo a escolha do local do destino para desempenho da atividade produto de um processo complexo. No entanto, há estudos que indicam que em função da habilidade cognitiva os indivíduos são propensos a relacionar seus mapas mentais às escolhas de viagem, escolha dos modos, das rotas e, principalmente, para escolha do local das atividades (GOLLEDGE; GÄRLING, 2004).

Dentro deste contexto é plausível que a escolha dos locais da atividade primária dentro do processo decisório da programação diária de atividades seja influenciada pelo conhecimento baseado em experiência anteriores do ambiente em que o indivíduo reside e pelo seu histórico de participação em atividades (mapa cognitivo).

Independentemente do grau de complexidade que envolve a seleção do destino da atividade primária, principalmente referente ao local de emprego e estudo que é condicio-

\footnotetext{
${ }^{21} \mathrm{O}$ termo original em língua inglesa é long-term memory. A tradução do vocábulo para português é de autoria do autor deste texto.

${ }^{22} \mathrm{O}$ termo original em língua inglesa é working memory e refere-se ao espaço cognitivo em que as informações são utilizadas para processar as decisões de momento. A tradução do vocábulo para português é de autoria do autor deste texto.
} 
nada por um conjunto mais amplo de fatores, além daqueles ligados ao individuo, é aceitável que decisões referentes a destinos estejam diretamente ligadas como os indivíduos percebem o acesso aos locais para desempenho das atividades na formação dos mapas cognitivos. Segundo Weibull (1980), a acessibilidade afeta a liberdade das ações individuais na escolha dos destinos.

Particularmente quanto ao tempo de viagem, esta medida de acessibilidade é explorada em estudos do comportamento individual relacionando à escolha do destino, incluindo modelos de viagens baseadas em atividades.

Kitamura (1984) apresentou um estudo para escolha dos destinos em cadeias de viagens, demonstrando que há diferenças significativas no modelo quando a variável tempo de viagem é incluída (melhor representatividade do comportamento individual).

No modelo desenvolvido para a cidade de Portland, Bowman (1998) explorou o uso do tempo de viagem pelos modos não motorizados nas escolhas dos destinos para realização das atividades e cadeias de viagens. Os resultados comprovaram que o tempo de viagem pelos modos não motorizados influencia as escolhas individuais sobre os destinos das atividades e o número de viagens.

Investigando as diferenças entre abordagens para o processo de modelagem do comportamento individual referente as escolhas discretas de destino para uma atividade específica, entre as conclusões apresentadas por Bekhor e Prashker (2008) está a importância do tempo de viagem e sua significância estatística nos modelos construídos.

Outros estudos em que o tempo de viagem é explorado na modelagem do comportamento individual referente aos destinos (escolhas discretas e padrões de viagens) são: Ansah (1977); Arentze, Ettema, Timmemans (2010); Bowman e Ben-Akiva (2000); Burns e Golob (1976) e Niemeier (1997).

\subsubsection{Locais Preferenciais para Desempenho de Outras Atividades}

Os locais de preferências para desempenho de outras atividades (atividades que não são incluídas na lista de atividades prioritárias) referem-se aos espaços que são frequentados pelo desejo de repetir a atividade no local. Este fenômeno ocorre devido a características peculiares relacionados à execução de uma atividade em particular e que recaem nas idiossincrasias dos indivíduos. 
De forma análoga aos locais para desempenho das atividades prioritárias, as atividades não primárias são associadas ao mapa cognitivo e são influenciados pela acessibilidade. No entanto, a complexidade do processo de escolha destes locais difere das características do processo associado aos locais de atividades primárias.

Em geral, as localizações destas atividades incidem na rota do domicílio ao local da atividade prioritária, ou são escolhidas em função da qualidade da oferta da atividade ou recaem nas idiossincrasias do indivíduo, por exemplo, preferência pela cozinha de um restaurante quando a atividade refere-se a alimentação; número de lojas com opções para um item pretendido quando a atividade refere-se a compras, etc.

\subsubsection{Alocação do Tempo: Duração da Atividade Prioritária e de Atividades Não Prioritá- rias}

O estudo da duração da atividade prioritária e de atividades não prioritárias pode ser analisado pela perspectiva da alocação do tempo na programação diária de atividades para os planos de participação em atividades e realização de viagens nas 24 horas do dia que o individuo dispõe.

Segundo Bhat e Koppelman (1999), algumas propostas para alocação do tempo dentro da análise de viagens baseadas em atividades classificam as atividades em relação ao propósito da necessidade para em seguida analisar a alocação do tempo para estes tipos de atividades baseadas em características individuais e do domicílio.

$\mathrm{Na}$ visão destes pesquisadores estas propostas ignoram o contexto em que as atividades são realizadas. As propostas apresentadas não consideram o período do dia do desempenho da atividade, a sequência das atividades na programação, a duração de participação em cada atividade, o local para desempenho da atividade e as restrições de capacidade (sozinho, com cônjuge, com filhos, etc) para realização da atividade.

A primeira discussão (associada a concepção de viagens baseadas em atividades) sobre a alocação do tempo no contexto das restrições de espaço e tempo surge na proposta do prisma espaço-tempo elaborada por Hägerstrand (1970), detalhado no Capítulo 2. Pela perspectiva apresentada por Härgestrand as restrições espaciais e temporais para acesso a destinos potenciais para desempenho de atividades são representadas através de uma estrutura prismática identificando o deslocamento associado para realização da atividade (graficamente expresso em duas dimensões); e o tempo disponível para realização da viagem até o destino pelo sistema de transportes e exercer a atividade no destino (grafica- 
mente expresso na terceira dimensão). 0 esquema do prisma espaço-tempo foi apresentado na Figura 1.2 e é reproduzido na Figura 3.2.

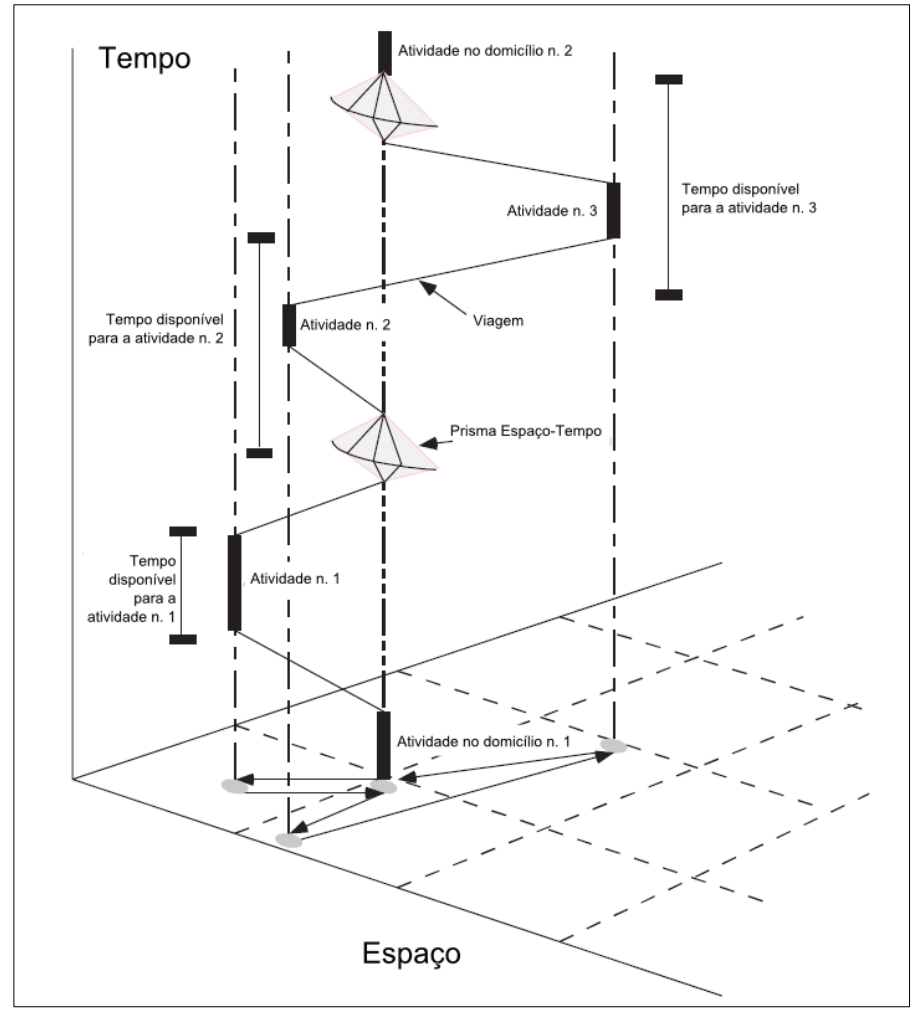

Figura 3.2 - Exemplo do padrão de viagens de um indivíduo e o prisma espaço-tempo, adaptado de Hägerstrand (1970) e Recker, Chen, McNally (2001).

Uma derivação da teoria de Hägerstrand é apresentada por Cullen e Godson (1975). Estes pesquisadores apresentam as restrições temporais com maior grau de rigidez que as restrições espaciais (por exemplo, a duração das atividades prioritárias) e à medida que a alocação do tempo para realização da atividade não prioritária e de não subsistência se aproxima do fim do dia, mais flexível a componente temporal se torna.

Em síntese, para Cullen e Godson (1975) a duração das atividades prioritárias e sua alocação no prisma são mais rígidas ao passo que a duração das atividades não prioritárias é mais flexível na programação diária de atividades.

Para Steed e Bhat (2000), além de mais flexível em comparação às atividades prioritárias, a duração das atividades não prioritárias é dada em função de características demográficas e da acessibilidade enquanto a duração da atividade primária é relacionada às características intrínsecas às atividade, por exemplo, regime de trabalho de 8 horas diárias, escola, 5 horas diárias. Rosen, Shankar e Ulfarsson (2004) demonstraram que a duração da atividade de compras tem relação com o tempo de viagem. 
Segundo Pant e Bullen (1982) há relação entre a duração das atividades não prioritárias com a duração da atividade prioritária. Enquanto as atividades prioritárias são fixas em termos de duração e podem ser fixas em termos de horário na programação, a duração das atividades não prioritárias é encaixada em função das janelas de tempo disponíveis pelas atividades prioritárias (ARENTZE; ETTEMA; TIMMERMANS, 2010).

Acredita-se que pela concepção do prisma-espaço tempo de Hägerstrand (1970) e pela teoria de alocação do tempo apresentada em Becker (1965) que, de maneira geral, indivíduos planejam as durações das atividades secundárias baseados na duração da atividade primária, facilidade de acesso às atividades primárias e secundárias sob as restrições de capacidade e do prisma espaço-tempo (tempo disponível).

\subsubsection{Posse de Automóvel}

A posse do automóvel é um fator relevante na determinação dos padrões de mobilidade de membros do domicílio. Segundo Roorda, Carrasco e Miller (2009) há uma necessidade de entender, não apenas os fatores relacionados a alta motorização das populações, mas o caminho trilhado para este fenômeno.

Entender a relevância da posse do automóvel em modelos de atividades (a relação da posse do automóvel e o comportamento individual relacionado aos padrões de viagens) é essencial para o desenvolvimento de políticas públicas voltadas para a redução do uso do automóvel nas cidades e prevenção da necessidade do uso massivo do automóvel nas viagens.

Apesar da noção da renda (individual e familiar), quantidade de membros no domicílio e número de trabalhadores determinarem a posse de automóvel no domicílio (BHART; PULUGURTA, 1998; DARGAY, 2001; KITAMURA, 2009; ROUWENDAL; POMMER, 2004), estudos indicam que o tempo de viagem para acesso aos locais para desempenho das atividades também influencia a decisão da posse do automóvel no domicílio.

Train (1980) demonstrou que a facilidade com que membros do domicílio se deslocam a vários destinos para desempenho de atividades afeta a demanda por automóvel no domicílio. Badoe e Miller (2000) sugerem que a redução no tempo de viagem em acessar as atividades tornam as viagens por modos não motorizados ou coletivos mais atrativas, reduzindo a posse do automóvel no domicílio. 
Analisando a posse do automóvel na Região Metropolitana de São Paulo nos anos de 1987 e 1997 através da aplicação de um modelo logit para a posse de automóveis no domicílio, Pfeiffer e Strambi (2005) concluíram que ao longo do período considerado, as características familiares mantiveram ou perderam a sua importância como fatores explicativos:

- O tamanho da família foi a única variável que ganhou importância no período;

- A renda familiar confirmou a sua relevância, mas os coeficientes associados aos valores da renda familiar em 1997 são sistematicamente menores que os valores estimados para 1987;

- O efeito do número de trabalhadores sobre a posse de automóvel revelou ser negativo;

- O número de estudantes não afeta significativamente as decisões familiares relacionadas com a posse de autos;

- A presença de crianças na família influencia negativamente a posse de mais de um automóvel;

- Os coeficientes da variável sexo do chefe da família indicam que famílias chefiadas por mulheres têm menor probabilidade de possuir automóveis;

- Os resultados confirmam o efeito da variável idade do chefe da família, com uma elevação da posse de automóvel até a faixa de 50 a 60 anos.

Segundo Pfeiffer e Strambi (2005), a análise realizada revela que as variáveis de estrutura familiar utilizadas na análise e modelagem da posse de autos perderam importância ao longo do tempo, assim como a própria renda familiar.

Isto sugere que as famílias têm passado a dar maior importância a outros fatores para tomar decisões relacionadas com a posse de autos. Alguns desses fatores podem estar vinculados à maior facilidade de aquisição de automóveis por uma família. Facilidades para o financiamento de veículos novos e usados, os consórcios de veículos e a oferta de veículos populares são alguns dos indícios das alternativas disponibilizadas para as famílias que querem adquirir um automóvel. Adicionalmente, a evolução das condições do transporte público, assim como da organização espacial da região podem contribuir para esta tendência (PFEIFFER; STRAMBI, 2005). 
Analisando o efeito de variáveis de uso do solo, de transportes e demográficas Bhat e Guo (2007) concluíram que há influência do tempo de viagem (acessibilidade) pelo transporte coletivo e motorizado individual na posse de automóvel nos domicílios: a propensão dos domicílios para a posse de automóvel aumenta com o tempo de viagem (privado) e diminui com a melhoria da acessibilidade pelo transporte coletivo, quanto menor o tempo, menor a propensão para a posse de automóvel no domicilio (BHAT; GUO, 2007).

\subsubsection{Definição das Atividades que serão Realizadas no Dia, Hierarquia entre as Ativida- des e Sequência das Atividades}

De acordo com a abordagem de viagens baseadas em atividades, as viagens são consideradas como uma atividade derivada pelo desejo de conectar atividades espacialmente distribuídas em locais distintos seguindo uma sequência lógica. Esta visão para viagens implica que a sequência e período em que as viagens ocorrem não dependem apenas das características das viagens que variam em função da hora do dia, e sim de um conjunto mais amplo de fatores relacionados a programação diária de atividades (ETTEMA et al., 2007).

Um dos problemas para análise do comportamento individual relacionado a decisão sobre as atividades que serão realizadas no dia, hierarquia entre as atividades e a sequência em que elas serão realizadas na elaboração da programação diária de atividades é o tempo em que estas decisões ocorrem: cada atividade é analisada separadamente, ou todas as atividades são consideradas simultaneamente no processo (GÄRLING et al., 1998).

Seguindo o princípio do comportamento humano da satisfação proposto por Simon (1982) a estrutura de tomada de decisão é propensa a ser incremental: as decisões ocorrem separadamente por atividade. No entanto, analisando o comportamento individual em relação ao processo de decisão para realização de atividades distribuídas espacialmente, Hayes-Roth e Hayes-Roth (1979) propõem que o planejamento das atividades segue uma sequência pré-determinada.

Uma premissa para explicação deste processo é que o planejamento das atividades (definição, hierarquia e sequência) depende das circunstâncias em que o indivíduo está envolvido. Em geral, assume-se que a atividade primária será a primeira candidata a ser programada e a primeira atividade a ser realizada.

Entretanto, pela perspectiva microeconômica para entendimento do comportamento individual para a definição das atividades que serão realizadas no dia, hierarquia entre 
as atividades e sequência das atividades, existe a noção de que o indivíduo tentará utilizar racionalmente os recursos que ele dispõe.

Sob esta ótica, o indivíduo na programação tentará reduzir custos e buscar por formas mais adequadas de racionalização do tempo e por indução, é plausível que no contexto da programação nenhuma atividade seja programada isoladamente antes da avaliação do tempo e custo requeridos para sua realização em combinação com outras atividades.

Para Huber (1990), Montdomery (1989) e Tversky (1972) o processo de decisão sobre as atividades que serão realizadas no dia, hierarquia entre as atividades e a sequência em que elas serão realizadas pode ser descrito com uma estrutura de vários estágios com diferentes regras de comportamento aplicadas a cada estágio.

Ainda segundo estes autores, estas regras são caracterizadas como compensatórias e não compensatórias. Para Gärlinget al. (1998) um importante aspecto na programação das atividades é que as decisões dependentes são realizadas simultaneamente.

Segundo Bowman e Ben-Akiva (2000) na programação de atividades as pessoas organizam as suas atividades em "pacotes diários", permitindo interações significativas entre as decisões de participação em atividades enfrentando limitações (restrições de tempo e espaço, condições de mobilidade, capacidade) para tentar alcançar os objetivos de suas atividades.

Com relação ao processo para representação do comportamento individual relacionado às atividades que serão realizadas no dia, hierarquia entre as atividades na programação e sequência de realização, várias abordagens têm sido propostas no processo de modelagem destas decisões, incluindo a análise da acessibilidade nas decisões que são tomadas.

Bowman e Ben-Akiva (1998), ao analisarem os efeitos de características do sistema de transportes, uso do solo e características individuais nos padrões de viagens através de um modelo hierárquico, apresentam nos resultados influência do tempo de viagem por modos motorizados de forma indireta ${ }^{23}$ nas escolhas do padrão de viagens (escolha das atividades e sequência entre elas) e no período em que são realizadas.

Os efeitos do tempo de viagem por modos motorizados foram também apresentados em Ettema et al. (2007) para padrões de atividades formados pela atividade trabalho (prio-

\footnotetext{
${ }^{23}$ Através do logaritmo da utilidade do modo e destino da viagem no processo de modelagem da escolha do padrão de viagens e período que são realizadas.
} 
ritária) e Vovsha e Bradley (2004) apresentam a influência do tempo de viagem para os diversos modelos para análise da demanda por atividades na formação dos padrões de atividade (escolha da atividade e sequência) para atividades prioritárias e não prioritárias.

\subsubsection{Restrições de Capacidade}

As restrições de capacidade referem-se a realização das atividades que são desempenhadas em conjunto ou com a presença de outro membro do domicílio. Segundo Gliebe e Koppelman (2005) o reconhecimento da interação de membros do domicílio em modelos de atividades possibilita análises das respostas comportamentais do domicílio a mudanças na distribuição das atividades no meio urbano, características do sistema de transportes, e características socioeconômicas dos indivíduos e do domicílio.

Srinivasan e Athuru (2005) examinaram a distribuição de atividades de manutenção (compras, pagamentos, servir crianças na escola, etc.) entre membros do domicílio. A especificação do modelo foi voltada se a atividade foi realizada sozinha ou na presença de outro membro, e quais membros dos domicílios eram envolvidos nas atividades. As análises dos resultados dos modelos sugerem que variáveis como, situação no domicílio, sexo, renda individual, disponibilidade de automóvel, situação de trabalho (empregado/desempregado) e a presença de criança no domicílio são as principais variáveis que são determinantes se a atividade é realizada sozinha ou com acompanhante. A presença de criança do domicílio para realização das atividades que são desempenhadas em conjunto é especialmente reforçada em Bradley e Vovsha (2005) e Kato e Matsumoto (2008).

Em síntese, para diversos autores (FERDOUS et al., 2010; BHAT; PENDYALA, 2005; MEISTER; FRICK; AXHAUSEN, 2005; SRIVIVASAN; BHAT, 2005) a definição desta decisão é dada em função das características dos membros do domicílio, das características de participação em atividades e dos papéis desempenhados no domicílio. Não foram encontrados na revisão da literatura indícios que confirmem a relação da acessibilidade com a restrição de capacidade.

\subsubsection{Uso do Automóvel no Domicílio}

Segundo Sonh e Yun (2009) há uma noção que o uso habitual do automóvel para realização das viagens é diretamente relacionada a natureza psicológica dos viajantes alheio às características externas dos atributos dos modos. Para Ellawayet al. (2003) os benefícios 
psicológicos são caracterizados como sentimento magistral, amor próprio, autonomia, proteção e prestígio ${ }^{24}$.

No domicílio, a decisão de cessão do uso do automóvel para um membro em particular no domicílio pode ser influenciada principalmente pela:

- Prioridade da atividade no domicílio: atividades como trabalho e estudo possuem relevância no domicílio, por exemplo, o chefe de família que necessita do automóvel para realizar a viagem com motivo trabalho para subsistência da família; atividades de subsistência do domicílio, por exemplo, membros que necessitam do veículo para realizar compras de alimentos para o domicílio;

- Renda domiciliar: o poder econômico do domicílio é associado ao aumento de número de veículos no domicílio (acúmulo de bens) que eleva a taxa motorização entre membros do domicílio e induz os membros aptos para condução ao uso do automóvel, e;

- Dificuldade de acesso ao local para desempenho da atividade: em áreas onde a oferta do sistema de transporte público é insuficiente para promover o acesso dos indivíduos, pessoas de alto e baixo poder aquisitivo utilizam o automóvel para acessar atividades prioritárias no domicílio.

\subsubsection{Modos de Transportes para Acessar as Atividades}

As opções que os indivíduos têm no meio urbano (escolhas espaciais, de transportes, de programação horária etc.) produzem demandas agregadas que dão forma a dinâmica urbana, por exemplo, as condições de tráfego, acesso as atividades distribuídas espacialmente e as provisões de capacidade de serviços oferecidos.

Esta premissa induz ao planejamento de transportes que na análise de políticas públicas relacionadas a transportes é importante saber como características dos domicílios, atributos individuais, características do sistema de transportes e políticas públicas influenciam o comportamento individual relacionada às escolhas dos modos disponíveis no sistema de transportes.

A literatura sobre o entendimento do processo de decisão sobre as escolhas individuais para os modos de transportes é vasta e diversificada em relação ao tema. Em geral, a década de 1970 notabilizou-se pela aplicação de modelos microeconômicos para simulação

\footnotetext{
${ }^{24}$ Vocábulos traduzidos para o português da forma como foi redigido em inglês: feelings of mastery, selfesteem and autonomy, protection, and prestige.
} 
do comportamento individual em relação às opções modais de transportes (MCFADDEN, 2000).

Ao longo dos anos, os estudos sobre escolhas modais foram diversificados com a investigação sendo conduzida na exploração das funções associadas aos custos dos modos de transportes; estudos de acessibilidade; estudos de equidade; estimação de modelos com base em informações obtidas em pesquisas de preferência declaradas; interação com características de uso do solo, e; adoção da agenda sustentável, com apelo aos modos de transportes não motorizados ${ }^{25}$.

Segundo Axhausen (2010) o estudo do comportamento individual relacionado ao processo de decisão da escolha do modo da viagem pode ser explorado em relação ao contexto temporal, que envolve os horizontes das decisões, e em relação à unidade de decisão: a viagem discreta como unidade de análise, ou as cadeias de viagens como unidade de análise.

O problema dos horizontes das decisões é caracterizado pela influência de decisões no longo prazo, por exemplo, localização da residência e do emprego, posse de automóvel no domicílio, e sua influência do comportamento de membros do domicílio nas escolhas dos modos de transportes, enquanto as decisões no curto prazo são relacionadas à características circunstancias do sistema de transportes, dos indivíduos e do domicílio na escolha do modo, por exemplo, a relação do custo do modo com a renda individual, ou renda domiciliar.

No contexto da viagem discreta como unidade de análise da decisão do modo de viagem no comportamento individual, cada viagem é considerada como um evento independente para o qual o indivíduo realiza decisões em relação ao modo de transportes, em contraposição às análises vinculadas às cadeias de viagens que consideram as viagens realizadas durante um dia como resultado das decisões da programação diária de atividades.

Tradicionalmente, a análise do modo de transportes vem sendo explorada no contexto das viagens discretas com diferentes horizontes na análise das decisões. Contudo, é crescente o número de estudos voltados ao desenvolvimento de modelos do comportamento individual relacionadas às opções de mobilidade dentro do contexto de viagens baseadas em atividades (AXHAUSEN, 2010).

\footnotetext{
${ }^{25}$ Uma retrospectiva sobre o progresso de estudos sobre escolha dos modos de transportes é associada a retrospectiva sobre as pesquisas na área de transportes em Banister, Browne, Givoni (2010) e na retrospectiva sobre pesquisas área de modelos desagregados de transportes em McFadden (2000).
} 
Segundo Arentze e Timmermans (2000), em modelos de demanda por viagens baseadas em atividades as decisões sobre modos de transportes ditam as ações no espaço em que indivíduos podem selecionar as localidades para desempenho das atividades.

Em relação a influência da medida de acessibilidade no processo de decisão em relação a escolha do modo de viagem, o tempo de viagem é uma condição sine qua non dos modos disponíveis no sistema de transporte e um atributo largamente utilizado para decisões quanto a escolha do modo para realização da viagem discreta, por exemplo, Hess, Bierlaire e Polak (2005), Kawamoto (1994), McFadden (1974), Train (1980), Sohn, Yun (2009), Swait e Ben-Akiva (1987), ou dos modos utilizados nas cadeias de viagens, por exemplo, Bowman e Ben-Akiva (2000), Cirillo e Axhausen (2002), Ettema (1996) e Krygsman, Arentze e Timmermans (2007).

\subsubsection{Programação Horária do Dia}

A programação horária do dia corresponde ao início e término das viagens e das atividades que fazem parte da programação diária de atividades. Em geral, o inicio e término das atividades primárias, que determinam a duração da atividade primária, são alocados em um eixo imaginário do tempo.

A programação horária do dia continua com a adição da duração das atividades secundárias e os tempos de viagens entre o domicílio e os locais para realização das atividades e entre os locais para realização das atividades. Além do tempo de viagem no modo principal, são incluídos os tempos de acesso e egresso, espera e de transferência no sistema de transportes. Se alguma atividade é realizada em conjunto, uma adaptação do horário é realizada para combinação da programação dos indivíduos.

\subsection{Considerações Finais}

Analisando os estudos que testaram a hipótese da interferência da acessibilidade no comportamento individual relacionado aos padrões de viagens, há indícios ${ }^{26}$ de que esta hipótese não seja refutada no comportamento individual relacionado às seguintes etapas do processo de decisão da programação diária de atividades:

\footnotetext{
${ }^{26}$ Estudos comprovaram a interferência do tempo de viagem, medida adotada para representar a acessibilidade, no comportamento individual relacionado ao padrão de viagens.
} 
- Decisões no longo prazo:

- Local do domicílio;

- Locais para desempenho das atividades prioritárias;

- Locais preferenciais para desempenho de outras atividades;

○ Posse do automóvel;

- Decisões no médio e curto prazo:

- Definição das atividades que serão realizadas no dia;

- Hierarquia entre as atividades;

○ Duração de atividades não prioritárias;

- Sequência das atividades;

- Uso do automóvel no domicílio;

- Modos de transportes para acessar as atividades;

- Programação horária do dia.

Em relação aos níveis de decisão na programação diária de atividades em que há indícios, comprovados por experiências apresentadas na literatura, da interferência do tempo de viagem nas decisões, neste trabalho é apresentado um estudo sobre a influência da acessibilidade nas decisões relacionadas a opção modal para realização da viagem, destino da atividade e de padrão de viagens que em relação a estrutura apresentada na Figura 4.3, referem-se às:

- Decisões no longo prazo:

- Locais para desempenho das atividades prioritárias;

- Decisões no médio e curto prazo:

- Definição das atividades que serão realizadas no dia;

- Hierarquia entre as atividades; 
- Sequência das atividades;

- Modos de transportes para acessar as atividades.

A principal justificativa para a seleção destes níveis de decisão é a importância destas respostas individuais na busca de respostas à questões centrais no planejamento urbano e sua utilidade em solucionar as demandas diárias de transportes, por exemplo:

- Locais para desempenho das atividades prioritárias:

- Para qual região no meio urbano os indivíduos se deslocam?

- Qual é o motivo dos deslocamentos para determinadas áreas urbanas?

- Modos de transportes para acessar as atividades:

- Qual modo eles utilizam nestes deslocamentos e os atributos que influenciaram na escolha?

- Definição das atividades que serão realizadas no dia, hierarquia entre as atividades e sequência das atividades;

- Quantas viagens cada indivíduo produz e por quê?

- Quantas viagens cada domicílio produz e em quais circunstâncias (problema do padrão de viagens)?

- Qual é a frequência destes deslocamentos e seu motivo (problema do padrão de viagens)?

Com avaliação nestes níveis de decisão é possível mapear não somente a intensidade da influência da acessibilidade no comportamento individual, mas a influência de outros atributos que interferem nas decisões que são relacionados às características socioeconômicas dos indivíduos e domicílios, a distribuição das atividades no meio urbano, participação em atividades e outros atributos do sistema de transportes, e como estes fatores se relacionam na estrutura de um processo de modelagem com a acessibilidade.

Outra justificativa recai no tratamento da complexidade da estrutura de decisão da programação diária, processo de modelagem e requisito de dados. Um maior número de decisões do comportamento individual poderia ser adicionado ao processo de verificação da hipótese nula, mas implicaria uma maior complexidade no processo de modelagem (por 
exemplo, estrutura matemática para modelar a hierarquia e as interfaces entre decisões) que, face às exigências em termos de dados, maior número de informações para representação do comportamento individual e sua provável indisponibilidade tornariam mais difícil o processo de modelagem de um maior número de decisões. 


\section{Capítulo 4}

\section{Delineamento do Método}

[...] A maior invenção do século XIX foi a invenção da invenção do método. [...]

A. N. Whitehead

\subsection{Considerações Iniciais}

O propósito da tese é integrar características do sistema de transportes por meio de indicadores individuais de acessibilidade ao conjunto de informações formado pelas características demográficas, participação em atividades e de uso do solo na análise das relações dessas informações no comportamento individual relacionado à programação de atividades fora do domicílio.

A partir do problema central da tese (como a acessibilidade a oportunidades influencia o comportamento relacionado às viagens encadeadas?) e da hipótese proposta (acessibilidade a oportunidades influencia o comportamento dos padrões de viagens encadeadas desempenhados pelos indivíduos) ficaram caracterizados os objetivos para o desenvolvimento deste trabalho.

O objetivo principal (investigar como a acessibilidade influencia o acesso das pessoas na realização de atividades fora do domicílio, afetando assim a forma como os indiví- 
duos programam suas atividades e o comportamento dos padrões de encadeamento de viagens no meio urbano) subentende todo o conjunto de desenvolvimento da tese, ao passo que os objetivos secundários levaram ao desenvolvimento de partes específicas deste trabalho.

Os objetivos secundários relacionados à base teórica do trabalho (propor uma estrutura para representação das decisões individuais relacionadas à programação diária de atividade e dentro desta estrutura desenvolver uma proposta para análise da acessibilidade nas decisões sobre a programação diária de atividades e selecionar uma medida de acessibilidade que reflita a facilidade de acesso do sistema de transportes a destinos potenciais para realização de atividades) foram apresentados nos capítulos anteriores.

Os objetivos restantes são abordados neste capítulo que é divido em três etapas, conforme apresentado pelo esquema da Figura 4.1:

- Etapa 1: Tratamento dos dados e construção das variáveis

Objetivo contemplado:

- Elaborar um conjunto de variáveis a ser utilizado na análise da demanda por viagens encadeadas e que represente informações sobre características socioeconômicas dos indivíduos; dos domicílios; participações individuais em atividades realizadas fora do domicílio; intensidade e distribuição geográficas das atividades no meio urbano; características dos padrões de mobilidade, e; características de acesso da população às atividades.

- Etapa 2: Proposta de uma estrutura para modelagem do comportamento individual em relação às opções de mobilidade, escolha dos destinos das atividades e padrões de viagens.

Objetivos contemplados:

- Propor um processo para modelagem do comportamento individual relacionado às decisões na programação diária de atividades com a interação entre variáveis dependentes que representam as decisões na programação e variáveis independentes que representam os atributos considerados na formação das decisões, incluindo a acessibilidade;

- Testar a significância das variáveis propostas e o desempenho dos modelos. 


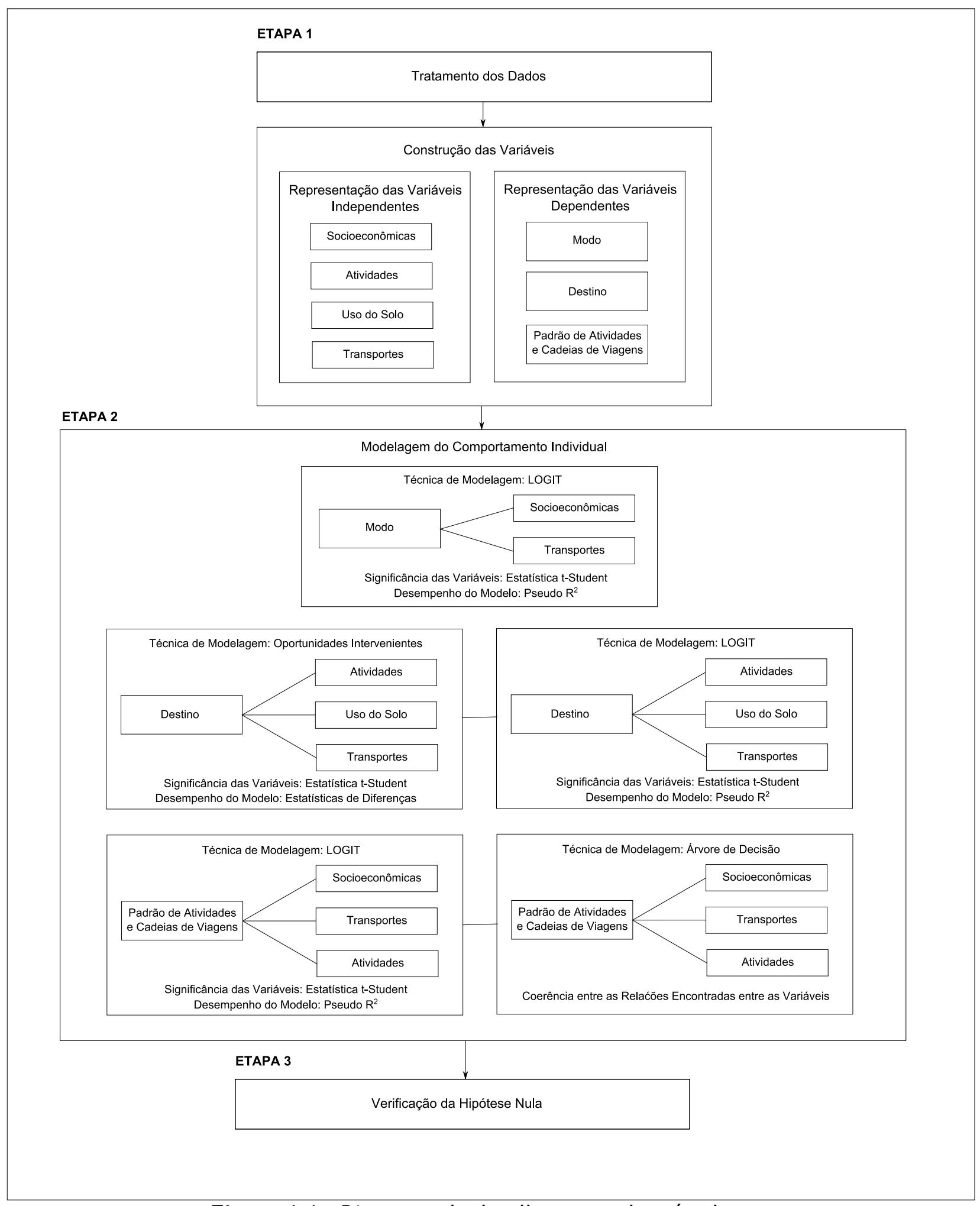

Figura 4.1 - Diagrama do detalhamento do método 
- Etapa 3: Verificação da hipótese nula.

Objetivo contemplado:

- Elaborar a conclusão sobre a hipótese.

A partir da proposta para incorporação da acessibilidade na análise dos padrões de viagens é desenvolvido a primeira etapa do método, preparação do experimento, com o delineamento da fase de tratamento dos dados, coletados a partir da cidade utilizada no estudo de caso, e o processo de construção das variáveis que são utilizadas no processo de modelagem do comportamento individual relacionado aos padrões de viagens.

Esta etapa envolve as atividades de limpeza e codificação da base de dados para proposição de variáveis que representem o conjunto de informações formado pelas características socioeconômicas dos indivíduos, dos domicílios, participação em atividades, intensidade e distribuição geográficas das atividades no meio urbano, características dos padrões de mobilidade, características de acesso da população às oportunidades.

Estabelecida a proposta para estudo da acessibilidade na análise do comportamento individual relacionado às decisões de participação em atividades e viagens e à construção da base de informações para realização deste estudo, a segunda etapa do método propõe formulação de hipóteses auxiliares ${ }^{27}$ e procedimentos para sua verificação.

As hipóteses auxiliares são empregadas na descrição dos efeitos dos fatores que influenciam o comportamento individual relacionado às decisões na programação de atividades e sua demonstração é dada através da aplicação de técnicas de modelagem do comportamento individual ao conjunto de dados.

A verificação da hipótese é realizada na última etapa por estatísticas para significância dos parâmetros das variáveis independentes na modelagem da variável dependente e desempenho do modelo em representar o comportamento individual nos níveis de decisão dentro da programação diária de atividades.

A partir dos testes de hipóteses (auxiliares) propostos e com a atenção da análise dos resultados voltada para o delineamento da influência da acessibilidade nos modelos, são reunidos indícios para elaboração da conclusão da rejeição, ou não rejeição da hipótese nula do projeto.

\footnotetext{
${ }^{27}$ Sua finalidade é auxiliar a verificação da hipótese nula do projeto de pesquisa, pode também ser denominada de hipótese secundária.
} 


\section{ETAPA 1}

\subsection{Tratamento dos Dados e Construção das Variáveis}

O propósito da etapa de preparação do experimento é apresentar o procedimento utilizado para o tratamento dos dados (coletados a partir da cidade estudo de caso) e construção das variáveis utilizadas no processo de verificação da hipótese nula.

Os procedimentos descritos nesta etapa da pesquisa buscam atender o caráter de uma investigação científica e permitir que outros pesquisadores repliquem os procedimentos descritos para verificação da hipótese nula com o interesse de confirmar os resultados aqui obtidos ou verificar a hipótese em outro contexto urbano. Para atingir sua finalidade esta seção é dividida em duas partes, tratamento dos dados e construção das variáveis (Figura 4.2).

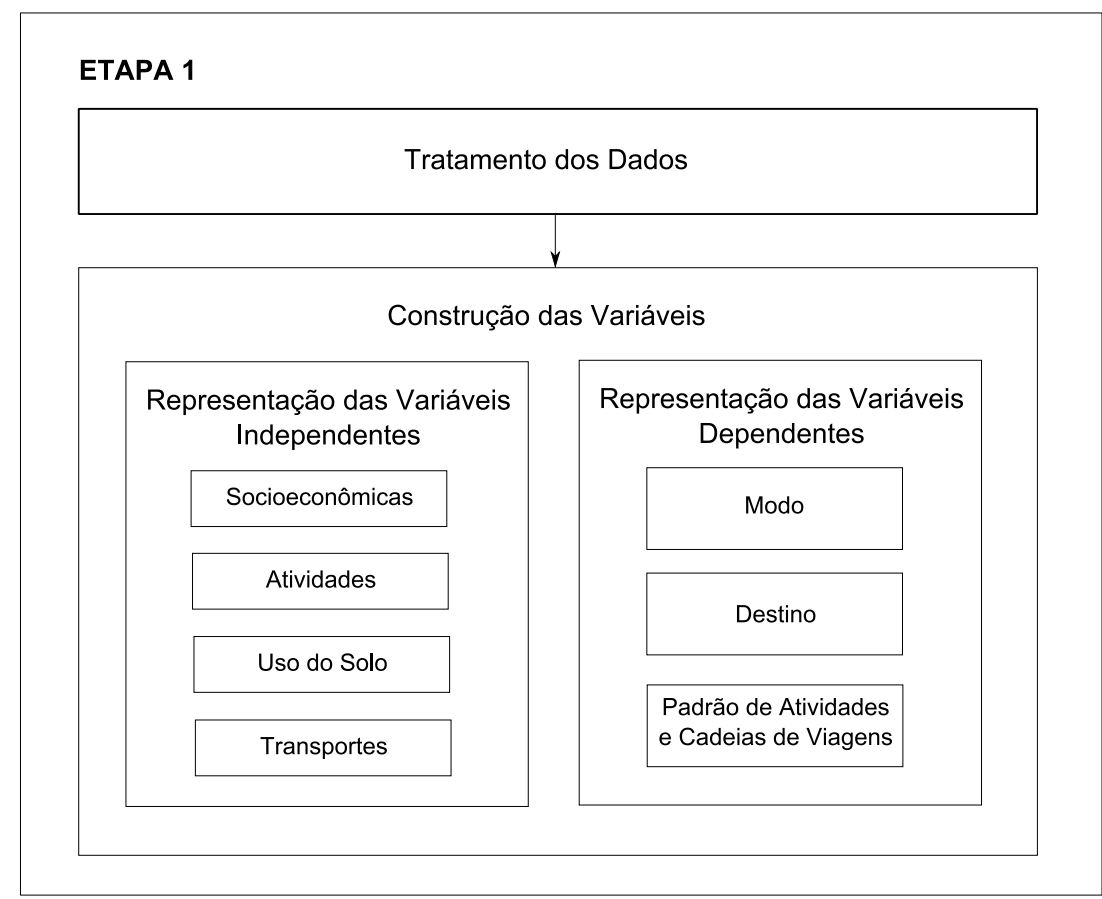

Figura 4.2 - Detalhamento da proposta para tratamento dos dados e construção das variáveis.

A primeira parte, tratamento dos dados, envolve uma breve descrição das informações que foram coletadas (fonte dos dados), limpeza ${ }^{28}$ e manipulação dos dados para a construção da base de dados. 
Na segunda etapa, construção das variáveis, é apresentado o sistema utilizado para codificação e construção das variáveis para representação das características socioeconômicas dos indivíduos; características dos domicílios; participação em atividades; intensidade e distribuição geográficas das atividades no meio urbano; características dos padrões de mobilidade, e; características de acesso da população às atividades.

\subsubsection{Tratamento dos Dados}

\section{Coleta dos Dados}

O desenvolvimento do estudo de caso é baseado em informações obtidas na cidade de Uberlândia, localizada no Estado de Minas Gerais, que, em função de suas características sócio demográficas e da disponibilidade dos dados necessários para o desenvolvimento do projeto, foi selecionada como estudo de caso.

Os dados foram coletados a partir de três levantamentos de informações: (i) Pesquisa de Preferência Revelada ou Pesquisa Origem-Destino (Pesquisa O-D), conduzida pela Universidade Federal de Uberlândia (UFU) por meio de entrevista domiciliar; (ii) Dados agregados sobre Uso do Solo, obtidos no Ministério do Trabalho e Emprego (MTE) por meio da Relação Anual de Informações Sociais (RAIS), e; (iii) Dados sobre o Sistema de Transportes, obtidos por intermédio da UFU junto a Prefeitura de Uberlândia.

(i) Pesquisa de Preferência Revelada ou Pesquisa Origem-Destino

No ano de 2002 foi realizada pela UFU uma Pesquisa de Preferência Revelada com a aplicação de um questionário informativo aos domicílios de Uberlândia para a coleta dos dados sobre os deslocamentos individuais na cidade. O questionário foi dividido em três tipos:

- O primeiro refere-se a informações relativas ao domicílio (tipo do domicílio, condição de moradia e valor do aluguel), a informações relativas à família (tempo de residência no bairro, tamanho e itens de conforto) e a informações relativas às características socioeconômicas de cada pessoa da família (posição na família, idade, sexo, nível de instrução, ocupação profissional e classe de atividade da empresa em que trabalha e faixa de renda mensal); 
- O segundo tipo corresponde a informações sobre o local de trabalho e/ou estudo, e;

- O terceiro tipo de questionário corresponde a informações relativas às viagens realizadas no dia anterior ao da entrevista pelas pessoas do domicílio (origem, destino, hora de início e término da viagem, motivo, modo e duração).

O período da coleta compreendeu os meses de maio a junho de 2002. A amostra representativa da área foi constituída de 3.126 domicílios com 10.891 pessoas que, segundo o relatório da pesquisa garante erro menor que $3 \%$ e nível de confiança de $97,5 \%$.

Para a determinação da amostra representativa, os 3.216 domicílios foram distribuídos em toda a cidade de Uberlândia que, para efeito de planejamento, foi dividida em 65 zonas de tráfego e a pesquisa domiciliar foi aplicada para todos os residentes nos domicílios selecionados (UFU, 2002).

\section{Dados sobre Uso do Solo}

$\mathrm{Na}$ presente pesquisa foram coletadas apenas informações para caracterização das atividades relacionadas ao trabalho. Podem ser citados como razões para a escolha da atividade trabalho:

- Em função de sua predominância nas cadeias de atividades em detrimento às demais atividades, afinal trata-se de uma atividade de subsistência do indivíduo e do domicílio (atividade prioritária);

- Por esta atividade ser a mais frequente como propósito da viagem em relação a outras (por exemplo, como saúde, lazer, negócios etc.) em estudos de demanda por transportes baseados em atividades, e;

- Pela estabilidade na decisão no longo prazo dentro do processo de modelagem: como se trata de uma decisão estável (a opção do trabalho) e dada a relativa simplificação da estrutura do processo de decisão da programação diária de atividades, segundo Golledge e Gärling (2001) a modelagem desta decisão na análise da demanda por viagens urbanas tem obtido bons resultados, quando comparados os dados estimados com os dados reais.

Ainda segundo Golledge e Gärling (2001), a modelagem dos padrões de comportamento em relação aos demais motivos das viagens, ou em dias de final de semana, implica uma 
investigação além da estrutura simplificada do processo de decisão da programação diária de atividades.

Os dados sobre trabalho (quantidade de pessoas empregadas por bairro e por atividade econômica em 2002) foram obtidos através da Relação Anual de Informações Sociais - RAIS, Instituída pelo Decreto n. 76.900, de 23/12/75, e coordenada pelo Ministério do Trabalho e Emprego (BRASIL, 2002).

A RAIS tem por objetivo suprir as necessidades de controle da atividade trabalhista no País, e ainda, prover dados para a elaboração de estatísticas do trabalho e disponibilizar informações do mercado de trabalho às entidades governamentais. Segundo dados da RAIS havia em Uberlândia 107.237 postos de trabalhos ocupados em 31.12.2002.

\section{(iii) Dados sobre o Sistema de Transportes}

Juntamente com a Pesquisa O-D foram obtidos dados sobre o sistema de transporte de Uberlândia correspondentes a rede viária, as linhas e paradas de ônibus (incluindo terminais), delineamento das zonas de tráfego e dos bairros. Adicionalmente foram obtidas informações operacionais do sistema, como velocidade máxima permitida nas vias e relatórios operacionais do sistema de transporte público.

\section{Síntese das Informações}

Na Tabela 4.1 é apresentado um sumário do tipo de informação coletada. Mais detalhes sobre Uberlândia e as estatísticas descritivas dos dados são apresentados no próximo capítulo. 
Tabela 4.1 - Características das informações coletadas.

\begin{tabular}{|c|c|}
\hline $\begin{array}{l}\text { Característica } \\
\text { da Informação }\end{array}$ & Descrição \\
\hline Individuais & $\begin{array}{l}\text { Informações sociais: sexo, idade, situação familiar e grau de instrução. Infor- } \\
\text { mações econômicas: renda individual e setor de atividade. }\end{array}$ \\
\hline \multirow{2}{*}{ Domicílios } & $\begin{array}{l}\text { Informações sociais: espécie (particular, coletivo), condição de moradia (alu- } \\
\text { gado, próprio), tempo de moradia, número de pessoas e número de famílias. }\end{array}$ \\
\hline & $\begin{array}{l}\text { Informações econômicas: itens de conforto, nível de motorização, valor do } \\
\text { aluguel ou prestação do imóvel e renda familiar. }\end{array}$ \\
\hline $\begin{array}{l}\text { Atividades } \\
\text { Desempenhadas }\end{array}$ & Tipo de atividade e localização da atividade (endereço) \\
\hline Deslocamentos & $\begin{array}{l}\text { Número de viagens, origem e destino (endereços), motivo da viagem, modo } \\
\text { principal utilizado, período em que foi realizada a viagem, tempo reportado de } \\
\text { viagem (por viagem e por modo utilizado) e tipo de estacionamento. }\end{array}$ \\
\hline Uso do Solo & $\begin{array}{l}\text { Informações sobre as atividades: setor de atividade, localização (bairro) e } \\
\text { quantidade ofertada da atividade por área do bairro. }\end{array}$ \\
\hline Sistema de Transportes & $\begin{array}{l}\text { Rede viária, linhas e paradas de ônibus (incluindo terminais), delineamento das } \\
\text { zonas de tráfego e dos bairros. }\end{array}$ \\
\hline
\end{tabular}

\section{Tratamento dos Dados}

O objetivo desta etapa é descrever as fases de tratamento dos dados, sumarizados pelo esquema da Figura 4.3, para posterior aplicação na etapa de modelagem.

\section{(i) Pesquisa de Preferência Revelada ou Pesquisa Origem-Destino}

\section{i.1) Limpeza dos dados}

Consiste na retirada dos dados inconsistentes ou incompletos, eliminando da amostra os indivíduos que realizaram uma viagem ${ }^{29}$, que não tiveram a primeira viagem com origem a partir do domicílio e destino final o domicílio e eliminação dos indivíduos que não viajaram no dia anterior ao da pesquisa.

\footnotetext{
${ }^{29}$ Apenas para a base de dados com viagens encadeadas.
} 


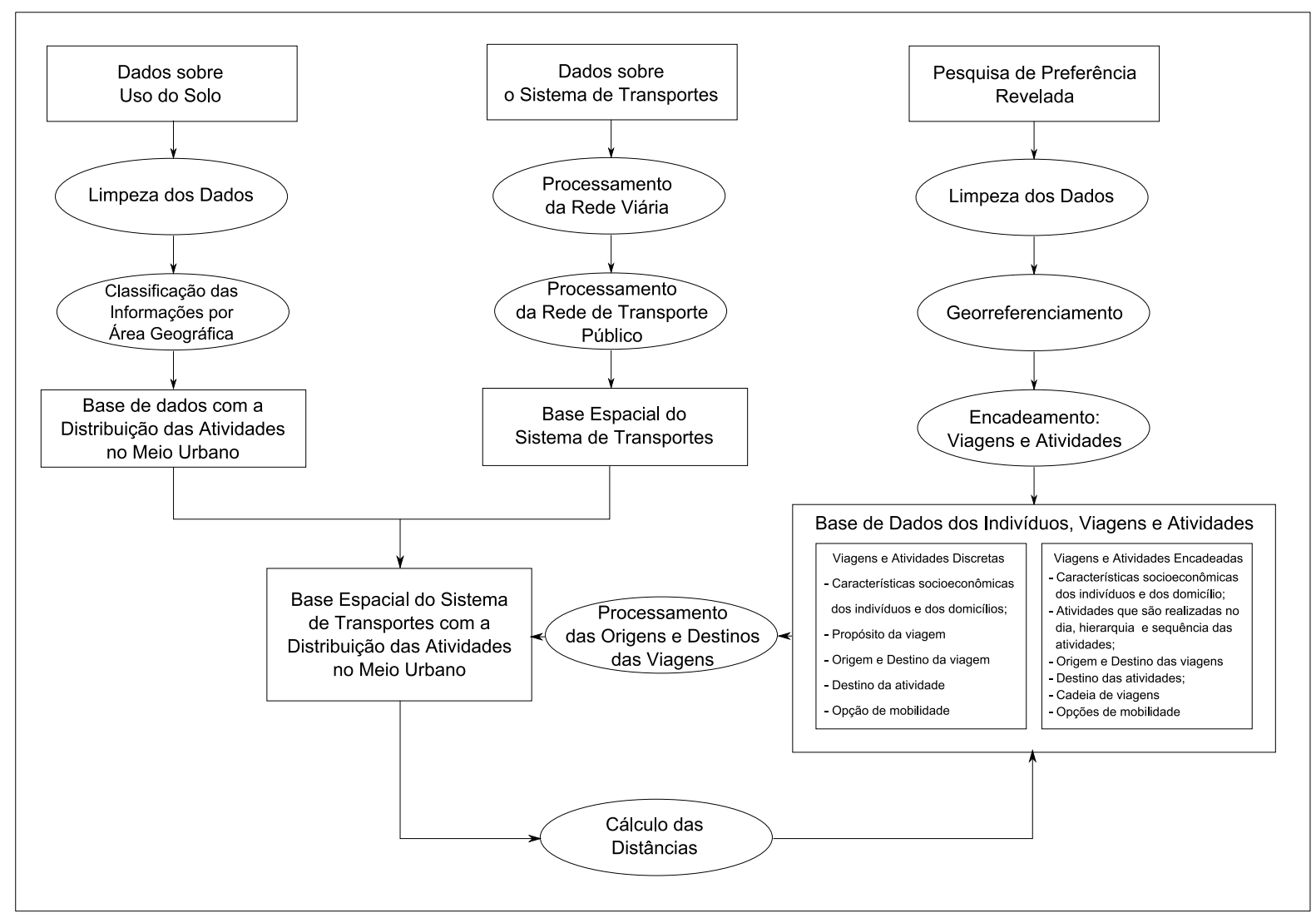

Figura 4.3 - Detalhamento do tratamento dos dados.

A opção de limitar o máximo de viagens em quatro deve-se à variabilidade do número dos padrões de viagens. A inclusão de indivíduos que tenham realizado mais de quatro viagens aumentaria o número de padrões.

\section{i.2) Georreferenciamento}

Consiste na padronização dos endereços das origens e destinos das viagens e a obtenção de suas coordenadas geográficas através de um procedimento baseado no Google Earth. Há vários tutoriais para georreferenciamento de endereços baseado no Google Earth $^{30}$ disponíveis na internet. O procedimento utilizado foi desenvolvido no ano de 2007 com base no tutorial disponível em um sítio de internet e adaptado para a cidade de Uberlândia/MG.

Procedimento desenvolvido para o Microsoft Excel 2007, Microsoft Access 2007 e Google Earth (versão 5.2.1.1588).

Passo 1: A base de dados de endereços deve ser armazenada em uma planilha do Microsoft Excel conforme o exemplo abaixo:

\footnotetext{
${ }^{30}$ Um exemplo é descrito em: http://code.google.com/intl/pt-BR/apis/kml/articles/geocodingforkml.html acessado em 2 de novembro de 2010.
} 
address (título da coluna, na primeira linha, célula A1)

logradouro e número (célula A2)

logradouro e número (célula A3)

Passo 2: Crie no Microsoft Access uma base de dados denominada "Address", no modo de exibição preencha o nome com "address". Salve e feche a tabela.

Passo 3: Importe a base de endereços do Microsoft Excel 2007 para a tabela "Address" no Microsoft Access 2007.

Passo 4: Crie uma consulta denominada "generateKML". Inclua a tabela "Address" na consulta.

Passo 5: Em consulta clique na guia campo e em seguida selecione a opção “zoom”.

Passo 6: Na caixa de diálogo digite o código:

$$
\begin{aligned}
& \text { Expr1: "<Placemark> } \\
& \text { <description>" \& [address] \& "</description> } \\
& \text { <address>" \& [address] \& ", Uberlandia, Brasil</address> } \\
& \text { <name>" \& [address] \& "</name> } \\
& </ \text { Placemark>" }
\end{aligned}
$$

Passo 7: Execute a consulta.

Passo 8: Selecione todos os registros e copie. Abra um programa de texto e cole todos os registros.

Passo 9: Ao início dos registros colados adicione o seguinte código:

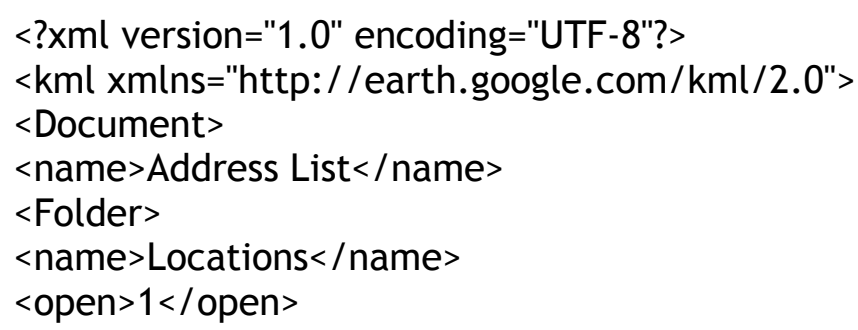

Passo 10: Ao final dos registros colados adicione o seguinte código: 
</Folder
</Document
</kml

Passo 11: Salve o arquivo como "Address.txt", depois modifique para a extensão KML (“Address.kml".

Passo 12: Abra o arquivo “Address.kml” no Google Earth.

Passo 13: Após o carregamento dos endereços no mapa, na opção lugares no painel de camadas salve a pasta “Address" (clique direito, opção "salvar lugar como”). Salve o arquivo como “AddressCode" e selecione a extensão do arquivo kml.

Passo 14: Abra o Microsof Excel 2007, selecione a opção abrir arquivo e selecione o arquivo “AddressCode.kml”. O Microsoft Excel 2007 reconhecerá o arquivo como tabela.

Passo 15: Salve o arquivo no formato xlsx e efetue a organização dos dados.

Passo 16: Utilize rotinas do Microsoft Excel 2007 para atribuir às coordenadas geográficas (latitude e longitude) a base de endereços das origens e destinos das viagens.

i.3) Encadeamento de viagens e atividades

Consiste na criação de uma base de dados (cópia espelho) com a disposição das informações de participação dos indivíduos em atividades e viagens em sequência temporal.

Ao final destes três procedimentos são obtidas duas bases de dados (viagens e atividades discretas, e viagens e atividades encadeadas) contendo informações sobre os indivíduos, os domicílios, participação em atividades e descrição das viagens.

\section{(ii) Dados sobre Uso do Solo}

ii.1) Limpeza dos dados

Consiste na retirada dos dados inconsistentes ou incompletos sobre os estoques de emprego (quantidade de pessoas empregadas) e padronização da nomenclatura da área 
geográfica ${ }^{31}$ (no caso dos dados da RAIS de Uberlândia a unidade geográfica disponível é bairro).

Devido a problemas de amostragem da distribuição das viagens com motivo de trabalho associada ao setor de atividade (por exemplo, setor agrícola, setor industrial e setor de serviços) aos bairros de Uberlândia (75 áreas) para caracterização da atividade trabalho foi considerado unicamente o número de empregos do estabelecimento, sem subdivisão por setor de atividade.

ii.2) Classificação das informações por área geográfica

Nesta fase os estoques (número de empregos) dos estabelecimentos são totalizados por bairro. Ao final destes dois processos a base de dados com a distribuição das atividades no meio urbano é composta pela informação do bairro associada a informação do número de empregos dentro de seus limites.

\section{Dados sobre o Sistema de Transportes}

iii.1) Processamento da rede viária

Consolidação da parte gráfica (tramos e nós) e operacional da rede viária (velocidade máxima nas vias) no TransCAD, importação das áreas correspondentes aos bairros e zonas de tráfego e ajustes à rede, por exemplo, redesenho das zonas de tráfego e bairros com a eliminação das áreas inabitadas ${ }^{32}$ baseado em imagens aéreas da extensão territorial de Uberlândia.

iii.2) Processamento da rede de transporte público

Construção da rede de transporte público no TransCAD com o desenho das linhas de ônibus, pontos de parada e terminais de integração. Ao final destes procedimentos a base espacial do sistema de transportes de Uberlândia é composta pelas vias de circulação com informações das velocidades máximas permitidas; rede de transporte público com detalhamento das linhas de ônibus, pontos de parada e terminais de integração, e; zoneamento da cidade (zonas de tráfego e bairros).

\footnotetext{
${ }^{31}$ No banco de dados há inúmeros verbetes para a identificação de um bairro, por exemplo, Santa Mônica, verbetes utilizados, Sta Mônica, S.Mônica, Mônica.

${ }^{32}$ Em uma das etapas do projeto será utilizado os centroides dos bairros como unidade de referência para localização das atividades de trabalho. 0 redesenho das áreas geográficas permite uma diminuição no erro da representação geográfica prevenindo que o centroide dos bairros, por exemplo, seja localizado em uma área inabitada e/ou verde.
} 
(iv) Base Espacial do Sistema de Transportes com a Distribuição das Atividades no Meio Urbano

Para interação espacial, a base de dados com a distribuição das atividades no meio urbano é unificada à base espacial do sistema de transporte (TransCAD) através da alocação dos totais de emprego às áreas geográficas de bairros.

Em cada uma das 75 áreas geográficas que representam os bairros de Uberlândia é calculado o centroide e considerado que o ponto médio entre os estabelecimentos localizados em um mesmo bairro pode ser representado pelo centroide da área geográfica do bairro e por indução considera-se que a localização geográfica dos empregos dentro dos limites do bairro pode ser representada pelo centroide da área. Ao par oferta da atividade e sua localização (representada por um par de coordenadas geográficas) denomina-se oportunidade.

Prosseguindo com a manipulação espacial dos dados, as coordenadas obtidas na etapa de georreferenciamento das origens e destinos das viagens na base de dados dos indivíduos, viagens e atividades são exportadas para o TransCAD e o cálculo das distâncias (euclidianas, pela rede viária e pela rede de transporte público) entre as origens e destinos das viagens e entre as origens (domicílios) e as oportunidades é realizado.

Estas distâncias são transferidas à base de dados dos indivíduos, viagens e atividades em que cada registro na matriz de viagens e atividades discreta e encadeada passa a contar com a distância viajada, e a distância entre as oportunidades disponíveis nos setenta e cinco bairros.

\subsubsection{Construção das Variáveis}

Nesta seção são apresentados os procedimentos envolvidos na construção das variáveis independentes para representação das variáveis dependentes.

\section{Variáveis Independentes}

As variáveis independentes, ou variáveis preditoras, escolhidas para explicar o comportamento do viajante urbano são relacionadas às: (i) características socioeconômicas dos indivíduos e dos domicílios; (ii) participação em atividades; (iii) características do uso do 
solo, e; (iv) características do sistema de transportes. Esta escolha é baseada em estudos das escolas de ciências humanas, dos trabalhos de análise de demanda por transporte com abordagem em atividades e disponibilidade de dados para realização do experimento (aplicação das etapas de verificação da hipótese nula ao estudo de caso).

\section{(i) Características Socioeconômicas}

$\mathrm{Na}$ literatura existente predomina a afirmação de que as características socioeconômicas influenciam o comportamento individual relacionado às decisões na programação diária de atividades, por exemplo, pelo seu poder econômico, definido não somente como renda, mas também posse e uso de automóveis; papel do domicílio e estrutura familiar, definidos como características gerais domiciliares - número de pessoas no domicílio, presença de crianças, posição do indivíduo no domicílio, e; sexo (PITOMBO, 2007).

Baseando-se na literatura foram selecionadas algumas classes de informações do bando de dados para construção das variáveis. Algumas informações foram mantidas na forma como foram coletas, outras sofreram um processo de adaptação. Na Tabela 4.2 são apresentadas as características socioeconômicas utilizadas como variáveis independentes, sua descrição e codificação utilizada.

Tabela 4.2 - Variáveis socioeconômicas.

\begin{tabular}{|c|c|c|}
\hline Variável & Descrição & Codificação \\
\hline \multirow[t]{2}{*}{$\begin{array}{l}\text { Número de Pessoas no } \\
\text { Domicílio }\end{array}$} & $\begin{array}{l}\text { Número de pessoas residentes no } \\
\text { domicílio }\end{array}$ & Categórica: a ser determinada \\
\hline & & $\begin{array}{l}\text { Contínua, medida em número de } \\
\text { veículos (un) }\end{array}$ \\
\hline Posse de Automóvel & Número de automóveis no domicílio & $\begin{array}{l}\text { Categórica: a ser determinada medi- } \\
\text { ante análise de cluster }\end{array}$ \\
\hline \multirow[t]{2}{*}{$\begin{array}{l}\text { Presença de Criança no } \\
\text { Domicílio }\end{array}$} & $\begin{array}{l}\text { Presença de criança que realiza via- } \\
\text { gem no dia }\end{array}$ & $\begin{array}{l}\text { Categórica: a ser determinada medi- } \\
\text { ante análise de cluster }\end{array}$ \\
\hline & & Contínua, medida em reais (R\$) \\
\hline Renda Domiciliar & Renda domiciliar & $\begin{array}{l}\text { Categórica: até } R \$ 800,00 ; \text { de } R \$ \\
800,01 \text { a } R \$ 1.200 \text {, e; acima de } R \$ \\
1.200,00\end{array}$ \\
\hline Renda Individual & Renda individual & $\begin{array}{l}\text { Categórica: até } \mathrm{R} \$ 400,00 ; \text { de } \mathrm{R} \$ \\
400,01 \text { a } \mathrm{R} \$ 800 \text {, e; acima de } \mathrm{R} \$ \\
800,00\end{array}$ \\
\hline Situação Familiar & $\begin{array}{l}\text { Papel desempenhado pelo indivíduo } \\
\text { no âmbito familiar }\end{array}$ & $\begin{array}{l}\text { Categórica: chefe; cônjuge; filho, e; } \\
\text { outros }\end{array}$ \\
\hline
\end{tabular}


A definição das categorias referentes ao número de pessoas no domicílio, posse de automóvel e faixa etária para criança foi realizada pela aplicação da análise de clusters (ou agrupamento) que é um conjunto de técnicas estatísticas cujo objetivo é agrupar ou dividir objetos segundo suas características, formando grupos ou conglomerados homogêneos, segundo critérios.

A análise de cluster a um conjunto de dados foi realizada através dos procedimentos sugeridos por Malhotra (2001):

- O problema de aglomeração ou objetivo da aplicação da análise de cluster: encontrar grupos homogêneos para representar, separadamente, as categorias referentes ao número de pessoas no domicílio, posse de automóvel e faixa etária para criança;

- Escolha das variáveis: nesta fase foi escolhido apenas o atributo em discussão para aglomeração de cada variável;

- Escolha da medida de similaridade ou dissimilaridade e do processo de aglomeração: o processo de aglomeração escolhido foi o não hierárquico (algoritmo mais simplificado) e a medida de similaridade foi o logaritmo da função verossimilhança, e;

- Definição prévia de número de clusters: para este estudo não foi adotado um número de clusters fixos para a solução final. 0 resultado do número de agrupamentos é gerado pelo algoritmo em busca da melhor homogeneidade interna e melhor heterogeneidade externa.

A análise de cluster pode ser caracterizada como descritiva e não inferencial. Embora seja classificada como uma técnica de análise multivariada (HAIR et al., 1998), a análise de cluster não é uma técnica de inferência estatística na qual os parâmetros de uma amostra podem ser estimados.

Esta ferramenta de análise é usada principalmente como uma técnica exploratória. Pode haver diversas soluções para o problema de agrupamento, principalmente quando se modificam as variáveis ou números de grupos, por exemplo. Assim, a adição ou retirada de informações relevantes pode causar impactos substanciais na solução final (PITOMBO, 2007). 
As demais categorias para as variáveis renda (domiciliar e individual) e situação familiar foram adaptadas da classificação original proposta (as informações foram armazenadas em classes).

\section{(ii) Participação em Atividades}

Foram selecionadas para caracterizar a participação dos indivíduos em atividades variáveis que representem o propósito da viagem, duração da atividade, e o setor de atividade (para a atividade trabalho), como apresentado na Tabela 4.3.

Estas variáveis foram construídas a partir da seleção de informações do banco de dados: duração da atividade (trabalho), calculado a partir da programação horária do inicio e término das atividades; propósito da viagem, adaptado da informação original (de 9 classes para 4 classes), e; setor de atividade (trabalho), adaptado da informação original (9 subdivisões para a atividade trabalho para duas classes).

Tabela 4.3 - Variáveis de participação em atividades.

\begin{tabular}{lll}
\hline \multicolumn{1}{c}{ Variável } & \multicolumn{1}{c}{ Descrição } & \multicolumn{1}{c}{ Codificação } \\
\hline Duração da Atividade & $\begin{array}{l}\text { Representa a duração da atividade } \\
\text { engajada }\end{array}$ & $\begin{array}{l}\text { Categórica: abaixo de } 8 \text { horas e acima } \\
\text { de } 8 \text { horas }\end{array}$ \\
Propósito da Atividade & $\begin{array}{l}\text { O tipo de atividade em que o indiví- } \\
\text { duo participa }\end{array}$ & $\begin{array}{l}\text { Categórica: domicílio, escola, traba- } \\
\text { lho e outras atividades }\end{array}$ \\
Setor de Atividade & $\begin{array}{l}\text { A formalidade do setor da atividade } \\
\text { trabalho }\end{array}$ & Categórica: formal e informal \\
\hline
\end{tabular}

A definição do número de categorias considerou a jornada de 40 horas semanais (8 horas diárias) para definição da classe. 0 número de categorias do propósito da viagem é baseado na codificação utilizada em trabalhos anteriores da linha de pesquisa que este trabalho é engajado (ICHIKAWA, 2002; PITOMBO, 2003; SOUZA, 2004; AGUIAR, 2005; SILVA, 2006; PITOMBO, 2007) e a divisão do trabalho é resultado do agrupamento das classes de atividade informada pelo indivíduo na Pesquisa O-D:

- Formal: (1) agrícola, (2) construção civil, (3) industrial, (4) comercial, (5) funcionário público, (6) serviços de transportes, (7) empresas de serviços, e (8) autônomos.

- Informal: (0) não informado e (9) outros. 


\section{(iii) Características do Uso do Solo}

As variáveis de uso do solo fazem parte do conjunto de fatores que afetam decisões individuais de realização de viagens. A complexidade da inter-relação entre atributos de uso do solo e a sequência de viagens vem sendo estudada ao longo dos anos, havendo divergências quanto as respostas encontradas (WEE, 2002; KITAMURA; MOKHTARIAN; LADET, 1997).

A incorporação de tais variáveis ao estudo de viagens encadeadas envolve uma série de dificuldades, por exemplo, representar ou mensurar tais atributos e, a forma como tais variáveis podem ser incorporadas aos modelos, já que, intuitivamente, espera-se que a estrutura urbana influencie a sequência de viagens realizadas pelos indivíduos durante o dia (PITOMBO, 2007).

Como mencionado anteriormente, optou-se por utilizar a atividade trabalho para caracterizar a distribuição do uso do solo para a cidade de Uberlândia. Assim, restava a esta pesquisa explorar e propor uma forma para representação ou medida de intensidade desta atividade no meio urbano.

É comum utilizar variáveis que representem o padrão de uso do solo como: função da oferta da atividade pela população; função da oferta da atividade pela área em relação às demais zonas, e; oferta relativa da oportunidade.

Em estudos recentes para o entendimento entre uso do solo e comportamento relativo a viagens Pitombo, Kawamoto e Quintanilha (2006) propuseram uma caracterização de uso do solo baseada na distribuição da atividade na região de estudo (taxas relativas das atividades), bem como na localização das zonas de tráfego (latitude e longitude dos centroides das zonas), e Pitombo (2007) propôs a distribuição de uso do solo através da oportunidade relativa por faixas de distância a partir do centroide da zona de tráfego da origem com auxílio da análise de cluster.

Contudo, neste trabalho, a variável básica a ser utilizada para representação do padrão de uso do solo será a oferta da oportunidade na zona (representada pela quantidade de vagas de trabalho ocupadas na zona), apoiada na percepção individual sobre a distribuição das atividades de trabalho no meio urbano.

Este trabalho refuta a noção de que há relação expressa na percepção individual de variáveis do tipo oferta por área, ou oferta por habitantes e apoia a hipótese que o que é 
realmente percebido pelo indivíduo é a quantidade da oferta da atividade, geralmente medida numa relação comparativa entre regiões, como alta oferta ou baixa oferta da atividade na região " $x$ ” em relação a região “y”. Desta forma, é plausível que a oportunidade possa ser percebida na sua forma absoluta (quantidade de emprego) em cada bairro.

\section{(iv) Características do Sistema de Transportes}

Atributos do sistema de transporte, incluindo as redes de infraestrutura, os modos disponíveis e suas peculiaridades influenciam a localização das diversas atividades nas cidades bem como o comportamento individual em relação as escolhas de viagens, por exemplo, modo e destino das atividades (BEN-AKIVA; LERMAN, 1978; BURNS; GOLOB, 1976).

Para analisar a influencia de atributos do sistema de transportes no comportamento individual relacionado à programação diária de atividades são propostas as variáveis da Tabela 4.4 construídas, ou mantidas em sua forma original, a partir das informações coletadas para a cidade de Uberlândia.

Tabela 4.4 - Variáveis do sistema de transportes.

\begin{tabular}{|c|c|c|}
\hline Variável & Descrição & Codificação \\
\hline Custo monetário & Custo da viagem pelo modo disponível & Contínuo em reais ( $\mathrm{R} \$$ ) \\
\hline Distância pela Rede Viária & $\begin{array}{l}\text { Distância percorrida para realização } \\
\text { da viagem na rede viária }\end{array}$ & $\begin{array}{l}\text { Contínuo em quilômetro }(\mathrm{Km}) \\
\text { Categórica: a ser determinada. }\end{array}$ \\
\hline $\begin{array}{l}\text { Distância pela Rede de } \\
\text { Transporte Público Urbano }\end{array}$ & $\begin{array}{l}\text { Distância percorrida para realização } \\
\text { da viagem na rede de transporte } \\
\text { coletivo }\end{array}$ & Contínuo em quilômetro $(\mathrm{Km})$ \\
\hline Gratuidade para idosos & $\begin{array}{l}\text { Gratuidade estabelecida por lei para } \\
\text { pessoas com idade igual ou acima de } \\
65 \text { anos }\end{array}$ & Categórica: sim e não \\
\hline Modo e Acessibilidade & $\begin{array}{l}\text { Combinação dos atributos do sistema } \\
\text { de transporte modo utilizado e a } \\
\text { acessibilidade (tempo de viagem) em } \\
\text { classes }\end{array}$ & $\begin{array}{l}\text { Categórica: modos (não motorizado, } \\
\text { motorizado individual e motorizado } \\
\text { coletivo) e faixas de acessibilidade (a } \\
\text { ser determinada) }\end{array}$ \\
\hline $\begin{array}{l}\text { Oferta do Transporte Pú- } \\
\text { blico Urbano }\end{array}$ & $\begin{array}{l}\text { Proposição de uma medida para quan- } \\
\text { tificar a oferta do transporte coletivo }\end{array}$ & $\begin{array}{l}\text { Contínuo medido em frequência de } \\
\text { ônibus vezes extensão da linha no } \\
\text { bairro pela área do bairro }\left(\frac{\text { Freq·m }}{\mathrm{m}^{2}}\right)\end{array}$ \\
\hline $\begin{array}{l}\text { Tempo de Viagem (Acessi- } \\
\text { bilidade) }\end{array}$ & $\begin{array}{l}\text { Tempo despendido para realização da } \\
\text { viagem }\end{array}$ & $\begin{array}{l}\text { Tempo reportado e o estimado, am- } \\
\text { bos medidos em horas }(\mathrm{h})\end{array}$ \\
\hline Uso do vale transportes & Provável uso do vale transporte & Categórica: sim e não \\
\hline
\end{tabular}


Para elaboração da variável custo monetário foram calculadas alternativas para os custos das viagens motorizadas individual (moto e carro) e transporte público (ônibus). Para o modo individual motorizado foram calculados os custos unitários por quilômetro, total (fixo mais variável), variável e queima de combustível (considerando apenas o consumo de combustível). A variável custo monetário é dada pelo produto entre o custo unitário (adotado um entre as três alternativas) e a distância (rede viária) entre os pontos de interesse na rede viária.

Para o modo motorizado coletivo foram calculados os custos (por viagem) considerando a tarifa cheia (todos pagam a tarifa cheia), isenção de tarifa (idosos e crianças abaixo de sete anos possuem gratuidade e trabalhadores com carteira assinada possuem valetransporte e não percebem o custo) e tarifa reduzida (estudantes pagam 60\% da tarifa cheia e trabalhadores com carteira assinada pagam o menor entre $6 \%$ do salário bruto ou 0 custo das viagens que realizam da sua residência ao trabalho no mês).

As distâncias na rede viária e distância na rede de transporte coletivo são variáveis propostas que associadas ao tempo de viagem nos modelos para representação do comportamento individual traduzem as dificuldades de locomoção no meio urbano. 0 cálculo das distâncias foi realizado em uma das etapas do tratamento dos dados.

Além da proposta da variável distância pela rede viária de forma contínua também é proposto a variável distância pela rede viária para representação da média dos percursos entre o domicílio e o local (ou locais) de trabalho. Para caracterização desta variável a distância é apresentada em classes determinada pela análise de cluster. 0 processo de aglomeração escolhido foi o não hierárquico e a medida de similaridade foi o logaritmo da função verossimilhança. Não foi adotado um número de clusters fixos para a solução final.

A gratuidade para idosos e o uso provável do vale transportes são variáveis que representam políticas públicas para incentivo do uso do sistema de transporte coletivo. Para o cálculo da variável gratuidade para idoso foi considerado que o indivíduo com idade igual ou acima de 65 anos tem direito ao benefício da gratuidade. Para o cálculo do uso provável de vale transportes foi considerado o indivíduo com o propósito da viagem a trabalho, ou retorno do trabalho ao domicílio uma vez que esta informação não estava disponível na Pesquisa O-D de Uberlândia. Em função de menores aprendizes terem direito ao vale transportes, não foi utilizado o limite inferior de idade de 18 anos. 
Para o cálculo do tempo de viagem, medida para representação da acessibilidade, foi desenvolvido um procedimento baseado no tempo de viagem reportado na Pesquisa 0 D. Segundo Rietveld (2002) é frequente na investigação sobre o comportamento individual relacionado a viagens o uso de tempos de viagens reportados por indivíduos.

Em geral, trata-se de uma medida próxima à real uma vez que a maioria dos viajantes possui um relógio, adicionalmente os viajantes procuram controlar o tempo de viagem para que não ocorram atrasos ao início de atividades programadas. Em se tratando de tempo de viagem com destino a atividades repetidas é esperado que o valor reportado seja próximo ao valor real. Apesar das premissas expostas, é esperado que valores discrepantes ocorram.

Dentro da estrutura de análise da acessibilidade há duas situações distintas para emprego do tempo de viagem:

- Para a situação em que há necessidade de uso do tempo de viagem seja o tempo correspondente ao modo utilizado na viagem, optou-se em utilizar o tempo de viagem reportado na Pesquisa O-D, e;

- Na situação em que há necessidade de utilização dos tempos de viagens entre os modos de viagens disponíveis no sistema de transportes foi utilizado um procedimento para estimação dos tempos de viagens pelos modos baseados nos valores reportados na Pesquisa O-D.

A ideia central neste procedimento é estimar para cada indivíduo o tempo de viagem para as opções modais disponíveis no sistema de transportes entre locais de interesse dentro da rede viária a partir dos valores reportados na Pesquisa O-D.

As opções modais consideradas no sistema de transportes de Uberlândia são: a pé, bicicleta, coletivo (ônibus) e individual motorizado (devido a semelhança a opção automóvel/moto motorista e automóvel/moto passageiro foi considerado como individual motorizado). Como mencionado na Pesquisa O-D os indivíduos foram questionados sobre o tempo de viagem para o modo utilizado, sendo os tempos dos demais modos não informados.

A partir da base de dados de viagens desagregadas foram geradas cinco novas bases de dados: viagens a pé, viagens de bicicleta, viagens de coletivo, viagens individual motorizado e estimação do tempo de viagem. Os quatro primeiros bancos de dados representam 
exclusivamente viagens realizadas pelos modos indicados, enquanto o último apresenta todo o conjunto de viagens (independente do modo).

A cada registro das novas bases de dados foram mantidas as características socioeconômicas dos indivíduos e as características das viagens, principalmente, o tempo de viagem reportado e a distância, classificadas em euclidiana, rede viária e rede de transporte coletivo.

Em função da característica do modo uma distância é selecionada para representar a mais próxima à distância real percorrida, por exemplo, se a opção de modo do sistema de transporte foi ônibus, a distância mais próxima a distância real percorrida adotada é a rede de transporte coletivo (que possui rede distinta da rede viária).

Com o intuito de tentar mapear as adversidades impostas para se atingir a velocidade máxima permitida nas vias ${ }^{33}$, é proposta a construção de uma variável latente para representação das condições operacionais do sistema através da associação da densidade populacional (habitantes/área); densidade de postos de emprego ocupados (emprego/área); densidade de vagas escolares preenchidas (matrículas/área); densidade de viagens produzidas (proporção relativa); densidade de viagens atraídas (proporção relativa) e densidade da rede viária (extensão das vias/área) com as condições de tráfego da região.

Tem-se por premissa básica para criação da variável latente que uma região de alta intensidade demográfica e de atividades, com alto poder de geração e/ou atração de viagens e com baixa oferta de infraestrutura de transportes tem propensão para ocorrência de conflitos de tráfego.

Para esta caracterização foi utilizada a análise de cluster aplicada as informações agregadas por bairro. 0 processo de aglomeração escolhido foi o não hierárquico e a medida de similaridade foi o logaritmo da função verossimilhança. Não foi adotado um número de clusters fixos para a solução final.

A partir das características socioeconômicas, características dos deslocamentos, incluindo a distância adotada e o tempo de viagem, de cada base de dados (viagens a pé,

\footnotetext{
${ }^{33}$ As informações coletadas sobre a operação do sistema de transporte de Uberlândia utilizadas neste projeto limitaram-se as velocidades máximas permitidas nas vias, não sendo possível obter informações sobre as condições de tráfego da rede de Uberlândia, ou informações em que fosse possível esboçar regiões em que conflitos de tráfego são recorrentes.
} 
viagens de bicicleta, viagens de coletivo, viagens de individual motorizado) são testados modelos de previsão do tempo de viagem (modelos paramétricos e não paramétricos).

Os modelos mais adequados para representar o tempo de viagem pelos modos disponíveis são aplicados aos registros da base estimação do tempo de viagem. Assim, para cada viagem são estimados os tempos de viagem para os modos não reportados e reportados.

Para analisar o efeito da acessibilidade combinada a um modo particular de transportes é proposta a variável modo acessibilidade, elaborada a partir:

- Dos modos do sistema de transportes classificados em não motorizados (a pé e bicicleta), coletivo (ônibus) e individual motorizado (automóvel/moto motorista e automóvel/moto passageiro). Para simplificação na análise em que esta variável é envolvida, os modos a pé e bicicleta foram classificados como não motorizados e, novamente, as opções automóvel/moto motorista e automóvel/moto passageiro foram agrupadas como individual motorizado, e;

- Das faixas de acessibilidade, calculadas a partir da análise de cluster.

- O problema de aglomeração ou objetivo da aplicação da análise de cluster: encontrar grupos homogêneos para representar as categorias referentes a acessibilidade;

- Escolha das variáveis: acessibilidade;

- Escolha da medida de similaridade ou dissimilaridade e do processo de aglomeração: o processo de aglomeração escolhido foi o não hierárquico e a medida de similaridade foi o logaritmo da função verossimilhança, e;

- Definição prévia de número de clusters: para este estudo foi adotado dois clusters fixos para a solução final, para controle das classes da variável ( 3 modos $x$ 2 classes $=6$ combinações).

A oferta do transporte público urbano é uma variável proposta neste projeto criada a partir da extensão total de linhas de ônibus em uma área multiplicada pela frequência diária do serviço de transporte coletivo dividido pela área, como descrito pela Equação 1. Sua proposição é uma tentativa de capturar as diferenças da oferta do serviço de transporte público urbano no meio urbano e como esta variabilidade é percebida pelos indivíduos. 


$$
\begin{aligned}
& \text { Capítulo } 4 \text { - Delineamento do Método } \\
& T P U_{i}=\frac{\sum_{n, i} l_{n, i} \cdot f_{n}}{S_{i}}
\end{aligned}
$$

Em que $T P U_{i}$ representa a oferta do transporte público na zona $i, l_{n}$ extensão da linha de ônibus $n$ na zona $i, f_{n}$ frequencia da linha de ônibus $n$ e $S_{i}$ a área.

\section{Variáveis Dependentes}

A representação adequada das variáveis envolvidas na análise é fundamental para obtenção das relações das mesmas. Na subseção anterior, foram apresentadas as variáveis independentes que fazem parte de quatro grupos de variáveis (características socioeconômicas dos indivíduos e dos domicílios; participação em atividades; características do uso do solo, e; características do sistema de transportes). Nesta parte do método são apresentadas as variáveis dependentes para representação das decisões individuais no processo de programação diária de atividades: (i) modo; (ii) destino, e; (iii) padrão de viagens.

(i) Modo

$\mathrm{Na}$ Pesquisa O-D os indivíduos foram questionados sobre o modo principal em cada viagem, sendo apresentada uma lista com dez alternativas para escolha: (1) ônibus; (2) ônibus escolar; (3) automóvel motorista; (4) automóvel passageiro; (5) van; (6) motocicleta; (7) bicicleta; (8) a pé; (9) caminhão, e; (10) outros.

Baseado em similaridades entre os modos de viagens as dez alternativas foram reagrupadas em cinco modos de transportes: (1) a pé; (2) bicicleta; (3) ônibus/coletivo; (4) automóvel motorista e (5) automóvel passageiro.

Em geral, na análise do comportamento individual em relação às decisões na programação diária de atividades, a opção modal é representada pela sequência de modos de transportes utilizados para acessar as atividades distribuídas espacialmente ao longo de um dia.

A principal desvantagem desta abordagem é a descrição do conjunto de alternativas, por exemplo, para o estudo de caso são 25 combinações possíveis em duas viagens, 125 combinações possíveis em padrões com três viagens e 625 combinações possíveis em padrões com quatro viagens, totalizando 775 possíveis sequências de modos de viagens em padrões com até 4 viagens e a estrutura analítica do modelo que difere em termos de maior complexidade que para a situação descrita envolve no processo de modelagem um con- 
junto de escolha com 775 alternativas em comparação com a análise tradicional das viagens discretas que envolve um conjunto de escolha com 5 alternativas.

Uma alternativa proposta para a modelagem das sequências dos modos de viagem é dada para situação em que os indivíduos são invariáveis aos modos de transportes, ou seja, não alteram o modo durante a realização das viagens para acesso às atividades.

Para esta situação, a estrutura analítica do processo de modelagem para entendimento do comportamento individual relacionado às escolhas dos modos de transportes sob o contexto das viagens discretas pode ser semelhante ${ }^{34}$ ao processo de modelagem para entendimento do comportamento individual relacionado às escolhas das combinações dos modos de transportes sob o contexto das viagens encadeadas.

Analisando a base de dados das viagens e atividades encadeadas observa-se um comportamento invariável de grande parte dos indivíduos à escolha do modo de transportes na programação das atividades (Tabela 4.5)

Tabela 4.5 - Descrição da distinção dos modos de transportes nos padrões individuais de viagens da base de dados das viagens e atividades encadeadas da Pesquisa O-D de Uberlândia.

\begin{tabular}{lcc}
\hline \multicolumn{1}{c}{ Descrição } & Quantidade & Percentual (\%) \\
\hline Padrões individuais de viagens & 4.562 & $100,00 \%$ \\
Modos iguais em todas as viagens do padrão & 4.128 & $90,49 \%$ \\
Modos diferentes nas viagens do padrão: & 434 & $9,51 \%$ \\
1 modo distinto em padrões com 2 viagens & 247 & $5,41 \%$ \\
1 modo distinto em padrões com 3 viagens & 33 & $0,72 \%$ \\
1 modo distinto em padrões com 4 viagens & 30 & $0,66 \%$ \\
1 modo distinto em padrões com mais de 4 viagens & 11 & $0,24 \%$ \\
2 modos distintos em padrões com 4 viagens & 85 & $1,86 \%$ \\
2 modos distintos em padrões com mais de 4 viagens & 18 & $0,39 \%$ \\
Mais de 2 modos distintos em padrões com mais de 4 viagens & 5 & $0,11 \%$ \\
Padrões de viagens em que todos os modos são distintos & 5 & $0,11 \%$ \\
\hline
\end{tabular}

Desta forma, sem perda de associação com a teoria de viagens baseadas em atividades, é proposta a modelagem dos modos de viagens com a decisão representada pela variável dependente categorizada em: (1) a pé; (2) bicicleta; (3) ônibus/coletivo; (4) automóvel motorista e (5) automóvel passageiro.

\footnotetext{
${ }^{34} \mathrm{Em}$ geral, modelos de modos de viagens discretas são descritos na literatura pelo modelo multinomial logit, ao passo que modelos de modos de viagens encadeadas são descritos pelo modelo logit hierárquico. Há apenas uma evidência empírica recente que em diferentes estruturas de modelos, o conjunto de variáveis é o mesmo e com valores de parâmetros similares (ver BEKHOR; PRASHKER, 2008)
} 
(ii) Destino

Como exposto no item sobre a descrição dos dados de uso do solo, nesta pesquisa para caracterização das opções de atividades no meio urbano é utilizado apenas informações relacionadas à atividade trabalho.

Para representação da decisão dos destinos desta atividade foi adotado o conjunto de 75 bairros da cidade de Uberlândia (representados pelos centroides dos bairros) e mapeados a partir das informações sobre uso do solo (RAIS) e do sistema de transportes que correspondem as 75 alternativas de destino para execução da atividade trabalho.

\section{(iii) Padrão Viagens}

A variável padrão de viagens representa a sequência de atividades que são realizadas durante um dia típico ${ }^{35}$ pelo indivíduo, elaborada a partir da informação sobre os motivos das viagens (em sequência cronológica) declarados na Pesquisa O-D além de identificar a sequência de viagens realizadas para participação das atividades diárias.

A construção da variável padrão de viagens é baseada nas informações da base de dados sobre indivíduos, viagens e atividades encadeadas e dada pela concatenação dos motivos das viagens, iniciando com a origem da viagem (residência), seguido pelas atividades que foram realizadas no dia e, finalmente, com o retorno ao domicílio.

$\mathrm{Na}$ construção dos padrões de viagens foram consideradas as cadeias de viagens com origem e destino final no domicílio, desta forma a menor cadeia de viagens possível, para os indivíduos que realizaram atividades fora do domicílio, é de duas viagens com a participação em apenas uma atividade.

Em uma das etapas deste levantamento os indivíduos foram questionados sobre os propósitos das viagens sendo apresentada uma lista com nove alternativas para seleção: (1) trabalho/indústria; (2) trabalho/comércio; (3) trabalho/serviço; (4) escola/universidade; (5) compras; (6) negócios; (7) saúde; (8) lazer, e; (9) residência.

\footnotetext{
${ }^{35}$ Em geral, a Pesquisa de Preferência Revelada é conduzida por meio de entrevistas domiciliares em que são solicitados aos membros dos domicílios informações sobre os deslocamentos realizados no dia anterior à pesquisa. O relato destes deslocamentos deve retratar um dia "típico" de viagens, terça-feira, ou quarta-feira, ou quinta-feira, evitando-se o levantamento das informações em época de férias, em semanas que contenham feriados, e antes e após o final de semana (segunda-feira e sexta-feira). 0 objetivo deste levantamento é obter informações sobre o comportamento relacionado a viagens em dias úteis, que são estáveis no longo prazo.
} 
Dado o grande número de combinações possíveis com os propósitos das viagens classificados em nove categorias de atividades (por exemplo, em cadeias de quatro viagens são 648 padrões possíveis) é proposto neste trabalho a representação das atividades em quatro grupos de atividades: $(\mathrm{H})$ domicílio; $(\mathrm{S})$ educação; (W) trabalho, englobando os propósitos de trabalho/indústria, trabalho/comércio e trabalho/serviço; (A) outras atividades, englobando compras, negócios, saúde e lazer.

As letras "H", "S", "W" e "A" são cunhadas das iniciais dos vocábulos da língua inglesa home, school, work e activity (domicílio, escola, trabalho e atividade) e são empregadas como identificadores das atividades em estudos de análise de demanda por transportes, aplicados, por exemplo, em Ichikawa (2002), Pitombo (2003), Souza (2004), Aguiar (2005), Silva (2006) e Pitombo (2007).

Assim, um indivíduo que realiza durante um dia a atividade de trabalho fora do domicílio é representado pela variável $\mathrm{HWH}$, que representa a sequência de atividade domicílio $\rightarrow$ trabalho $\rightarrow$ domicílio e uma cadeia com duas viagens domicílio $\rightarrow$ trabalho e trabalho $\rightarrow$ domicílio.

Finalmente, a base de dados contendo informações sobre os indivíduos, viagens e atividades encadeadas com a sequência dos propósitos da viagem é mais uma vez modificada com o agrupamento de padrões semelhantes em relação ao tipo de sequência de atividade trabalho.

O interesse na construção da variável padrão é voltado para análise das cadeias de viagens que contenham a atividade trabalho (não exclusivamente). Este propósito pode ser justificado:

- Pela importância da atividade trabalho na programação diária de atividades, afinal trata-se de uma atividade de subsistência do indivíduo e do domicílio (atividade prioritária);

- Por esta atividade ser a mais frequente como propósito da viagem em relação a outras (por exemplo, como saúde, lazer, negócios etc.) em estudos de demanda por transportes baseados em atividades, e;

- Pela estrutura analítica proposta para análise do comportamento individual, no processo de modelagem da decisão do destino das atividades foi considerada apenas a atividade trabalho em razão de motivos já expostos. 
A principal justificativa recai no apelo pela simplificação da estrutura do processo de modelagem e análise dos resultados, com a possibilidade de extrair relações entre variáveis independentes e dependentes em um contexto de relativa simplicidade sem comprometer os objetivos da pesquisa.

Desta forma, os padrões de viagens que contenham atividades trabalho são agrupados em quatro categorias que representam a variável padrão de viagens, como apresentado na Tabela 4.6.

Tabela 4.6 - Categorias da variável dependente padrão de viagens.

\begin{tabular}{|c|c|}
\hline Padrão & Descrição \\
\hline $\mathrm{HWH}$ & Corresponde ao padrão domicílio $\rightarrow$ trabalho $\rightarrow$ domicílio. \\
\hline $\mathrm{H}+\mathrm{W}+\mathrm{H}$ & $\begin{array}{l}\text { Corresponde aos padrões que contem a atividade trabalho associada a outras ativida- } \\
\text { des, com retorno ao domicílio apenas ao final da sequência de viagens, por exemplo, } \\
\text { domicílio } \rightarrow \text { trabalho } \rightarrow \text { escola } \rightarrow \text { domicílio. }\end{array}$ \\
\hline HWHWH & $\begin{array}{l}\text { Corresponde aos padrões que contem a atividade trabalho com apenas um retorno ao } \\
\text { domicílio durante a sequência de viagens: domicí- } \\
\text { lio } \rightarrow \text { trabalho } \rightarrow \text { domicílio } \rightarrow \text { trabalho } \rightarrow \text { domicílio. }\end{array}$ \\
\hline $\mathrm{H}+\mathrm{W}+\mathrm{H}+\mathrm{W}+\mathrm{H}$ & $\begin{array}{l}\text { Corresponde aos padrões que contem a atividade trabalho associada a outras ativida- } \\
\text { des, com retorno ao domicílio durante a sequência de viagens, por exemplo: domicí- } \\
\text { lio } \rightarrow \text { trabalho } \rightarrow \text { domicílio } \rightarrow \text { trabalho } \rightarrow \text { escola } \rightarrow \text { domicílio. }\end{array}$ \\
\hline
\end{tabular}

Na próxima etapa do método são apresentadas as técnicas empregadas na modelagem do comportamento individual em níveis de decisão na programação diária de atividades relacionadas a escolha do modo de viagem, seleção do destino da atividade primária e padrão de viagens.

\section{$>$ ETAPA 2}

\subsection{Modelagem do Comportamento Individual}

Estabelecida a proposta para estudo da acessibilidade na análise do comportamento individual relacionado às decisões de participação em atividades e viagens, e a construção da base de informações para realização deste estudo, a terceira e última etapa do método descreve o processo de modelagem adotado para representação do comportamento individual em três níveis de decisão da programação diária de atividades: modo de viagem; destino da atividade, e; padrão de viagens. 
Nesta etapa, o comportamento individual é representado pela aplicação de técnicas de modelagem para interação entre variáveis independentes (incluindo a acessibilidade) e variáveis dependentes que representam as decisões na programação diária (modo de viagem, destino da atividade e padrão de viagens), com a análise dos resultados voltada para a verificação da hipótese nula deste projeto.

Pela proposta em pauta, em cada nível de decisão da programação diária de atividades é formulado uma hipótese auxiliar relacionada a hipótese nula do projeto para interação das variáveis independentes (incluindo a acessibilidade) na variável dependente.

A verificação da hipótese é realizada por estatísticas para significância dos parâmetros das variáveis independentes na modelagem da variável dependente, desempenho do modelo em representar o comportamento individual nos níveis de decisão dentro da programação diária de atividades e consistência das relações encontradas.

A partir dos testes de hipóteses (auxiliares) propostos e com a atenção da análise dos resultados voltada a para o delineamento da influência da acessibilidade nos modelos, são reunidos indícios para elaboração da conclusão da rejeição ou não rejeição da hipótese nula do projeto:

- Acessibilidade a oportunidades influencia o comportamento dos padrões de viagens encadeadas desempenhados pelos indivíduos.

Na Figura 4.4 é apresentado um diagrama desta etapa do método e nas seções seguintes é realizada uma descrição sucinta das fases que o compõe. 


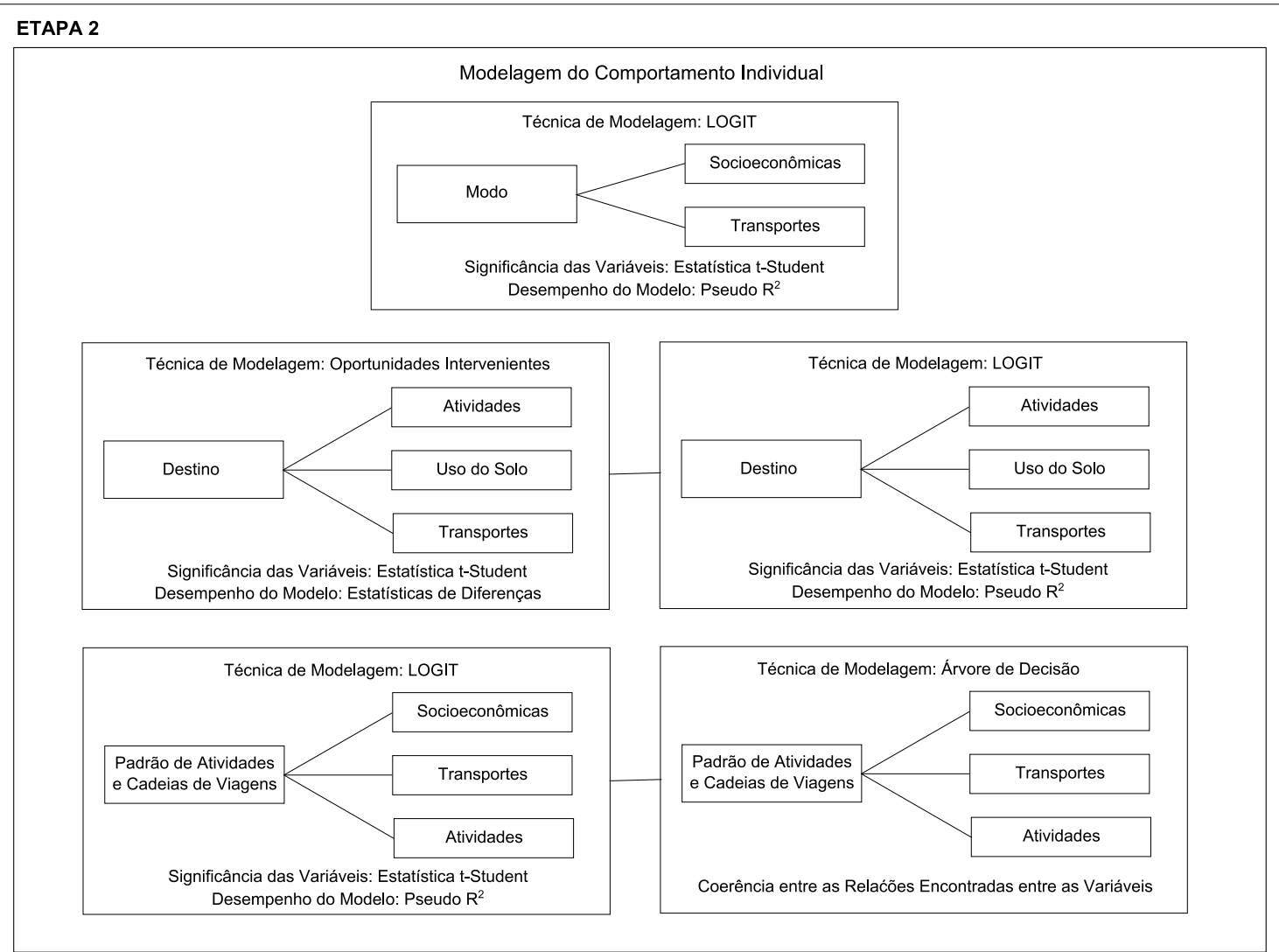

Figura 4.4 - Detalhamento da proposta para modelagem do comportamento individual.

A estrutura analítica do processo de modelagem da escolha do modo de viagem, da escolha do destino da atividade e da seleção do padrão de viagens (apresentadas nas próximas seções) é composta(o) pela/por: (i) teoria subjacente ao processo de representação do comportamento individual; (ii) objeto da decisão (variável dependente); (iii) conjunto de atributos avaliados na decisão (variáveis independentes); (iv) hipótese de interferência; (v) especificação de um modelo comportamental; (vi) estimativa dos parâmetros do modelo; (vii) estatística para avaliação da significância das variáveis, e; (viii) estatística para desempenho do modelo. 


\subsubsection{Modo de Viagem}

(i) Teoria Subjacente ao Processo de Modelagem do Comportamento Individual

As decisões sobre os modos de viagens que os indivíduos realizam no sistema de transportes produzem demandas que agregadas e interagindo com a oferta dão forma às condições de tráfego do sistema e afetam a qualidade de acesso às atividades distribuídas no meio urbano. Esta premissa torna imperiosa a identificação de fatores e a avaliação de sua interferência no comportamento individual relacionado às escolhas dos modos de transportes em um sistema.

A tarefa do entendimento do comportamento individual relacionado às escolhas não é trivial, devido a inviabilidade da observação de todos os fatos que influenciam o comportamento e porque o próprio ato da observação influencia as ações dos indivíduos em suas decisões. Torna-se então necessário a aplicação de modelos do comportamento individual relacionado às escolhas baseados em dados obtidos por amostragens da população.

Modelos de escolha discreta baseados na maximização da utilidade são elaborados para analisar os efeitos de vários atributos no comportamento individual relacionado em um conjunto de escolhas.

A principal abordagem dos modelos desta natureza é que no processo decisório o indivíduo tentará maximizar a utilidade da sua escolha, um processo de "troca" entre custos associados aos benefícios das escolhas.

Este processo de "trocas" é modelado dentro na estrutura analítica de funções de utilidade como os indivíduos caracterizados por um comportamento racional de consumo. 0 resultado deste processo é traduzido em termos de probabilidade de relacionar uma alternativa a partir de regras de comportamento.

Uma crítica apresentada a esta abordagem refere-se ao comportamento racional dos indivíduos no processo das escolhas, como estabelecido na maximização da utilidade. No entanto, como descrito em McFadden (1973, p. 106), sobre a modelagem do comportamento humano referente às escolhas:

[...] Convencionalmente em análises de consumo com alternativas continuum, é plausível e frequentemente assumido que todos os indivíduos da população possuem um comportamento comum, exceto por puramente erros estocásticos de otimização [...] 
Sob a égide da replicação da modelagem do comportamento comum observado na população, restava à própria natureza deste projeto científico, de caráter exploratório e investigativo, explorar esta abordagem, entender o mecanismo de funcionamento, confirmar a sua aplicabilidade aos propósitos desta tese e aplicá-lo ao estudo de caso.

\section{(ii) Objeto da Decisão (Variável Dependente)}

É proposta a modelagem dos modos de viagens com a decisão representada pela variável dependente categorizada em: (1) a pé; (2) bicicleta; (3) ônibus/coletivo; (4) automóvel motorista e (5) automóvel passageiro

\section{(iii) Conjunto de Atributos Avaliados na Decisão}

As variáveis independentes, ou variáveis preditoras, escolhidas para explicar o comportamento do viajante urbano são relacionadas às características socioeconômicas dos indivíduos e dos domicílios (Tabela 4.3) e características do sistema de transportes (Tabela 4.4). Nesta etapa a acessibilidade é representada pelo tempo de viagem da alternativa do modo em consideração na função de utilidade.

\section{(iv) Hipótese de Interferência}

A hipótese de interferência a ser testada nesta fase é:

- A escolha do modo de viagem é influenciada pelas características individuais, características do domicílio e características do sistema de transportes, incluindo a acessibilidade.

Para verificação desta hipótese cada variável independente incluída no modelo é submetida a um teste de estatístico para verificar se o parâmetro da variável é diferente de zero. Desta forma a hipótese nula a ser verificada é:

$$
\begin{aligned}
& H_{0}: B=0 \\
& H_{1}: B \neq 0
\end{aligned}
$$

Em que B é o parâmetro da variável independente. 


\section{(v) Especificação de um Modelo Comportamental}

Denotando $X$ o universo dos objetos de escolha e $S$ o universo dos vetores contendo os atributos medidos pelos indivíduos. Um indivíduo qualquer da população terá um vetor $s \in S$ e enfrentará um conjunto de alternativas disponíveis (e finito) $B \subseteq X$.

Seja $P(x \mid s, B)$ a probabilidade condicional que um indivíduo qualquer da população irá escolher a alternativa $x$, dado que ele avaliou (mediu) os atributos $s$ e enfrentou o conjunto de alternativas $B$. A escolha observada com atributos $s$ e alternativas $B$ pode ser interpretada como uma extração de uma distribuição com probabilidade $P(x \mid s, B)$ para $x \in B$ :

$$
P(x \mid s, B)=\pi[\{h \in H \mid h(s, B)=x\}]
$$

Em que: $h$ : é uma função que representa o comportamental individual, que mapeia cada vetor de atributos medidos $s$ de uma alternativa do conjunto $B$; $H$ : é o modelo que representa o conjunto $h$ que representa a população; $\pi$ : é a probabilidade da escolha.

Utilizando os princípios da maximização da utilidade da escolha da Teoria Econômica, a função de utilidade (representa o comportamental individual, que mapeia cada vetor de atributos medidos $s$ de uma alternativa do conjunto $B$ ), pode ser escrita:

$$
U=V(s, x)+\varepsilon(s, x)
$$

Em que: $V(s, x)$ : representa os atributos observáveis avaliados pelo indivíduo (parte determinística); $\varepsilon(s, x)$ : representa os atributos que não são observáveis pelo indivíduo (parte estocástica)

Seja $B=\left\{x_{1}, \ldots, x_{j}\right\}$, a probabilidade que um indivíduo qualquer extraído da população escolher a alternativa $x_{i}$ é igual a:

$$
\begin{gathered}
P_{i} \equiv P\left(x_{i} \mid s, B\right)=\pi\left[\left\{h \in H \mid h(s, B)=x_{i}\right\}\right] \\
U_{i}=V_{i}\left(s, x_{i}\right)+\varepsilon_{i}\left(s, x_{i}\right) \\
U_{j}=V_{j}\left(s, x_{j}\right)+\varepsilon_{j}\left(s, x_{j}\right)
\end{gathered}
$$




$$
\begin{gathered}
U_{i}>U_{j} \\
V_{i}\left(s, x_{i}\right)+\varepsilon_{i}\left(s, x_{i}\right)>V_{j}\left(s, x_{j}\right)+\varepsilon_{j}\left(s, x_{j}\right) \\
\varepsilon_{j}\left(s, x_{j}\right)-\varepsilon_{i}\left(s, x_{i}\right)<V_{i}\left(s, x_{i}\right)-V_{j}\left(s, x_{j}\right), \text { substituindo } \\
P\left(x_{i} \mid s, B\right)=\left[\varepsilon_{j}\left(s, x_{j}\right)-\varepsilon_{i}\left(s, x_{i}\right)<V_{i}\left(s, x_{i}\right)-V_{j}\left(s, x_{j}\right), j \neq i\right]
\end{gathered}
$$

Sendo $F(\varepsilon)$ a função cumulativa de densidade de $\varepsilon\left(\varepsilon_{1} \ldots \varepsilon_{j}\right)$ a probabilidade de escoIha da alternativa $x_{i}$ perante todo o conjunto de escolha é dado por:

$$
P\left(x_{i} \mid s, B\right)=\int_{-\infty}^{+\infty} F_{i}\left(\varepsilon+V_{i}-V_{1}, \ldots, \varepsilon+V_{i}-V_{j}\right) d \varepsilon
$$

Assumindo que a porção estocástica siga a distribuição de Gumbel:

$$
P\left(\varepsilon\left(s, x_{j}\right) \leq \varepsilon\right)=e^{-e^{-\varepsilon}}
$$

Substituindo e resolvendo a integral obtém-se:

$$
P\left(x_{i} \mid s, B\right)=\frac{e^{V_{i}}}{\sum_{j=1}^{j} e^{V_{j}}}
$$

A função $V_{j}$ pode ser representada pelo vetor de atributos $s^{\prime}$ e o vetor de parâme$\operatorname{tros} \beta^{\prime}$

$$
P_{i}=\frac{e^{\beta \prime S^{\prime} i}}{\sum_{j=1}^{j} e^{\beta \prime^{\prime} j}}
$$

A probabilidade de escolha da alternativa $i$ pelo indivíduo $n$ é então dada por:

$$
P_{n i}=\frac{e^{\beta \prime S^{\prime} n i}}{\sum_{j=1}^{j} e^{\beta \prime s^{\prime} n j}}
$$

Este método numérico só terá validade se os seguintes axiomas forem seguidos: 
- Axioma 1: Independência das alternativas irrelevantes. Para todas as alternativas possíveis do conjunto $B$ com atributos s e membros $x$ e $y$ de $B, P(x \mid s,\{x, y\}) P(y \mid s, B)=$ $P(y \mid s,\{x, y\}) P(x \mid s, B)$, as alternativas não podem ser substitutas, McFadden (1974).

- Axioma 2: A porção estocástica da função utilidade, $\varepsilon_{i}$, seja identicamente distribuída com o Tipo I de distribuição de Valor Extremo: $P\left(\varepsilon_{i} \leq \varepsilon\right)=\exp \left(-e^{\frac{\varepsilon}{\sigma}}\right)$ em que $\sigma$ é um fator escalar, McFadden (1974).

- Axioma 3: Assumindo que a porção estocástica da função utilidade, $\varepsilon_{i}$, seja identicamente distribuída e sejam independentes entre as alternativas é assumir que $\varepsilon_{i}$ possuem a mesma média e variância e não são correlacionados (qualquer atributo omitido na função utilidade da alternativa $i$ não afeta a função utilidade da alternativa $j$ ) , McFadden (1974).

- Axioma 4: Positividade. $P(x \mid s, B)>0$ para todas as alternativas possíveis em $B$, com atributos $s$ e para $x \in B$, McFadden (1974)

- Axioma 5: Irrelevância do efeito do conjunto de alternativas, McFadden (1974).

- Axioma 6: Monotonicidade em relação ao tamanho do conjunto da escolha. A adição de uma escolha ao conjunto de escolhas de um indivíduo não diminui o status de benefício anterior, Ben-Akiva e Lerman (1985).

\section{(vi) Estimativa dos Parâmetros do Modelo}

O logaritmo da função verossimilhança é o método mais empregado para estimativa dos parâmetros do modelo logit, dado por:

$$
L L\left(\beta^{\prime}\right)=\sum_{n=1}^{N} \sum_{i} y_{n i} \ln P_{n i}
$$

Em que $P_{n i}$ é a probabilidade de escolha da alternativa $i$ pelo indivíduo $n, y_{n i}=1$ se o indivíduo $n$ escolhe $i$ (zero se a escolha for diferente) e $\beta^{\prime}$ é o vetor de parâmetros que maximiza o valor da função.

A função verossimilhança é côncava, desta forma a solução da derivada de primeira ordem é única $(d L L(\beta) / d \beta=0)$. Além do mais, sob condições gerais os parâmetros estima- 
dos pela verossimilhança são consistentes, assimptoticamente eficientes e normais (PINDYCK; RUBINFELD, 1998).

Vários pacotes estatísticos são disponíveis para estimação dos parâmetros dos modelos logit pela função de verossimilhança. Neste trabalho é utilizado o BIOGEME - Bierlaire Optimization toolbox for GEV Estimation, (BIERLAIRE, 2009), projetado para o desenvolvimento de pesquisas no contexto de modelos de escolha discreta.

\section{(vii) Estatística para Avaliação da Significância dos Parâmetros das Variáveis}

Para verificação da hipótese de interferência e avaliação da significância dos parâmetros das variáveis no modelo é adotado o teste da estatística $t$ a um nível de significância $a=0,05$ ( $p$-valor, a probabilidade de recair no erro Tipo I usando o teste estatístico é de $5 \%)$. A estatística $t$ é dada por:

$$
t=\frac{\left(\bar{X}-\mu_{x}\right)}{S / \sqrt{n}}
$$

Em que, $\bar{X}$ é a média da amostra, $\mu_{x}$ é a média da população definido pela hipótese, $S$ é o desvio padrão da amostra e, $n$ é o número de observação da amostra.

Para um nível de significância de $5 \%$ o valor crítico da estatística t é de 1,96 ( $t_{c}$ $=1,96)$. Se o valor da estatística $t$ for menor que o valor crítico a hipótese nula é rejeitada.

\section{(viii) Estatística para Desempenho do Modelo}

Uma estatística denominada de índice de razão da verossimilhança é frequentemente utilizada em modelos de escolha discreta para medida de desempenho. Esta estatística mede o desempenho do modelo em duas situações: uma com os valores estimados, a outra com os valores dos parâmetros zerados (equivalente a não ter um modelo).

O cálculo desta comparação é realizado através da função de verossimilhança, com avaliação da função com os valores estimados para os parâmetros e com os valores dos parâmetros iguais a zero. O índice de razão da verossimilhança é dado por:

$$
\rho=1-\frac{L L(\hat{\beta})}{L L(0)}
$$


Em que $L L(\hat{\beta})$ é o valor da função verossimilhança para os parâmetros estimados e $L L(0)$.

0 valor do índice de razão da verossimilhança $(\rho)$ varia de zero, menor valor quando os parâmetros estimados não são melhores que os valores zerados, até um, quando os parâmetros perfeitamente simulam as escolhas da amostra de indivíduos.

Segundo Train (2003) a interpretação de $\rho$ não é tão semelhante quanto a interpretação estatística do $\mathrm{R}^{2}$ em modelos de regressão, apesar de ambos terem variação entre zero e um. $O \mathrm{R}^{2}$ indica a porcentagem dos valores da variável dependente que são explicados pelo modelo de regressão. $O$ índice de verossimilhança não apresenta qualquer relação intuitiva entre valores entre zero e um.

Entretanto comparando dois modelos estimados com a mesma base de dados e com o mesmo conjunto de alternativas ( $L L(0)$ possui o mesmo valor em ambos), em geral, é válido afirmar que o modelo com maior $\rho$ se adéqua melhor aos dados e ao conjunto de alternativas.

\subsubsection{Destino da Atividade Primária}

Para a modelagem da seleção do destino da atividade são utilizadas duas abordagens: o modelo de escolha discreta, descrito na seção anterior, e o modelo de oportunidades intervenientes, descrito nesta seção.

A aplicação destas duas abordagens para modelagem do comportamento individual em relação à seleção do destino da atividade primária é motivada pela ausência de elementos teóricos que justifiquem a aplicação de apenas uma das abordagens selecionadas.

Ao empregar o modelo de escolha discreta, utilizando a maximização da utilidade, pressupõe-se que o indivíduo é o único responsável pela escolha da oportunidade, que ele tem pleno conhecimento das oportunidades disponíveis e que a competição pelas oportunidades não afeta a sua escolha (a condição de pleno emprego).

Acredita-se que não é típico do comportamento dos brasileiros relativo as escolhas dos destinos a plena consciência de todas as oportunidades disponíveis no meio urbano para o exercício da atividade. 
Ainda que surjam soluções para evitar um conjunto formado por uma grande quantidade de alternativas como a utilização de subconjuntos como proposto por Ben-Akiva e Lerman (1985), segundo Train (1990) estatisticamente consistentes, e processos de modelagem mais robustos com resultados satisfatórios, a dúvida ainda persiste.

Embora exista uma pré-disposição para acreditar que as premissas do modelo de escolha discreta não são válidas no contexto do mercado de trabalho no Brasil, ou mais especificamente, para a cidade estudo de caso, não há evidência teórica ou empírica que dê embasamento à escolha ou refutação deste modelo, restando a natureza deste trabalho testar aplicação desta abordagem.

Há uma sugestão que o mercado de trabalho no Brasil seja competitivo, que os indivíduos não possuem total conhecimento de todos os locais de oportunidades e que não são os únicos responsáveis pela escolha do local de trabalho. A escolha do local de trabalho passa a ser uma seleção compartilhada pelo desejo do indivíduo pela oportunidade, pela competição e pelo empregador escolher o trabalhador.

Para esta situação o modelo de oportunidades intervenientes é o mais apropriado, conforme é descrito na seção a seguir, entretanto, não há evidência teórica ou empírica que dê embasamento à escolha ou refutação deste modelo, restando a natureza deste trabalho testar aplicação desta abordagem.

\section{Modelo de Escolha Discreta - LOGIT}

Como a técnica de modelagem empregada nesta etapa do processo decisório é semelhante a que é empregada na fase de decisão sobre o modo de viagem, para evitar a repetição ficam suprimidos a descrição da (i) teoria subjacente ao processo de modelagem do comportamento individual; (v) especificação de um modelo comportamental; (vi) estimativa dos parâmetros do modelo; (vii) estatística para avaliação da significância das variáveis, e; (viii) estatística para desempenho do modelo.

\section{(ii) Objeto da Decisão (Variável Dependente)}

Para representação da decisão dos destinos desta atividade foi adotado o conjunto de 75 bairros da cidade de Uberlândia (representados pelos centroides dos bairros) e mapeados a partir das informações sobre uso do solo (RAIS) e do sistema de transportes que correspondem às 75 alternativas de destino para execução da atividade trabalho. 


\section{(iii) Conjunto de Atributos Avaliados na Decisão}

As variáveis independentes, ou variáveis preditoras, escolhidas para explicar o comportamento do viajante urbano são relacionadas às oportunidades e à acessibilidade às oportunidades.

Com relação à medida de acessibilidade utilizada, nesta etapa é posto em prática a média do tempo de viagem pelos modos disponíveis do sistema de transportes ao indivíduo. A proposta do tempo médio pelos modos disponíveis é dada pelas seguintes razões:

- Horizonte da decisão: a decisão do destino da atividade primária, como já exposto, ocorre no longo prazo, ao passo que a decisão do modo de viagem ocorre em prazos menores. É plausível que o indivíduo mude a opção modal ao longo do tempo (por inúmeras razões) permanecendo o exercício da atividade primária no mesmo local. Para simplificação desta dinâmica é proposta a média do tempo de viagem dos modos disponíveis, e;

- Influência da localização das atividades nos modos de viagem: na Pesquisa O-D é retratado a opção de um modo de viagem para uma situação caracterizada por um conjunto de fatores que inclui a realização da viagem a um destino particular. É aceitável que o tempo de viagem entre os modos de um conjunto de alternativas disponíveis influencia o comportamento individual na seleção do modo de viagem. Em geral, acredita-se que para localidades mais distantes exista uma propensão por modos motorizados e para localidades mais próximas exista uma propensão por modos não motorizados. ${ }^{36} \mathrm{Na}$ construção de cenários hipotéticos para desempenho de atividades em locais com distintos graus de acesso é aceitável que os indivíduos projetem o seu acesso a estas atividades por diferentes modos de transportes. Para simplificação desta dinâmica é proposta a média do tempo de viagem dos modos disponíveis.

\section{Hipótese de Interferência}

A hipótese de interferência a ser testada nesta fase é:

- A escolha do destino da atividade primária é influenciada pelas oportunidades e pela acessibilidade.

\footnotetext{
${ }^{36} \mathrm{O}$ emprego dos vocábulos mais distantes e mais próximos ainda que inadequados em um texto científicos sejam empregados apenas para introduzir uma noção espacial de separação.
} 
Para verificação desta hipótese cada variável independente incluída no modelo é submetida a um teste estatístico para verificar se o parâmetro da variável é diferente de zero. Desta forma a hipótese nula a ser verificada é:

$$
\begin{aligned}
& H_{0}: B=0 \\
& H_{1}: B \neq 0
\end{aligned}
$$

Em que B é o parâmetro da variável independente.

\section{Modelo de Oportunidades Intervenientes}

\section{(i) Teoria Subjacente ao Processo de Modelagem do Comportamento Individual}

Uma abordagem aplicada a modelagem do comportamento individual quanto ao problema de localização das atividades é através do modelo de oportunidades intervenientes. Stouffer (1940) desenvolveu este modelo baseado na ideia de que o número de pessoas viajando a uma dada distância é diretamente proporcional ao número de oportunidades à aquela distância e inversamente proporcional ao número de oportunidades intervenientes.

Assim, considerando o processo de distribuição espacial de um determinado componente com origem numa zona $i$, a parte alocável a uma determinada zona $j$ será diretamente proporcional ao número de oportunidades intervenientes a partir da zona $i$ (ALMEIDA, 1999).

Neste modelo os processos de distribuição espacial não apresentam relação explícita com o custo percebido. 0 que governa tais processos é a competição entre as oportunidades existentes num determinado destino, confrontadas com as oportunidades mais acessíveis (STOUFFER, 1940).

Este método surgiu como opção aos modelos clássicos utilizados em planejamento de transportes que admitem a distribuição espacial de atividades como uma função explícita da distância ou de outra variável diretamente ligada a ela, e se configura como uma alternativa à abordagem microeconômica para comportamento individual da escolha dos destinos de viagem, preconizados principalmente pelo modelo logit e suas derivações.

Dentre as vantagens da aplicação do modelo de oportunidades intervenientes a problemas de localização citam-se: a descrição bastante completa sobre o processo de circu- 
lação das pessoas (ALMEIDA, 1999); mais apropriado para fazer estimativas de viagens onde a escolha do destino final esteja sujeita a um julgamento de um conjunto de oportunidades por parte do viajante (KÜHLKAMP, 2003), e; leva em conta, de forma mais consistente, os efeitos de impedância à realização de viagens decorrentes das modificações nos padrões de intensidade e localização das atividades humanas.

A integração entre as teorias (de oportunidades intervenientes e a de viagens baseada em atividades) pode ser viabilizada através da ideia de que o processo de escolha dos destinos na programação de atividades dos indivíduos pode ser representado pelo modelo de oportunidades intervenientes.

Para esta situação o modelo alocaria indivíduos a atividades distribuídas espacialmente no meio urbano e dentro da estrutura do modelo o comportamento individual (ou de grupos de indivíduos) seria refletido na definição do conjunto de oportunidades intervenientes entre cada par origem-destino classificados segundo a medida de acessibilidade. Para o desenvolvimento do modelo em pauta foram definidas propriedades gerais desejáveis:

Propriedade 1: A oportunidade é a representação da atividade distribuída geograficamente no espaço, representado pelo par oferta e localização.

Propriedade 2: São características das oportunidades: oferta da atividade, localização e exercem uma atração que é percebida pelos indivíduos.

Propriedade 3: São características dos indivíduos: localização, possuem uma necessidade específica, esperam que a necessidade seja atendida pelas oportunidades, possuem uma habilidade específica para atingir as oportunidades, os indivíduos estão cientes de que há oferta limitada da atividade, estão cientes que há competição pelas oportunidades, cada oportunidade possui uma resistência específica (tempo, custo e esforço) para ser alcançada que é percebida pelos indivíduos;

Propriedade 4: No processo para seleção da oportunidade os indivíduos levam em consideração a localização do domicílio e, por indução, é aceitável que indivíduos de diferentes localizações de domicílios possuem diferentes percepções da facilidade em se alcançar a mesma oportunidade.

Propriedade 5: Como há mais de um indivíduo buscando por satisfazer suas necessidades e considerando que as atividades possuem ofertas limitadas, pode-se considerar que há casos em que há competição pelas oportunidades em diferentes níveis. 
Propriedade 6: Uma oportunidade infinita com distância zero é preferível a qualquer outra configuração de oportunidade, desde que a demanda por esta atividade não seja infinita.

Propriedade 7: Um local sem oportunidade não deverá atrair indivíduos que buscam satisfazer suas necessidades.

Propriedade 8: A atratividade de um destino deve ser não crescente com o aumento do custo da viagem e não decrescente com o aumento da oportunidade ofertada, considerando níveis constantes para a competição.

Propriedade 9: Para que um indivíduo se desloque para um destino desejado para desempenho de uma atividade é necessário que a oportunidade (atividade e localização) esteja mais acessível a ele do que aos demais e que nela ele encontre uma posição disponível para engajamento na atividade desejada. Caso contrário ele irá buscar pela segunda oportunidade mais acessível, até engajar-se na atividade.

Propriedade 10: A disponibilidade da oportunidade é dada pela oferta da atividade e pela possibilidade de acesso a esta oportunidade pelos indivíduos.

Propriedade 11: Para ordenamento das oportunidades os indivíduos levam em consideração a localização do domicílio. Parece então razoável que indivíduos de diferentes localizações de domicílios, possuem diferentes percepções do agrupamento das oportunidades (ou acúmulo das oportunidades).

Propriedade 12: 0 individuo considera cada oportunidade na medida em que ela é alcançada.

Propriedade 13: Quando o efeito da posição espacial de várias oportunidades que competem entre si é considerado, surge um novo efeito sobre os fluxos de viagens, o efeito das oportunidades intervenientes, (ULYSSÉA NETO, 1988).

Propriedade 14: Todas as oportunidades oferecidas por uma zona são consideradas como se estivessem situadas em seu centroide.

Propriedade 15: A função oportunidade acumulada é não decrescente com relação à distância.

Propriedade 16: Existe uma probabilidade definida de que sua necessidade seja atendida através desta oportunidade, isto é, de que a oportunidade seja aceita. 
Propriedade 17: É esperado que diferentes tipos de pessoas tenham acesso a diferentes tipos de oportunidades de emprego que apresentam distribuições espaciais distintas. Há, portanto, para distintos segmentos de pessoas, diferentes conjuntos de oportunidades intervenientes.

\section{(ii) Objeto da Decisão (Variável Dependente)}

Para representação da decisão dos destinos desta atividade foi adotado o conjunto de 75 bairros da cidade de Uberlândia (representados pelos centróides dos bairros) e mapeados a partir das informações sobre uso do solo (RAIS) e do sistema de transportes que correspondem às 75 alternativas de destino para execução da atividade trabalho.

(iii) Conjunto de Atributos Avaliados na Decisão

As variáveis independentes, ou variáveis preditoras, escolhidas para explicar o comportamento do viajante urbano são relacionadas as oportunidades e a acessibilidade às oportunidades que definem o conjunto de oportunidades intervenientes.

Existem várias maneiras diferentes para definição do conjunto de oportunidades intervenientes. Uma das maneiras mais simples de se definir tal conjunto é uma das formas apresentadas por Stouffer (1940), que consiste em considerar como intervenientes entre as zonas $i$ e $j$, (considerando $i$ como a origem das viagens) todas as oportunidades situadas em zonas $k$ para as quais a distância de $i$ até $k$ é menor do que a distância de $i$ até $j$.

Uma representação geométrica da região onde estas oportunidades estão situadas pode ser obtida traçando um círculo com centro na zona $i$, isto é, no centroide da zona $i$, e raio igual à distância entre esta zona e a zona de destino $j$.

Variações desta forma de definir as oportunidades intervenientes podem ser obtidas substituindo a distância da zona $i$ até a zona que oferece a oportunidade em consideração, pelo tempo ou custo da viagem entre as zonas. A representação geométrica neste caso é substituída por curvas formadas pelos pontos da área de estudo atingido a partir de $i$ com custo ou tempo de viagem igual, respectivamente, ao custo ou o tempo de viagem de $i$ para $j$.

Stouffer (1960) apresenta uma forma de definir o conjunto de oportunidades intervenientes entre duas zonas $i$ e $j$. Esta maneira consiste em considerar como intervenientes 
entre as zonas $i$ e $j$ as oportunidades oferecidas pelas zonas contidas no círculo que tem como diâmetro o segmento de reta que une os centroides das zonas $i$ e $j$.

Analisando o aspecto sobre a forma segundo a qual se admite que as oportunidades intervenientes interferem na distribuição espacial fornecida pelo modelo, Kühlkamp (p. 46, 2003) menciona a insensibilidade da influência da posição da oportunidade nos resultados do modelo:

[...] Oportunidades ocupando as mais variadas posições espaciais relativas dentro do conjunto das zonas de tráfego (delimitado como sendo o que contém as oportunidades intervenientes) são tratadas da mesma maneira no modelo, e apresentam a mesma interferência no número de viagens por ele predito. Ou seja, a influência de uma oportunidade na distribuição de viagens, segundo o modelo, permanece inalterada, mesmo quando esta oportunidade é deslocada para as mais variadas posições dentro do conjunto das zonas que contém as oportunidades intervenientes [...]

Como alternativa a esta abordagem, Kühlkamp (2003) desenvolveu um modelo de oportunidades intervenientes com ponderação das posições espaciais relativas das oportunidades.

Outra abordagem foi adotada por Almeida (1999), que incluiu o comportamento individual das escolhas, para seleção do conjunto de oportunidades intervenientes em modelo de interação espacial.

Baseado em um modelo de escolha discreta calibrado a partir de uma amostra de preferência declarada, Almeida (1999) estimou a utilidade de cada uma das zonas na área de estudo para a atividade de interesse, considerando características relacionadas ao acesso às zonas e características das oportunidades.

Para formação do conjunto de oportunidades intervenientes entre cada par origemdestino Almeida (1999) considerou como intervenientes as zonas que apresentassem uma utilidade superior a zona de destino com um custo menor ou igual ao custo para se atingir a zona de destino.

Neste projeto será adotada a medida de acessibilidade para definição do conjunto de oportunidades intervenientes. Para cada indivíduo, a partir do seu domicilio, será calculado a sua acessibilidade aos destinos (centroides das zonas) através da medida do tempo de viagem, para em seguida formar a matriz de oportunidades intervenientes para cada indivíduo. 


\section{$\underline{\text { Hipótese de Interferência }}$}

A hipótese de interferência a ser testada nesta fase é:

- A escolha do destino da atividade primária é influenciada pelas oportunidades e pela acessibilidade.

Para verificação desta hipótese cada variável independente incluída no modelo é submetida a um teste estatístico para verificar se o parâmetro da variável é diferente de zero. Desta forma a hipótese nula a ser verificada é:

$$
\begin{aligned}
& H_{0}: B=0 \\
& H_{1}: B \neq 0
\end{aligned}
$$

Em que B é o parâmetro da variável independente.

\section{(v) Especificação de um Modelo Comportamental}

Para dedução do modelo em pauta (SCHNEIDER, 1959), consideram-se duas zonas de tráfego $i$ e $j$ fixas, sendo $i$ a origem da viagem e $j$ o destino da viagem. A probabilidade que uma viagem entre $i$ e $j$ ocorra pode ser escrita:

$$
p_{i j}=p_{i} \times p_{j / i}
$$

Em que $p_{i j}$ probabilidade de uma viagem com origem em i e destino em $\mathrm{j}, p_{i}$ probabilidade de uma viagem tenha origem em $\mathrm{i}, p_{j / i}$ probabilidade de uma viagem que teve origem em $\mathrm{i}$ terminar em $\mathbf{j}$

Introduzindo as seguintes notações: $\lambda=$ probabilidade de uma oportunidade ser aceita se for considerada (que se admite constante); $p_{j / i}=$ probabilidade de uma viagem que teve origem em $i$ terminar em $j ; p_{k}=$ probabilidade de uma viagem ter seu final na zona $k ; p_{k}^{u}=$ probabilidade de zona $k$ ser ultrapassada; $V_{k}=$ oportunidade oferecida pela zona $\mathrm{k} ; W_{i j}=$ oportunidades intervenientes entre $i$ e $j$;

Ordenam-se as zonas pela atratividade segundo a ordem decrescente a partir de $i$. Sejam 1, 2, 3,.., $m$ estas zonas já ordenadas segundo este critério. Assim, toda viagem iniciada em $i$ atingirá com certeza a zona 1 , tendo ali seu final se uma oportunidade en- 
contrada nesta zona for aceita pelo viajante. Caso contrário, a viagem prosseguirá até a zona 2, nestas condições a probabilidade de uma viagem ter seu final na zona 1 é:

$$
\begin{gathered}
p_{k=1}=\lambda \cdot V_{k=1} \\
p_{1}=\lambda \cdot V_{1}
\end{gathered}
$$

Assim, a probabilidade de a viagem atingir a zona 2 , ou seja, ultrapassar a zona 1 é:

$$
p_{1}^{u}=1-p_{1}=1-\lambda \cdot V_{1}
$$

e como a probabilidade de ser encontrada na zona 2 uma oportunidade aceitável (dado que esta zona foi atingida) é $\lambda \cdot V_{2}$, a probabilidade de a zona 2 ser ultrapassada é:

$$
\begin{gathered}
p_{2}^{u}=p\left[\begin{array}{c}
\text { a zona } 2 \text { ser } \\
\text { alcançada }
\end{array}\right] \cdot p\left[\begin{array}{c}
\text { não encontrar oportunidade } \\
\text { aceitável na zona } 2
\end{array}\right] \\
=p_{1}^{u} \cdot\left(1-\lambda \cdot V_{2}\right)
\end{gathered}
$$

Analogamente obtém-se,

$$
p_{3}^{u}=p_{2}^{u} \cdot\left(1-\lambda \cdot V_{3}\right)
$$

e por indução,

$$
p_{k}^{u}=p_{k-1}^{u} \cdot\left(1-\lambda \cdot V_{k}\right)
$$

de onde se obtém,

$$
\frac{p_{k}^{u}}{p_{k-1}^{u}}=1-\lambda \cdot V_{k}
$$

ou,

$$
\frac{p_{k}^{u}-p_{k-1}^{u}}{p_{k-1}^{u}}=-\lambda \cdot V_{k}
$$


Fazendo,

$$
G_{k}=\sum_{s=1}^{k} V_{s}
$$

Tem-se que,

$$
V_{k}=G_{k}-G_{k-1}
$$

Substituindo,

$$
\frac{p_{k}^{u}-p_{k-1}^{u}}{p_{k-1}^{u}}=-\lambda \cdot\left(G_{k}-G_{k-1}\right)
$$

ou,

$$
\frac{\Delta p_{k-1}^{u}}{p_{k-1}^{u}}=-\lambda \cdot \Delta G_{k-1}
$$

ou, omitindo os sub-índices de $p$ e $G$,

$$
\frac{\Delta p^{u}}{p^{u}}=-\lambda \cdot \Delta G
$$

onde,

$$
\Delta G=\Delta G_{k-1}=G_{k}-G_{k-1}
$$

e,

$$
\Delta p^{u}=\Delta p_{k-1}^{u}=p_{k}^{u}-p_{k-1}^{u}
$$

Naturalmente $G_{k}$ só pode assumir valores inteiros, porém, para que possam ser utilizadas as ferramentas do cálculo diferencial e integral, utiliza-se o artifício comum de admitir a variação contínua desta variável. Isto significa que a variável $G_{k}$ é estendida ao conjunto dos números reais, ou seja, admite-se que a variável $G_{k}$ tenha variação num conjunto não discreto. Feita esta hipótese pode-se então escrever:

$$
\frac{d p^{u}}{p^{u}}=-\lambda \cdot d G
$$


e,

$$
\int \frac{d p^{u}}{p^{u}}=-\lambda \cdot \int d G
$$

o que fornece,

$$
\ln p^{u}=-\lambda \cdot G+c
$$

ou,

$$
\begin{gathered}
p^{u}=e^{-\lambda \cdot G+c} \\
p^{u}=K \cdot e^{-\lambda \cdot G}
\end{gathered}
$$

Da maneira como $G_{k}$, foi definido tem-se,

$$
G_{m}=\sum_{s=1}^{m} V_{s}=W_{i j}
$$

sendo $m$ a última zona em ordem decrescente de $j$. Substituindo,

$$
p_{m}^{u}=K \cdot e^{-\lambda \cdot W_{i j}}
$$

e,

$$
p_{j}^{u}=K \cdot e^{-\lambda \cdot\left(W_{i j}+V_{j}\right)}
$$

Assim, a probabilidade de uma viagem que teve seu início na zona i, ter seu final na zona $j$ é dada por,

$$
p_{j / i}=p_{m}^{u}-p_{j}^{u}
$$




$$
\begin{gathered}
=K \cdot e^{-\lambda \cdot W_{i j}}-K \cdot e^{-\lambda \cdot\left(W_{i j}+V_{j}\right)} \\
=K \cdot e^{-\lambda \cdot W_{i j}} \cdot\left(1-e^{-\lambda \cdot V_{j}}\right)
\end{gathered}
$$

como a constante $K$ está associada à zona $i$, assinala-se $k_{i}$

$$
p_{j / i}=k_{i} \cdot e^{-\lambda \cdot W_{i j}} \cdot\left(1-e^{-\lambda \cdot V_{j}}\right)
$$

atendendo a condição:

$$
\sum_{j=1}^{n} p_{j / i}=1
$$

ou seja,

$$
\sum_{j=1}^{n} k_{i} \cdot e^{-\lambda \cdot W_{i j}} \cdot\left(1-e^{-\lambda \cdot V_{j}}\right)=1
$$

\section{(vi) Estimativa dos Parâmetros do Modelo}

No modelo de oportunidades de Schneider (1959) tem-se a probabilidade $\lambda$ de uma oportunidade ser aceita, se for considerada, e os fatores de balanceamento $k_{i}$ para determinar. Quatro maneiras simples para determinação da probabilidade $\lambda$ são apresentadas:

- Baseado na formulação simples da probabilidade:

$$
\lambda=\frac{1}{W}
$$

Em que $W$ representa o total de oportunidades.

- Baseado na densidade média dos destinos (RUITER, 1967):

$$
\lambda=\frac{1}{4 \cdot \rho \overline{r^{2}}}
$$


Em que $\rho$ é a densidade média de destinos terminais de viagens, dada por $\rho=$ destinos terminais de viagens (oportunidades)/unidade de área e $\bar{r}$ representa o comprimento médio das viagens.

- Baseado na matriz observada de viagens (RUITER, 1967):

$$
\lambda=\frac{T^{*}}{\sum_{i, j} T_{i j}^{*}\left(W_{i j}+V_{j}\right)}
$$

Em que $T^{*}$ representa o total de viagens observada e $T_{i j}^{*}$ as viagens observadas entre pares O-D.

- Baseado na matriz estimada de viagens através de um processo interativo (RUITER, 1967):

$$
\begin{gathered}
\hat{\lambda}=\frac{\sum_{i, j} T_{i j}}{\sum_{i, j} T_{i j}\left(W_{i j}+V_{j}\right)} \\
\lambda=\frac{\hat{\lambda}+\lambda_{0}}{2}
\end{gathered}
$$

Entre os métodos apresentados acima, será adotado aquele que apresentar melhor desempenho do modelo. Para realizar o processamento do modelo de oportunidades será utilizado o Microsoft Excel com o pacote de ferramentas de teste de hipóteses, denominado Solver.

Com o Solver é possível obter um valor ideal (máximo ou mínimo) para uma fórmula em uma célula - chamada célula de objetivo - conforme restrições, ou limites, sobre os valores de outras células de fórmula em uma planilha. O Solver trabalha com células denominadas variáveis de decisão, ou simplesmente de variáveis, que participam do cálculo das fórmulas nas células de objetivo e de restrição, ajustando os valores das variáveis de decisão para satisfazer aos limites de restrição e produzir o resultado que se deseja para a célula objetiva. 
Utilizando o Solver o objetivo será estimar a probabilidade $\lambda$ pelas quatro formas apresentadas minimizando a diferença absoluta e quadrática entre os valores observados e estimados. Para realizar o cômputo das diferenças absolutas e quadráticas adota-se um zoneamento com um número menor de divisão de áreas em relação à segregação espacial original (75 bairros).

Esta divisão é proposta em função da baixa representatividade dos números de viagens entre os pares O-D. Dos 5.625 pares, apenas 74 possuem observações acima de 30 viagens. A solução proposta é agregar os bairros (obtendo macrozonas) para obter conjuntos estatisticamente representativos (maior número de observações acima de 30 ).

Para criação das macrozonas é utilizado como critério de fusão as distâncias euclidianas entre os centroides dos bairros. Para cada interação é elaborado uma nova matriz de distancia entre centroides para realizar a união entre as áreas de menor distância.

O critério de parada adotado para a fusão das zonas é baseado no maior número possível de macrozonas com pares O-D estatisticamente válidos (maior número possível de pares O-D com um maior número de viagens). Adicionalmente é estabelecido como limite inferior um valor de $20 \%$ do total de divisões da segregação espacial original para não comprometer o estudo dos deslocamentos individuais.

Para verificar se as macrozonas representam o conjunto original de bairros é estabelecida a hipótese para representar a configuração original:

- Os tempos médios (estimados) entre macrozonas devem ser próximos aos tempos médios originais entre os bairros.

Para verificação desta hipótese os tempos médios entre macrozonas são comparados aos tempos médios entre bairros respeitando um limite de desvio. 0 desvio adotado neste trabalho será a diferença relativa (D). Caso $D>D_{\text {crítico, }}$, rejeita-se a hipótese nula. Se $D<D_{\text {crítico }}$, então não se rejeita a hipótese nula.

\section{(vii) Estatística para Avaliação da Significância dos Parâmetros das Variáveis}

Ao contrário do modelo logit em que há uma definição sobre o teste estatístico para avaliação da significância dos parâmetros das variáveis, nos modelos de oportunidades intervenientes não existe esta definição. 
Para análise da significância das variáveis no modelo de oportunidades é utilizado regressão linear múltipla. 0 objetivo principal de sua aplicação é associar inferência estatística às variáveis independes, no caso, tempo médio de viagem, oportunidade acumulada e oportunidade interveniente.

A aplicação da regressão linear múltipla é dada pela variável dependente representada pela propensão da escolha individual para desempenho da atividade em cada bairro. Deve-se deixar claro que o objetivo da regressão linear não é a qualidade de explicação do comportamento dos indivíduos em relação às escolhas, e sim, propor um método para mensurar a significância das variáveis envolvidas. No entanto, os modelos devem ser robustos quanto aos pressupostos, para que valores de estatística $t$ e coeficientes estimados sejam significativos.

\section{(viii) Estatística para Desempenho do Modelo}

De modo geral, o desempenho de um modelo de distribuição de viagens é avaliado medindo-se a proximidade entre a matriz de fluxos estimada pelo modelo e a matriz de fluxos observada na área de estudo.

Para medir a proximidade entre a matriz observada e a matriz estimada pelo modelo são usadas algumas estatísticas, conhecidas na literatura como medidas de "qualidade de adequação" (goodness-of-fit).

Para avaliar a proposta atual em andamento são descritas três testes estatísticos: diferença relativa, diferença quadrática e índice de dissimilaridade. Para as equações que serão apresentadas convencionou-se o uso dos termos, $T_{i j}$, $T_{i j}^{*}$ e $T^{*}$ para representar respectivamente o número estimado de indivíduos entre o par origem-destino $(i, j)$, número observado de indivíduos entre o par origem-destino $(i, j)$ e número total de viagens observadas na área de estudo.

- Diferença relativa: mede em porcentagem a dispersão da diferença entre o valor observado e estimado.

$$
\text { Diferença } a_{\%}=\frac{\left|T_{i j}^{*}-T_{i j}\right|}{T_{i j}^{*}}
$$

- Índice de dissimilaridade: mede a porcentagem de viagens que necessitam ser realocadas entre os pares de origem-destino $(i, j)$ 


$$
I D=\frac{50}{T^{*}} \sum_{i, j}\left|T_{i j}^{*}-T_{i j}\right|
$$

- Diferença Quadrática: mede a razão entre diferença quadrática entre o valor observado e estimado pelo valor estimado.

$$
\text { Diferença Quadrática } a_{\%}=\frac{\left(T_{i j}^{*}-T_{i j}\right)^{2}}{T_{i j}^{*}}
$$

Adicionalmente ao teste realizado entre a matriz estimada com a medida de acessibilidade proposta pelo tempo médio de viagem serão realizados testes entre a matriz observada e matrizes estimadas com a distância (euclidiana e na rede viária) e outras formas de tempo para comparação do desempenho do modelo.

\subsubsection{Padrão de Viagens}

Uma forma para melhor compreensão da análise de viagens baseada em atividades é a segmentação da demanda, que pode ser definido como um recurso que simplifica a análise, facilitando a compreensão e interpretação dos comportamentos em relação às viagens, ao identificar grupos mais homogêneos e diminuir a complexidade e variabilidade associada a uma abordagem desagregada.

Segundo Van de Bilt (2002, p. 7):

[...] Somente através da utilização do enfoque desagregado é possível, num contexto de crescente complexidade, formular e analisar políticas de transportes, para tentar sanar ou minorar os problemas relacionados à demanda crescente por transportes e avaliar os impactos das políticas de transportes sobre os diferentes segmentos da população, tarefa particularmente importante devido a um aumento da preocupação com os critérios de equidade na distribuição dos recursos [...].

$\mathrm{Na}$ literatura sobre segmentação da demanda há duas técnicas que são comumente citadas e utilizadas na análise dos padrões de viagens encadeadas: modelos baseados na maximização da utilidade, e modelos baseados em regras.

Os modelos baseados na maximização da utilidade representam as escolhas dos padrões diários de atividades e cadeias de viagens como processos individuais de "trocas" de custos percebidos e benefícios associados a escolha dos padrões dentro de um conjunto de alternativas. 
A técnica de maximização da utilidade é largamente difundida na literatura sobre modelos de atividades, podem ser citados como exemplos:

- Simulação de Respostas de Viagem e Atividade para Decisões Logísticas Interativas do Complexo do Domicílio (Simulation of Travel / Activity Responses to Complex Household Interactive Logistic Decisions - STARCHILD, RECKER et al., 1986a; RECKER et al., 1986b);

- Modelo desenvolvido com dados da cidade de Boston (BOWMAN, 1995);

- Sistema de Programação Diária da Atividade para Portland (Portland Day Activity Schedule System, BOWMAN, 1998), e;

- Modelo de Simulação da Heurística Programação de Atividade (Simulation Model of Activity Scheduling Heuristics - SMASH), (ETTEMA, 1996).

O modelo baseado em regra é uma estrutura alternativa para representação da influência de fatores na formação dos padrões diários de atividades e são baseados na ideia que o comportamento individual pode ser caracterizado pela realização de metas, dentro de limites impostos por condições e restrições ${ }^{37}$.

A partir de uma amostra contendo informações sobre escolhas individuais (por exemplo, o padrão de viagens) é aplicado uma técnica de mineração de dados para extrair padrões desta base de dados.

Existe uma grande variedade de métodos de mineração de dados que são utilizados. Entre as técnicas mais utilizadas estão às técnicas de inteligência artificial (do inglês Artificial Intelligence - Al) com o emprego das redes neurais, árvores de decisão, algoritmos genéticos, vizinho mais próximo (do inglês nearest neighbor), lógica nebulosa ou difusa (fuzzy logic), regras de indução e visualização (WESTPHAL; BLAXTON, 1998).

Vários estudos demonstraram a aplicabilidade de modelos baseados em regras para análise da demanda por transportes: Thill e Wheeler (2000); Gahegan (2000); Wets et al. (2000); Yamamoto et al. (2002); Xie et al. (2003); Moons et al. (2005), e; Arentze e Timmermans (2007).

\footnotetext{
${ }^{37}$ Arentze e Timmermans (2007) citam que o principal fundamento do modelo baseado em regras é a Teoria da Racionalidade Limitada de Simon (1992).
} 
O modelo de atividade de maior destaque na literatura é o Sistema de Simulação Orientado de Transporte Baseado em Aprendizagem (A Learning-Based Transportation Oriented Simulation System - ALBATROSS), desenvolvido por Arentze e Timmermans (2004).

Comparado aos modelos de maximização da utilidade, a principal vantagem dos modelos baseados em regras é a possibilidade de representar diversos tipos de interação entre as variáveis no mesmo modelo ${ }^{38}$. Entretanto, a principal desvantagem dos modelos baseados em regras é a ausência de estatísticas entre as variáveis analisadas e a quantificação da influência de uma variável no contexto em que é analisada ${ }^{39}$.

Em busca de uma melhor compreensão da influência da acessibilidade e outros fatores que influenciam a formação dos padrões individuais de viagens (por exemplo, renda individual, posse de automóvel, situação família, etc.), neste trabalho é proposta a aplicação das duas técnicas de segmentação da demanda: modelo de escolha discreta e modelo baseado em regras.

No modelo de escolha discreta, o objetivo da análise é verificar a influência das variáveis nos padrões de viagens, com especial atenção a influência da acessibilidade na formação dos padrões de viagens. No modelo baseado em regras, o objetivo da análise é investigar a dependência entre as variáveis, principalmente entre a acessibilidade e as demais variáveis.

A aplicação das técnicas é realizada em quatro etapas. Na primeira etapa é considerada toda a amostra de indivíduos e as informações sobre deslocamentos, participação em atividades, acessibilidade representada pelo tempo de viagem associada ao modo de transportes e características individuais e do domicílio.

O objetivo desta etapa é verificar (e quantificar) a influência das variáveis nos padrões de viagens (por exemplo, qual o impacto do aumento da renda individual nas propensões dos padrões de viagens? Qual o impacto do aumento do tempo de ônibus, pela migração de classe de tempo, na escolha dos padrões?). Para atingir a finalidade proposta a técnica empregada nesta etapa é o modelo logit.

\footnotetext{
${ }^{38} \mathrm{Em}$ modelos hierárquicos de utilidade é possível apresentar a interação entre variáveis em níveis, entretanto, os níveis são limitados em comparação aos modelos baseados em regras. Há um grande esforço de pesquisadores em relaxar os axiomas do modelo logit multinomial em busca de modelos que possam representar com maior fidelidade as situações reais de escolha.

${ }^{39}$ Os modelos baseados em regras produzem um problema denominado de efeito da descontinuidade dos atributos das variáveis (ARENTZE; TIMMERMANS, 2007). Na fase de desenvolvimento, o modelo baseado em regras transforma as variáveis contínuas em variáveis categóricas, segundo as regras extraídas do banco de dados. Esta categorização pode gerar grupos que não são homogêneos em relação à variável analisada, enquanto, espera-se que os agrupamentos obtidos devem apresentar uma homogeneidade interna (dentro de cada categoria), como uma grande heterogeneidade externa (entre categorias).
} 
Na segunda etapa, a amostra é dividida em três grupos segundo o modo de transporte utilizado ${ }^{40}$ para realizar o padrão de viagens: não motorizado (a pé e bicicleta), coletivo (ônibus) e individual motorizado (automóvel/moto motorista e passageiro).

O objetivo desta etapa é verificar a influência das variáveis nos padrões de viagens e a dependência entre as variáveis, segundo o modo utilizado (por exemplo, o que pode ser obtido se ocorrer a redução do tempo de viagem por ônibus? Como é a dependência da renda e a acessibilidade?). A acessibilidade nesta etapa é representada pelo tempo de viagem reportado na pesquisa e são aplicados o modelo logit e a árvore de decisão.

O interesse em dividir a amostra segundo o modo predominante no padrão de viagens é a possibilidade de redução da complexidade do delineamento da acessibilidade no comportamento destes indivíduos em comparação a uma análise sem segregação. Na Tabela 4.7 é apresentada uma descrição dos modelos empregados nesta etapa do trabalho

Tabela 4.7 - Descrição dos modelos aplicados na segmentação da demanda.

\begin{tabular}{|c|c|c|}
\hline Modelo & Amostra & $\begin{array}{l}\text { Técnica de } \\
\text { Modelagem }\end{array}$ \\
\hline 1-FULL & Todos os indivíduos & LOGIT \\
\hline \multirow[t]{2}{*}{$2-N-L$} & & LOGIT \\
\hline & $\begin{array}{l}\text { Modo não motorizado } \\
\text { (modos a pé e bicicleta) }\end{array}$ & \\
\hline $2-\mathrm{N}-\mathrm{A}$ & & Árvore de Decisão \\
\hline \multirow[t]{2}{*}{$3-C-L$} & & LOGIT \\
\hline & $\begin{array}{l}\text { Modo coletivo } \\
\text { (modo ônibus) }\end{array}$ & \\
\hline $3-C-A$ & & Árvore de Decisão \\
\hline \multirow[t]{2}{*}{ 4-P-L } & & LOGIT \\
\hline & $\begin{array}{c}\text { Modo privado } \\
\text { (automóvel/moto motorista e passageiro) }\end{array}$ & \\
\hline 4-P-A & & Árvore de Decisão \\
\hline
\end{tabular}

"FULL" - todos os indivíduos da amostra; "N" - modo não motorizado; "C" - modo coletivo; "P" - modo individual motorizado; "L” - LOGIT; “A”- Árvore de Decisão.

\footnotetext{
${ }^{40}$ Modo predominante no padrão de viagens.
} 


\section{Modelo de Escolha Discreta - LOGIT}

Modelos: “1-FULL”; “2-N-L”; “3-C-L”; “4-P-L”.

Como esta técnica de modelagem é semelhante a que é empregada na fase de decisão sobre o modo de viagem e de destino da viagem, para evitar a repetição ficam suprimidos a descrição da (i) teoria subjacente ao processo de simulação do comportamento individual; (v) especificação de um modelo comportamental; (vi) estimativa dos parâmetros do modelo; (vii) estatística para avaliação da significância das variáveis, e; (viii) estatística para desempenho do modelo.

(ii) Objeto da Decisão (Variável Dependente)

A variável dependente nesta etapa do processo de modelagem é formada pelo padrão de viagens em quatro categorias apresentados na Tabela 4.6: (1) "HWH"; (2) "H+W+H"; (3) "HWHWH", e; (4) "H+W+H+W+H".

(iii) Conjunto de Atributos Avaliados na Decisão

As variáveis independentes, ou variáveis preditoras, escolhidas para explicar o comportamento do viajante urbano são relacionadas às características socioeconômicas dos indivíduos e dos domicílios (Tabela 4.3), participação em atividades (Tabela 4.4) e características do sistema de transportes (Tabela 4.5).

No modelo "1-FULL" a acessibilidade é representada pelo tempo de viagem associada ao modo de transportes, nos modelos "2-N-L"; “3-C-L"; “4-P-L” a acessibilidade é representada pelo tempo de viagem.

(iv) Hipótese de Interferência

A hipótese de interferência a ser testada no modelo "1-FULL” é:

- A escolha do padrão de viagens é influenciada pelas características individuais, características do domicílio, participação em atividades e características do sistema de transportes, incluindo a acessibilidade associada ao modo de transportes.

As hipóteses de interferência a serem testadas nos modelos "2-N-L”; “3-C-L”; “4-P-L" é: 
- A escolha do padrão de viagens é influenciada pelas características individuais, características do domicílio, participação em atividades e características do sistema de transportes, incluindo a acessibilidade.

Para verificação das hipóteses cada variável independente incluída no modelo é submetida a um teste de estatístico para verificar se o parâmetro da variável é diferente de zero. Desta forma a hipótese nula a ser verificada é:

$$
\begin{aligned}
& H_{0}: B=0 \\
& H_{1}: B \neq 0
\end{aligned}
$$

Em que B é o parâmetro da variável independente.

\section{Modelo Baseado em Regras - Árvore de Decisão}

Modelos: “2-N-A”; “3-C-A”; “4-P-A”.

A técnica de árvore de decisão, um dos métodos de mineração de dados, se constitui em uma forma simples de representação, classificando exemplos de uma base de dados em um número finito de classes (QUINLAN, 1983).

A árvore é estruturada em uma sequência de questões simples, e as respostas para essas questões traçam o caminho da árvore. O produto final é um conjunto de regras hierárquicas que dividem os dados dentro de grupos onde uma divisão (classificação ou predição) é feita para cada grupo, formando uma árvore, com um nó raiz (conjunto original que contém os dados), nós intermediários (que representam grupos de dados) e o nós finais, também chamado de folhas (quando os dados do nó não podem ser mais subdivididos em outro subconjunto).

\section{(i) Objeto da Decisão (Variável Dependente)}

A variável dependente nesta etapa do processo de modelagem é formada pelo padrão de viagens em quatro categorias apresentados na Tabela 4.6: (1) "HWH"; (2) "H+W+H"; (3) "HWHWH", e; (4) "H+W+H+W+H". 


\section{(ii) Conjunto de Atributos Avaliados na Decisão}

As variáveis independentes, ou variáveis preditoras, escolhidas para explicar o comportamento do viajante urbano são relacionadas às características socioeconômicas dos indivíduos e dos domicílios (Tabela 4.3), participação em atividades (Tabela 4.4) e características do sistema de transportes (Tabela 4.5).

\section{(iii) Investigação da Dependência Entre Variáveis}

$\mathrm{Na}$ árvore de decisão a etapa de verificação da hipótese de interferência é substituída pela investigação da dependência entre variáveis na formação dos padrões de viagens. A premissa a ser analisada nos modelos elaborados é:

- Há coerência entre as relações de dependência entre variáveis no modelo estimado.

\section{(iv) Estimativa do Modelo}

Entre os programas computacionais que disponibilizam o processo analítico de mineração de dados, será utilizado o S+ (versão 8.1). A técnica de árvore de decisão utilizada pelo S+ é baseada no algoritmo CART (do inglês, Classification and Regression Trees), considerado por Bell (1996) como um modelo de regressão não paramétrico que têm por objetivo estabelecer uma relação entre um vetor de variáveis preditoras e uma variável resposta. O algoritmo é ajustado mediante sucessivas divisões binárias no conjunto de dados, de modo a tornar os subconjuntos resultantes cada vez mais homogêneos, em relação à variável resposta.

Ao escolher e apresentar as variáveis em ordem de importância, as árvores de decisão permitem aos usuários visualizar imediatamente quais fatores mais influenciam as suas classificações ou previsões. Oferecem assim uma estrutura clara e maior facilidade de compreensão dos resultados.

$\mathrm{Na}$ CART, as variáveis explicativas e as variáveis respostas podem assumir valores contínuos ou categóricos. 0 modelo recebe o nome de árvore de regressão para as respostas contínuas e árvore de classificação para variáveis categóricas.

O S+ possui restrições quanto ao processamento de dados. Há um limite máximo de 128 tipos de variáveis respostas e 32 categorias em relação ao nível das variáveis explicativas discretas. 
Quanto à seleção do tipo de árvore, este é automaticamente selecionado pelo programa quando se define a variável resposta, que assume uma distribuição multinomial. A divisão dos dados dentro de cada nó é progressiva, tendendo à homogeneidade até que os nós contenham poucas observações. 0 critério quanto ao mínimo número de observações antes da divisão e no nó final é definido pelo usuário, sendo o limite mínimo estabelecido de 5 observações.

Nas árvores de classificação, a heterogeneidade de cada nó é medida pelo desvio (D) da seguinte forma:

$$
\mathrm{D}=-2 \times \sum_{t} \sum_{j \in t} \mathrm{n}(j \mid t) \log \mathrm{p}(j \mid t)
$$

Em que: $n(j \mid t)$ é o número de casos no nó $t$ com a resposta categórica $j$;

$\mathrm{P}(j \mid t)$ denota a proporção dos casos na categoria $j$ em relação a todos os casos pertencentes ao nó $t$.

Para o S+ o desvio foi definido como recíproco da função verossimilhança elevada ao quadrado, isto significa que o desvio é uma medida da heterogeneidade dos grupos resultantes. Quanto menor o valor do desvio (D), maior é a complexidade da árvore, ocorrendo ramificações e um maior número de nós terminais.

\section{(v) Coerência nas Relações Encontradas entre Variáveis}

Para a análise de modelos não-paramétricos não há formalização de estatísticas clássicas. Nestes modelos, em geral, a consistência dos resultados baseia-se na interpretação do modelo e coerência das relações encontradas.

\section{ETAPA 3}

\subsection{Verificação da Hipótese Nula}

Nesta etapa será realizada a verificação da hipótese nula:

Acessibilidade a oportunidades influencia o comportamento dos padrões de viagens encadeadas desempenhados pelos indivíduos. 
A verificação é realizada em três etapas:

- Significância da variável medida de acessibilidade nos modelos;

- Verificação do desempenho dos modelos e

- Verificação das relações encontradas nos modelos.

\subsubsection{Significância da Variável Medida de Acessibilidade nos Modelos}

Pela proposta em pauta em cada nível de decisão da programação diária de atividades é formulado uma hipótese auxiliar relacionada à hipótese nula do projeto para interferência das variáveis independentes (incluindo a acessibilidade) na variável dependente.

A verificação da hipótese é realizada por estatísticas para significância dos parâmetros das variáveis independentes na modelagem da variável dependente e desempenho do modelo em representar o comportamento individual nos níveis de decisão dentro da programação diária de atividades.

No modelo para representação do comportamento individual em relação ao modo de viagem a hipótese de interferência a ser testada nesta fase é:

- A escolha do modo de viagem é influenciada pelas características individuais, características do domicílio e características do sistema de transportes, incluindo a acessibilidade.

No modelo para representação do comportamento individual em relação à escolha do destino da atividade prioritária a hipótese de interferência a ser testada nesta fase é:

- A escolha do destino da atividade primária é influenciada pelas oportunidades e pela acessibilidade.

No modelo para representação do comportamento individual em relação a escolha do padrão de viagens a hipótese de interferência a ser testada nesta fase é: 
- A escolha do padrão de viagens é influenciada pelas características individuais, características do domicílio, participação em atividades e características do sistema de transportes, incluindo a acessibilidade associada ao modo de transportes.

Para verificação das hipóteses cada variável independente incluída no modelo é submetida a um teste estatístico para verificar se o parâmetro da variável é diferente de zero. Desta forma a hipótese nula a ser verificada é:

$$
\begin{aligned}
& H_{0}: B=0 \\
& H_{1}: B \neq 0
\end{aligned}
$$

Em que B é o parâmetro da variável independente.

A partir dos testes de hipóteses (auxiliares) propostos e com a atenção da análise dos resultados voltada a para o delineamento da influência da acessibilidade nos modelos, são reunidos indícios para elaboração da conclusão da rejeição, ou não rejeição da hipótese nula do projeto.

\subsubsection{Verificação do Desempenho do Modelo}

Outro elemento importante na elaboração da conclusão da rejeição, ou não rejeição da hipótese nula, é o desempenho dos modelos em representar o comportamento individual nas decisões da programação diária de atividades. Para cada modelo será adotado uma estatística para avaliação do seu desempenho e a rejeição ou não rejeição da hipótese é relacionado ao valor desta estatística.

\subsubsection{Verificação das Relações Encontradas no Modelo}

Cria-se uma expectativa de que indivíduos com maior poder aquisitivo, maior nível de motorização, sem restrição às alternativas do sistema de transportes estarão relacionados a medidas de acessibilidade elevadas, enquanto indivíduos com menor poder aquisitivo, baixo ou zero nível de motorização, e com restrição às alternativas de transportes estarão relacionadas a medidas de acessibilidade baixas. A coerência destas relações, e outras, serão analisadas. 


\section{Capítulo 5}

\section{Preparação Do Experimento}

[...] toda experiência da pesquisa deve ser descrita para permitir que outros pesquisadores repitam a pesquisa, quer para replicar os experimentos, quer para constatar que os resultados aqui encontrados foram de natureza casual e que não se deveram à intenção do autor, mas a outros fatores que não foram considerados [...]

\subsection{Considerações Iniciais}

Neste capítulo é apresentada uma breve descrição da cidade estudo de caso e apresentadas as fases de preparação do experimento composta pelo tratamento dos dados e construção das variáveis que são utilizados na verificação da hipótese nula.

\subsection{Município de Uberlândia}

Fundada em 1888 e com uma população de 534.943 habitantes no ano de $2002^{41}$ (UBERLANDIA, 2003), a cidade de Uberlândia é considerada um centro predominantemente urbano, apenas $2,44 \%$ da população reside na área rural. Possui uma conformação típica de

\footnotetext{
41579.005 habitantes em 2010 (IBGE, 2010)
} 
Capítulo 5 - Preparação do Experimento

crescimento radial que aliada à especulação imobiliária concentra um expressivo adensamento vertical nas áreas centrais e uma grande expansão horizontal e rarefeita nos bairros periféricos (UFU, 2002).

A existência de grandes vias de deslocamentos com características radiais reforçaram ainda mais o poder de atração da área central onde estão concentradas as atividades de comércio, de prestação de serviços e de administração pública. Esta área é envolvida por um anel de bairros com densidade populacional entre 50 e 70 habitantes por hectare. Mais afastados do centro estão localizados os bairros com densidade populacional abaixo de 40 habitantes por hectare e com população de menor poder aquisitivo (Figura 5.1).

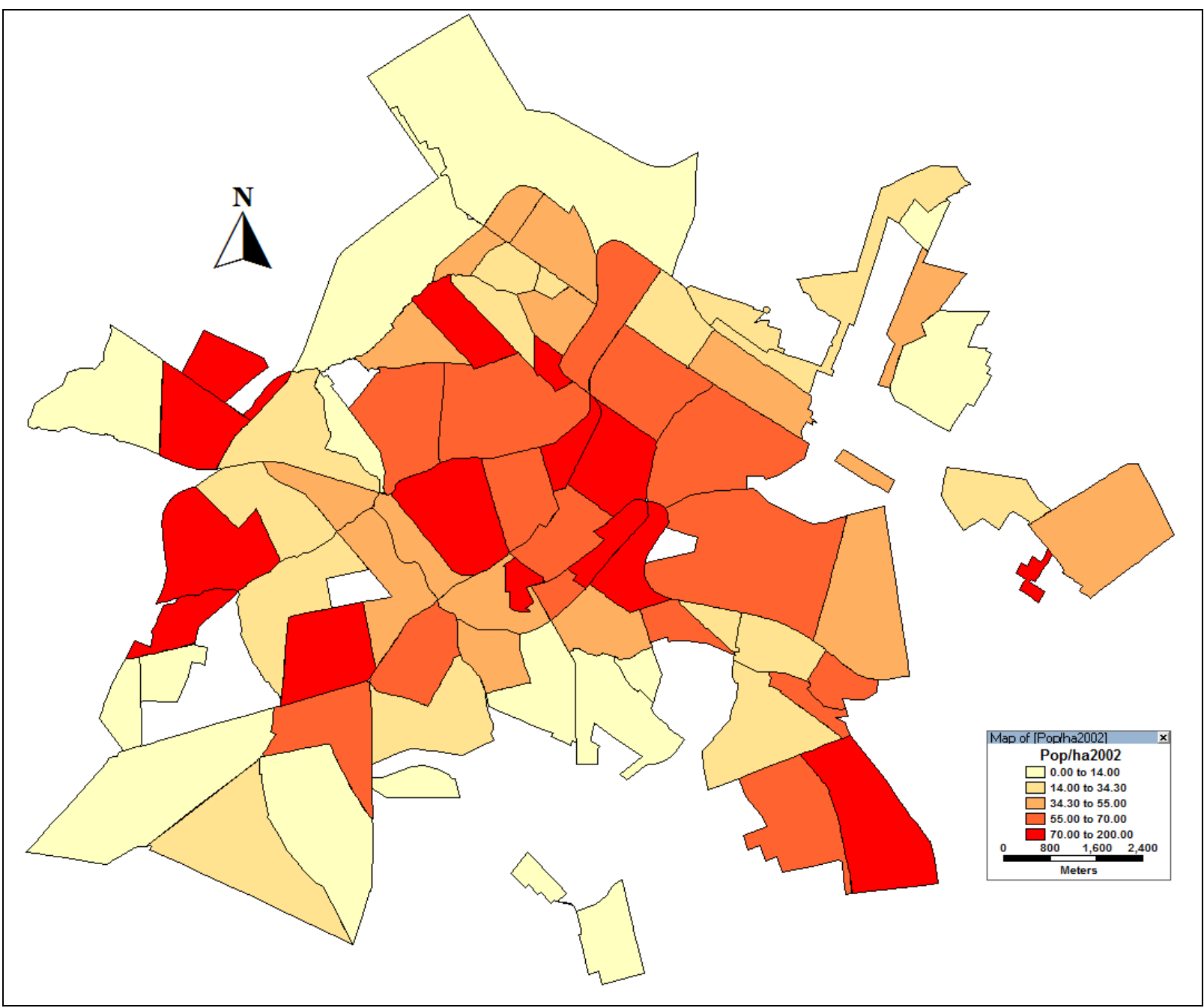

Figura 5.1 - Densidade populacional (habitantes por hectare) segundo a estimativa de previsão para Uberlândia em 2002.

Segundo o Painel de Informações Municipais de Uberlândia (CESPE, 2007), Uberlândia apresentou entre a década de 1980 e 2000 um expressivo crescimento demográfico: a população em 2000 representava o dobro de pessoas que residiam no município em 1980, e quatro vezes a população de 1970. 
Capítulo 5 - Preparação do Experimento

Esta expansão populacional ocorreu por conta das expressivas taxas de crescimento, entre 1970 e 1980, 6,7\% a.a. e no período 1991 e 2000, 3,6\% a.a. Nestes períodos, as taxas de crescimento uberlandenses ficaram bem acima das verificadas para o estado de Minas Gerais, 1,5\% e 1,4\% a.a., respectivamente, e do Brasil, 2,5\% e 1,6\% a.a.. Na Tabela 5.1 são apresentadas informações sobre o número de habitantes e domicílios (em 2000 e 2002) e na Tabela 5.2 é apresentada a distribuição da população por faixa etária em 2002.

Tabela 5.1 - Atributos sociais da população de Uberlândia.

\begin{tabular}{lc}
\hline \multicolumn{1}{c}{ Atributos } & Valor \\
\hline Área $\left(\mathrm{km}^{2}\right)^{1}-2000$ & 219,00 \\
População ${ }^{1}-2000$ & 485.492 \\
População $^{2}$ (estimativa 2002) & 534.943 \\
Domicílios $^{1}$ - 2000 & 141.319 \\
Densidade: número de habitantes por hectare $^{3}-2000$ & 57,94 \\
Tamanho Médio dos Domicílios $^{1}-2000$ & 3,44 \\
\hline
\end{tabular}

Fonte: ${ }^{1}$ IBGE (2000), ' ${ }^{2}$ CESPE (2007), ${ }^{3}$ Considerado apenas as áreas dos setores censitários.

Tabela 5.2 - Distribuição da população por faixa etária em $2002^{1}$ (CESPE 2007).

\begin{tabular}{ccc}
\hline Faixa Etária & População & Frequência Relativa \% \\
\hline Menos de 1 ano & 8.345 & $1,56 \%$ \\
1 a 4 anos & 35.520 & $6,64 \%$ \\
10 a 9 anos 14 anos & 46.272 & $8,65 \%$ \\
15 a 19 anos & 49.001 & $9,16 \%$ \\
20 a 24 anos & 53.120 & $9,93 \%$ \\
25 a 29 anos & 55.313 & $10,34 \%$ \\
30 a 34 anos & 48.573 & $9,08 \%$ \\
35 a 39 anos & 46.112 & $8,62 \%$ \\
40 a 49 anos & 44.614 & $8,34 \%$ \\
50 a 59 anos & 68.633 & $12,83 \%$ \\
60 a 69 anos & 39.318 & $7,35 \%$ \\
70 a 79 anos & 23.644 & $4,42 \%$ \\
Mais de 80 anos & 11.983 & $2,24 \%$ \\
Total & 4.495 & $0,84 \%$ \\
\hline
\end{tabular}

${ }^{1}$ Segundo a estimativa do IBGE para 2002

Os dados da Tabela 5.2 apresentam uma população com um maior contingente de pessoas em idades centrais, (população que busca trabalho e pressiona a economia local). A idade média estimada de 29 anos confirma a apresentação de uma população residente jovem.

No levantamento realizado pelo Painel de Informações Municipais de Uberlândia (CESPE, 2007) as taxas de crescimento geométrico por grupo etário mostraram que, por 
Capítulo 5 - Preparação do Experimento

conta da baixa fecundidade e do aumento da longevidade, os grupos de pessoas com idades até 15 anos continuam com taxas de crescimento decrescentes, enquanto os grupos etários superiores à idade de 20 anos apresentam taxas crescentes, incluindo os grupos mais idosos.

As tendências apontadas pelos levantamentos populacionais destacam que a população uberlandense ainda cresce num ritmo acentuado e, mantidos os atuais níveis de natalidade e mortalidade, bem como os movimentos migratórios, o município poderá atingir um milhão de habitantes por volta do ano 2020 (CESPE, 2007).

A economia do município está voltada para os setores de serviços, produção, consumo, com destaque para o setor de distribuição de mercadorias. Dentre os setores que formam o Produto Interno Bruto (PIB) local, apresentados na Tabela 5.3, os que mais se destacaram foram o industrial e o de serviços, com superioridade do segundo em relação ao primeiro. Em 2002, o setor de serviços apresentou uma participação de 49,80\% e o setor industrial, de $36,69 \%$.

Tabela 5.3 - Distribuição da população por faixa etária em 2002 (CESPE 2007).

\begin{tabular}{lr}
\hline \multicolumn{1}{c}{ Atributos } & Valor \\
\hline Produto Interno Bruto - $2002(R \$)$ & $6.226 .439 .000,00$ \\
Setor Agrícola (R\$) & $228.371 .000,00$ \\
Setor Industrial (R\$) & $2.283 .798 .000,00$ \\
Setor de Comércio e Serviços (R\$) & $3.100 .875 .000,00$ \\
Demais Setores (R\$) & $613.395 .000,00$ \\
Produto Interno Bruto per Capita (R\$) & $11.537,00$ \\
\hline
\end{tabular}

O PIB per capta de Uberlândia, no período abordado acima, é superior ao do Estado de Minas Gerais (R\$ 6.775,00) e ao do Brasil (R\$ 7.630,93) em 2002, apresentando um crescimento de 8,86\% em relação ao ano anterior (CESPE, 2007).

De acordo com os dados da Relação Anual de Informações Sociais (RAIS) do Ministério do Trabalho e Emprego, a distribuição do emprego formal segundo os setores da atividade econômica em Uberlândia em toda década de 1990 e no ano de 2000, não apresentou alterações significativas.

Em 2000, o segmento formal foi responsável por 101.374 empregos. Os setores da atividade econômica que mais absorveram trabalhadores, no ano de 2000 , em ordem crescente foram: indústria (15\%), comércio (27\%) e serviços (46\%). Apesar da elevação do peso 
Capítulo 5 - Preparação do Experimento

do setor industrial no PIB da cidade ao longo da década de 1990, esse setor não apresentou grandes variações em sua participação no total de trabalhadores empregados no segmento formal. Isto pode ser explicado pela ausência de um crescimento autossustentado nesse período e quando a produção cresce a frente da produtividade o impacto sobre o emprego pode ser positivo. (RIBEIRO; CUNHA; BORGES, 2002).

De acordo com a pesquisa de campo sobre trabalho e renda realizada na cidade de Uberlândia em 2001 pelo Instituto de Economia da Universidade Federal de Uberlândia (IEUFU), os títulos ocupacionais mais frequentes dentre a população ocupada são, em ordem decrescente: vendedor, empregada doméstica, serviços gerais, professor, comerciante, motorista e pedreiro (UFU, 2001).

Segundo os dados da pesquisa realizada pelo IE-UFU, o mercado formal ${ }^{42}$ de trabatho na cidade absorve $52,73 \%$ das pessoas ocupadas; já o mercado informal representa $43,92 \%$ das pessoas ocupadas. Apesar de não ser comparável devido às metodologias distintas, confrontando as informações de informalidade do trabalho de Uberlândia com a Região Metropolitana de Belo Horizonte, havia no mercado de trabalho de Uberlândia em 2001 um peso maior para a informalidade.

Os assalariados representam 58,79\% da população ocupada, sendo que os trabalhadores com vínculos trabalhistas representam o maior percentual dentre a população ocupada, atingindo $44,47 \%$, enquanto os trabalhadores sem vínculos trabalhistas apresentam uma participação de 14,32\%. Outro destaque cabe aos trabalhadores por conta própria, com um percentual de $26,90 \%$ da população ocupada (UFU, 2001).

Em 2001, 62,54\% das pessoas ocupadas em Uberlândia recebiam até 3 salários mínimos o que contribui em parte para explicar o elevado índice de pobreza populacional. A elevada concentração de pessoas recebendo baixos rendimentos está em sintonia com o Estado de Minas Gerais.

Grande parte da população ocupada, segundo a posição na ocupação, possui $1^{\circ} \mathrm{Grau}$ incompleto $(43,25 \%)$, ficando as exceções por conta dos empregadores, trabalhadores temporários com contrato e funcionários públicos. Boa parte dos empregadores, 42,86\%, possui $2^{\circ}$ Grau incompleto ou completo. Quanto aos trabalhadores temporários com contrato, verifica-se que $20,66 \%$ possuem $2^{\circ}$ Grau completo e $31,71 \%$ apresentam curso superior in-

\footnotetext{
${ }^{42}$ Ribeiro, Cunha e Borges (2002) consideraram como trabalhador formal os trabalhadores com carteira assina$\mathrm{da}$, os trabalhadores temporários com contratos, os funcionários públicos e militares. 0 trabalhador informal corresponde aos trabalhadores permanentes sem carteira, trabalhadores temporários em contratos, trabalhadores eventuais e trabalhadores por conta própria.
} 
Capítulo 5 - Preparação do Experimento

completo, completo ou pós-graduação. Dentre as diversas posições na ocupação, os funcionários públicos apresentam o maior percentual $(47,25 \%)$ de pessoas com curso superior incompleto, completo ou pós-graduação. A baixa escolaridade entre a população ocupada na cidade também está sintonia com o resto do país (UFU, 2001).

Segundo dados do Sistema de Registro Nacional de Veículos Automotores (DENATRAN, 2002) em 2002 a frota de automóveis de Uberlândia era composta por 98.637 automóveis e 37.251 motos, que em relação ao total da população representa uma taxa de motorização de 0,18 automóveis por habitante, ou uma taxa de motorização dos domicílios de 0,63 automóveis por domicílio (mantendo-se a proporção entre número de domicílios e habitantes em Uberlândia de 2000 para 2002), ou seja, em média 63\% dos domicílios de Uberlândia possuem pelo menos um automóvel. A distribuição da frota do Estado de Minas Gerais $^{43}$ segundo idade em 2002 indica que 24,62\% dos veículos têm até 4 anos; 26,97\% entre 5 e 10 anos; e 48,41\% possuem mais de 10 anos (DENATRAN, 2002).

Uberlândia já contava em 2002 com Sistema Integrado de Transportes (SIT), um sistema de transporte coletivo com linhas troncais, alimentadores e interbairros com cinco terminais urbanos (Central, Santa Luzia, Umuarama, Industrial e Planalto) onde ocorre o embarque/desembarque de passageiros, utilizando-se de uma única tarifa.

A infraestrutura do sistema de transporte de Uberlândia era composta por vias (com os níveis hierárquicos distintos), calçadas ao longo das vias, estacionamentos, pontos de ônibus e cinco terminais de ônibus. Mais detalhes sobre a infraestrutura do sistema de transportes é apresentado nas próximas seções em consonância com a descrição das etapas de tratamento dos dados e construção das variáveis.

\footnotetext{
${ }^{43}$ Não foi possível encontrar registros sobre a idade da frota de veículos de Uberlândia.
} 


\subsection{Tratamento dos Dados}

Esta seção envolve a descrição das etapas de tratamento dos dados envolvidos no estudo, coletados a partir da Pesquisa de Origem e Destino (Pesquisa de Preferência Revelada), Relação Anual de Informações Sociais (dados sobre uso do solo) e da Prefeitura de Uberlândia (dados sobre o sistema de transportes).

Como apresentado pelo diagrama da Figura 4.6, ao final do processo de tratamento dos dados foram elaboradas duas bases de dados que são utilizadas no processo de verificação da hipótese nula: base de dados dos indivíduos, viagens e atividades (discretas e encadeadas) e base espacial do sistema de transportes com a distribuição das atividades no meio urbano.

\subsubsection{Base de Dados dos Indivíduos, Viagens e Atividades (Discretas e Encadeadas)}

Com a aplicação dos procedimentos para tratamento dos dados da Pesquisa Domiciliar de Origem e Destino, o total resultante dos registros da amostra original são 4.666 indivíduos com 10.757 viagens (Tabela 5.4).

Tabela 5.4 - Amostra da Pesquisa Origem-Destino.

\begin{tabular}{ccccc}
\hline Amostra & Indivíduos (quant.) & $\begin{array}{c}\text { Frequência } \\
\text { Relativa de } \\
\text { Indivíduos (\%) }\end{array}$ & Viagens (quant.) & $\begin{array}{c}\text { Frequência } \\
\text { Relativa de } \\
\text { Viagens (\%) }\end{array}$ \\
\hline Original & 5.078 & $100 \%$ & 11.887 & $100 \%$ \\
Modificada & 4.666 & $91,88 \%$ & 10.757 & $90,49 \%$ \\
\hline
\end{tabular}

Analisando os dados da distribuição etária da população (Figura 5.2) é confirmada a tendência verificada no levantamento realizado pelo IE-UFU sobre a distribuição da faixa etária da população em idades centrais, com uma idade média mais elevada em comparação ao levantamento realizado pela IE-UFU em 2001: 29 anos contra 32 da amostra modificada da Pesquisa O- $\mathrm{D}^{44}$.

$\mathrm{Na}$ amostra modificada da Pesquisa O-D, 49,53\% das viagens são realizadas por mulheres, ao passo que $50,47 \%$ das viagens são realizadas por homens. Não há diferença considerável entre as idades médias entre homens e mulheres na amostra modificada considerando as viagens (32 anos contra 31 anos respectivamente).

\footnotetext{
$\overline{44}$ Considerando as viagens discretas.
} 
Capítulo 5 - Preparação do Experimento

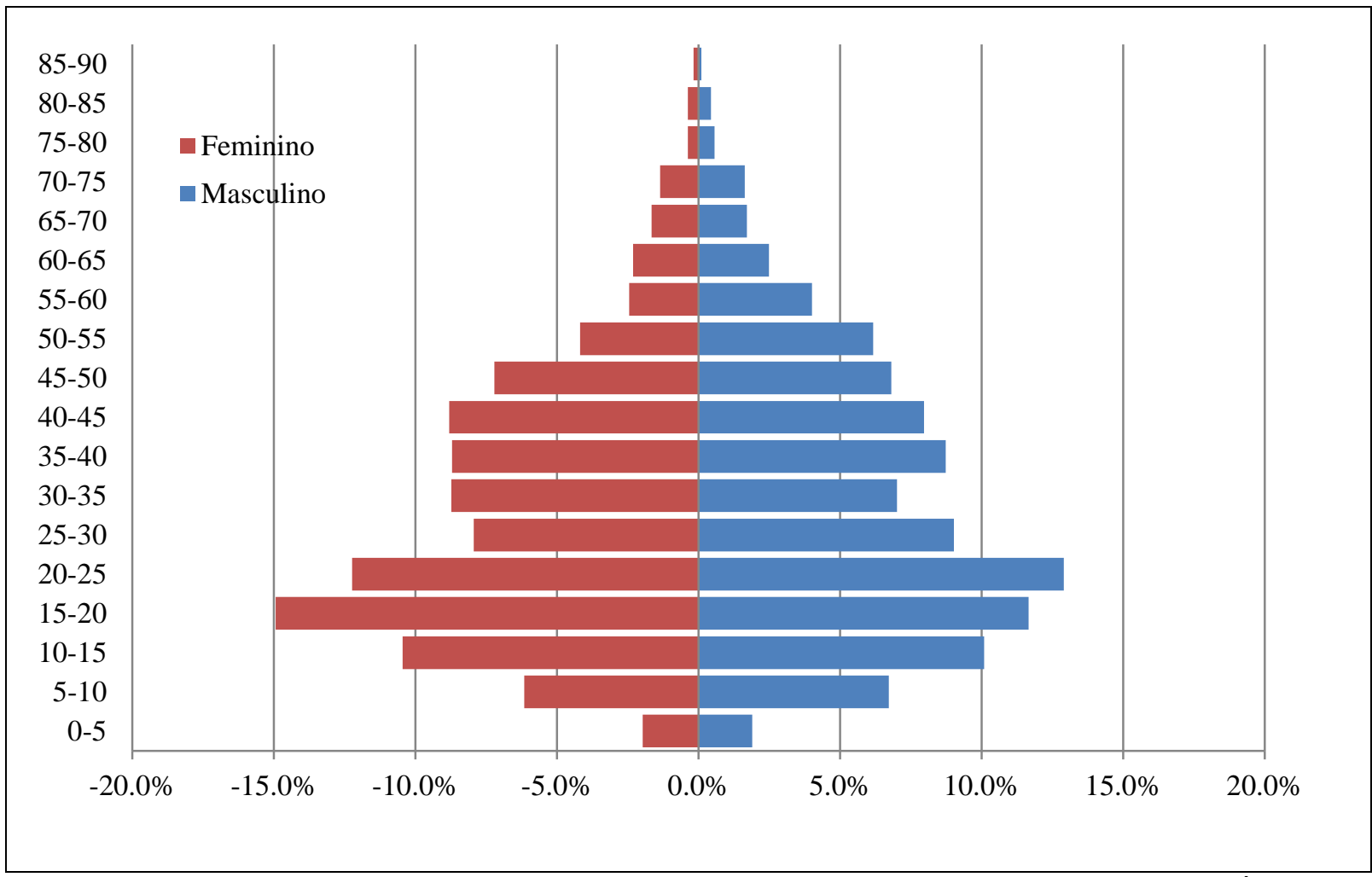

Figura 5.2 - Distribuição da população da amostra modificada da Pesquisa O-D por faixa etária.

A baixa remuneração dos trabalhadores em função dos cargos ocupados, reportada pelo estudo do IE-UFU, também é confirmada ao analisar a distribuição da renda individual da amostra modificada da Pesquisa O-D (Figura 5.3). Enquanto 69,5\% das mulheres da amostra modificada recebiam até $\mathrm{R} \$ 400,00$ (quatrocentos reais), a proporção em relação aos homens foi de $49,2 \%$.

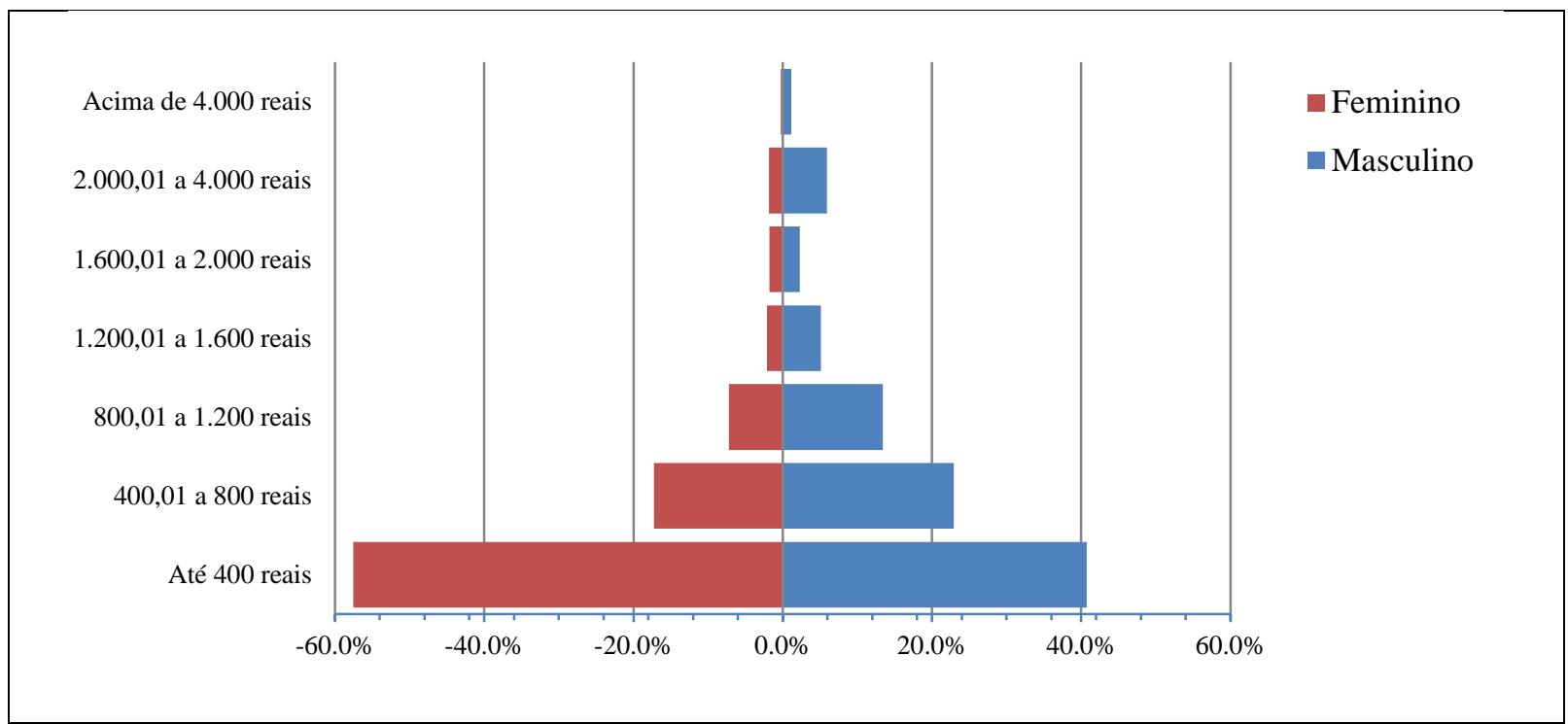

Figura 5.3 - Distribuição da população da amostra modificada da Pesquisa O-D por faixa de renda individual.

\footnotetext{
${ }^{45}$ Considerando as viagens discretas.
} 
Capítulo 5 - Preparação do Experimento

Uma possível explicação para o comportamento distinto da distribuição da renda domiciliar na Figura 5.4 em relação à distribuição da renda individual da Figura 5.3 pode ser relacionada à quantidade de indivíduos responsáveis pela subsistência do domicílio (mais um indivíduo além do chefe da família).

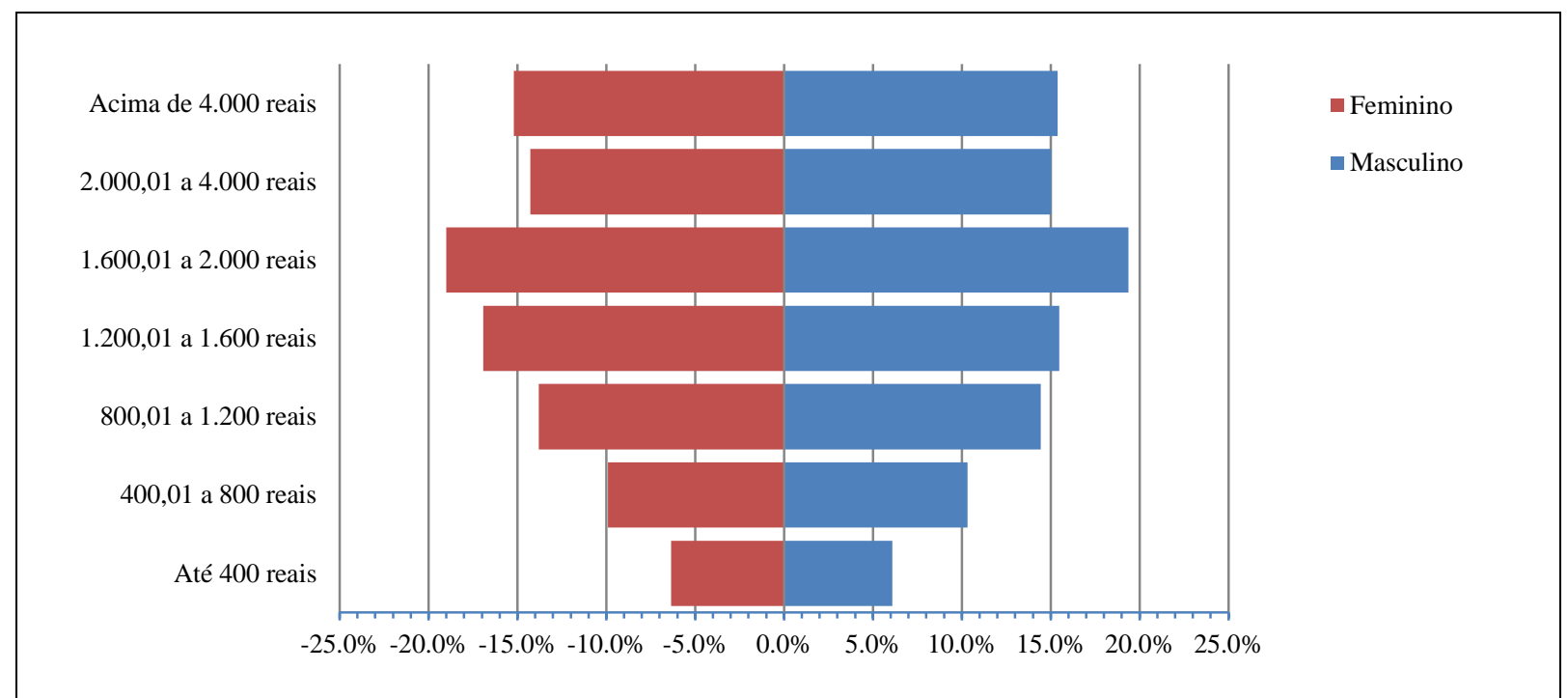

Figura 5.4 - Distribuição da população da amostra modificada da Pesquisa O-D por faixa de renda domiciliar.

Analisando os propósitos das viagens, apresentado na Tabela 5.5, com exceção do retorno ao domicílio, a demanda por trabalho é atividade que gerou o maior número de viagens, seguido pela necessidade de engajamento na atividade escola e outros motivos que englobam assuntos pessoais, tais como ir ao banco, consulta a advogado, obtenção de documentos, procura por emprego, lazer, saúde e compras.

Os dados da Tabela 5.5 confirmam as expectativas sobre os propósitos das viagens de Uberlândia, mencionado no Capítulo 4 para a justificativa da utilização de dados se uso do solo sobre a atividade trabalho.

Tabela 5.5 - Propósito da viagem da amostra modificada da Pesquisa O-D.

\begin{tabular}{lcc}
\hline \multicolumn{1}{c}{ Atributo } & Frequência & Frequência Relativa (\%) \\
\hline Retorno ao Domicílio & 5.068 & $47,11 \%$ \\
Escola & 1.910 & $17,76 \%$ \\
Trabalho & 2.732 & $25,40 \%$ \\
Outras Atividades & 1.047 & $9,73 \%$ \\
\hline
\end{tabular}

Em relação as escolhas dos modos de viagens, entre as cinco opções modais consideradas (a pé, bicicleta, ônibus, automóvel motorista e automóvel passageiro) o modo de 
Capítulo 5 - Preparação do Experimento

transporte mais utilizado nas viagens foi o ônibus (Tabela 5.6). Considerando-se a divisão das viagens entre modos motorizados e não motorizados, a proporção é de $33,74 \%$ para os modos não motorizados contra $66,26 \%$ para os modos motorizados.

Tabela 5.6 - Divisão modal da amostra modificada da Pesquisa O-D.

\begin{tabular}{lcc}
\hline \multicolumn{1}{c}{ Atributo } & Frequência & Frequência Relativa (\%) \\
\hline A pé & 3.179 & $29,55 \%$ \\
Bicicleta & 451 & $4,19 \%$ \\
Ônibus & 3.936 & $36,59 \%$ \\
Automóvel Motorista & 1.975 & $18,36 \%$ \\
Automóvel Passageiro & 1.216 & $11,30 \%$ \\
\hline
\end{tabular}

A divisão das viagens entre os modos indica maior participação das viagens em modos motorizados quanto maior é a renda individual (Tabela 5.7), aumentando a participação desse tipo de viagem em todas as faixas de renda consideradas. Na faixa de renda até $\mathrm{R} \$ 1.200,00$ a participação das viagens por meio de modos coletivos é predominante (exceção dos indivíduos com renda até 400 reais) e, a partir desse valor, predomina o modo motorizado individual.

Tabela 5.7 - Divisão modal segundo as faixas de renda individual da amostra modificada da Pesquisa O-D.

\begin{tabular}{|c|c|c|c|c|c|}
\hline Renda Individual & A pé (\%) & Bicicleta (\%) & Ônibus (\%) & $\begin{array}{c}\text { Automóvel } \\
\text { Motorista (\%) }\end{array}$ & $\begin{array}{c}\text { Automóvel } \\
\text { Passageiro (\%) }\end{array}$ \\
\hline $\begin{array}{l}\text { Sem renda ou não declara- } \\
\text { da }\end{array}$ & $37,81 \%$ & $2,37 \%$ & $41,74 \%$ & $3,38 \%$ & $14,70 \%$ \\
\hline Até $\mathrm{R} \$ 400$ & $38,66 \%$ & $4,81 \%$ & $38,08 \%$ & $8,24 \%$ & $10,21 \%$ \\
\hline $\mathrm{R} \$ 400,01$ a $R \$ 800,00$ & $19,14 \%$ & $6,10 \%$ & $43,69 \%$ & $22,24 \%$ & $8,83 \%$ \\
\hline $\mathrm{R} \$ 800,01$ a $\mathrm{R} \$ 1.200,00$ & $18,18 \%$ & $2,97 \%$ & $30,69 \%$ & $36,45 \%$ & $11,70 \%$ \\
\hline $\mathrm{R} \$ 1.200,01$ a $R \$ 1.600,00$ & $13,01 \%$ & $1,02 \%$ & $22,19 \%$ & $47,70 \%$ & $16,07 \%$ \\
\hline $\mathrm{R} \$ 1.600,01$ a $R \$ 2.000,00$ & $14,09 \%$ & $0,00 \%$ & $24,09 \%$ & $44,55 \%$ & $17,27 \%$ \\
\hline $\mathrm{R} \$ 2.000,01$ a $\mathrm{R} \$ 4.000,00$ & $4,74 \%$ & $0,47 \%$ & $9,48 \%$ & $66,82 \%$ & $18,48 \%$ \\
\hline Acima de $R \$ 4.000,00$ & $8,00 \%$ & $0,00 \%$ & $4,00 \%$ & $66,67 \%$ & $21,33 \%$ \\
\hline
\end{tabular}

Excetuando o motivo educação para as viagens, feitas preponderantemente a pé, nos demais motivos prevalecem os modos motorizados (Tabela 5.8) com destaque para o ônibus nos motivos trabalho e outros (saúde, compras e lazer). 
Capítulo 5 - Preparação do Experimento

Tabela 5.8 - Propósito da viagem por modo de transportes da amostra modificada da Pesquisa O-D.

\begin{tabular}{lcccccc}
\hline \multirow{2}{*}{ Modo } & \multicolumn{2}{c}{ Outras Atividades } & \multicolumn{2}{c}{ Escola } & \multicolumn{2}{c}{ Trabalho } \\
& Frequência & $\begin{array}{c}\text { Frequência } \\
\text { Relativa (\%) }\end{array}$ & Frequência & $\begin{array}{c}\text { Frequência } \\
\text { Relativa (\%) }\end{array}$ & $\begin{array}{c}\text { Frequência } \\
\text { Frequência } \\
\text { Relativa (\%) }\end{array}$ \\
\hline A pé & 228 & $21,78 \%$ & 909 & $47,59 \%$ & 497 & $18,19 \%$ \\
Bicicleta & 18 & $1,72 \%$ & 47 & $2,46 \%$ & 175 & $6,41 \%$ \\
Ônibus & 453 & $43,27 \%$ & 586 & $30,68 \%$ & 1.040 & $38,07 \%$ \\
Automóvel Motorista & 205 & $19,58 \%$ & 120 & $6,28 \%$ & 755 & $27,64 \%$ \\
Automóvel Passageiro & 143 & $13,66 \%$ & 248 & $12,98 \%$ & 265 & $9,70 \%$ \\
\hline
\end{tabular}

Da amostra de 4.666 indivíduos e 10.757 viagens foi possível concatenar as jornada diárias de atividades e de viagens de 4.563 indivíduos (10.462 viagens). Em relação a esta amostra modificada de padrões de atividades e viagens encadeadas, 69,19\% dos padrões são referentes a indivíduos que não são chefe de família (Tabela 5.9); 57,09\% dos indivíduos desta amostra residem em domicílios com um ou mais automóvel disponível (Tabela 5.10); e 70,48\% dos indivíduos moram em residências alugadas (Tabela 5.11).

Tabela 5.9 - Situação familiar dos indivíduos da amostra modificada da Pesquisa O-D.

\begin{tabular}{cccc}
\hline Situação Familiar & Frequência & Frequência Relativa (\%) & Taxa de Viagens \\
\hline Chefe & 1.406 & 30,81 & 2,35 \\
Cônjuge & 711 & 15,58 & 2,31 \\
Filho & 1.956 & 42,87 & 2,25 \\
Parente & 375 & 8,22 & 2,21 \\
Agregado & 29 & 0,64 & 2,35 \\
Empregada Residente & 6 & 0,13 & 2,00 \\
Outros & 65 & 1,43 & 2,51 \\
Não reportado & 15 & 0,33 & 2,33 \\
\hline
\end{tabular}

Tabela 5.10 - Posse de automóvel nos domicílios da amostra modificada da Pesquisa O-D.

\begin{tabular}{cccc}
\hline $\begin{array}{c}\text { Quantidade de } \\
\text { Automóvel }\end{array}$ & Frequência & Frequência Relativa (\%) & Taxa de Viagens \\
\hline 0 & 1.958 & $42,91 \%$ & 2,21 \\
1 & 2.040 & $44,71 \%$ & 2,31 \\
2 & 469 & $10,28 \%$ & 2,46 \\
$\geq 3$ & 96 & $2,10 \%$ & 2,78 \\
\hline
\end{tabular}


Capítulo 5 - Preparação do Experimento

Tabela 5.11 - Posse de automóvel nos domicílios da amostra modificada da Pesquisa O-D.

\begin{tabular}{cccc}
\hline Condição de Moradia & Frequência & Frequência Relativa (\%) & Taxa de Viagens \\
\hline Residência Alugada & 3.216 & 70,48 & 2,29 \\
Residência Própria & 1.125 & 24,65 & 2,30 \\
Não Informado / Não Aplicado & 222 & 4,87 & 2,30 \\
\hline
\end{tabular}

Entre os papéis desempenhados no domicílio, papéis com relações familiares mais próximas (chefe de família, cônjuge e filho) possuem taxas de viagens menores que os indivíduos com outro grau de relação no domicílio, declarados como "outros" (Tabela 5.9). Analisando a posse de automóvel no domicílio, quanto maior o número de automóveis no domicílio, maior o número de viagens diárias realizadas por pessoa (Tabela 5.10). A condição de moradia dos indivíduos é, praticamente, indiferente em relação às taxas de viagens.

A renda individual é a principal variável relacionada à mobilidade (medida em termos de número de viagens por pessoa). Quanto maior a renda individual, maior o número de viagens diárias realizadas por pessoa (Tabela 5.12).

Tabela 5.12 - Taxas de viagens por faixa de renda individual da amostra modificada da Pesquisa O-D.

\begin{tabular}{lccc}
\hline \multicolumn{1}{c}{ Renda Individual } & Frequência & $\begin{array}{c}\text { Frequência Relativa } \\
(\%)\end{array}$ & $\begin{array}{c}\text { Número } \\
\text { Médio de Viagens }\end{array}$ \\
\hline Sem renda ou não declarada & 523 & $11,46 \%$ & 2,13 \\
Até $R \$ 400$ & 2309 & $50,60 \%$ & 2,23 \\
R\$ 400,01 a R\$ 800,00 & 920 & $20,16 \%$ & 2,32 \\
R\$ 800,01 a R\$ 1.200,00 & 427 & $9,36 \%$ & 2,44 \\
R\$ 1.200,01 a R\$ 1.600,00 & 142 & $3,11 \%$ & 2,47 \\
R\$ 1.600,01 a R\$ 2.000,00 & 81 & $1,78 \%$ & 2,77 \\
Acima de R\$ 2.000,00 & 161 & $3,52 \%$ & 2,77 \\
\hline
\end{tabular}

A faixa etária que apresenta maior mobilidade é entre 27 e 37 anos com 2,40 viagens por pessoa, seguida pela faixa etária entre 38 e 49 anos com 2,38 viagens por pessoa. As taxas de viagens mais baixas são para os indivíduos até 15 anos $(2,10$ viagens por pessoa) e acima de 65 anos (2,11 viagens por pessoa). Em relação aos sexos o índice de mobilidade é semelhante (2,30 viagens por pessoa). 
5.3.2 Base Espacial do Sistema de Transportes com a Distribuição das Atividades no Meio Urbano

Segundo os dados obtidos pela RAIS (BRASIL, 2002), Uberlândia em 2002 possuía 107.237 postos de trabalho ocupados ${ }^{46}$. Após a limpeza dos dados e a alocação geográfica dos postos de emprego ocupados de Uberlândia nos 75 bairros em que a cidade é dividida, segundo a divisão apresentada na Figura 5.5, as regiões que concentram o maior número de vagas preenchidas, em ordem decrescente, eram: Santa Mônica (15.356; 14,32\%), Centro (13.246; 12,35\%), Distrito Industrial (12.180; 11,36\%), Brasil (11.079; 10,33\%), São José (7.818; 7,29\%) e Martins $(6.397 ; 5,97)$, como apresentado na Tabela 5.13 e Figura 5.6.

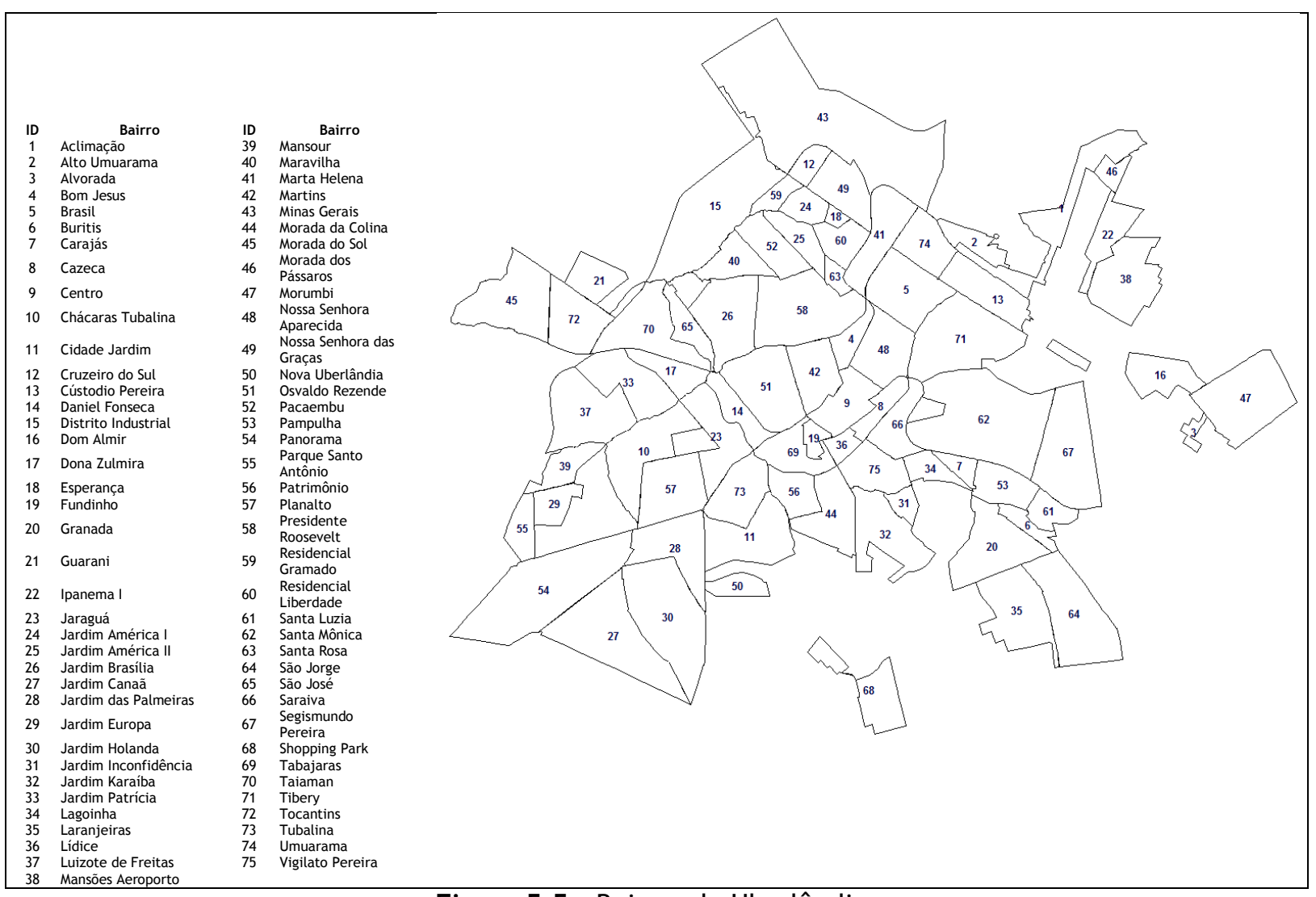

Figura 5.5 - Bairros de Uberlândia.

Em relação a Figura 5.6, o gráfico apresentado nesta figura retrata a proporção relativa da quantidade de empregos por área geográfica com o intuito de transmitir impressão de intensidade da distribuição da oferta de emprego na cidade. As ordenadas no plano demarcam o polígono com os limites dos bairros e o eixo vertical representa a proporção relativa da quantidade de empregos. Para construção deste gráfico foi utilizado o método de krigagem.

\footnotetext{
${ }^{46}$ Postos de trabalho (formal) ocupados na área urbana.
} 
Capítulo 5 - Preparação do Experimento

Tabela 5.13 - Postos de emprego ocupados em Uberlândia (BRASIL, 2002).

\begin{tabular}{|c|c|c|c|}
\hline Bairro & $\begin{array}{c}\text { Frequência Relativa de } \\
\text { Empregos Ocupados }\end{array}$ & Bairro & $\begin{array}{c}\text { Frequência Relativa de } \\
\text { Empregos Ocupados }\end{array}$ \\
\hline Aclimação & $0,28 \%$ & Mansour & $0,05 \%$ \\
\hline Alto Umuarama & $0,01 \%$ & Maravilha & $0,01 \%$ \\
\hline Alvorada & $0,02 \%$ & Marta Helena & $1,12 \%$ \\
\hline Bom Jesus & $0,84 \%$ & Martins & $5,97 \%$ \\
\hline Brasil & $10,33 \%$ & Minas Gerais & $0,39 \%$ \\
\hline Buritis & $0,04 \%$ & Morada da Colina & $0,31 \%$ \\
\hline Carajás & $0,01 \%$ & Morada do Sol & $0,03 \%$ \\
\hline Cazeca & $0,34 \%$ & Morada dos Pássaros & $0,05 \%$ \\
\hline Centro & $12,35 \%$ & Morumbi & $0,08 \%$ \\
\hline Chácaras Tubalina & $0,35 \%$ & Nossa Senhora Aparecida & $5,54 \%$ \\
\hline Cidade Jardim & $0,24 \%$ & Nossa Senhora das Graças & $0,39 \%$ \\
\hline Cruzeiro do Sul & $0,02 \%$ & Nova Uberlândia & $0,01 \%$ \\
\hline Cústodio Pereira & $1,48 \%$ & Osvaldo Rezende & $0,86 \%$ \\
\hline Daniel Fonseca & $0,49 \%$ & Pacaembu & $0,33 \%$ \\
\hline Distrito Industrial & $11,36 \%$ & Pampulha & $0,56 \%$ \\
\hline Dom Almir & $0,05 \%$ & Panorama & $0,00 \%$ \\
\hline Dona Zulmira & $0,35 \%$ & Parque Santo Antônio & $0,00 \%$ \\
\hline Esperança & $0,00 \%$ & Patrimônio & $1,23 \%$ \\
\hline Fundinho & $0,19 \%$ & Planalto & $0,90 \%$ \\
\hline Granada & $0,14 \%$ & Presidente Roosevelt & $2,15 \%$ \\
\hline Guarani & $0,21 \%$ & Residencial Gramado & $0,01 \%$ \\
\hline Ipanema I & $0,01 \%$ & Residencial Liberdade & $0,01 \%$ \\
\hline Jaraguá & $0,30 \%$ & Santa Luzia & $0,81 \%$ \\
\hline Jardim América I & $0,08 \%$ & Santa Mônica & $14,32 \%$ \\
\hline Jardim América II & $0,00 \%$ & Santa Rosa & $0,10 \%$ \\
\hline Jardim Brasília & $0,32 \%$ & São Jorge & $0,16 \%$ \\
\hline Jardim Canaã & $0,10 \%$ & São José & $7,29 \%$ \\
\hline Jardim das Palmeiras & $0,31 \%$ & Saraiva & $0,70 \%$ \\
\hline Jardim Europa & $0,74 \%$ & Segismundo Pereira & $0,37 \%$ \\
\hline Jardim Holanda & $0,01 \%$ & Shopping Park & $0,63 \%$ \\
\hline Jardim Inconfidência & $0,00 \%$ & Tabajaras & $0,64 \%$ \\
\hline Jardim Karaíba & $0,21 \%$ & Taiaman & $0,11 \%$ \\
\hline Jardim Patrícia & $0,49 \%$ & Tibery & $3,76 \%$ \\
\hline Lagoinha & $0,15 \%$ & Tocantins & $0,15 \%$ \\
\hline Laranjeiras & $0,07 \%$ & Tubalina & $0,89 \%$ \\
\hline Lídice & $1,77 \%$ & Umuarama & $5,05 \%$ \\
\hline Luizote de Freitas & $0,76 \%$ & Vigilato Pereira & $0,60 \%$ \\
\hline Mansões Aeroporto & $0,00 \%$ & & \\
\hline
\end{tabular}


Capítulo 5 - Preparação do Experimento

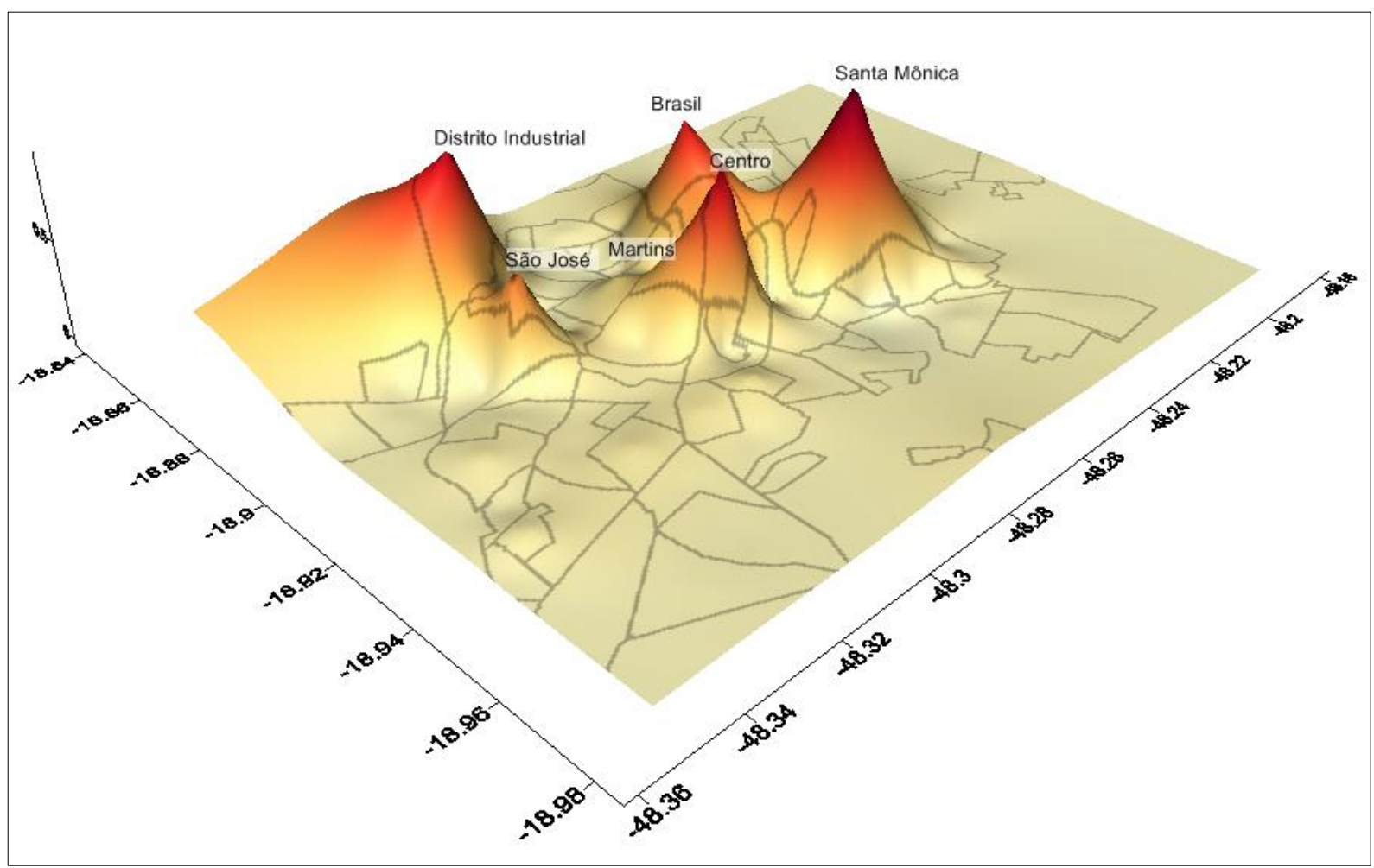

Figura 5.6 - Distribuição proporcional do número de empregos ocupados na cidade de Uberlândia (BRASIL, 2002).

Analisando a Figura 5.6 observa-se a concentração de empregos na área central da cidade, fruto da intensa atividade de comércio e serviços (como mencionado na seção 5.2). Outro polo de empregos correspondente ao distrito industrial, fruto da intensa atividade industrial nesta área.

A descrição dos dados da infraestrutura do sistema de transportes utilizada na pesquisa é apresentada na Tabela 5.14 e graficamente ilustrada na Figura 5.7 (rede viária) e Figura 5.8 (rede de transporte coletivo).

Tabela 5.14 - Descrição de parte da infraestrutura de transportes de Uberlândia em 2002.

\begin{tabular}{cc}
\hline Atributo & Valor \\
\hline Tramos & 25.101 \\
Interseções & 16.951 \\
Linhas de Ônibus (uma direção) & 160 \\
Pontos de Parada & 1.731 \\
Terminais & 5 \\
\hline
\end{tabular}


Capítulo 5 - Preparação do Experimento

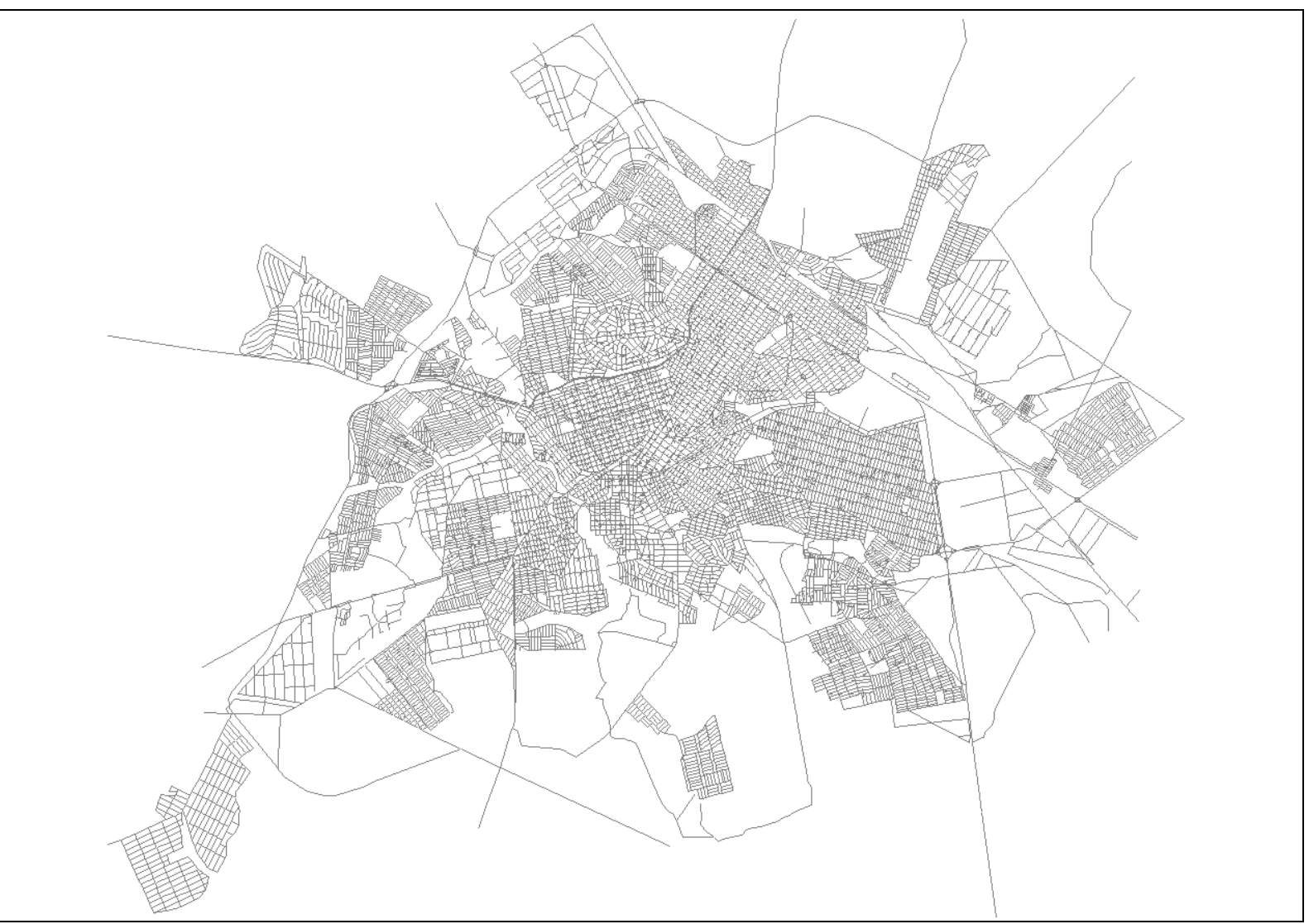

Figura 5.7 - Rede viária de Uberlândia.

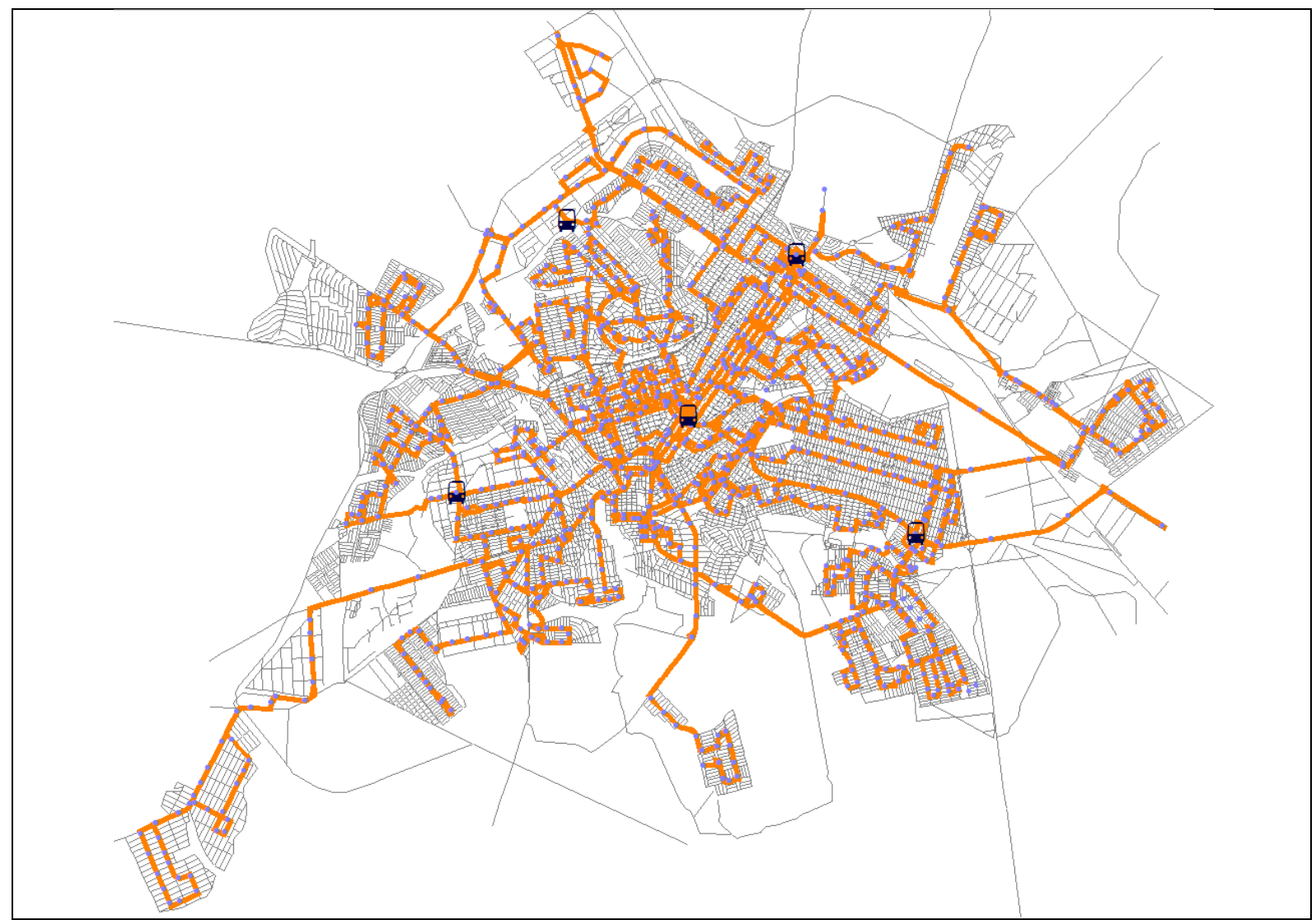

Figura 5.8 - Rede viária com a rede de transporte coletivo de Uberlândia (terminais em destaque na cor preto). 
Capítulo 5 - Preparação do Experimento

Ainda na fase de tratamento dos dados, trabalhando com a base de viagens discretas, após subtrair os registros duplicados e padronizar as informações dos endereços pelo logradouro (por exemplo, R. Marechal Deodoro, para registros escritos como R. Mal. Deodoro, R. M. Deodoro, ou para especificações incorretas como, R. Marexal Teodoro ou R. Marichal Teodoro) do total de 23.774 endereços de origens e destinos das viagens, 5.123 são considerados como exclusivos e deste total foi possível obter as coordenadas geográficos, por meio do georreferenciamento, de 4.798 , ou $93,7 \%$ do total de casos exclusivos.

Na Tabela 5.15 é apresentada uma síntese com detalhes da amostra final e o resultado do georreferencimento é ilustrado na Figura $5.9 \mathrm{com}$ a distribuição dos pontos das origens e destinos das viagens na cidade.

Tabela 5.14 - Descrição da amostra modificada de endereços das viagens da Pesquisa O-D de Uberlândia para georreferenciamento.

\begin{tabular}{cc}
\hline Amostra & Número de Endereços \\
\hline Dados originais & 23,774 \\
Casos exclusivos & 5,123 \\
Casos não identificados & 325 \\
Amostra final georreferenciada & 4,798 \\
\hline
\end{tabular}

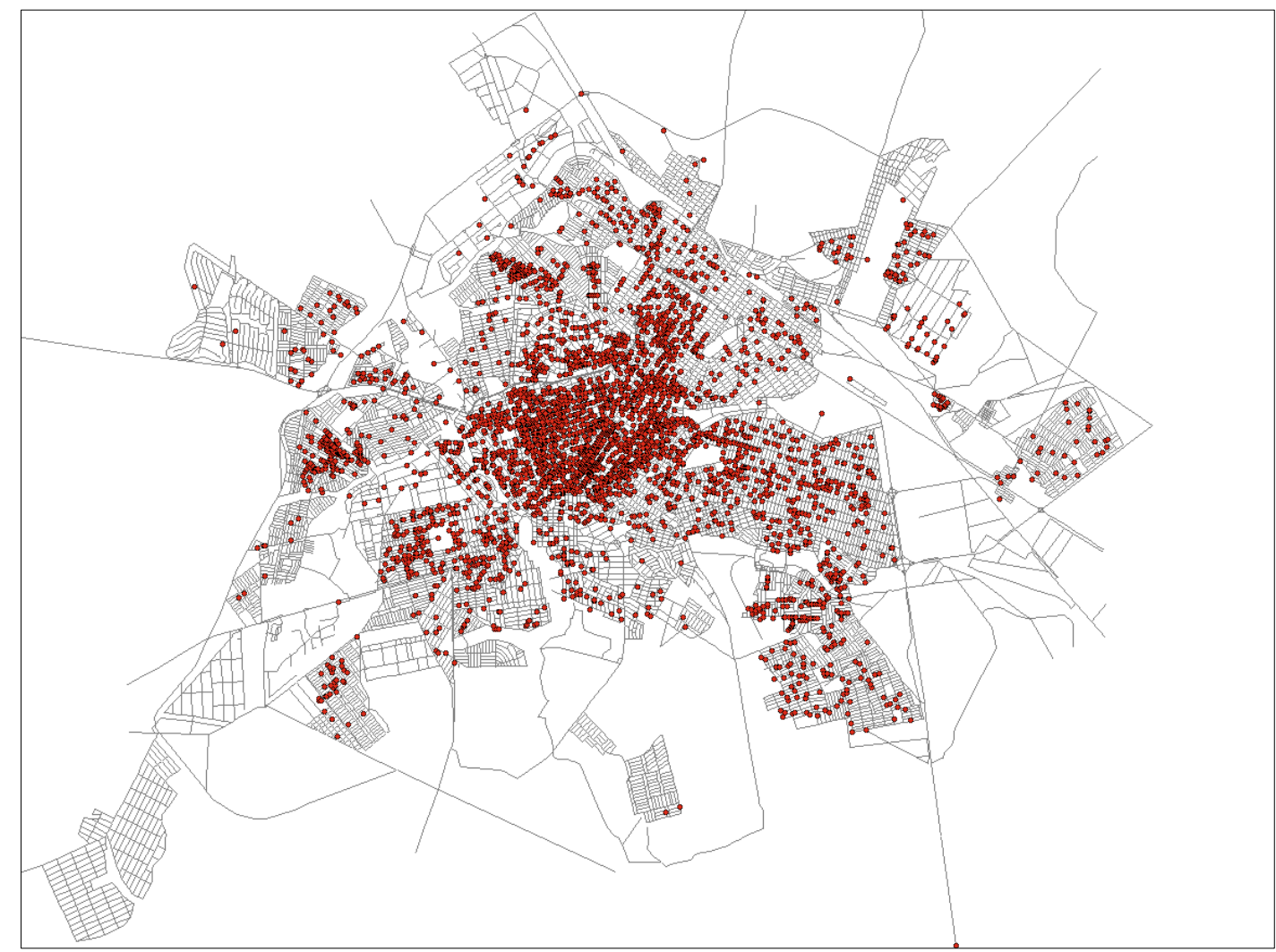

Figura 5.9 - Representação gráfica do resultado do georreferenciamento dos endereços das origens e destinos das viagens. 
Capítulo 5 - Preparação do Experimento

Pela revisão da literatura, não foi encontrado um procedimento formalizado para verificação da qualidade do georreferenciamento pelo Google Earth. Graficamente, foi observado que os pontos são locados a uma distância média de $20 \mathrm{~m}$ do eixo das vias logradouro e de pontos de intersecção, e que o logradouro do endereço georreferenciado corresponde ao logradouro da via mais próxima.

No entanto, com o propósito de validar o método empregado através de uma inferência estatística foi adotado um procedimento para mensurar a diferença na correspondência entre a localização geográfica para um nível de agregação do endereço de origem ou destino da viagem reportada na entrevista e a resposta obtida para o mesmo nível de agregação obtido pelo endereço georreferenciado com auxílio do TransCAD.

Para esta comparação foram utilizadas as zonas de tráfego (área média de $2,16 \mathrm{~km}^{2}$ ) em função desta informação ter sido preenchida pelos entrevistadores da Pesquisa O-D que tinham conhecimento do sistema de repartição das zonas de tráfego da cidade. Assim, comparando a localização geográfica em termos de zona de tráfego do ponto (endereço de origem ou destino da viagem) georreferenciado em relação a localização geográfica (zona de tráfego) do endereço de origem e destino da viagem reportado pelo indivíduo na Pesquisa O-D é encontrado uma diferença na correspondência entre as zonas dos endereços (estimado ${ }^{47}$ versus observado) em $27,46 \%$ dos casos comparados.

Como há casos em que os pontos estão localizados em regiões limítrofes de zonas, em que a posição em relação ao eixo da rua (direita ou esquerda) altera o zoneamento do ponto, para esta situação dos 1.373 casos (27,46\% do total) em que não houve correspondência, 955 estão em zonas adjacentes. Desta forma, se for considerado a zona adjacente, a diferença é reduzida a 418 casos ou $8,36 \%$ da amostra total.

De posse dos pares O-D georreferenciados foram calculados as distâncias viajadas na rede viária ${ }^{48}$ e suas médias em função de atributos socioeconômicos. Segundo dados da Tabela 5.15 os homens possuem percursos médios de viagens mais extensos que as mulheres e dentro da estrutura do domicílio o chefe de família é quem tem a viagem mais extensa, provavelmente em função do local do emprego.

\footnotetext{
47 Obtido pelo processo de georreferencimamento.

${ }^{48}$ Distância calculada pelo menor caminho.
} 
Capítulo 5 - Preparação do Experimento

Tabela 5.15 - Distâncias médias viajadas por atributo social da amostra modificada da Pesquisa O-D.

\begin{tabular}{lccc}
\hline Atributo & Frequência de Viagens & $\begin{array}{c}\text { Frequência Relativa } \\
\text { de Viagens (\%) }\end{array}$ & $\begin{array}{c}\text { Distância Média } \\
\text { das Viagens } \mathbf{~}^{1} \text { (km) }\end{array}$ \\
\hline Sexo & 5.429 & $50,47 \%$ & 3,84 \\
Masculino & 5.328 & $49,53 \%$ & 3,47 \\
Feminino & & & 4,18 \\
Situação Familiar & 3.498 & $32,52 \%$ & 3,91 \\
Chefe & 1.707 & $15,87 \%$ & 3,29 \\
Cônjuge & 4.467 & $41,53 \%$ & 3,18 \\
Filho & 822 & $7,64 \%$ & 3,50 \\
Parente & 72 & $0,67 \%$ & 1,77 \\
Agregado & 13 & $0,12 \%$ & 2,49 \\
Empregada Residente & 163 & $1,52 \%$ & 2,74 \\
Outros & 15 & $0,14 \%$ &
\end{tabular}

'Distância calculada pela rede viária.

Analisando as distâncias médias de viagens em função das faixas de renda (Tabelas 5.16 e 5.17) observa-se que as maiores distâncias são para indivíduos com renda individual entre $\mathrm{R} \$ 400,01$ a $\mathrm{R} \$ 800,00$ (Tabela 5.16) e renda domiciliar $\mathrm{R} \$ 800,01$ a $\mathrm{R} \$ 1.200,00$ (Tabela 5.17).

Tabela 5.16 - Distâncias médias viajadas por faixa de renda individual da amostra modificada da Pesquisa O-D.

\begin{tabular}{lccc}
\hline \multicolumn{1}{c}{ Renda Individual } & $\begin{array}{c}\text { Frequência de } \\
\text { Viagens }\end{array}$ & $\begin{array}{c}\text { Frequência Relativa } \\
\text { de Viagens }(\%)\end{array}$ & $\begin{array}{c}\text { Distância Média } \\
\text { das Viagens } \\
(\mathbf{k m})\end{array}$ \\
\hline Sem renda ou não declarada & 1.095 & $10,18 \%$ & 3,38 \\
Até R\$ 400 & 5.279 & $49,08 \%$ & 3,30 \\
R\$ 400,01 a R\$ 800,00 & 2.163 & $20,11 \%$ & 4,34 \\
R\$ 800,01 a R\$ 1.200,00 & 1.111 & $10,33 \%$ & 4,02 \\
R\$ 1.200,01 a R\$ 1.600,00 & 392 & $3,64 \%$ & 3,99 \\
R\$ 1.600,01 a R\$ 2.000,00 & 220 & $2,05 \%$ & 3,84 \\
R\$ 2.000,01 a R\$ 4.000,00 & 422 & $3,92 \%$ & 3,93 \\
Acima de R\$ 4.000,00 & 75 & $0,70 \%$ & 4,03 \\
\hline
\end{tabular}


Capítulo 5 - Preparação do Experimento

Tabela 5.17 - Distâncias médias viajadas por faixa de renda familiar da amostra modificada da Pesquisa O-D.

\begin{tabular}{lccc}
\hline \multicolumn{1}{c}{ Renda Familiar } & $\begin{array}{c}\text { Frequência de } \\
\text { Viagens }\end{array}$ & $\begin{array}{c}\text { Frequência Relativa } \\
\text { de Viagens (\%) }\end{array}$ & $\begin{array}{c}\text { Distância Média } \\
\left.\text { das Viagens } \mathbf{~}^{1} \mathbf{k m}\right)\end{array}$ \\
\hline Sem renda ou não declarada & 451 & $4,19 \%$ & 3,04 \\
Até R\$ 400 & 669 & $6,22 \%$ & 3,73 \\
R\$ 400,01 a R\$ 800,00 & 1.088 & $10,11 \%$ & 3,83 \\
R\$ 800,01 a R\$ 1.200,00 & 1.519 & $14,12 \%$ & 3,90 \\
R\$ 1.200,01 a R\$ 1.600,00 & 1.743 & $16,20 \%$ & 3,58 \\
R\$ 1.600,01 a R\$ 2.000,00 & 2.065 & $19,20 \%$ & 3,60 \\
R\$ 2.000,01 a R\$ 4.000,00 & 1.576 & $14,65 \%$ & 3,46 \\
Acima de R\$ 4.000,00 & 1.646 & $15,30 \%$ & 3,80
\end{tabular}

${ }^{1}$ Distância calculada pela rede viária.

Entre os modos de viagens, as viagens a pé são realizadas em etapa médias de $1,64 \mathrm{~km}$ ao passo que a viagens realizadas por ônibus são mais longas (Tabela 5.18). Viagens com propósito de engajamento ao trabalho são as que possuem maior etapa, enquanto viagens com outros propósitos possuem o menor comprimento médio de viagem (Tabela 5.19).

Tabela 5.18 - Distâncias médias viajadas por modo da amostra modificada da Pesquisa O-D.

\begin{tabular}{lccc}
\hline \multicolumn{1}{c}{ Modo } & Frequência de Viagens & $\begin{array}{c}\text { Frequência Relativa } \\
\text { de Viagens (\%) }\end{array}$ & $\begin{array}{c}\text { Distância Média } \\
\text { das Viagens }\end{array}$ \\
\hline A pé & 3.179 & $29,55 \%$ & 1,64 \\
Bicicleta & 451 & $4,19 \%$ & 3,38 \\
Ônibus & 3.936 & $36,59 \%$ & 5,03 \\
Automóvel Motorista & 1.975 & $18,36 \%$ & 4,21 \\
Automóvel Passageiro & 1.216 & $11,30 \%$ & 3,66 \\
\hline
\end{tabular}

'Distância calculada pela rede viária.

Tabela 5.19 - Distâncias médias viajadas por propósito da amostra modificada da Pesquisa O-D.

\begin{tabular}{lccc}
\hline Propósito da Viagem & Frequência de Viagens & $\begin{array}{c}\text { Frequência Relativa } \\
\text { de Viagens (\%) }\end{array}$ & $\begin{array}{c}\text { Distância Média } \\
\text { das Viagens }{ }^{1}(\mathbf{k m})\end{array}$ \\
\hline Retorno ao domicílio & 1.047 & $9,73 \%$ & 3,63 \\
Escola & 5.068 & $47,11 \%$ & 3,62 \\
Outras Atividades & 1.910 & $17,76 \%$ & 2,75 \\
Trabalho & 2.732 & $25,40 \%$ & 4,37
\end{tabular}

${ }^{1}$ Distância calculada pela rede viária. 


\subsection{Construção das Variáveis}

Nesta seção são apresentados os resultados dos procedimentos aplicados para o cálculo das variáveis e estatísticas sobre as informações que elas representam. A fim de evitar repetições em relação ao que já foi exposto na seção 5.3 algumas variáveis (independentes e dependentes) não são apresentadas.

\subsubsection{Variáveis Independentes}

\section{(i) Características Socioeconômicas}

Fazem parte das variáveis que representam as características socioeconômicas dos indivíduos: o número de pessoas no domicílio (codificada em categorias); posse de automóvel (codificada em categorias e de forma contínua); presença de criança no domicílio (codificada em categorias); renda domiciliar (codificada em categorias e de forma contínua); renda individual (codificada em categorias); e situação familiar (codificada em categorias).

Na seção anterior foram expostas as estatísticas de Frequência sobre a posse de automóvel (contínua), renda domiciliar, renda individual e situação familiar. Com exceção da posse de automóvel as demais variáveis sofreram um rearranjo de classes (fusão de categorias) para diminuição do número categorias sem prejuízo a informação que elas representam. Em relação as demais variáveis restava determinar o número de categorias pela análise de cluster.

Com exceção da variável presença de criança no domicílio em que foi adotada a classificação binária sim/não, as demais categorias foram obtidas pela análise de cluster e os resultados são apresentados na Tabela 5.20. 
Capítulo 5 - Preparação do Experimento

Tabela 5.20 - Frequência das categorias das variáveis independentes que representam as características socioeconômicas dos indivíduos da base de dados dos indivíduos, viagens e atividades (encadeadas) ${ }^{49}$.

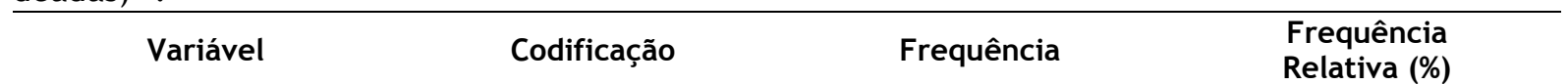

Até 4 pessoas

1.496

$69,61 \%$

Domicílio

Acima de 4 pessoas

Nenhum automóvel

Posse de

Automóvel Domicílio

Renda Domiciliar

Renda Individual

Situação Familiar
Até 1 automóvel

Acima de 1 automóvel

Não possui criança que viaja até 7 anos

Possui pelo menos uma criança que viaja até 7

anos

Até $\mathrm{R} \$ 800,00$

$\mathrm{R} \$ 800,01$ a $\mathrm{R} \$ 1.200,00$

Acima de R\$ $1.200,00$

Até $\mathrm{R} \$ 400,00$

$\mathrm{R} \$ 400,01$ a $R \$ 800,00$

Acima de $\mathrm{R} \$ 800,00$

Chefe

Cônjuge

Filho

Outros
653

$30,39 \%$

915

$42,58 \%$

937

$43,60 \%$

297

$13,82 \%$

1.897

$88,27 \%$

252

$11,73 \%$

657

$30,57 \%$

803

$37,37 \%$

689

$32,06 \%$

779

$36,25 \%$

736

$34,25 \%$

634

$29,50 \%$

985

$45,84 \%$

402

$18,71 \%$

580

$26,99 \%$

182
$8,47 \%$

\section{(ii) Participação em Atividades}

Na Tabela 5.21 é apresentada a Frequência de ocorrência das variáveis selecionadas para caracterizar a duração da atividade e o setor de atividade (para a atividade trabalho). A Frequência de ocorrência dos propósitos das viagens foi exposta na seção 5.3.

\footnotetext{
${ }^{49}$ Contendo apenas registros com padrões de viagens com propósito de engajamento ao trabalho.
} 
Capítulo 5 - Preparação do Experimento

Tabela 5.21 - Descrição das variáveis independentes que representam a participação dos indivíduos em atividades a partir da amostra de dados dos indivíduos, viagens e atividades (encadeadas) ${ }^{50}$.

\begin{tabular}{cccc}
\hline Variável & Codificação & Frequência & $\begin{array}{c}\text { Frequência } \\
\text { Relativa (\%) }\end{array}$ \\
\hline \multirow{2}{*}{ Duração da Atividade } & Até 8 horas & 1.340 & $62,35 \%$ \\
& Acima de 8 horas & 809 & $37,65 \%$ \\
Setor de Atividade & Formal & 1.656 & $77,06 \%$ \\
& Informal & 493 & $22,94 \%$ \\
\hline
\end{tabular}

\section{(iii) Características do Uso do Solo}

Na seção 5.3 foram expostas as características desta variável.

\section{(iv) Características do Sistema de Transportes}

As variáveis independentes relacionadas ao sistema de transportes são: custo monetário; distância pela rede viária; distância pela rede de transporte coletivo; gratuidade para idosos; modo e acessibilidade; oferta do transporte público urbano; tempo de viagem; e uso do vale transportes.

\section{v.1) Custo Monetário}

Na Tabela 5.22 são apresentadas as alternativas com hipóteses a serem testadas sobre o custo monetário percebido pelos indivíduos para o transporte coletivo, envolvendo: a gratuidade para o idoso; gratuidade para crianças com idade inferior a 7 anos ${ }^{51}$; desconto na tarifa para estudantes; uso do vale transportes e tarifa integral. Para a última, é adotado o termo custo fixo do transporte coletivo e para as demais o termo custo marginal.

Tabela 5.22 - Alternativas para o custo monetário percebido pelos indivíduos no transporte coletivo.

\begin{tabular}{llcc}
\hline \multicolumn{1}{c}{ Passageiro } & \multicolumn{1}{c}{ Atributo } & Custo Marginal (R\$) & Custo Fixo (R\$) \\
\hline Indivíduo $\geq 65$ anos & Passe de Idoso & 0,00 & 1,25 \\
Criança $\leq 6$ anos & Gratuidade Informal & 0,75 & \\
Estudante & $\begin{array}{l}\text { Desconto de } 40 \% \\
\text { na Tarifa }\end{array}$ & $6 \%$ da Renda Individual & \\
Trabalhador & Uso do Vale Transportes & $6 \%$
\end{tabular}

\footnotetext{
${ }^{50}$ Contendo apenas registros com padrões de viagens com propósito de engajamento ao trabalho.

${ }^{51}$ Não há legislação específica para regulamentar a gratuidade para crianças abaixo de 6 anos, mas havia uma política informal, entre motoristas, para isenção de crianças abaixo de 6 anos.
} 
Capítulo 5 - Preparação do Experimento

Para medir o custo do modo automóvel motorista são apresentadas na Tabela 5.23 as três alternativas com hipóteses sobre o custo monetário percebido pelos indivíduos: custo da queima de combustível, custo variável e custo total (soma do custo variável mais o custo fixo).

Tabela 5.23 - Alternativas para o custo monetário percebido pelos indivíduos no transporte coletivo.

\begin{tabular}{lc}
\multicolumn{1}{c}{ Alternativa } & Valor (R\$/Km) \\
\hline Custo da Queima de Combustível & 0,24 \\
Custo Variável: incluindo taxas, custos de manutenção e consumo de combustível. & 0,44 \\
Custo Total: Custo Variável + Custo Fixo. & 0,68 \\
\hline
\end{tabular}

v.2) Distância

$\mathrm{Na}$ Tabela 5.24 é apresentado o resultado da análise de cluster aplicado aos dados da amostra de dados dos indivíduos, viagens e atividades (encadeadas) para as médias das distâncias pela rede viária entre o domicílio e o local (ou locais) de trabalho.

Tabela 5.24 - Descrição da variável distância pela rede viária em categorias pela amostra de dados dos indivíduos, viagens e atividades (encadeadas) ${ }^{52}$.

\begin{tabular}{cccc}
\hline Variável & Codificação & Frequência & $\begin{array}{c}\text { Frequência } \\
\text { Relativa (\%) }\end{array}$ \\
\hline \multirow{2}{*}{ Distância pela Rede Viária } & Até 5,45 km & 1.460 & $67,94 \%$ \\
& Acima de 5,45km & 689 & $32,06 \%$ \\
\hline
\end{tabular}

Na seção 5.3 foram expostas as características sobre a distância na rede viária. Julga-se não haver necessidade de complementar com a exposição da distância pela rede de transporte coletivo.

\section{v.3) Gratuidade e Uso do Vale Transportes}

Analisando a amostra de viagens discretas foram consideradas as viagens com possível uso de vale transportes os deslocamentos realizados a partir do domicílio ao trabalho e do trabalho ao domicílio. Para esta situação do total de 10.757 viagens, 2.932 (27,26\%) foram consideradas como possível uso de vale transportes. Quanto a gratuidade em função da idade acima ou igual a 65 anos, do total de 10.757 viagens, $471(4,38 \%)$ foram consideradas como isenta de cobrança.

\footnotetext{
${ }^{52}$ Contendo apenas registros com padrões de viagens com propósito de engajamento ao trabalho.
} 
v.4) Tempo de viagem

Os modelos para cálculo do tempo de viagem são baseados em estimativas de velocidades nos percursos entre pares de origem e destino das viagens: distância percorrida pela rede viária dividido pelo tempo de viagem reportado. Para a elaboração dos modelos a partir das bases de dados são estabelecidos limites para os valores de velocidades em função da curva de distribuição da Frequência ${ }^{53}$ e de valores apresentados na literatura (HCM, 2000). Os registros das bases de dados que excederam os limites estabelecidos foram excluídos.

Realizada esta etapa, na Tabela 5.25 é apresentando para cada modo de viagem a descrição da amostra dos dados utilizados na elaboração do modelo de previsão e na Figura 5.11 é apresentado o resultado da análise de cluster para caracterização das regiões numa tentativa de mapear possíveis conflitos de tráfego.

Tabela 5.25 - Amostra de viagens discretas modificada da Pesquisa Origem-Destino.

\begin{tabular}{lccc}
\hline \multicolumn{1}{c}{ Modo } & Viagens & $\begin{array}{c}\text { Velocidade } \\
\text { Média }(\mathrm{km} / \mathrm{h})\end{array}$ & $\begin{array}{c}\text { Desvio } \\
\text { Padrão }\end{array}$ \\
\hline A pé (até 7,93km/h) & 3.216 & 3,21 & 1,71 \\
Bicicleta (até $30,29 \mathrm{~km} / \mathrm{h})$ & 462 & 9,13 & 5,09 \\
Ônibus (todos os dados) & 3.842 & 19,57 & 14,90 \\
Automóvel Motorista (até $87.63 \mathrm{~km} / \mathrm{h})$ & 2.042 & 16,53 & 12,00 \\
\hline
\end{tabular}

Antes de realizar a construção do modelo foram realizadas análises de variâncias nos bancos de dados de cada modo de transporte (viagens a pé, viagens de bicicleta, viagens de coletivo, viagens de individual motorizado) para verificar a influência dos atributos formados pelas características socioeconômicas (sexo e idade), características dos deslocamentos e condições de tráfego nos valores das velocidades.

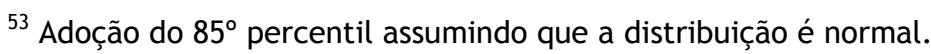


Capítulo 5 - Preparação do Experimento

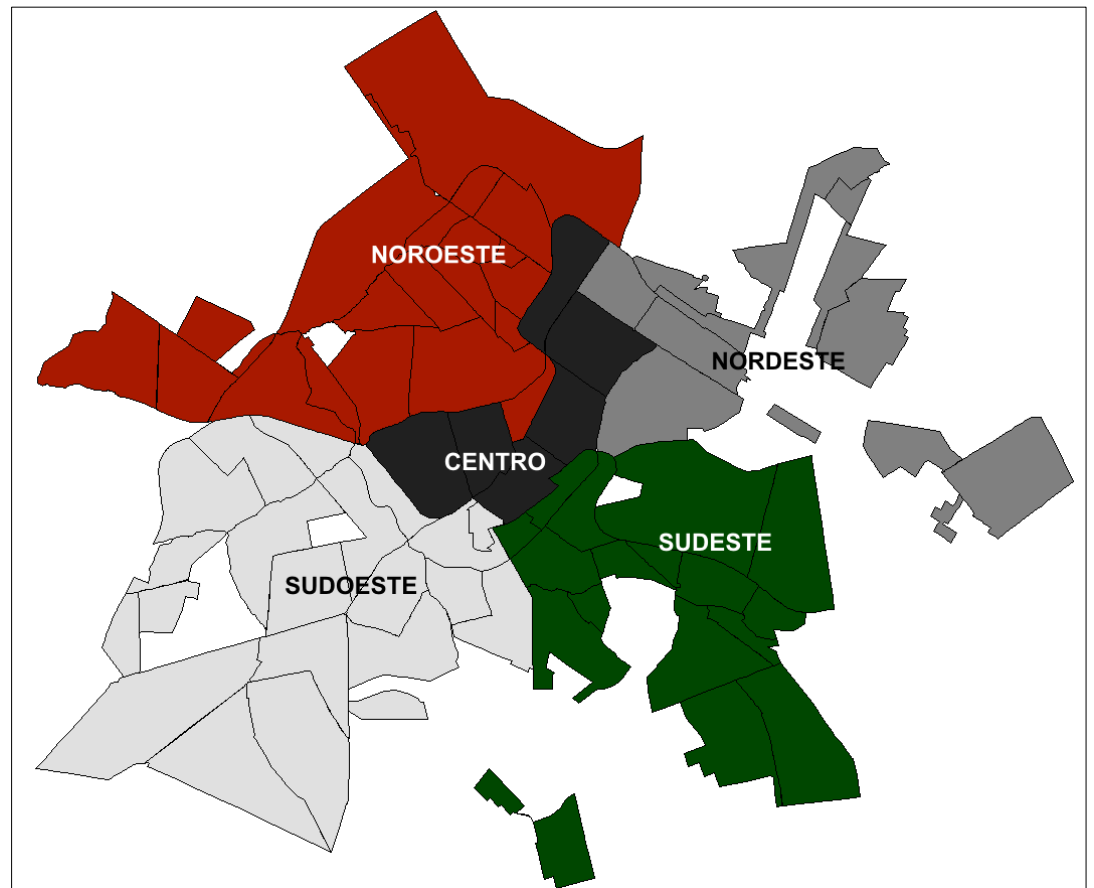

Figura 5.11 - Resultado do agrupamento dos bairros em função dos atributos selecionados para caracterização das condições de tráfego da cidade.

Segundo os resultados da análise de variância ${ }^{54}$ para os modos não motorizados não foram identificados influências dos fatores sexo, idade, direção da viagem e hora pico no comportamento dos valores das velocidades. Para os modos motorizados a análise de variância ${ }^{41}$ indicou que a hora pico (ônibus e automóvel motorista), número de transferências nos terminais (ônibus) e a direção da viagem (automóvel motorista) influenciam nos valores das velocidades.

A solução proposta para estimar o tempo de viagem para os modos não motorizados foi baseada nas velocidades médias calculadas nos banco de dados: 3,21 km/h para o modo a pé; e 9,13 km/h para viagens realizadas por bicicleta. O cálculo do tempo de viagem para esta situação é simplificada pela divisão da distância euclidiana pela velocidade de $3,21 \mathrm{~km} / \mathrm{h}$ nos casos de viagens realizadas a pé e distância pela rede viária dividido pela velocidade de $9,13 \mathrm{~km} / \mathrm{h}$ para as viagens realizadas por bicicleta.

Em relação aos modos motorizados os modelos que obtiveram melhor desempenho na previsão do tempo de viagem foram a regressão linear múltipla para o modo ônibus apresentada na Tabela 5.26 e modelo baseado na árvore de regressão para o modo automóvel motorista, apresentado na Tabela 5.27.

Para cálculo do tempo das viagens realizadas por ônibus foram utilizadas o tempo em rota dado pela regressão descrita na Tabela 5.26 somado aos tempos de espera média

\footnotetext{
${ }^{54}$ Intervalo de confiança de $95 \%$.
} 
Capítulo 5 - Preparação do Experimento

(por bairro) e tempos viagem a pé: tempo de viagem do domicílio/local de atividade ao ponto de ônibus (acesso) e do ponto de ônibus até o domicílio/local de atividade (egresso). Os tempos de acesso e egresso são calculados em função da distância na rede viária pela velocidade média de $3,21 \mathrm{~km} / \mathrm{h}$.

Tabela 5.26 - Resultados do modelo de regressão linear múltipla para cálculo do tempo de viagem por ônibus.

\begin{tabular}{lcc}
\multicolumn{1}{c}{ Atributo } & Valor do Coeficiente & Estatística $t$ \\
\hline Constante & - & - \\
Distância da rede de transporte coletivo $(\mathrm{km})$ & 0,0444 & 29,53 \\
Hora Pico (1 - Sim; 0 - Não) & 0,0666 & 5,99 \\
Número de Transferências & 0,0741 & 5,89 \\
$\mathrm{R}^{2}=0,6466$ & & \\
\hline
\end{tabular}

Tabela 5.27 - Resultados do modelo de árvore de regressão para cálculo da velocidade de viagem por automóvel.

\begin{tabular}{|c|c|c|c|c|c|}
\hline Agrupamento & Observações & Origem & Destino & Hora Pico & $\begin{array}{c}\text { Velocidade } \\
\text { Média }(\mathrm{Km} / \mathrm{h})\end{array}$ \\
\hline 1 & 128 & \multirow{5}{*}{ Centro } & \multirow{2}{*}{ Centro } & Sim & 13,05 \\
\hline 2 & 174 & & & Não & 13,52 \\
\hline 3 & 206 & & \multirow{2}{*}{ NW, SW e SE } & Sim & 15,09 \\
\hline 4 & 221 & & & Não & 15,94 \\
\hline 5 & 37 & & NE & - & 16,69 \\
\hline 6 & 186 & \multirow{2}{*}{ SE } & SE & - & 12,92 \\
\hline 7 & 174 & & Centro & - & 15,94 \\
\hline 8 & 177 & NE e NW & \multirow{2}{*}{ Centro } & - & 15,77 \\
\hline 9 & 118 & SW & & - & 17,11 \\
\hline 10 & 138 & $N E, N W, S W$ & SE & - & 21,11 \\
\hline 11 & 156 & NE, NW and SW & SW & - & 16,85 \\
\hline 12 & 146 & NE e NW & \multirow{2}{*}{ NE e NW } & - & 15,92 \\
\hline 13 & 41 & SW & & - & 26,23 \\
\hline 14 & 140 & SE & $N E, N W$ and $S W$ & - & 26,23 \\
\hline
\end{tabular}


v.5) Modo e Acessibilidade

Na Tabela 5.28 são apresentados os resultados obtidos pela análise de cluster para definição das classes de acessibilidade por modo de viagem (não motorizado, coletivo e individual motorizado) e a Frequência de ocorrência das combinações modo-acessibilidade.

Tabela 5.28 - Descrição das variáveis independentes que representam o modo e a acessibilidade a partir da amostra de dados dos indivíduos, viagens e atividades (encadeadas) ${ }^{55}$.

\begin{tabular}{rccc} 
Modo & Acessibilidade & Frequência & $\begin{array}{c}\text { Frequência } \\
\text { Relativa (\%) }\end{array}$ \\
\hline \multirow{2}{*}{ Não motorizado } & Até 20 minutos $^{1}$ & 361 & $16,80 \%$ \\
& Acima de 20 minutos $^{1}$ & 186 & $8,66 \%$
\end{tabular}

$\begin{array}{lrrr}\text { Coletivo/Ônibus } & \text { Até } 40 \text { minutos } & 547 & 25,45 \% \\ & \text { Acima de } 40 \text { minutos } & 344 & 16,00 \%\end{array}$

$\begin{array}{lrrr} & \text { Até } 25 \text { minutos }^{2} & 552 & 25,69 \% \\ \text { Individual motorizado } & \text { Acima de } 25 \text { minutos }^{2} & 159 & 7,40 \%\end{array}$

'Valor obtido pela análise de cluster: 22,5 minutos. Valor adotado: 20 minutos. ${ }^{2}$ Valor obtido pela análise de cluster: 26,3 minutos. Valor adotado: 25 minutos.

\section{v.6) Oferta do Transporte Público Urbano}

Após o cálculo da oferta do transporte público urbano pela Equação 1 as regiões que possuem melhor oferta, em ordem decrescente, eram em 2002: Fundinho $(13,90$ Freq $\left.\cdot \mathrm{m} / \mathrm{m}^{2}\right)$, Santa Luzia $\left(7,62 \mathrm{Freq} \cdot \mathrm{m} / \mathrm{m}^{2}\right)$, Centro $\left(7,60 \mathrm{Freq} \cdot \mathrm{m} / \mathrm{m}^{2}\right)$ e Umuarama $(3,99$ Freq $\cdot \mathrm{m} / \mathrm{m}^{2}$ ), como apresentado na Figura 5.12 e Tabela 5.28 .

\footnotetext{
${ }^{55}$ Contendo apenas registros com padrões de viagens com propósito de engajamento ao trabalho.
} 
Capítulo 5 - Preparação do Experimento

Tabela 5.29 - Postos de emprego ocupados em Uberlândia (BRASIL, 2002).

\begin{tabular}{|c|c|c|c|}
\hline Bairro & $\begin{array}{l}\text { Oferta de Transporte } \\
\left.\text { Público (Freq } \cdot \mathrm{m} / \mathrm{m}^{2}\right)\end{array}$ & Bairro & $\begin{array}{l}\text { Oferta de Transporte } \\
\text { Público }\left(\text { Freq } \cdot \mathrm{m} / \mathrm{m}^{2}\right)\end{array}$ \\
\hline Aclimação & 0,84 & Mansour & 1,10 \\
\hline Alto Umuarama & 0,26 & Maravilha & 0,72 \\
\hline Alvorada & 1,51 & Marta Helena & 0,97 \\
\hline Bom Jesus & 3,54 & Martins & 1,64 \\
\hline Brasil & 1,64 & Minas Gerais & 0,12 \\
\hline Buritis & 1,06 & Morada da Colina & 0,69 \\
\hline Carajás & 2,34 & Morada do Sol & 0,00 \\
\hline Cazeca & 1,03 & Morada dos Pássaros & 0,00 \\
\hline Centro & 7,60 & Morumbi & 0,63 \\
\hline Chácaras Tubalina & 0,56 & Nossa Senhora Aparecida & 1,34 \\
\hline Cidade Jardim & 0,28 & Nossa Senhora das Graças & 0,40 \\
\hline Cruzeiro do Sul & 0,69 & Nova Uberlândia & 0,43 \\
\hline Cústodio Pereira & 0,90 & Osvaldo Rezende & 1,71 \\
\hline Daniel Fonseca & 3,02 & Pacaembu & 0,62 \\
\hline Distrito Industrial & 0,25 & Pampulha & 0,66 \\
\hline Dom Almir & 0,13 & Panorama & 0,06 \\
\hline Dona Zulmira & 1,05 & Parque Santo Antônio & 0,01 \\
\hline Esperança & 0,05 & Patrimônio & 0,34 \\
\hline Fundinho & 13,90 & Planalto & 0,55 \\
\hline Granada & 0,69 & Presidente Roosevelt & 0,84 \\
\hline Guarani & 1,14 & Residencial Gramado & 0,23 \\
\hline Ipanema I & 0,46 & Residencial Liberdade & 0,34 \\
\hline Jaraguá & 0,62 & Santa Luzia & 7,62 \\
\hline Jardim América I & 0,11 & Santa Mônica & 1,04 \\
\hline Jardim América II & 0,06 & Santa Rosa & 0,40 \\
\hline Jardim Brasília & 0,40 & São Jorge & 0,97 \\
\hline Jardim Canaã & 0,32 & São José & 0,28 \\
\hline Jardim das Palmeiras & 0,66 & Saraiva & 1,03 \\
\hline Jardim Europa & 0,00 & Segismundo Pereira & 0,95 \\
\hline Jardim Holanda & 0,03 & Shopping Park & 0,03 \\
\hline Jardim Inconfidência & 0,00 & Tabajaras & 2,23 \\
\hline Jardim Karaíba & 0,56 & Taiaman & 1,25 \\
\hline Jardim Patrícia & 0,55 & Tibery & 0,63 \\
\hline Lagoinha & 0,21 & Tocantins & 1,15 \\
\hline Laranjeiras & 0,52 & Tubalina & 0,97 \\
\hline Lídice & 0,22 & Umuarama & 3,99 \\
\hline Luizote de Freitas & 1,11 & Vigilato Pereira & 0,37 \\
\hline Mansões Aeroporto & 0,00 & & \\
\hline
\end{tabular}




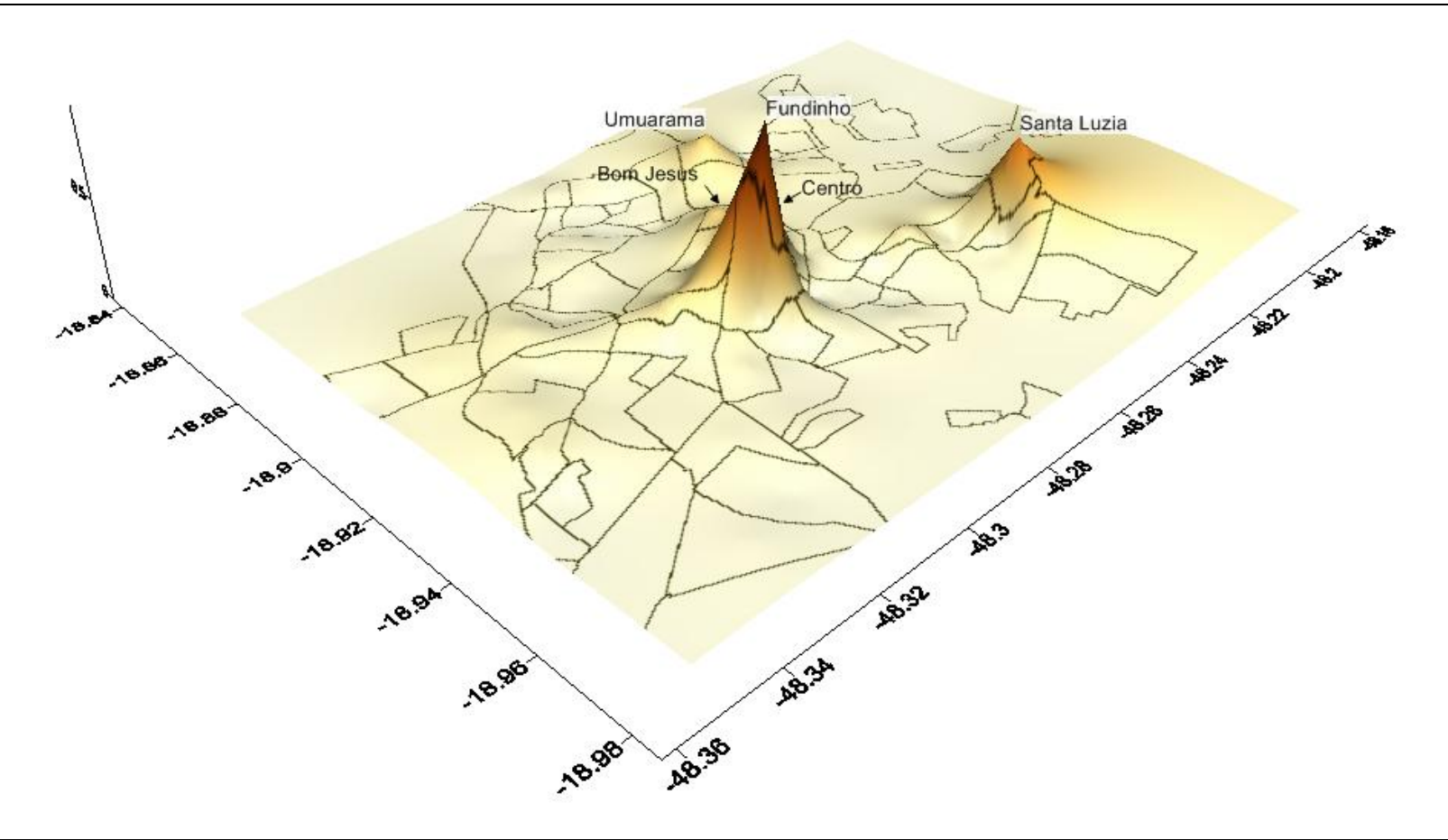

Figura 5.12 - Distribuição proporcional da oferta do transporte público urbano na cidade de Uberlândia.

\subsubsection{Variáveis Dependentes}

A fim de evitar repetições em relação ao que já foi exposto sobre as variáveis dependentes modo selecionado para a viagem e destino da atividade primária, nesta seção é apresentado apenas a variável padrão de viagens com apresentação pela Tabela 5.30 da Frequência de observações seguindo a codificação proposta pela Tabela 4.7.

Tabela 5.30 - Frequência de ocorrência dos padrões de viagens da amostra dados dos indivíduos, viagens e atividades (encadeadas) ${ }^{56}$.

\begin{tabular}{ccc}
\hline Padrão & Frequência & $\begin{array}{c}\text { Frequência } \\
\text { Relativa (\%) }\end{array}$ \\
\hline HWH & 1.682 & $78,27 \%$ \\
$\mathrm{H}+\mathrm{W}+\mathrm{H}$ & 95 & $4,42 \%$ \\
$\mathrm{HWHWH}$ & 210 & $9,77 \%$ \\
$\mathrm{H}+\mathrm{W}+\mathrm{H}+\mathrm{W}+\mathrm{H}$ & 162 & $7,54 \%$ \\
\hline
\end{tabular}

\footnotetext{
${ }^{56}$ Contendo apenas registros com padrões de viagens com propósito de engajamento ao trabalho.
} 


\subsection{Considerações}

\subsubsection{Expansão dos dados}

Em função dos procedimentos adotados na etapa de tratamento de dados, os registros das amostras (viagens discretas, viagens encadeadas e viagens encadeadas com atividade trabalho) não podem ser expandidos para o universo da cidade de Uberlândia. Não houve preocupação durante a etapa de exclusão dos registros em manter-se a proporcionalidade da amostra em relação ao universo.

\subsubsection{Trabalho Informal}

Foi realizada uma tentativa de estimar o número de empregos informais de Uberlândia a partir de valores encontrados da formalidade e informalidade do mercado de trabalho para o Estado de Minas Gerais em 2002 obtidos através da Pesquisa Nacional de Amostra de Domicílios - PNAD (IBGE, 2002), apresentados na Tabela 5.31. Foram considerados trabalhadores informais os empregados que não contribuem para a previdência oficial.

Tabela 5.31 - Proporção entre trabalhadores formais e informais do Estado de Minas Gerais (IBGE, 2002).

\begin{tabular}{lcc}
\hline \multicolumn{1}{c}{ Setor de Atividade } & $\begin{array}{c}\text { Trabalhadores } \\
\text { Formais (\%) }\end{array}$ & $\begin{array}{c}\text { Trabalhadores } \\
\text { Informais (\%) }\end{array}$ \\
\hline Agrícola & $14,09 \%$ & $85,91 \%$ \\
Indústria & $60,47 \%$ & $39,53 \%$ \\
Indústria de transformação & $58,78 \%$ & $41,22 \%$ \\
Construção & $32,64 \%$ & $67,36 \%$ \\
Comércio e reparação & $53,13 \%$ & $46,87 \%$ \\
Alojamento e alimentação & $39,32 \%$ & $60,68 \%$ \\
Transporte, armazenagem e comunicação & $63,51 \%$ & $36,49 \%$ \\
Administração pública & $89,90 \%$ & $10,10 \%$ \\
Educação, saúde e serviços sociais & $84,12 \%$ & $15,88 \%$ \\
Serviços domésticos & $32,09 \%$ & $67,91 \%$ \\
Outros serviços coletivos, sociais e pessoais & $31,81 \%$ & $68,19 \%$ \\
Outras atividades & $73,18 \%$ & $26,82 \%$ \\
Atividades mal definidas ou não declaradas & $17,05 \%$ & $82,95 \%$ \\
\hline
\end{tabular}

O intuito desta estimação foi verificar se as distorções encontradas na distribuição dos indivíduos aos locais de trabalho na etapa de seleção de destino na programação diária 
Capítulo 5 - Preparação do Experimento

de atividade poderiam ser explicadas pela distribuição do trabalho informal ser distinta do trabalho formal. Os resultados desta estimação são apresentados na Tabela 5.32.

Tabela 5.32 - Empregos totais segundo estimativa baseado na PNAD 2002.

\begin{tabular}{|c|c|c|c|c|c|c|c|c|c|}
\hline \multirow{2}{*}{ Bairro } & \multirow{2}{*}{$\begin{array}{c}\text { Formal } \\
\%\end{array}$} & \multirow{2}{*}{$\begin{array}{c}\text { Informal } \\
\%\end{array}$} & \multicolumn{2}{|c|}{ Total } & \multirow{2}{*}{ Bairro } & \multirow{2}{*}{$\begin{array}{c}\text { Formal } \\
\%\end{array}$} & \multirow{2}{*}{$\begin{array}{c}\text { Informal } \\
\%\end{array}$} & \multicolumn{2}{|c|}{ Total } \\
\hline & & & Obs. & $\%$ & & & & Total & $\%$ \\
\hline 1 & $0,28 \%$ & $0,30 \%$ & 572 & $0,29 \%$ & 39 & $0,05 \%$ & $0,06 \%$ & 107 & $0,05 \%$ \\
\hline 2 & $0,01 \%$ & $0,01 \%$ & 19 & $0,01 \%$ & 40 & $0,01 \%$ & $0,03 \%$ & 39 & $0,02 \%$ \\
\hline 3 & $0,02 \%$ & $0,06 \%$ & 75 & $0,04 \%$ & 41 & $1,12 \%$ & $1,28 \%$ & 2.343 & $1,19 \%$ \\
\hline 4 & $0,84 \%$ & $0,63 \%$ & 1.458 & $0,74 \%$ & 42 & $5,97 \%$ & $5,39 \%$ & 11.204 & $5,71 \%$ \\
\hline 5 & $10,33 \%$ & $8,52 \%$ & 18.669 & $9,51 \%$ & 43 & $0,39 \%$ & $0,20 \%$ & 588 & $0,30 \%$ \\
\hline 6 & $0,04 \%$ & $0,03 \%$ & 64 & $0,03 \%$ & 44 & $0,31 \%$ & $0,11 \%$ & 428 & $0,22 \%$ \\
\hline 7 & $0,01 \%$ & $0,02 \%$ & 26 & $0,01 \%$ & 45 & $0,03 \%$ & $0,02 \%$ & 51 & $0,03 \%$ \\
\hline 8 & $0,34 \%$ & $0,38 \%$ & 696 & $0,35 \%$ & 46 & $0,05 \%$ & $0,04 \%$ & 93 & $0,05 \%$ \\
\hline 9 & $12,35 \%$ & $11,89 \%$ & 23.841 & $12,14 \%$ & 47 & $0,08 \%$ & $0,07 \%$ & 147 & $0,08 \%$ \\
\hline 10 & $0,35 \%$ & $0,38 \%$ & 716 & $0,36 \%$ & 48 & $5,54 \%$ & $6,04 \%$ & 11.324 & $5,77 \%$ \\
\hline 11 & $0,24 \%$ & $0,44 \%$ & 649 & $0,33 \%$ & 49 & $0,39 \%$ & $0,33 \%$ & 718 & $0,37 \%$ \\
\hline 12 & $0,02 \%$ & $0,03 \%$ & 50 & $0,03 \%$ & 50 & $0,01 \%$ & $0,01 \%$ & 13 & $0,01 \%$ \\
\hline 13 & $1,48 \%$ & $1,37 \%$ & 2.812 & $1,43 \%$ & 51 & $0,86 \%$ & $0,85 \%$ & 1.673 & $0,85 \%$ \\
\hline 14 & $0,49 \%$ & $0,55 \%$ & 1.014 & $0,52 \%$ & 52 & $0,33 \%$ & $0,58 \%$ & 866 & $0,44 \%$ \\
\hline 15 & $11,36 \%$ & $13,78 \%$ & 24.458 & $12,46 \%$ & 53 & $0,56 \%$ & $0,39 \%$ & 952 & $0,49 \%$ \\
\hline 16 & $0,05 \%$ & $0,08 \%$ & 128 & $0,07 \%$ & 54 & $0,00 \%$ & $0,00 \%$ & 1 & $0,00 \%$ \\
\hline 17 & $0,35 \%$ & $0,45 \%$ & 782 & $0,40 \%$ & 56 & $1,23 \%$ & $2,14 \%$ & 3.226 & $1,64 \%$ \\
\hline 18 & $0,00 \%$ & $0,00 \%$ & 0 & $0,00 \%$ & 57 & $0,90 \%$ & $0,61 \%$ & 1.514 & $0,77 \%$ \\
\hline 19 & $0,19 \%$ & $0,33 \%$ & 506 & $0,26 \%$ & 58 & $2,15 \%$ & $2,09 \%$ & 4.171 & $2,12 \%$ \\
\hline 20 & $0,14 \%$ & $0,13 \%$ & 261 & $0,13 \%$ & 59 & $0,01 \%$ & $0,01 \%$ & 13 & $0,01 \%$ \\
\hline 21 & $0,21 \%$ & $0,34 \%$ & 524 & $0,27 \%$ & 60 & $0,01 \%$ & $0,00 \%$ & 10 & $0,01 \%$ \\
\hline 22 & $0,01 \%$ & $0,01 \%$ & 28 & $0,01 \%$ & 61 & $0,81 \%$ & $0,56 \%$ & 1.367 & $0,70 \%$ \\
\hline 23 & $0,30 \%$ & $1,06 \%$ & 1.259 & $0,64 \%$ & 62 & $14,32 \%$ & $11,00 \%$ & 25.159 & $12,81 \%$ \\
\hline 24 & $0,08 \%$ & $0,11 \%$ & 188 & $0,10 \%$ & 63 & $0,10 \%$ & $0,11 \%$ & 200 & $0,10 \%$ \\
\hline 25 & $0,00 \%$ & $0,00 \%$ & 0 & $0,00 \%$ & 64 & $0,16 \%$ & $0,16 \%$ & 315 & $0,16 \%$ \\
\hline 26 & $0,32 \%$ & $0,30 \%$ & 614 & $0,31 \%$ & 65 & $7,29 \%$ & $5,71 \%$ & 12.909 & $6,57 \%$ \\
\hline 27 & $0,10 \%$ & $0,07 \%$ & 177 & $0,09 \%$ & 66 & $0,70 \%$ & $0,92 \%$ & 1.571 & $0,80 \%$ \\
\hline 28 & $0,31 \%$ & $0,71 \%$ & 969 & $0,49 \%$ & 67 & $0,37 \%$ & $1,30 \%$ & 1.553 & $0,79 \%$ \\
\hline 29 & $0,74 \%$ & $5,16 \%$ & 5.390 & $2,74 \%$ & 68 & $0,63 \%$ & $0,18 \%$ & 834 & $0,42 \%$ \\
\hline 30 & $0,01 \%$ & $0,00 \%$ & 14 & $0,01 \%$ & 69 & $0,64 \%$ & $0,65 \%$ & 1.264 & $0,64 \%$ \\
\hline 31 & $0,00 \%$ & $0,00 \%$ & 4 & $0,00 \%$ & 70 & $0,11 \%$ & $0,11 \%$ & 218 & $0,11 \%$ \\
\hline 32 & $0,21 \%$ & $0,10 \%$ & 318 & $0,16 \%$ & 71 & $3,76 \%$ & $3,00 \%$ & 6.704 & $3,41 \%$ \\
\hline 33 & $0,49 \%$ & $0,55 \%$ & 1.008 & $0,51 \%$ & 72 & $0,15 \%$ & $0,13 \%$ & 274 & $0,14 \%$ \\
\hline 34 & $0,15 \%$ & $0,12 \%$ & 267 & $0,14 \%$ & 73 & $0,89 \%$ & $1,22 \%$ & 2.040 & $1,04 \%$ \\
\hline 35 & $0,07 \%$ & $0,08 \%$ & 145 & $0,07 \%$ & 74 & $5,05 \%$ & $3,19 \%$ & 8.261 & $4,21 \%$ \\
\hline 36 & $1,77 \%$ & $2,20 \%$ & 3.854 & $1,96 \%$ & 75 & $0,60 \%$ & $0,78 \%$ & 1.339 & $0,68 \%$ \\
\hline 37 & $0,76 \%$ & $0,52 \%$ & 1.276 & $0,65 \%$ & 76 & $3,26 \%$ & $16,34 \%$ & 18.058 & $9,20 \%$ \\
\hline 38 & $0,00 \%$ & $0,02 \%$ & 24 & $0,01 \%$ & Total & & & 196.345 & \\
\hline
\end{tabular}

(1) Aclimação (2) Alto Umuarama (3) Alvorada (4) Bom Jesus (5) Brasil (6) Buritis (7) Carajás (8) Cazeca (9) Centro (10) Chácaras Tubalina (11) Cidade Jardim (12) Cruzeiro do Sul (13) Cústodio Pereira (14) Daniel Fonseca (15) Distrito Industrial (16) Dom Almir (17) Dona Zulmira (18) Esperança (19) Fundinho (20) Granada (21) Guarani (22) Ipanema I (23) Jaraguá (24) Jardim América I (25) Jardim América II (26) Jardim Brasília (27) Jardim Canaã (28) Jardim das Palmeiras (29) Jardim Europa (30) Jardim Holanda (31) Jardim Inconfidência (32) Jardim Karaíba (33) Jardim Patrícia (34) Lagoinha (35) Laranjeiras (36) Lídice (37) Luizote de Freitas (38) Mansões Aeroporto (39) Mansour (40) Maravilha (41) Marta Helena (42) Martins (43) Minas Gerais (44) Morada da Colina (45) Morada do Sol (46) Morada dos Pássaros (47) Morumbi (48) Nossa Senhora Aparecida (49) Nossa Senhora das Graças (50) Nova Uberlândia (51) Osvaldo Rezende (52) Pacaembu (53) Pampulha (54) Panorama (55) Parque Santo Antônio (56) Patrimônio (57) Planalto (58) Presidente Roosevelt (59) Residencial Gramado (60) Residencial Liberdade (61) Santa Luzia (62) Santa Mônica (63) Santa Rosa (64) São Jorge (65) São José (66) Saraiva (67) Segismundo Pereira (68) Shopping Park (69) Tabajaras (70) Taiaman (71) Tibery (72) Tocantins (73) Tubalina (74) Umuarama (75) Vigilato Pereira. 
Capítulo 5 - Preparação do Experimento

\subsubsection{Georreferenciamento e Cálculo do Tempo de Viagem}

O georreferenciamento dos endereços dos pares de origem e destino das viagens oferece inúmeras vantagens na análise do comportamento individual relacionada as viagens, ademais a indisponibilidade deste tipo de informação é recorrente em dados coletados a partir de Pesquisas de Preferência Revelada em cidades brasileiras ${ }^{57}$.

Desvantagens do procedimento de georreferenciamento, como a falta de um procedimento para verificar o ajuste do processo de obtenção das coordenadas geográficas sem a necessidade de um levantamento em campo pode ser superado por meio de validações espaciais com auxílio de um SIG.

Por este processo a diferença entre os casos observados e os casos obtidos com o processo de georreferenciamento revelou uma diferença global de $27,46 \%$, considerando um nível de agregação espacial da zona de tráfego, e 8,36\% considerando a possibilidade dos pontos locados em zonas adjacentes devido à posição em relação ao eixo da via na rede viária. Cabe neste ponto ressaltar que este teste é aproximação das diferenças reais (a diferença pode ser superior ou inferior aos valores encontrados). Um estudo aprofundado das diferenças reais é indicado para pesquisas futuras.

Embora as estimativas de tempo de viagem sejam baseadas em valores reportados pelos indivíduos durante a entrevista domiciliar, é plausível de questionamento se estes valores podem representar percepções futuras da população em relação a alterações no modo de viagem e/ou alteração nos itinerários da viagens. Numa situação de discordância, os modelos baseados nesta informação não seriam úteis para descrever o comportamento individual relacionado às viagens.

No entanto, também é plausível que, uma vez que as estimativas o tempo de viagem real são baseadas em percepções cognitivas dos indivíduos é esperado que os modelos desenvolvidos a partir destas informações sejam mais próximos aos comportamentos dos indivíduos, em comparação aos modelos baseados em valores sem relação direta com as decisões individuais.

Além do mais, ao adotar valores da amostra são mantidas as diferenças entre os modos de transportes. Esta característica é relevante nos modelos que avaliam as escolhas

\footnotetext{
${ }^{57}$ A primeira Pesquisa de Preferência Revelada georreferenciada no Brasil foi conduzida na Região Metropolitana de São Paulo nos anos de 2007 e 2008.
} 
Capítulo 5 - Preparação do Experimento

de transportes, particularmente em modelos de escolha discreta: o que interessa são as diferenças entre as alternativas. Neste contexto, os valores obtidos podem ser utilizados. 


\section{Capítulo 6}

\section{Resultados e Discussão}

[...] A compulsão em incluir todos os resultados da pesquisa, não deixando nada de fora, não prova que a pesquisa possui resultados ilimitados; prova que falta ao pesquisador senso de discernimento $[\ldots]$

Adaptado de Scott Aaronson

[...] É devido a nossa falta de retórica que não podemos afirmar sobre um fato sem parecer que estamos desmentindo alguns outros [...]

Ralph Waldo Emerson

\subsection{Considerações Iniciais}

Neste capítulo são discutidos os resultados dos modelos obtidos para simulação do comportamento individual em três níveis de decisão da programação diária de atividades: modo de viagem; destino da atividade primária, e; padrão de viagens.

Pelo método adotado, para cada nível de decisão da programação diária de atividades em que foi aplicada uma técnica de modelagem para representação do comportamento individual foi formulada uma hipótese auxiliar, relacionada a hipótese nula do projeto, 
para interação das variáveis independentes (incluindo a acessibilidade) na variável dependente. Adicionalmente, para análise dos padrões de viagens foram elaborados modelos baseados em regras para investigar a dependência entre variáveis incluídas na modelagem.

Os modelos obtidos foram avaliados através de medidas de desempenho e cada hipótese auxiliar foi submetida a um teste de verificação por meio da estatística de significância dos parâmetros estimados. A consistência das relações encontradas entre as variáveis dependentes e independentes foi, também, analisada.

A partir dos resultados encontrados em cada etapa do processo de modelagem e com a atenção da análise voltada para o delineamento da influência da acessibilidade no comportamento individual, foram reunidos indícios para elaboração da conclusão da rejeição ou não rejeição da hipótese nula do projeto (acessibilidade a oportunidades influencia o comportamento dos padrões de viagens encadeadas desempenhados pelos indivíduos) que é apresentada ao final deste capítulo.

\subsection{Modo de Viagem: Especificação do Modelo e Resultados}

Esta seção descreve o modelo obtido para estimar as probabilidades individuais nas escolhas dos modos de viagens do sistema de transportes de Uberlândia. Para estimação do modelo foram consideradas as informações sobre as características socioeconômicas e características do sistema de transportes apresentadas nas Tabelas 4.2 e 4.3.

Para formação dos conjuntos individuais de alternativas foram consideradas cinco opções de modos de transportes: (1) a pé; (2) bicicleta; (3) ônibus/coletivo; (4) automóvel motorista, e; (5) automóvel passageiro.

As alternativas a pé, bicicleta, ônibus e automóvel passageiro foram consideradas disponíveis a todos os indivíduos, enquanto o modo automóvel motorista foi considerado indisponível aos indivíduos que declararam não possuir automóvel no domicílio e/ou a idade inferior a 18 anos (limite mínimo permitido pela legislação para habilitação de motorista). A hipótese de interferência testada no modelo foi:

- A escolha do modo de viagem é influenciada pelas características individuais, características do domicílio e características do sistema de transportes, incluindo a acessibilidade. 
Para verificação desta hipótese cada variável independente incluída no modelo foi submetida a um teste de significância para verificar se o parâmetro da variável é diferente de zero. Assim, a hipótese nula verificada pelo modelo foi:

$$
\begin{aligned}
& H_{0}: B=0 \\
& H_{1}: B \neq 0
\end{aligned}
$$

Em que B é o parâmetro da variável independente.

As especificações das funções de utilidade das alternativas dos modos de transportes do modelo obtido são apresentadas pelas Equações 91-95. Para codificação das variáveis categóricas foi utilizada a codificação de efeito (effect coding) em alternativa à codificação dummy.

Na codificação dummy um atributo com $L$ categorias é transformado em $L-1$ variáveis dummy, em que cada dummy assume o valor de 1 quando a categoria é presente e 0 se ela é ausente. A $L^{a}$ categoria é excluída para evitar a perfeita colinearidade.

Entretanto, em modelos de escolha discreta, aplicação da codificação dummy para as variáveis categóricas implica que o efeito da $L^{a}$ categoria é correlacionado com a constante do modelo, ou seja, o efeito da $L^{a}$ categoria é intrinsecamente capturado pela constante da alternativa da função utilidade.

Vários autores, por exemplo, Adamowicz et al. (1994), Bech e Gyrd-Hansen (2005), Hensher et al. (2005), Louviere et al. (2000), Mark e Swait (2004), sugerem a utilização da codificação de efeito em modelos de escolha discreta para evitar que o efeito da variável possa ser separado da constante do modelo.

A codificação de efeito é semelhante à codificação dummy, entretanto é atribuído o valor de -1 a categoria dominante ${ }^{58}$. Na codificação de efeito um atributo com $L$ categorias é transformado em $L-1$ variáveis de efeito, em que cada de efeito assume o valor de 1 quando a categoria é presente, -1 quando o efeito dominante está presente, e 0 em qualquer outra situação. Para ilustração, na Tabela 6.1 é apresentado um exemplo da codificação dummy versus a codificação de efeito.

\footnotetext{
${ }^{58}$ Em geral, a categoria dominante é considera a que possui o maior número de observações na variável.
} 
Tabela 6.1 - Ilustração da codificação dummy versus codificação de efeito.

\begin{tabular}{cccccc}
\hline $\begin{array}{c}\text { Número de } \\
\text { Categorias }\end{array}$ & Categorias & $\begin{array}{c}\text { Codificação } \\
\text { Dummy 1 }\end{array}$ & $\begin{array}{c}\text { Codificação } \\
\text { Dummy 1 }\end{array}$ & $\begin{array}{c}\text { Codificação de } \\
\text { Efeito 1 }\end{array}$ & $\begin{array}{c}\text { Codificação de } \\
\text { Efeito 2 }\end{array}$ \\
\hline 2 & 1 & 0 & & -1 & \\
& 2 & 1 & 0 & +1 & \\
3 & 1 & 0 & 0 & -1 & -1 \\
& 2 & 1 & 1 & +1 & 0 \\
\hline
\end{tabular}

Entende-se que para uma melhor análise da influência das variáveis no comportamento individual relacionando à escolha do modo de viagem e padrão de atividade deve ser utilizado a codificação de efeito.

$U_{a \text { pé }}=\beta_{\text {acessibilidade a pé }} \cdot \delta_{\text {acessibilidade a pé }}+\beta_{\text {chefe de família (a pé) }} \cdot \delta_{\text {chefe de família }}$

$+\beta_{\text {renda individual } R \$ 400 \text { a } R \$ 800 \text { (a pé) }} \cdot \delta_{\text {renda individual } R \$ 400 \text { a } R \$ 800}$

$+\beta_{\text {renda individual }>R \$ 800 \text { ( } a \text { pé })} \cdot \delta_{\text {renda individual }>R \$ 800}$

Em que:

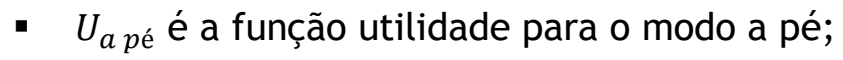

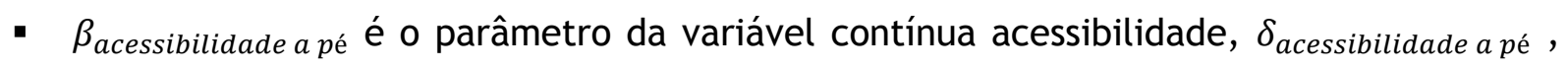
para o modo pé em horas;

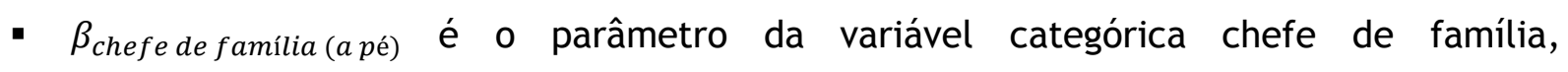
$\delta_{\text {chefe de família }}$, para o modo a pé: 1 se é chefe de família e -1 se não é chefe de família;

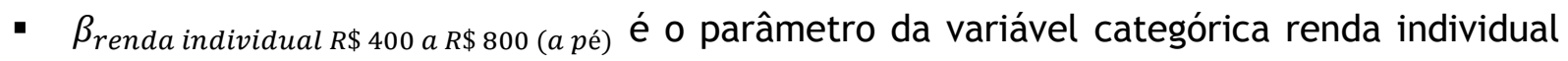

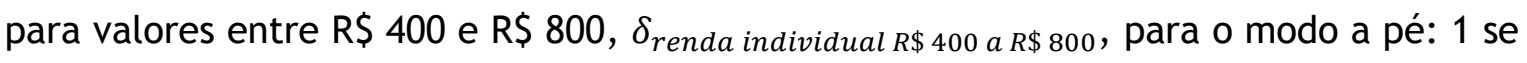
a renda individual é compreendida na faixa entre $400-800$ reais, 0 se a renda individual é superior a 800 reais e -1 se for inferior a 400 reais;

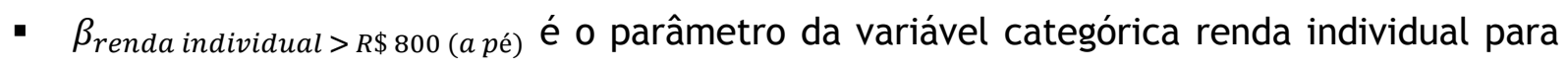
valores acima de $R \$ 800, \delta_{\text {renda individual }>R \$ 800}$, para o modo a pé: 1 se a renda individual é superior a 800 reais, 0 se a renda individual é compreendida na faixa entre 400 800 reais e -1 se for inferior a 400 reais).

$U_{\text {bicicleta }}=\beta_{\text {acessibilidade bicicleta }} \cdot \delta_{\text {acessibilidade bicicleta }}$

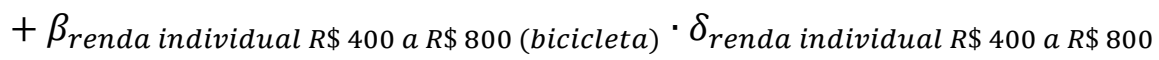

$+\beta_{\text {renda individual }>R \$ 800(\text { bicicleta })} \cdot \delta_{\text {renda individual }>R \$ 800}+\varepsilon_{\text {bicicleta }}$

Em que: 
- $U_{\text {bicicleta }}$ é a função utilidade para o modo bicicleta;

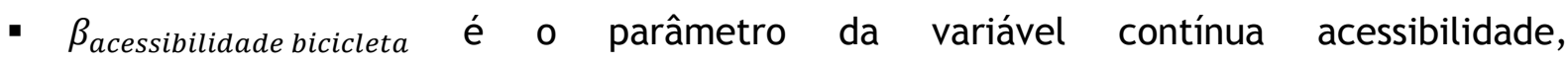
$\delta_{\text {acessibilidade bicicleta }}$, para o modo bicicleta em horas;

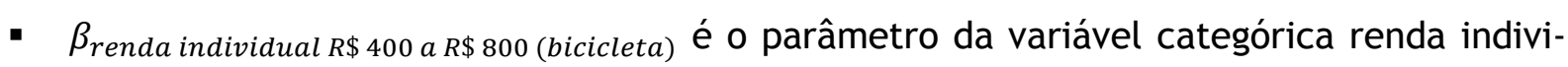

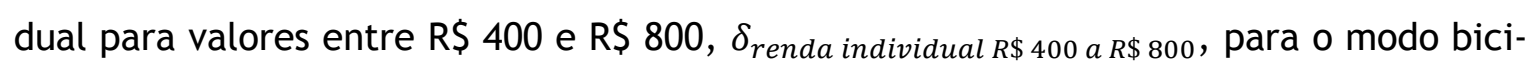
cleta: 1 se a renda individual é compreendida na faixa entre $400-800$ reais, 0 se a renda individual é superior a 800 reais e -1 se for inferior a 400 reais;

- $\beta_{\text {renda individual }>R \$ 800 \text { (bicicleta) }}$ é o parâmetro da variável categórica renda individual

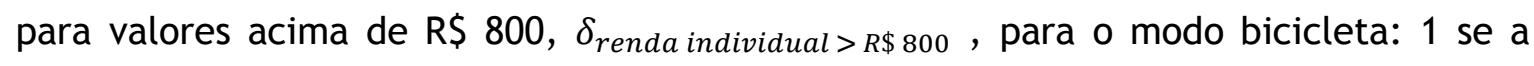
renda individual é superior a 800 reais, 0 se a renda individual é compreendida na faixa entre 400-800 reais e -1 se for inferior a 400 reais;

- $\varepsilon_{\text {bicicleta }}$ é a constante da alternativa bicicleta.

$U_{\text {ônibus }}=\beta_{\text {acessibilidade ônibus }} \cdot \delta_{\text {acessibilidade ônibus }}+\beta_{\text {chefe de família (ônibus) }}$

$\cdot \delta_{\text {chefe de família }}+\beta_{\text {vale transporte }} \cdot \delta_{\text {vale transporte }}+\beta_{\text {passe de idoso }} \cdot \delta_{\text {passe de idoso }}$

$+\beta_{\text {distância }} \cdot \delta_{\text {distância }}+\beta_{\text {renda individual } R \$ 400 \text { a } R \$ 800 \text { (ônibus) }}$

- $\delta_{\text {renda individual } R \$ 400 \text { a } R \$ 800}+\beta_{\text {renda individual }>R \$ 800 \text { (ônibus) }}$

$\cdot \delta_{\text {renda individual }>R \$ 800}+\beta_{\text {oferta TPU }} \cdot \log \left(\delta_{\text {oferta TPU }}\right)+e^{\beta_{\text {custo }} \cdot \delta_{\text {custo ônibus }}+\varepsilon_{\text {ônibus }}}$

Em que:

- $U_{\hat{o} n i b u s}$ é a função utilidade para o modo ônibus;

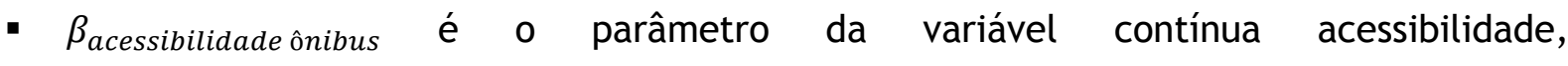
$\delta_{\text {acessibilidade ônibus, }}$, para o modo ônibus em horas;

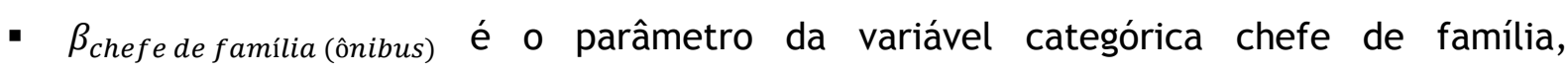
$\delta_{\text {chefe de família }}$, para o modo ônibus: 1 se é chefe de família e -1 se não é chefe de família;

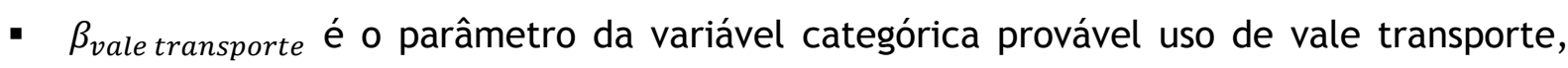
$\delta_{\text {vale transporte }}: 1 \mathrm{se}$, provavelmente, usa vale transporte e -1 se, provavelmente, não usa vale transporte;

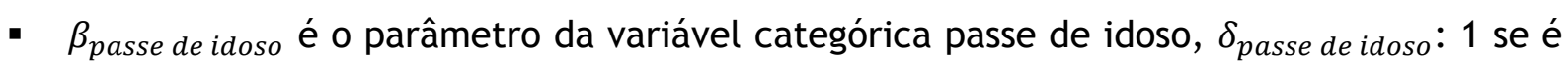
usuário de passe de idoso e - 1 se não é usuário de passe de idoso;

- $\beta_{\text {distância }}$ é o parâmetro da variável contínua distância, $\delta_{\text {distância }}$, em quilômetros;

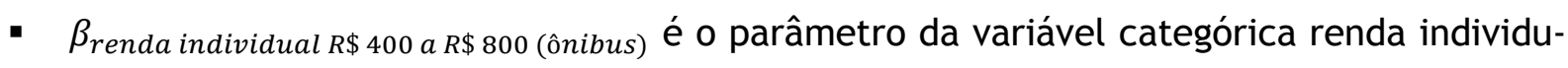
al no modo ônibus para valores entre $\mathrm{R} \$ 400$ e $\mathrm{R} \$ 800, \delta_{\text {renda individual } R \$ 400 \text { a } R \$ 800}$ : 1 se 
a renda individual é compreendida na faixa entre $400-800$ reais, 0 se a renda individual é superior a 800 reais e -1 se for inferior a 400 reais;

- $\quad \beta_{\text {renda individual }>R \$ 800 \text { (ônibus) }}$ é o parâmetro da variável categórica renda individual no modo ônibus para valores acima de R\$ $800, \delta_{\text {renda individual }>R \$ 800}: 1$ se a renda individual é superior a 800 reais, 0 se a renda individual é compreendida na faixa entre 400 800 reais e -1 se for inferior a 400 reais;

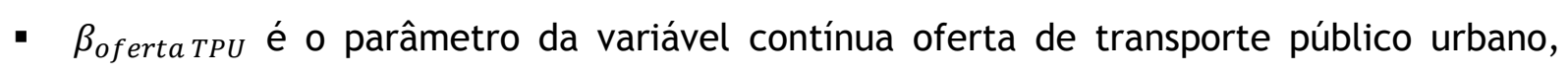
$\delta_{\text {oferta TPU }}$, em $\frac{\mathrm{Freq} \cdot \mathrm{m}}{\mathrm{m}^{2}}$;

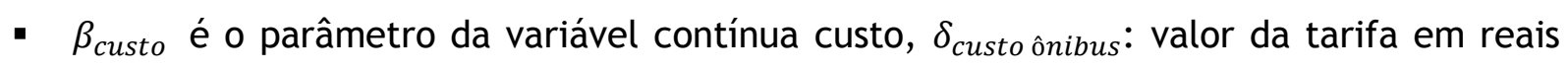
para o modo ônibus;

- $\varepsilon_{\hat{o} n i b u s}$ é a constante da alternativa ônibus.

$U_{\text {automóvel motorista }}=\beta_{\text {acessibilidade automóvel motorista }} \cdot \delta_{\text {acessibilidade automóvel motorista }}$

$+\beta_{\text {chefe de família (automóvel motorista) }} \cdot \delta_{\text {chefe de família }}$

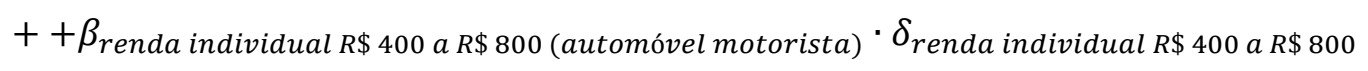

$+\beta_{\text {renda individual }>R \$ 800 \text { (automóvel motorista) }}$

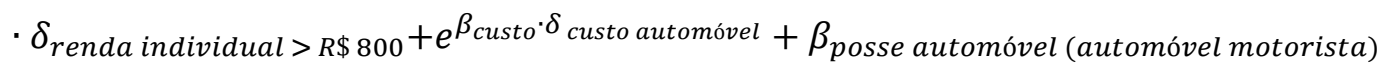

- $\delta_{\text {posse automóvel }}+\varepsilon_{\text {automóvel motorista }}$

Em que:

- Uatomóvel motorista é a função utilidade para o modo automóvel motorista;

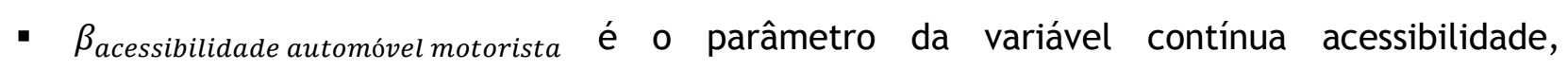
$\delta_{\text {acessibilidade automóvel motorista }}$, para o modo automóvel motorista em horas;

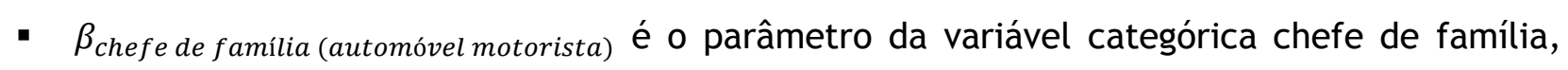
$\delta_{\text {chefe de família }}$, para o modo automóvel motorista: 1 se é chefe de família e -1 se não é chefe de família;

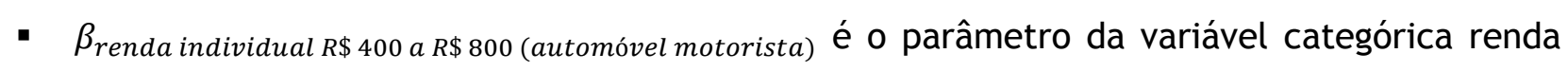
individual para o modo automóvel motorista para valores entre R\$ 400 e R\$ 800 , $\delta_{\text {renda individual } R \$ 400 \text { a } R \$ 800}$ : 1 se a renda individual é compreendida na faixa entre 400-800 reais, 0 se a renda individual é superior a 800 reais e -1 se for inferior a 400 reais;

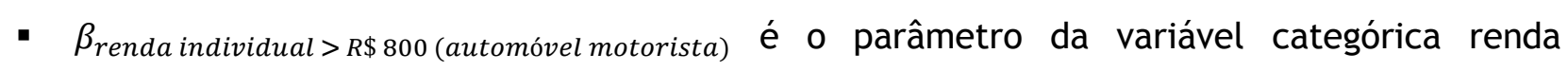
individual no modo automóvel motorista para valores acima de R\$ 800 , $\delta_{\text {renda individual }>R \$ 800}$ : 1 se a renda individual é superior a 800 reais, 0 se a renda individual é compreendida na faixa entre $400-800$ reais e -1 se for inferior a 400 reais; 


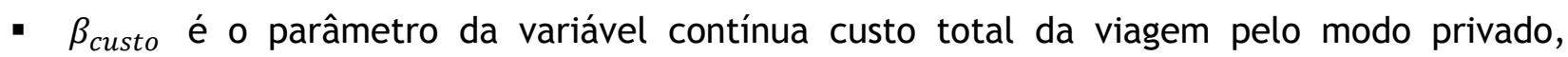
$\delta_{\text {custo automóvel }}$ : custo da queima de combustível em reais;

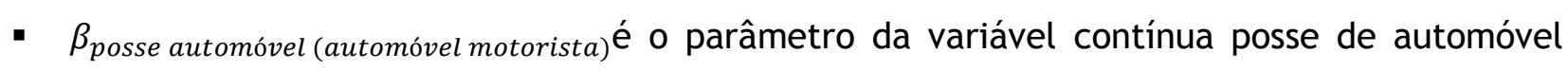
(quantidade no domicílio), $\delta_{\text {posse automóvel }}$, para o modo automóvel motorista;

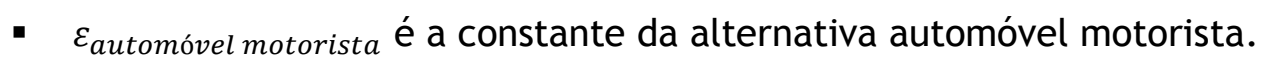

$U_{\text {automóvel passageiro }}=\beta_{\text {acessibilidade automóvel passageiro }}$

$\cdot \delta_{\text {acessibilidade automóvel passageiro }}+\beta_{\text {posse automóvel (automóvel motorista) }} \cdot \delta_{\text {posse automóvel }}$

$+\varepsilon_{\text {automóvel passageiro }}$

Em que:

- Uautomóvel passageiro é a função utilidade para o modo automóvel passageiro;

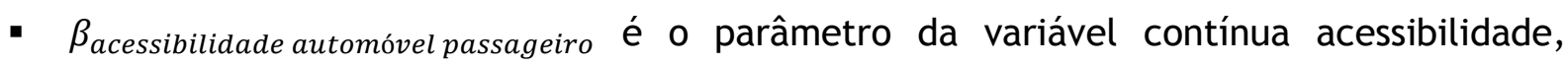

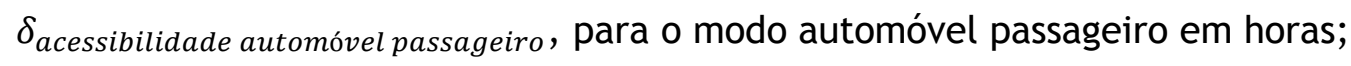

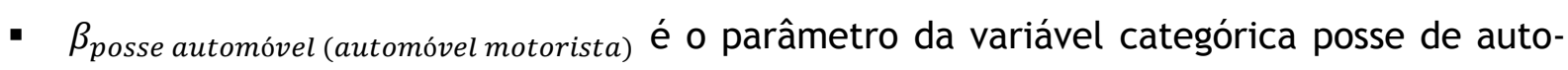
móvel (quantidade no domicílio), $\delta_{\text {posse automóvel }}$, para o modo automóvel passageiro;

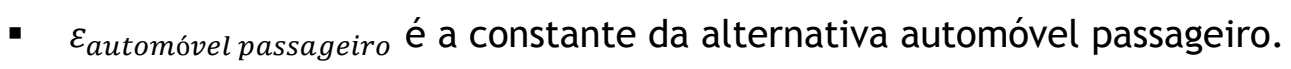

Na Tabela 6.2 são apresentadas as medidas de desempenho do modelo logit multinomial estimado para o cálculo das probabilidades individuais para escolha modal e na Tabela 6.3 são apresentados os valores dos parâmetros das funções de utilidade de cada alternativa de modo de transportes: os parâmetros $(B)$ encontram-se na coluna 2 , enquanto suas estatísticas de significância encontram-se na coluna 3. Os valores marcados com "*" indicam os parâmetros que não foram significativos ao nível de $5 \%$.

Tabela 6.2 - Estatísticas do modelo de escolha modal.

\begin{tabular}{cc}
\hline Estatística do Modelo & Valor \\
\hline Parâmetros estimados & 27 \\
Observações & 10.757 \\
$L L\left(\beta^{\prime}=0\right)$ & $-16.060,67$ \\
$L L\left(\beta^{\prime}=\hat{\beta}\right)$ & $-10.828,63$ \\
$\rho$ & 0,3240 \\
\hline
\end{tabular}


Tabela 6.3 - Estimativa do modelo de escolha modal.

Parâmetros da Função Utilidade (1)

Valor (2)

Estatística $t(3)$

1. Contantes

Bicicleta

$-3,21$

Ônibus

$-2,61$

Automóvel Motorista

$-2,96$

Automóvel Passageiro

$-3,30$

$(-37,87)$

2. Acessibilidade ( horas)

A pé

$-3,39$

Bicicleta

$-2,18$

Ônibus

$-0,63$

Automóvel Motorista

$-0,95$

Automóvel Passageiro

$-3,01$

$(-10,31)$

3. Distância (km).

Ônibus

0,05

4. Custo da Viagem (R\$)

Ônibus

$-0,69$

Automóvel Motorista

5. Vale Transportes $=1, \operatorname{sim} ;=-1$, não

Ônibus

0,07

6. $\quad$ Passe de Idoso = 1, sim; $=-1$, não

Ônibus

0,06

$(0,65)^{*}$

7. Oferta do Transporte Público Urbano (Freq. $\mathrm{m} / \mathrm{m}^{2}$ )

Ônibus

0,26

$(6,40)$

8. Renda Individual $R \$ 400$ a $R \$ 800$

A pé

0,10

Bicicleta

0,64

$(6,43)$

Ônibus

0,30

$(4,77)$

Automóvel Motorista

0,22

9. Renda Individual acima de $R \$ 800$

A pé

$-0,31$

Bicicleta

$-0,74$

Ônibus

$-0,31$

Automóvel Motorista

0,21

$(3,48)$

10. Posse de Automóvel (quant. de carros no domícilio)

Automóvel Motorista

0,87

Automóvel Passageiro

1,09

11. Chefe de Família $=1, \operatorname{sim} ;=-1$, não

A pé

$-0,22$

Ônibus

$-0,27$

Automóvel Motorista

0,21 


\subsubsection{Modo de Viagem: Discussão dos Resultados}

Não há limites fixados para se afirmar qual valor de razão da verossimilhança $(\rho)$ é suficiente para determinar o desempenho do modelo de escolha discreta, no entanto, com o propósito de situar o valor obtido para o índice são apresentados, na Tabela 6.4, alguns valores para este índice reportados na literatura sobre modelos de escolha de modos de transportes ${ }^{59}$. Ressalta-se que o propósito desta comparação é apenas situar o valor em relação aos valores reportados na literatura.

Tabela 6.4 - Medidas de desempenho de modelos multinomial logit para escolha do modo de transportes.

\begin{tabular}{ccccccc}
\hline Estudo & Cidade & $\begin{array}{c}\text { Parâmetros } \\
\text { estimados }\end{array}$ & Observações & $\boldsymbol{L L}\left(\boldsymbol{\beta}^{\prime}=\mathbf{0}\right)$ & $\boldsymbol{L L}\left(\boldsymbol{\beta}^{\prime}=\widehat{\boldsymbol{\beta}}\right)$ & $\boldsymbol{\rho}$ \\
\hline $\begin{array}{c}\text { McFadden } \\
\text { (1977) }\end{array}$ & $\begin{array}{c}\text { São } \\
\text { Francisco }\end{array}$ & 22 & 635 & $-964,40$ & $-526,40$ & 0,4542 \\
$\begin{array}{c}\text { Swait e Ben- } \\
\text { Akiva (1987) }\end{array}$ & São Paulo & 29 & 1.725 & $-2.480,50$ & $-1.437,00$ & 0,4207 \\
& & 15 & 398 & $-731,99$ & $-509,01$ & 0,3046 \\
$\begin{array}{c}\text { Jara-Díaz } \\
\text { (1991) }\end{array}$ & Santiago & 15 & 266 & $-460,02$ & $-370,80$ & 0,1939 \\
& 15 & 297 & $-423,12$ & $-288,90$ & 0,3172 \\
$\begin{array}{c}\text { Schwanen e } \\
\text { Mokhtarian } \\
(2005)\end{array}$ & Francisco & 15 & 317 & $-377,82$ & $-191,66$ & 0,4922 \\
\hline
\end{tabular}

Confrontando a medida de desempenho do modelo de escolha modal obtido com os valores da Tabela 6.4 observa-se que a medida de desempenho do modelo situa-se dentro da faixa dos valores encontrado na literatura.

Com relação ao modelo, foram estimados 23 parâmetros associados às variáveis independentes e 4 associados às constantes específicas (ASC). Todos os coeficientes estimados são em sinal esperado e com exceção do parâmetro calibrado para o passe de idoso, os demais são significantes para o nível de $5 \%$. Apesar de insignificante a variável passe de idoso foi mantida pela sua importância na análise de políticas pública no planejamento de transportes.

\footnotetext{
${ }^{59}$ Considerando aplicação do modelo multinomial logit na escolha do modo em viagens urbanas a partir de pesquisa de preferência revelada.
} 
Todas as ASC são negativas, e a análise do efeito das variáveis independentes quando os parâmetros assumem o valor de zero sobre a utilidade dos modos é uma propensão de 0,88 para escolha do modo a pé.

Quando um modelo de escolha não captura os efeitos das variáveis independentes no processo de escolha, um dos principais efeitos esperados na previsão é que o modelo reproduza as proporções das escolhas reveladas do banco de dados. Este efeito é causado pela influência do valor da ASC nas funções de utilidade.

Um teste para análise deste aspecto do modelo é considerar os valores dos parâmetros das variáveis independentes como zero e analisar os resultados da previsão. Como descrito, o valor obtido da previsão considerando apenas a influência do ASC é de $88 \%$ para o modo a pé (alternativa dominante), enquanto pelos dados da Tabela 5.6 a proporção do modo a pé é de $30 \%$.

Desta forma, pode se afirmar que as especificações das funções de utilidade capturam os efeitos das diferenças entre os modos de transportes do sistema de transportes e conclui-se que não há elementos para refutar o uso do modelo para simular o comportamento individual em relação às escolhas dos modos de transportes.

Analisando o efeito das variáveis no comportamento em relação às escolhas, a distância da viagem é positiva para o ônibus, indicando que para etapas de viagens longas os indivíduos são propensos a usar o ônibus. Isso pode ser em parte explicado pelo comprimento médio de viagem dos passageiros de ônibus na Tabela 5.18: é a maior média entre os modos.

Quanto à análise do custo percebido na viagem, entre as opções testadas a que apresentou melhor resultado foi o custo da queima do combustível, para o modo automóvel motorista, e a tarifa do transporte coletivo, para o modo ônibus.

Várias formas para representação da função custo foram verificadas e a que melhor de adequou na interação com as demais variáveis foi a função exponencial negativa. Esta forma de interação para o custo sugere uma sensibilidade da propensão a pequenas variações no custo da viagem.

Há um indício na amostra que colabora para argumentação sobre a sensibilidade da propensão a pequenas variações no custo da viagem, que é a distribuição da renda individual. Analisando o comportamento da Figura 5.3 é observada uma concentração da renda 
individual nas classes com rendimentos até 400 reais (quanto menor é a renda, maior são as restrições impostas na alocação dos recursos).

Como esperado, o comportamento da medida de oferta de transporte público indica que indivíduos em localidades bem providas de transporte público têm maior propensão em utilizar o transporte coletivo, e políticas públicas como gratuidade para idoso e desconto para trabalhadores possuem impacto positivo na utilidade para o ônibus.

A medida de oferta de transporte público e as políticas de gratuidade para idoso e desconto na tarifa para trabalhadores desempenham um papel importante na análise de parte dos problemas de planejamento urbano e de transportes, e os resultados da Tabela 6.3 indicam que promover o aumento da oferta do transporte, associados a políticas sociais de promoção ao acesso ao transporte coletivo terá um impacto positivo sobre a probabilidade individual de usar o ônibus.

Em relação a renda, pessoas com ganhos mensais acima de 800 reais tem uma maior propensão a utilização do automóvel em comparação aos indivíduos com ganhos mensais de até 400 reais. Indivíduos com ganhos entre 400 e 800 reais mensais possuem uma propensão ao modo não motorizado mais rápido (bicicleta).

A decisão de longo prazo de posse de automóvel no domicílio tem impacto positivo na utilidade dos modos automóvel motorista e automóvel passageiro. É esperado com o aumento do número de automóveis no domicilio ocorra uma diminuição da propensão para utilização dos modos não motorizados e coletivo e aumento do modo motorizado individual. A utilidade modo automóvel aumenta se o indivíduo ocupa o papel de chefe de família.

Analisando o comportamento das variáveis de acessibilidade, todos os parâmetros foram significativos e em sinal esperado (negativo, o aumento do tempo pelo modo reduz a propensão de sua utilização). Desta forma, a hipótese nula em relação ao efeito da acessibilidade no comportamento individual em relação às escolhas dos modos de transportes não pode ser rejeitada.

Ainda sobre acessibilidade, espera-se que quanto mais rápido é o modo, menor é o impacto do tempo de viagem na utilidade do modo. A maior desutilidade encontrada é para o modo a pé, no entanto, o parâmetro de tempo do modo automóvel motorista é $33,8 \%$ maior do que o modo de ônibus. Este resultado pode estar relacionado com os baixos valores de velocidades do modo individual motorizado no centro de Uberlândia, conforme apresentado na Tabela 5.27. 
Entretanto, ressalta que a análise do impacto do tempo na utilidade do modo deve ser realizada para etapas de viagens semelhantes. Por exemplo, para uma etapa de viagem com 1 hora de duração por ônibus ou 20 minutos de automóvel, o impacto na utilidade do ônibus é de -0,63, ao passo que o impacto na utilidade do automóvel é de -0,33.

Ainda sobre os coeficientes do tempo, como a constante específica da alternativa do modo a pé foi considerada como referência, isto é, assumiu o valor de 0 , algumas características da desutilidade do modo a pé podem ter sido capturadas pelo coeficiente do tempo, por exemplo, o cansaço físico da viagem a pé.

\subsection{Destino da Atividade Primária: Especificação do Modelo e Resultados}

Esta seção descreve os modelos obtidos para estimar as probabilidades individuais nas escolhas dos locais da atividade primária em Uberlândia. Para estimação do modelo foram estabelecidas as seguintes condições:

- Para formação dos conjuntos individuais de alternativas foram considerados os 75 bairros de Uberlândia;

- Todas as oportunidades foram consideradas disponíveis a todos os indivíduos do banco de dados;

- Para cada indivíduo do banco de dados é elaborado um vetor de oportunidades e calculado a probabilidade para se atingir cada um dos destinos contido neste vetor, respeitando as regras da abordagem subjacente do modelo comportamental em análise (modelo de oportunidades ou modelo de escolha discreta).

- Para o modelo de oportunidades intervenientes foram elaborados dois vetores: um vetor de oportunidades acumuladas e outro de oportunidades intervenientes. Para o modelo de escolha discreta foi elaborado apenas o vetor de oportunidades.

- Para o cálculo da probabilidade individual da escolha do local da atividade primária, o modelo considera a acessibilidade aos locais das oportunidades representados pelo tempo médio de viagem entre os modos disponíveis no sistema de transportes (adicionalmente foram testadas outras medidas de separação espacial para representação da acessibilidade, com o proposito de fornecer mais elementos na discussão dos resultados). 
- Considera-se em ambos os modelos que as oportunidades estão localizadas nos centroides dos bairros. Esta condição ocasiona a falácia ecológica denominado de Problema de Unidades de Área Modificáveis (PUAM) ${ }^{60}$. Não há como evitar este problema, uma vez que não há disponibilidade de dados em escala geográfica em nível de ruas, apenas de bairro.

Conforme o método delineado no Capítulo 4 foram aplicadas duas abordagens para modelagem do comportamento individual relacionado a escolha da atividade primária: modelo de oportunidades intervenientes e modelo de escolha discreta (logit). As especificações dos modelos e seus resultados são apresentados e discutidos nas próximas subseções.

\subsubsection{Modelo de Oportunidades Intervenientes}

A hipótese de interferência testada no modelo de oportunidades foi:

- A escolha do destino da atividade primária é influenciada pelas oportunidades e pela acessibilidade.

Para verificação desta hipótese cada variável independente incluída no modelo é submetida a um teste estatístico para verificar se o parâmetro da variável é diferente de zero. Desta forma a hipótese nula a ser verificada é:

$$
\begin{aligned}
& H_{0}: B=0 \\
& H_{1}: B \neq 0
\end{aligned}
$$

Em que $B$ é o parâmetro da variável independente.

Para formação dos conjuntos individuais de oportunidades acumuladas e intervenientes ao indivíduo foram consideradas quatro formulações de tempo médio de viagem para representar a acessibilidade. Estas formulações foram baseadas em hipóteses em como os indivíduos podem perceber o tempo médio de viagem dentro do sistema de transportes

\footnotetext{
${ }^{60}$ A falácia ecológica do Problema de Unidade de Área Modificáveis envolve a inferência não apropriada de relações em nível individual a partir de resultados agregados em unidades de área. Isto ocorre, tipicamente, quando o dado agregado é a única fonte disponível, porém o objeto de estudo são características e relacionamentos em nível do indivíduo. Devido aos efeitos de escala, zoneamento e homogeneidade, componentes do PUAM, os coeficientes de correlação tendem a ser maior em valor absoluto do que as correlações desconhecidas das variáveis em nível individual.
} 
- Tempo médio (1): A acessibilidade é percebida pelo indivíduo como o tempo médio de viagem (na rede de transportes) entre o domicílio e a oportunidade (centroide do bairro), considerando todos os modos de transportes disponíveis.

- Tempo médio (2) - modo disponível (a): A acessibilidade é percebida pelo indivíduo como o tempo médio de viagem (pelos modos disponíveis ao indivíduo na rede de transportes) entre o domicílio e a oportunidade. Os modos a pé, bicicleta e ônibus foram considerados disponíveis a todos os indivíduos e o modo automóvel motorista foi considerado disponível apenas aos indivíduos com automóvel no domicilio e com idade igual ou superior a 18 anos.

- Tempo médio (3) - modo disponível (b): A acessibilidade é percebida pelo indivíduo como o tempo médio de viagem (pelos modos disponíveis ao indivíduo na rede de transportes) entre o domicílio e a oportunidade. Os modos a pé e ônibus foram considerados disponíveis a todos os indivíduos. Os modos bicicleta e automóvel motorista foram considerados disponíveis apenas se os indivíduos utilizaram estes modos.

- Tempo médio (4) - produto da propensão por cada modo pelo tempo do modo: A acessibilidade é percebida pelo indivíduo como um tempo ponderado de viagem (o tempo do modo pela propensão de utilização do modo ao destino) entre o domicílio e a oportunidade. A propensão individual é calculada através do modelo de escolha modal, e o valor da propensão para cada modo de transportes é alterado segundo o local da oportunidade (as oportunidades possuem desutilidades distintas para serem alcançadas).

Adicionalmente, foram calibrados modelos de oportunidades considerando como medida de acessibilidade outras formas de representação da separação espacial:

- Distância euclidiana: A acessibilidade é expressa como a distância em linha reta, entre o domicílio e a oportunidade.

- Distância rede viária: A acessibilidade é expressa como a distância percorrida pelos indivíduos na rede viária entre o domicílio e a oportunidade.

- Tempo modo utilizado: A acessibilidade é expressa como o tempo de viagem do modo utilizado na viagem entre o domicílio e a oportunidade.

Considerando as sete medidas de separação utilizadas e as duas formas de representação das oportunidades (emprego formal e emprego formal mais informal) o resultado 
são 14 tipos diferentes de modelos de oportunidades intervenientes (Tabela 6.5) que foram desenvolvidos e calibrados.

Tabela 6.5 - Modelos de oportunidades intervenientes provenientes da combinação das medidas de separação espacial e oportunidades.

\begin{tabular}{|c|c|c|}
\hline Modelo & Oportunidade & Medida de Acessibilidade \\
\hline $\begin{array}{l}1-\mathrm{A} \\
1-\mathrm{B}\end{array}$ & $\begin{array}{c}\text { Formal + Informal } \\
\text { Formal }\end{array}$ & Distância Euclidiana \\
\hline $\begin{array}{l}2-A \\
2-B\end{array}$ & $\begin{array}{c}\text { Formal + Informal } \\
\text { Formal }\end{array}$ & Distância Rede Viária \\
\hline $\begin{array}{l}3-A \\
3-B\end{array}$ & $\begin{array}{c}\text { Formal }+ \text { Informal } \\
\text { Formal }\end{array}$ & Tempo Médio (1) \\
\hline $\begin{array}{l}4-\mathrm{A} \\
4-\mathrm{B}\end{array}$ & $\begin{array}{c}\text { Formal + Informal } \\
\text { Formal }\end{array}$ & $\begin{array}{l}\text { Tempo Médio (2) } \\
\text { Modo Disponível(a) }\end{array}$ \\
\hline $\begin{array}{l}5-A \\
5-B\end{array}$ & $\begin{array}{c}\text { Formal }+ \text { Informal } \\
\text { Formal }\end{array}$ & $\begin{array}{l}\text { Tempo Médio (3) } \\
\text { Modo Disponível(b) }\end{array}$ \\
\hline $\begin{array}{l}6-A \\
6-B\end{array}$ & $\begin{array}{c}\text { Formal }+ \text { Informal } \\
\text { Formal }\end{array}$ & $\begin{array}{l}\text { Tempo Médio (4) } \\
\text { Modo x Probabilidade do Modo }\end{array}$ \\
\hline $\begin{array}{l}7-A \\
7-B\end{array}$ & $\begin{array}{c}\text { Formal }+ \text { Informal } \\
\text { Formal }\end{array}$ & Tempo Modo Utilizado \\
\hline
\end{tabular}

Para análise da aderência dos resultados do modelo, comparação dos valores estimados das viagens e valores observados das viagens, os bairros foram agregados em 15 macrozonas, apresentado na Figura 6.1.

A fim de verificar a representatividade das macrozonas em relação ao conjunto original de 75 bairros foi estabelecida a hipótese de que para representar a configuração original:

- Os tempos médios (estimados) entre macrozonas devem ser próximos aos tempos médios originais entre os bairros.

Para verificação desta hipótese os tempos médios estimados entre macrozonas são comparados aos tempos médios entre bairros respeitando um limite de desvio (diferença 
relativa - D) de $25 \%$ (valor adotado). Caso $D>D_{\text {crítico }}$, rejeita-se a hipótese nula. Se $D<D_{\text {críti- }}$ co, então não se rejeita a hipótese nula.

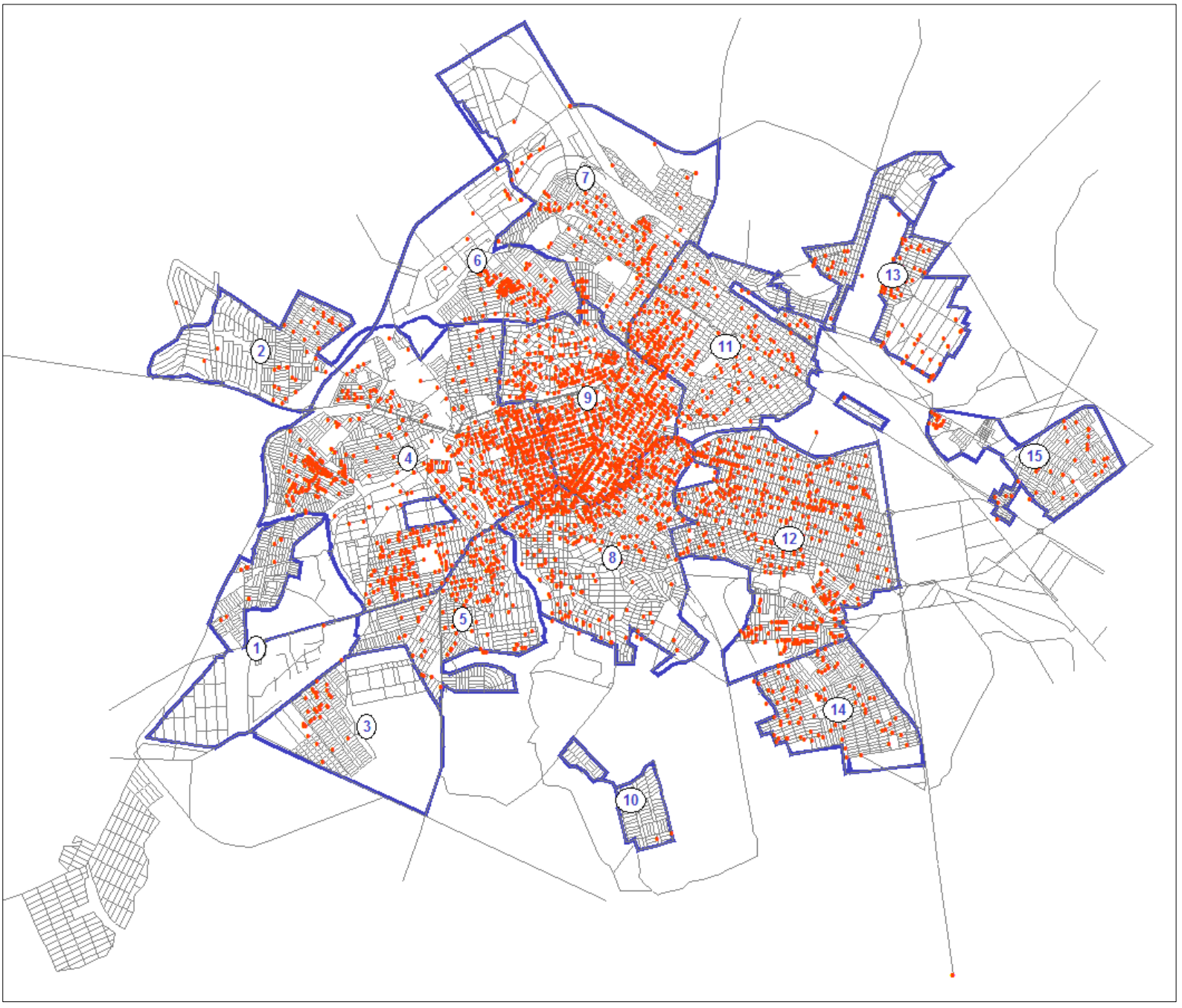

Figura 6.1 - Divisão espacial das macrozonas de Uberlândia.

A agregação dos bairros em 15 macrozonas resultou em 225 pares $0-D$, dos quais 100 pares não possuem observações de viagens; 80 pares possuem valores abaixo de 10 $(<10)$ viagens, 25 pares possuem valores abaixo de $30(<30)$ viagens e 20 pares possuem valores acima de 30 viagens.

Desconsiderando os pares OD com valores inferiores a 10 viagens, a diferença média relativa do tempo médio das viagens dos bairros em relação as macrozonas encontradas foram:

- Para os pares O-D acima de 10 viagens, a diferença média relativa encontrada é de $16,23 \%$ 
- Para os pares O-D acima de 20 viagens, a diferença média relativa encontrada é de $14,36 \%$;

- Para os pares O-D acima de 30 viagens, a diferença média relativa encontrada é de $16,43 \%$

Pela análise destes resultados, como $D<D_{\text {crítico }}$ então não se rejeita a hipótese nula, ou seja, as macrozonas representam o conjunto original de bairros.

Os 14 tipos de modelos de oportunidades apresentados na Tabela 6.5 foram estimados pela formulação simples da probabilidade com a minimização do erro quadrático. Entre os procedimentos testados, este foi o processo que rendeu o melhor resultado.

Na Tabela 6.6 são apresentados os resultados das estatísticas dos modelos de oportunidades intervenientes: índice de dissimilaridade (coluna 4), diferença quadrática média (coluna 5) e diferença média ( global - coluna 6 e para pares OD com valores acima de 30 viagens).

Na Tabela 6.7 são apresentados os resultados dos modelos pela diferença média relativa (Equação 87) para diversas faixas de viagens. Nas Tabela 6.8 a 6.10 são apresentados os resultados do modelo de regressão linear múltiplo aplicado ao Modelo 3-B para o Bairro Central para analisar a significância estatística das variáveis do modelo de oportunidades intervenientes (acessibilidade, oportunidades intervenientes e oportunidades acumuladas).

Em função da possível quantidade de modelos de regressão que podem ser obtida pela combinação dos tipos de modelos de oportunidades (14) pelo número de bairros em cada modelo de oportunidade (75), e dada a forte correlação dos resultados destes modelos de regressão linear, optou-se em apresentar no texto apenas o resultado do Modelo 3-B para o Bairro Central para análise da significância das variáveis.

Ressalta-se que a regressão linear múltipla foi aplicada no trabalho para fins complementares. 0 objetivo principal da sua aplicação é associar inferência estatística às variáveis do modelo de oportunidades intervenientes, especialmente mensurar a significância da acessibilidade. 
Tabela 6.6 - Resultados dos modelos de oportunidades intervenientes.

\begin{tabular}{|c|c|c|c|c|c|c|}
\hline Modelo (1) & Oportunidade (2) & $\begin{array}{c}\text { Medida de } \\
\text { Acessibilidade (3) }\end{array}$ & $\begin{array}{c}\text { Índice de } \\
\text { Dissimilaridade (\%) } \\
\text { (4) }\end{array}$ & $\begin{array}{c}\text { Diferença } \\
\text { Quadrática Média (5) }\end{array}$ & $\begin{array}{l}\text { Diferença Relativa } \\
\text { Global (\%) (6) }\end{array}$ & $\begin{array}{c}\text { Média Diferenças (\%) } \\
\text { Viagens >=30 (7) }\end{array}$ \\
\hline $1-\mathrm{A}$ & Formal + Informal & \multirow{2}{*}{ Distância Euclidiana } & 18,34 & 6,17 & $36,68 \%$ & $35,85 \%$ \\
\hline $1-B$ & Formal & & 16,99 & 5,44 & $33,98 \%$ & $34,32 \%$ \\
\hline $2-A$ & Formal + Informal & \multirow{2}{*}{ Distância Rede Viária } & 16,53 & 4,59 & $33,06 \%$ & $30,63 \%$ \\
\hline 2-B & Formal & & 16,46 & 5,20 & $32,93 \%$ & $34,02 \%$ \\
\hline $3-A$ & Formal + Informal & \multirow{2}{*}{ Tempo Médio (1) } & 17,92 & 6,04 & $35,84 \%$ & $34,59 \%$ \\
\hline 3-B & Formal & & 16,26 & 4,63 & $32,53 \%$ & $31,43 \%$ \\
\hline $4-\mathrm{A}$ & Formal + Informal & \multirow{2}{*}{$\begin{array}{l}\text { Tempo Médio (2): } \\
\text { Modo Disponível(a) }\end{array}$} & 16,77 & 4,80 & $33,53 \%$ & $30,52 \%$ \\
\hline 4-B & Formal & & 16,32 & 4,66 & $32,64 \%$ & $31,61 \%$ \\
\hline $5-A$ & Formal + Informal & \multirow{2}{*}{$\begin{array}{l}\text { Tempo Médio (3): } \\
\text { Modo Disponível(b) }\end{array}$} & 16,60 & 4,68 & $33,20 \%$ & $30,11 \%$ \\
\hline $5-B$ & Formal & & 16,15 & 4,56 & $32,31 \%$ & $31,13 \%$ \\
\hline $6-A$ & Formal + Informal & \multirow{2}{*}{$\begin{array}{c}\text { Tempo Médio (4): } \\
\text { Modo x Probabilidade } \\
\text { do Modo }\end{array}$} & 16,27 & 4,67 & $32,55 \%$ & $30,37 \%$ \\
\hline $6-B$ & Formal & & 15,85 & 4,53 & $31,70 \%$ & $31,08 \%$ \\
\hline 7-A & Formal + Informal & \multirow{2}{*}{$\begin{array}{l}\text { Tempo Modo } \\
\text { Utilizado }\end{array}$} & 17,45 & 5,67 & $34,90 \%$ & $33,42 \%$ \\
\hline 7-B & Formal & & 16,41 & 5,03 & $32,82 \%$ & $33,07 \%$ \\
\hline
\end{tabular}




\section{Capítulo 6 - Resultados e Discussão}

Tabela 6.7 - Resultados dos modelos de oportunidades intervenientes por frequência de viagens observadas.

\begin{tabular}{|c|c|c|c|c|c|c|c|c|c|c|c|c|c|c|c|c|}
\hline \multirow{2}{*}{$\begin{array}{c}\text { Observado } \\
\text { (1) }\end{array}$} & \multicolumn{2}{|c|}{$\begin{array}{c}\text { Frequência } \\
\text { Pares O-D (2) }\end{array}$} & \multicolumn{14}{|c|}{ Diferença Relativa por Faixa de Viagens (3) } \\
\hline & Quant. & $\%$ & 1-A & 1-B & 2-A & 2-B & $3-\mathrm{A}$ & $3-B$ & 4-A & 4-B & $5-A$ & $5-B$ & 6-A & 6-B & 7-A & 7-B \\
\hline 0 & 100 & $44,44 \%$ & - & - & - & - & - & - & - & - & - & - & - & - & - & - \\
\hline 1 & 29 & $12,89 \%$ & $146,69 \%$ & $96,17 \%$ & $143,41 \%$ & $92,05 \%$ & $146,16 \%$ & $94,39 \%$ & $146,24 \%$ & $94,64 \%$ & $145,53 \%$ & $94,12 \%$ & $141,78 \%$ & $94,95 \%$ & $136,35 \%$ & $102,11 \%$ \\
\hline 2 & 17 & $7,56 \%$ & $103,97 \%$ & $105,56 \%$ & $101,35 \%$ & $100,83 \%$ & $101,45 \%$ & $103,94 \%$ & $102,90 \%$ & $103,88 \%$ & $103,79 \%$ & $104,87 \%$ & $89,04 \%$ & $89,13 \%$ & $82,70 \%$ & $95,63 \%$ \\
\hline 3 & 5 & $2,22 \%$ & $75,55 \%$ & $82,66 \%$ & $92,24 \%$ & $81,39 \%$ & $72,27 \%$ & $91,66 \%$ & $91,08 \%$ & $91,85 \%$ & $89,77 \%$ & $91,06 \%$ & $88,66 \%$ & $86,02 \%$ & $71,97 \%$ & $69,71 \%$ \\
\hline 4 & 7 & $3,11 \%$ & $106,69 \%$ & $94,79 \%$ & $94,11 \%$ & $95,95 \%$ & $107,88 \%$ & $88,17 \%$ & $94,89 \%$ & $87,93 \%$ & $95,05 \%$ & $87,58 \%$ & $102,99 \%$ & $95,33 \%$ & $114,63 \%$ & $107,50 \%$ \\
\hline 5 & 6 & $2,67 \%$ & $87,78 \%$ & $79,42 \%$ & $77,75 \%$ & $81,64 \%$ & $87,77 \%$ & $73,22 \%$ & $78,89 \%$ & $73,74 \%$ & $77,27 \%$ & $73,32 \%$ & $76,50 \%$ & $73,40 \%$ & $84,79 \%$ & $86,61 \%$ \\
\hline $5-10$ & 18 & $8,00 \%$ & $55,72 \%$ & $55,04 \%$ & $55,10 \%$ & $54,95 \%$ & $55,26 \%$ & $55,11 \%$ & $54,49 \%$ & $55,30 \%$ & $54,21 \%$ & $54,83 \%$ & $51,91 \%$ & $52,21 \%$ & $53,00 \%$ & $54,34 \%$ \\
\hline $10-20$ & 19 & $8,44 \%$ & $51,24 \%$ & $49,76 \%$ & $51,08 \%$ & $47,94 \%$ & $51,15 \%$ & $52,25 \%$ & $52,97 \%$ & $52,34 \%$ & $52,18 \%$ & $51,87 \%$ & $46,64 \%$ & $47,05 \%$ & $43,03 \%$ & $46,48 \%$ \\
\hline $20-30$ & 7 & $3,11 \%$ & $63,10 \%$ & $61,69 \%$ & $56,26 \%$ & $61,29 \%$ & $62,31 \%$ & $55,72 \%$ & $56,16 \%$ & $55,99 \%$ & $55,26 \%$ & $55,08 \%$ & $53,83 \%$ & $52,68 \%$ & $58,78 \%$ & $55,60 \%$ \\
\hline $30-50$ & 8 & $3,56 \%$ & $39,62 \%$ & $41,85 \%$ & $44,00 \%$ & $44,25 \%$ & $41,97 \%$ & $43,53 \%$ & $42,73 \%$ & $43,78 \%$ & $42,26 \%$ & $43,42 \%$ & $43,15 \%$ & $44,36 \%$ & $39,08 \%$ & $40,53 \%$ \\
\hline$>50$ & 9 & $4,00 \%$ & $16,91 \%$ & $13,37 \%$ & $9,35 \%$ & $11,55 \%$ & $16,28 \%$ & $8,96 \%$ & $10,01 \%$ & $9,05 \%$ & $9,87 \%$ & $8,69 \%$ & $10,72 \%$ & $8,86 \%$ & $18,03 \%$ & $13,23 \%$ \\
\hline
\end{tabular}

(1) Quantidade de viagens observadas nas células da matriz O-D;

(2) Frequência de células na matriz O-D segunda a quantidade de viagens observadas

(3) valores da diferença relativa, dado pela Equação 87.

Exemplo: na sexta linha da tabela, para uma quantidade de 5 viagens foram observadas 6 células na matriz 0-D de um total de 225 células (2,67\%), e pelo processo de estimação do modelo $3-\mathrm{B}$, foi observado para esta faixa de viagens, uma diferença relativa (observado-estimado/observado) de $73,22 \%$. 
Tabela 6.8 - Estatísticas do modelo de escolha de destino.

\begin{tabular}{cc}
\hline Estatística de regressão & Valor \\
R múltiplo & 0,99 \\
R-Quadrado & 0,99 \\
R-quadrado ajustado & 0,99 \\
Erro padrão & 0,01 \\
Observações & 2.10 \\
\hline
\end{tabular}

Tabela 6.9 - Análise de variância - ANOVA.

\begin{tabular}{ccccc}
\hline & gl & SQ & MQ & F \\
\hline Regressão & 3 & 82,59 & 27,53 & 336084,81 \\
Resíduo & 2.144 & 0,18 & $\cong 0$ & \\
Total & 2.098 & 82,78 & & \\
\hline
\end{tabular}

gl -grau de liberdade para a distribuição $\mathrm{F}$.

$\mathrm{SQ}$ - soma dos quadrados dos desvios.

$M Q$ - média dos quadrados dos desvios.

Tabela 6.10- Parâmetros do modelo de regressão linear.

\begin{tabular}{ccccc}
\hline & Coeficientes & Erro padrão & Estatística $t$ & valor-P \\
\hline $\begin{array}{c}\text { Acessibilidade } \\
\text { (horas) }\end{array}$ & $-0,0066$ & 0.0011 & $-5,9122$ & $\cong 0$ \\
$\begin{array}{c}\text { Oportunidade In- } \\
\text { terveniente } \\
\begin{array}{c}\text { Oportunidade Acu- } \\
\text { mulada }\end{array}\end{array}$ & $-2,49136 \mathrm{E}-05$ & $\cong 0$ & $-613,6664$ & 0 \\
\hline
\end{tabular}

\subsubsection{Modelo de Oportunidades Intervenientes: Discussão dos Resultados}

As características do modelo de oportunidades intervenientes que levaram a sua escolha para simulação do comportamento individual relacionada à escolha do local da atividade primária foram descritas em detalhe no Capítulo 4. Há, entretanto, algumas peculiaridades do modelo de oportunidades com implicação nos resultados obtidos pela estimação da demanda que merecem atenção.

O modelo é insensível quanto à magnitude da desutilidade entre ordens de oportunidades. Se uma zona “n” qualquer é percebida pelo indivíduo em primeira ordem e uma 
zona " $n+1$ " é colocada em segunda ordem pelo mesmo indivíduo, a separação espacial entre a zona " $n$ " e “ $n+1$ " é indiferente ao modelo (por exemplo, se as diferenças entre o tempo médio das zonas " $n$ " e " $n+1$ " é de 5 minutos ou 50 minutos é indiferente), o que governa os processos de alocação é a posição relativa entre as zonas (definidos pela acessibilidade) e os valores das oportunidades.

Esta característica pode ter efeito irrelevante em cidades de pequeno e médio porte, por exemplo, Uberlândia, em que as dimensões dos bairros têm área média de 1,78 km² (raio estimado em 751 metros). Entretanto em regiões metropolitanas, este efeito é relevante. Alternativas para esta característica do modelo de oportunidades são apresentadas no Capítulo 7.

Outra peculiaridade do modelo é a ausência de equilíbrio para as viagens atraídas, ou seja, a condição de restrição no destino não é atendida o que ocasiona uma subestimação ou superestimação da atração das viagens nas zonas. 0 modelo satisfaz apenas a condição que o total de viagens alocadas seja igual ao total de viagens produzidas.

Contudo, esta característica não sugere uma desvantagem da aplicação do modelo de oportunidades. Se o total de viagens atraídas for igual ao número de oportunidades, a igualdade entre atração e produção é respeitada. Alternativas sobre esta característica são discutidas no Capítulo 7.

Em relação ao parâmetro lambda, Equação 57, o seu valor pode ser interpretado como a probabilidade de eventos independentes: (i) a probabilidade que os indivíduos entre os diversos extratos socioeconômicos aceitem uma vaga de emprego numa zona qualquer, e; (ii) a probabilidade do indivíduo ser aceito no emprego na zona considerada, incluindo a competição pela oportunidade e a decisão do empregador.

É esperado que diferentes tipos de pessoas tenham acesso a diferentes tipos de oportunidades de emprego, que apresentam distribuições espaciais distintas. Há, portanto, para distintos segmentos de pessoas, diferentes conjuntos de probabilidades. Na notação utilizada no modelo de oportunidades intervenientes é como ter diferentes valores de lambda para cada combinação de tipo de pessoa versus tipo de oportunidade.

Esta análise adicionaria uma complexidade ao modelo que o tornaria inviável de aplicação ao estudo de caso na cidade de Uberlândia, em função da amostra de dados disponível (quantidade e diversidade das informações). 
Entretanto, o valor de lambda obtido no modelo é interpretado como uma probabilidade média da população amostrada sobre percepção das oportunidades, competição e a chance de garantir a vaga.

Sob esta ótica, é plausível que o modelo possa produzir estimativas de probabilidades sobre escolhas individuais dos locais para desempenho da atividade primária coerentes com a realidade observada na população amostrada. Espera-se que as probabilidades individuais quando agregadas produzirão matrizes de deslocamentos que refletirão o estado médio da população em relação às escolhas da atividade primária.

Além do mais, em elaboração de cenários para previsões futuras, é mais difícil prever valores de variáveis explanatórias segregadas para diferentes tipos de pessoas, do que médias das variáveis exploratórias na população. Para este aspecto, um modelo calibrado a partir de valores médios da população é uma vantagem.

Outra característica do modelo de oportunidades é que ele sempre alocará indivíduos às localidades que possuam oportunidades, independentemente destas oportunidades serem ou não do interesse do indivíduo. Esta característica induz a desvios no processo de alocação.

Para esta situação em particular, a conceituação de oportunidades intervenientes poderia se valer dos princípios das restrições de espaço-tempo. A rigor, só devem ser consideras oportunidades aquelas que estiverem incluídas nos prismas espaço-tempo dos indivíduos. Porém, pode-se esperar que para uma cidade do porte de Uberlândia haja uma razoável cobertura espacial dos prismas, incluindo a maior parte das oportunidades de trabalho na região.

O modelo assume competição entre destinos, independentemente do grau das necessidades serem preenchidas nas zonas, as zonas competitivas sempre exercerão poder de atração nos indivíduos. A tendência é que a alocação intra-zona seja subestimada e a inter-zonas superestimada.

Atendo-se à discussão aos resultados apresentados na Tabela 6.10, os coeficientes estimados para as variáveis de acessibilidade, oportunidades intervenientes e oportunidades acumuladas são em sinal esperado: quanto maior o tempo médio de acesso à zona onde se encontra a oportunidade, menor é a propensão para a sua escolha; quanto maior o valor de oportunidades intervenientes, menor é a propensão da zona onde se encontra a oportunidade, e; quanto maior o número de oportunidades que o individuo acumula, maior é a propensão da zona onde se encontra a oportunidade. 
Ainda em relação aos valores obtidos na regressão linear, os coeficientes estimados são significativos para o nível de $5 \%$. Estes resultados implicam não ser possível refutar a hipótese nula de que a escolha do destino da atividade primária é influenciada pelas oportunidades e pela acessibilidade.

Analisando as estatísticas apresentadas na Tabela 6.6, observa-se que para as diferentes combinações de medidas de acessibilidade e forma de composição das oportunidades, os valores das estatísticas indicam que o modelo de oportunidades pode ser utilizado para representar o comportamento dos indivíduos da amostra de Uberlândia em relação à escolha dos destinos da atividade primária.

Colabora para esta afirmação, além das estatísticas de diferença relativa, o comparativo dos resultados dos índices de dissimilaridade com valores encontrados na literatura de trabalhos com aplicação do modelo de oportunidades intervenientes: Thomas (1977), 27,45\%; Gonçalves (1992), 19,23\%; Almeida (1999), 22,94\%, e; Akwawua e Pooler (2001) 31,28 a $34,70 \%$.

Pela Tabela 6.7 observa-se que à medida que aumenta o número de viagens entre os pares OD, a diferença relativa reduz significativamente para todas as medidas de acessibilidades testadas, indicando que há influência do número de viagens entre pares OD no resultado (os resultados são sensíveis quanto ao agrupamento).

O emprego formal apresenta melhor desempenho no modelo comparado à proposta de emprego formal mais informal. Entretanto, não há elementos suficientes para tecer conclusões a respeito da técnica empregada para reproduzir a informalidade do mercado e sua influência nos resultados do modelo de oportunidades.

As respostas individuais são sensíveis à alterações das medidas de acesso as oportunidades, ou seja, as diferentes medidas de acessibilidades produziram diferentes resultados nas estimativas das escolhas dos destinos.

As propostas que utilizaram o tempo de viagem para representar a acessibilidade possuem melhor desempenho do que medidas de separação espacial baseadas em distâncias geográficas. Entretanto, esta diferença não ultrapassou os 5 p.p. Uma possível explicação é que no modelo de estimação do tempo de viagem, os modos não motorizados (a pé e bicicleta) são diretamente proporcionais às distâncias, ou seja, refletem o mesmo comportamento de ordem das oportunidades comparado as distâncias. Os modos motorizados não deixam de ser proporcionais às distâncias, mas incluem características operacionais do sistema de transporte. 
Analisando as diversas medidas de tempo médio, os resultados obtidos com aplicação do modelo de oportunidades ${ }^{57}$ com a medida de acessibilidade baseada no tempo ponderado pela probabilidade do modo - tempo médio (4) - apresenta uma pequena vantagem de desempenho em relação aos demais modelos com formulações do tempo médio, por exemplo em relação ao tempo médio (1) o índice de dissimilaridade é 0, 41 p.p menor; diferença quadrática é 0,10 viagens menor, e; a diferença relativa é 0,83 p.p menor.

É importante ressaltar que a medida baseada no tempo ponderado pela probabilidade exige um aumento da complexidade em troca de um benefício ligeiramente melhor em comparação ao modelo obtido pelo tempo médio calculado pela média dos tempos de viagens entre os modos disponíveis no sistema de transportes. A lógica de comparação é semelhante ao tempo médio (3) - modo disponível (b).

Assim, a questão que emerge é se esta troca é compensatória. Acredita-se que a principal vantagem da manutenção do tempo médio (1) como medida de acessibilidade para a escolha do destino da atividade primária é baseado na simplicidade de seu cálculo em comparação às demais formulações que exigem um maior número de recursos para o seu cálculo e produzem resultados semelhantes aos obtidos com o tempo médio (1).

\subsubsection{Modelo de Escolha Discreta}

A hipótese de interferência testada no modelo de escolha discreta foi:

- A escolha do destino da atividade primária é influenciada pelas oportunidades e pela acessibilidade.

Para verificação desta hipótese cada variável independente incluída no modelo é submetida a um teste de estatístico para verificar se o parâmetro da variável é diferente de zero. Desta forma a hipótese nula a ser verificada é:

$$
\begin{aligned}
& H_{0}: B=0 \\
& H_{1}: B \neq 0
\end{aligned}
$$

Em que $B$ é o parâmetro da variável independente.

\footnotetext{
${ }^{57}$ Analisando apenas os modelos de oportunidades com emprego formal.
} 
Para o modelo de escolha discreta foram especificadas 75 funções de utilidade que representam as utilidades dos bairros, considerando a acessibilidade e as oportunidades como variáveis.

Optou-se em não haver distinção entre os bairros, assim os parâmetros de calibração da acessibilidade e das oportunidades foram considerados iguais para todas 75 funções de utilidade, sem a especificação de constantes para as alternativas (MCFADDEN, 1974). Várias formas para representação da função de acessibilidade foram verificadas e a que melhor de adequou na interação foi a função linear, conforme representado na Equação 96.

Ressalta-se que o objetivo principal da elaboração do modelo logit para escolha do destino é analisar o seu desempenho em comparação ao modelo de oportunidades para representação do comportamento individual relacionado às escolhas dos locais da atividade trabalho em Uberlândia.

Assim, foram consideradas na especificação da função de utilidade dos destinos apenas as variáveis de acessibilidade e oportunidades, um grau de simplificação semelhante ao modelo de oportunidades intervenientes. Recorda-se que nesta etapa de modelagem a situação de escolha é descrita apenas pelas oportunidades e as condições de acessos a elas (acessibilidade as oportunidades).

$$
U_{\text {bairro } j}=\beta_{\text {acessibilidade }} \cdot \delta_{\text {acessibilidade } i j}+\beta_{\text {oportunidade }} \cdot \delta_{\text {oportunidade } j}
$$

Em que:

- $U_{\text {bairro } j}$ é a função utilidade para o bairro j;

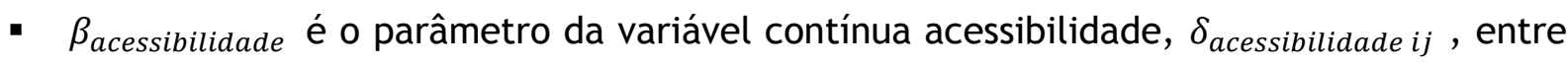
o domicilio (origem $i$ ) e o local da oportunidade (bairro $j$ );

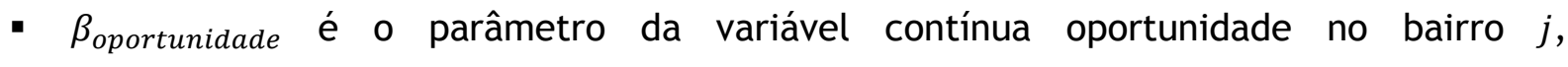
$\delta_{\text {oportunidade } j}$

Semelhante ao modelo de oportunidades foram consideradas quatro formulações de tempo médio de viagem para representar a acessibilidade: tempo médio (1); tempo médio (2) - modo disponível (a); tempo médio (3) - modo disponível (b), e; tempo médio (4). 
Adicionalmente, foram calibrados modelos de oportunidades considerando como medida de acessibilidade a distância euclidiana; distância rede viária; tempo modo utilizado, e; utilidade máxima para um conjunto de alternativas de transportes.

A utilidade máxima esperada foi adotada como medida de acessibilidade nesta etapa em função de sua aplicação em trabalhos divulgados na literatura sobre a investigação dos destinos das atividades utilizando modelos de escolha discreta.

Considerando as oito medidas de separação e as duas formas de representação das oportunidades (emprego formal e emprego formal mais informal) são produzidos 16 tipos de modelos de escolha discreta para análise, como descrito na Tabela 6.11, que foram desenvolvidos e calibrados.

Tabela 6.11 - Modelos logit provenientes da combinação das medidas de separação espacial e oportunidades.

\begin{tabular}{|c|c|c|}
\hline Modelo & Oportunidade & Medida de Acessibilidade \\
\hline $\begin{array}{l}1-A \\
1-B\end{array}$ & $\begin{array}{c}\text { Formal + Informal } \\
\text { Formal }\end{array}$ & Distância Euclidiana \\
\hline $\begin{array}{l}2-A \\
2-B\end{array}$ & $\begin{array}{c}\text { Formal }+ \text { Informal } \\
\text { Formal }\end{array}$ & Distância Rede Viária \\
\hline $\begin{array}{l}3-A \\
3-B\end{array}$ & $\begin{array}{c}\text { Formal }+ \text { Informal } \\
\text { Formal }\end{array}$ & Tempo Médio (1) \\
\hline $\begin{array}{l}4-A \\
4-B\end{array}$ & $\begin{array}{c}\text { Formal + Informal } \\
\text { Formal }\end{array}$ & $\begin{array}{l}\text { Tempo Médio (2) } \\
\text { Modo Disponível(a) }\end{array}$ \\
\hline $\begin{array}{l}5-A \\
5-B\end{array}$ & $\begin{array}{c}\text { Formal + Informal } \\
\text { Formal }\end{array}$ & $\begin{array}{l}\text { Tempo Médio (3) } \\
\text { Modo Disponível(b) }\end{array}$ \\
\hline $\begin{array}{l}6-A \\
6-B\end{array}$ & $\begin{array}{c}\text { Formal }+ \text { Informal } \\
\text { Formal }\end{array}$ & $\begin{array}{c}\text { Tempo Médio (4) } \\
\text { Modo x Probabilidade do Modo }\end{array}$ \\
\hline $\begin{array}{l}7-A \\
7-B\end{array}$ & $\begin{array}{c}\text { Formal + Informal } \\
\text { Formal }\end{array}$ & Tempo Modo Utilizado \\
\hline $\begin{array}{l}8-A \\
8-B\end{array}$ & $\begin{array}{c}\text { Formal }+ \text { Informal } \\
\text { Formal }\end{array}$ & Utilidade Máxima Esperada \\
\hline
\end{tabular}

Na Tabela 6.12 são apresentadas as medidas de desempenho do modelo logit multinomial estimado para o cálculo das probabilidades individuais para escolha do destino da atividade primária que são comuns aos 16 modelos calibrados e na Tabela 6.12 são apre- 
sentadas as medidas de desempenho distintas dos modelos, juntamente com os valores dos parâmetros das funções de utilidade e suas estatísticas de significância.

Tabela 6.12 - Estatísticas do modelo de escolha de destino da atividade primária.

\begin{tabular}{cc}
\hline Estatística do Modelo & Valor \\
\hline Parâmetros estimados & 2 \\
Observações & 2.101 \\
$L L\left(\beta^{\prime}=0\right)$ & $-9.071,04$ \\
\hline
\end{tabular}

Na Tabela 6.13 são apresentados os resultados das estatísticas dos modelos de escoIha discreta: índice de dissimilaridade (coluna 4), diferença quadrática média (coluna 5) e diferença média ( global - coluna 6 e para pares OD com valores acima de 30 viagens). 
Tabela 6.13 - Estatísticas e estimativa do modelo de escolha de destino da atividade primária.

\begin{tabular}{|c|c|c|c|c|c|c|}
\hline Modelo & $\boldsymbol{L} \boldsymbol{L}\left(\boldsymbol{\beta}^{\prime}=\widehat{\boldsymbol{\beta}}\right)$ & $\rho$ & $\begin{array}{l}\text { Parâmetro da } \\
\text { acessibilidade }\end{array}$ & Estatística $t$ & $\begin{array}{l}\text { Parâmetro das } \\
\text { oportunidades }\end{array}$ & Estatística $t$ \\
\hline $1-A$ & $-7.230,697$ & 0,203 & $-0,318$ & $(-29,61)$ & 0,000111 & $(53,60)$ \\
\hline $1-B$ & $-7.229,485$ & 0,203 & $-0,312$ & $(-29,03)$ & 0,000193 & $(53,75)$ \\
\hline $2-A$ & $-7.198,373$ & 0,206 & $-0,282$ & $(-30,66)$ & 0,00011 & $(53,04)$ \\
\hline 2-B & $-7.198,327$ & 0,206 & $-0,277$ & $(-30,07)$ & 0,000192 & $(53,16)$ \\
\hline $3-A$ & $-7.174,685$ & 0,209 & $-2,320$ & $(-31,65)$ & 0,000108 & $(52,01)$ \\
\hline 3-B & $-7.171,308$ & 0,209 & $-2,290$ & $(-31,16)$ & 0,000189 & $(52,18)$ \\
\hline $4-A$ & $-7.164,344$ & 0,210 & $-1,830$ & $(-31,96)$ & 0,000108 & $(51,76)$ \\
\hline 4-B & $-7.159,801$ & 0,210 & $-1,810$ & $(-31,51)$ & 0,000188 & $(51,96)$ \\
\hline $5-A$ & $-7.264,587$ & 0,199 & $-5,170$ & $(-29,20)$ & 0,000113 & $(54,55)$ \\
\hline $5-B$ & $-7.258,909$ & 0,200 & $-5,090$ & $(-28,68)$ & 0,000198 & $(54,83)$ \\
\hline $6-A$ & $-7.129,421$ & 0,214 & $-4,010$ & $(-34,72)$ & 0,000105 & $(50,58)$ \\
\hline $6-B$ & $-7.119,817$ & 0,215 & $-3,990$ & $(-34,42)$ & 0,000184 & $(50,92)$ \\
\hline 7-A & $7.298,796$ & 0,195 & $-3,330$ & $(-28,51)$ & 0,000107 & $(51,55)$ \\
\hline 7-B & $-7.284,840$ & 0,197 & $-3,310$ & $(-28,27)$ & 0,000188 & $(52,02)$ \\
\hline $8-A$ & $-7.182,786$ & 0,208 & 3,130 & $(33,40)$ & 0,000112 & $(53,61)$ \\
\hline 8-B & $-7.177,268$ & 0,209 & 3,080 & $(32,87)$ & 0,000195 & $(53,84)$ \\
\hline
\end{tabular}


Tabela 6.14 - Resultados dos modelos de escolha discreta.

\begin{tabular}{|c|c|c|c|c|c|c|}
\hline Modelo (1) & Oportunidade (2) & $\begin{array}{c}\text { Medida de } \\
\text { Acessibilidade (3) }\end{array}$ & $\begin{array}{c}\text { Índice de } \\
\text { Dissimilaridade (\%) } \\
\text { (4) }\end{array}$ & $\begin{array}{c}\text { Diferença } \\
\text { Quadrática Média (5) }\end{array}$ & $\begin{array}{l}\text { Diferença Relativa } \\
\text { Global (\%) (6) }\end{array}$ & $\begin{array}{c}\text { Média Diferenças (\%) } \\
\text { Viagens }>=30(7)\end{array}$ \\
\hline $1-\mathrm{A}$ & Formal + Informal & \multirow{2}{*}{ Distância Euclidiana } & 25,24 & 14,32 & $50,47 \%$ & $38,70 \%$ \\
\hline 1-B & Formal & & 25,61 & 15,75 & $51,22 \%$ & $41,53 \%$ \\
\hline $2-A$ & Formal + Informal & \multirow{2}{*}{ Distância Rede Viária } & 24,47 & 13,80 & $48,94 \%$ & $38,61 \%$ \\
\hline 2-B & Formal & & 24,90 & 15,38 & $49,80 \%$ & $41,38 \%$ \\
\hline $3-A$ & Formal + Informal & \multirow{2}{*}{ Tempo Médio (1) } & 23,81 & 12,86 & $47,62 \%$ & $37,53 \%$ \\
\hline $3-B$ & Formal & & 24,33 & 14,30 & $48,65 \%$ & $40,48 \%$ \\
\hline $4-A$ & Formal + Informal & \multirow{2}{*}{$\begin{array}{l}\text { Tempo Médio (2): } \\
\text { Modo Disponível(a) }\end{array}$} & 23,79 & 12,51 & $47,57 \%$ & $37,17 \%$ \\
\hline 4-B & Formal & & 24,33 & 13,93 & $48,66 \%$ & $40,20 \%$ \\
\hline $5-A$ & Formal + Informal & \multirow{2}{*}{$\begin{array}{l}\text { Tempo Médio (3): } \\
\text { Modo Disponível(b) }\end{array}$} & 25,59 & 14,52 & $51,18 \%$ & $38,80 \%$ \\
\hline $5-B$ & Formal & & 25,79 & 15,58 & $51,59 \%$ & $42,04 \%$ \\
\hline 6-A & Formal + Informal & \multirow{2}{*}{$\begin{array}{c}\text { Tempo Médio (4): } \\
\text { Modo x Probabilidade } \\
\text { do Modo }\end{array}$} & 22,91 & 11,50 & $45,82 \%$ & $36,69 \%$ \\
\hline $6-B$ & Formal & & 23,13 & 12,70 & $46,25 \%$ & $39,64 \%$ \\
\hline 7-A & Formal + Informal & \multirow{2}{*}{$\begin{array}{l}\text { Tempo Modo } \\
\text { Utilizado }\end{array}$} & 24,55 & 13,18 & $49,09 \%$ & $36,83 \%$ \\
\hline 7-B & Formal & & 24,67 & 13,98 & $49,33 \%$ & $39,57 \%$ \\
\hline $8-A$ & Formal + Informal & \multirow{2}{*}{$\begin{array}{l}\text { Utilidade Máxima } \\
\text { Esperada }\end{array}$} & 24,36 & 13,13 & $48,72 \%$ & $37,67 \%$ \\
\hline 8-B & Formal & & 24,91 & 14,60 & $49,81 \%$ & $41,02 \%$ \\
\hline
\end{tabular}


Tabela 6.15 - Resultados dos modelos de escolha discreta por frequência de viagens observadas.

\begin{tabular}{|c|c|c|c|c|c|c|c|c|c|c|c|c|c|c|c|c|}
\hline \multirow{2}{*}{$\begin{array}{c}\text { Observado } \\
\text { (1) }\end{array}$} & \multicolumn{2}{|c|}{$\begin{array}{l}\text { Frequência } \\
\text { Pares O-D (2) }\end{array}$} & \multicolumn{14}{|c|}{ Diferença Relativa por Faixa de Viagens (3) } \\
\hline & Quant. & $\%$ & $1-A$ & 1-B & $2-A$ & $2-B$ & $3-A$ & $3-B$ & $4-A$ & 4-B & $5-A$ & $5-B$ & $6-A$ & 6-B & $7-A$ & 7-B \\
\hline 0 & 100 & $44,44 \%$ & - & - & 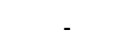 & - & - & - & - & - & - & - & - & - & - & - \\
\hline 1 & 29 & $12,89 \%$ & $213,42 \%$ & $194,84 \%$ & $196,21 \%$ & $177,53 \%$ & $195,39 \%$ & $176,70 \%$ & $195,39 \%$ & $176,70 \%$ & $218,79 \%$ & $194,99 \%$ & $185,47 \%$ & $165,41 \%$ & $202,54 \%$ & $181,92 \%$ \\
\hline 2 & 17 & $7,56 \%$ & $88,24 \%$ & $90,06 \%$ & $83,56 \%$ & $85,42 \%$ & $83,44 \%$ & $84,79 \%$ & $83,44 \%$ & $84,79 \%$ & $73,31 \%$ & $71,86 \%$ & $78,59 \%$ & $77,71 \%$ & $82,76 \%$ & $81,45 \%$ \\
\hline 3 & 5 & $2,22 \%$ & $144,34 \%$ & $148,84 \%$ & $137,59 \%$ & $141,27 \%$ & $139,58 \%$ & $142,32 \%$ & $139,58 \%$ & $142,32 \%$ & $128,51 \%$ & $130,77 \%$ & $134,13 \%$ & $135,12 \%$ & $124,30 \%$ & $128,71 \%$ \\
\hline 4 & 7 & $3,11 \%$ & $86,82 \%$ & $74,46 \%$ & $85,14 \%$ & $74,18 \%$ & $88,22 \%$ & $75,41 \%$ & $88,22 \%$ & $75,41 \%$ & $95,31 \%$ & $81,92 \%$ & $95,00 \%$ & $82,95 \%$ & $92,99 \%$ & $78,11 \%$ \\
\hline 5 & 6 & $2,67 \%$ & $71,61 \%$ & $70,48 \%$ & $63,97 \%$ & $62,85 \%$ & $67,71 \%$ & $66,36 \%$ & $67,71 \%$ & $66,36 \%$ & $62,01 \%$ & $61,98 \%$ & $58,94 \%$ & $58,28 \%$ & $53,57 \%$ & $53,60 \%$ \\
\hline $5-10$ & 18 & $8,00 \%$ & $39,74 \%$ & $38,27 \%$ & $37,19 \%$ & $36,16 \%$ & $36,89 \%$ & $36,00 \%$ & $36,89 \%$ & $36,00 \%$ & $50,84 \%$ & $48,76 \%$ & $37,65 \%$ & $35,28 \%$ & $41,64 \%$ & $39,04 \%$ \\
\hline $10-20$ & 19 & $8,44 \%$ & $70,84 \%$ & $65,51 \%$ & $68,05 \%$ & $63,37 \%$ & $63,35 \%$ & $58,84 \%$ & $63,35 \%$ & $58,84 \%$ & $71,71 \%$ & $66,25 \%$ & $57,42 \%$ & $52,19 \%$ & $64,40 \%$ & $60,45 \%$ \\
\hline $20-30$ & 7 & $3,11 \%$ & $52,58 \%$ & $54,21 \%$ & $52,97 \%$ & $54,59 \%$ & $53,37 \%$ & $54,93 \%$ & $53,37 \%$ & $54,93 \%$ & $55,42 \%$ & $56,55 \%$ & $49,85 \%$ & $51,62 \%$ & $55,47 \%$ & $56,52 \%$ \\
\hline $30-50$ & 8 & $3,56 \%$ & $41,99 \%$ & $51,65 \%$ & $46,52 \%$ & $52,05 \%$ & $44,37 \%$ & $49,78 \%$ & $44,37 \%$ & $49,78 \%$ & $50,88 \%$ & $57,00 \%$ & $44,35 \%$ & $49,40 \%$ & $43,48 \%$ & $49,28 \%$ \\
\hline$>50$ & 9 & $4,00 \%$ & $33,93 \%$ & $35,39 \%$ & $33,37 \%$ & $34,86 \%$ & $33,04 \%$ & $35,01 \%$ & $33,04 \%$ & $35,01 \%$ & $32,37 \%$ & $33,24 \%$ & $32,30 \%$ & $33,22 \%$ & $33,42 \%$ & $35,05 \%$ \\
\hline
\end{tabular}

(1) Quantidade de viagens observadas nas células da matriz O-D;

(2) Frequência de células na matriz O-D segunda a quantidade de viagens observadas

(3) valores da diferença relativa, dado pela Equação 87

Exemplo: na sexta linha da tabela, para uma quantidade de 5 viagens foram observadas 6 células na matriz 0-D de um total de 225 células (2,67\%), e pelo processo de estimação do modelo $3-B$, foi observado para esta faixa de viagens, uma diferença relativa (observado-estimado/observado) de $66,36 \%$. 


\subsubsection{Modelo de Escolha Discreta: Discussão dos Resultados}

Com relação ao modelo de escolha discreta para seleção do local da atividade primária, foram estimados 2 parâmetros associados às variáveis independentes que são em sinal esperado e significantes para o nível de 5\%: quanto maior o número de oportunidades na zona maior é propensão do indivíduo se deslocar para esta zona, e; quanto maior é a dificuldade de acesso às oportunidades (por exemplo, tempo médio elevado), menor é a propensão do individuo para se deslocar para esta zona.

O emprego formal mais o informal apresenta melhor desempenho no modelo comparado à proposta de emprego formal. Apesar do modelo 6-B com a proposta de emprego formal ter obtido melhor desempenho (menor logaritmo da função verossimilhança), comparando os resultados observados com os valores estimados pelo modelo a proposta de emprego formal mais informal possui melhores estatísticas.

As respostas individuais são sensíveis a alterações das medidas de acesso às oportunidades, ou seja, as diferentes medidas de acessibilidades produziram diferentes resultados nas estimativas das escolhas dos destinos.

As propostas que utilizaram o tempo de viagem para representar a acessibilidade possuem melhor desempenho do que medidas de separação espacial baseadas em distâncias geográficas. 0 resultado do modelo baseado na medida de acessibilidade representada pela utilidade máxima esperada foi semelhante aos modelos que empregaram o tempo médio.

Em termos de valores médios da amostra as medidas de acessibilidade baseadas no tempo produzem um maior valor de desutilidade na escolha do local da atividade do que as medidas de separação espacial, por exemplo:

- Distância euclidiana: 5,66 km, valor da utilidade de -1,77;

- Distância pela rede viária: 6,88 km, valor da utilidade de +1,91.

- Tempo médio (1): 0,93 horas, valor da utilidade de -2,12;

- Tempo médio (4): 0,67 horas, valor da utilidade de -2,67. 
Analisando as diversas medidas de tempo médio, os resultados obtidos com aplicação do modelo ${ }^{58}$ com a medida de acessibilidade baseada no tempo ponderado pela probabilidade do modo - tempo médio (4) - apresenta uma pequena vantagem de desempenho em relação aos demais modelos com formulações do tempo médio, por exemplo, em relação ao tempo médio (1): logaritmo da função verossimilhança é 51,49 pontos maior; as significâncias das variáveis maiores; o índice de dissimilaridade é 1,20 p.p menor; diferença quadrática é 1,60 viagens menor, e; a diferença relativa é 2,40 p.p menor.

Pela Tabela 6.14 observa-se que a medida que aumenta o número de viagens entre os pares OD, a diferença relativa reduz significativamente para todas as medidas de acessibilidades testadas, indicando que há influência do número de viagens entre pares OD no resultado (os resultados são sensíveis quanto ao agrupamento).

\subsubsection{Comparação entre o Modelo de Oportunidades e do Modelo de Escolha Discreta}

Comparando os resultados das Tabelas 6.6 e 6.7 com os resultados das Tabelas 6.14 e 6.15 observa-se um melhor desempenho do modelo de oportunidades do que o modelo de escolha discreta.

A aplicação das duas abordagens para modelagem do comportamento individual em relação a seleção do destino da atividade primária foi motivada pela ausência de elementos teóricos que justificasse a aplicação de uma das abordagens selecionadas, e pelos ensaios realizados e através das estatísticas de desempenho de ambos os modelos, pode-se afirmar que não há elementos que confirmem que o indivíduo é o único responsável pela escolha da oportunidade (que ele tem pleno conhecimento das oportunidades disponíveis e que a competição pelas oportunidades não afeta a sua escolha), como estabelece a premissa do modelo baseado na maximização da utilidade.

Para o estudo de caso realizado em Uberlândia o modelo de oportunidades intervenientes demonstrou ser o mais apropriado, não havendo elementos para refutar a afirmativa de que os indivíduos não possuem total conhecimento de todos os locais de oportunidades, que não são os únicos responsáveis pela escolha do local de trabalho e que a escolha do local de trabalho passa a ser uma seleção compartilhada pelo desejo do indivíduo pela oportunidade, pela competição e pelo empregador escolher o trabalhador.

Entretanto, ressalta-se que a comparação foi realizada para uma situação particular de escolha, descrita por variáveis que são comuns a ambos os modelos: acessibilidade às

\footnotetext{
${ }^{58}$ Analisando apenas os modelos de oportunidades com emprego formal mais informal.
} 
oportunidades e oportunidades. Para outras especificações da função de utilidade dos destinos (um maior número de variáveis), os resultados podem ser diferentes. Os resultados podem ser também diferentes para outras aplicações de modelos baseados na maximização da utilidade, como demonstrado por Bekhor e Prashker (2008). No Capítulo 7 é retomada esta discussão.

\subsection{Padrão de Viagens: Especificação do Modelo e Resultados}

Esta seção descreve os resultados da segmentação da demanda com a aplicação dos modelos logit e modelos baseados em regras (Tabela 6.16) para entendimento das relações entre o conjunto de informações formado por características socioeconômicas dos indivíduos e dos domicílios (Tabela 4.3), participação em atividades (Tabela 4.4) e características do sistema de transportes (Tabela 4.5) nas escolhas dos padrões de viagens para as quatro categorias apresentados na Tabela 4.6: (1) "HWH"; (2) "H+W+H"; (3) "HWHWH", e; (4) $" \mathrm{H}+\mathrm{W}+\mathrm{H}+\mathrm{W}+\mathrm{H} "$.

São verificadas a significância das variáveis e as relações de dependência entre as variáveis, principalmente a significância e a interação da acessibilidade com outras variáveis.

Tabela 6.16 - Descrição dos modelos aplicados na segmentação da demanda.

\begin{tabular}{ccc}
\hline Modelo & Amostra & $\begin{array}{c}\text { Técnica de } \\
\text { Modelagem }\end{array}$ \\
\hline 1-FULL & Todos os indivíduos & LOGIT \\
2-N-L & $\begin{array}{c}\text { Modo não motorizado } \\
\text { (modos a pé e bicicleta) }\end{array}$ & LOGIT \\
2-N-A & Árvore de Decisão \\
$3-\mathrm{C}-\mathrm{L}$ & Modo coletivo \\
(modo ônibus) & LOGIT \\
3-C-A & Árvore de Decisão \\
$4-\mathrm{P}-\mathrm{L}-\mathrm{A}$ & Modo privado & Árvore de Decisão
\end{tabular}

“FULL" - todos os indivíduos da amostra; "N" - modo não motorizado; "C" - modo coletivo; "P" - modo individual motorizado; "RB"- renda baixa; "RM" - renda média; “RA" - renda alta; "EC" - etapa curta de viagem; “EL" - etapa longa de viagem; “L” - LOGIT; “A”- Árvore de Decisão. 
Para facilitar a compreensão dos modelos obtidos, a discussão dos resultados é agrupada pela etapa em que foi realizada a modelagem. Inicialmente são apresentados os resultados dos modelos, e em seguida é apresentada a discussão dos resultados.

\subsubsection{Modelo 1-FULL}

Para formação dos conjuntos individuais de alternativas foram considerados os quatro padrões de viagens. Todas as alternativas foram consideradas disponíveis a todos os indivíduos. A hipótese de interferência testada no modelo foi:

- A escolha do padrão de viagens é influenciada pelas características individuais, características do domicílio, participação em atividades e características do sistema de transportes, incluindo a acessibilidade associado ao modo de transportes.

Para verificação desta hipótese cada variável independente incluída no modelo foi submetida a um teste de significância para verificar se o parâmetro da variável é diferente de zero. Assim, a hipótese nula verificada pelo modelo foi:

$$
\begin{aligned}
& H_{0}: B=0 \\
& H_{1}: B \neq 0
\end{aligned}
$$

Em que B é o parâmetro da variável independente.

Na especificação do modelo a alternativa "HWH" foi considerada dominante, assumindo o valor zero para a sua utilidade. Segundo Train (2009), este tipo de especificação torna mais fácil de interpretação dos resultados, na medida em que todos os parâmetros estimados das alternativas são relacionadas à alternativa dominante, ou seja, apenas as diferenças importam no modelo.

$\mathrm{Na}$ Equação 97 é apresentado a especificação da função utilidade empregado no modelo de escolha do padrão de viagens.

$$
U_{\text {padrão de viagens } i}=\sum_{n=1}^{n} \beta_{i n} \cdot \delta_{\text {in }}+\varepsilon_{i}
$$

Em que: 


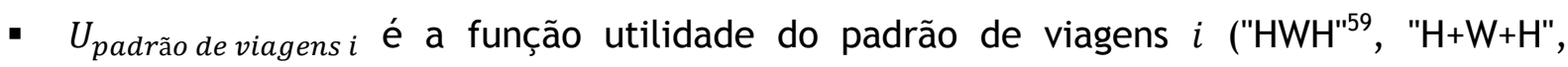
"HWHWH" e "H+W+H+W+H");

- $\quad \beta_{\text {in }}$, é o parâmetro da variável $n$ do padrão de viagens $i$;

- $\quad \delta_{i n}$, é o valor da variável $n$ do padrão de viagens $i$;

- $\varepsilon_{i}$, é o valor da constante da alternativa do padrão de viagens $i$.

Na Tabela 6.17 são apresentadas as medidas de desempenho do modelo logit multinomial estimado para o cálculo das probabilidades individuais para escolha padrão de viagens e na Tabela 6.18 são apresentados os valores dos parâmetros das funções de utilidade de cada alternativa com suas estatísticas de significância. Os valores marcados com "*" indicam os parâmetros que não foram significativos ao nível de $5 \%$.

Tabela 6.17 - Estatísticas do modelo de escolha do padrão de viagens.

\begin{tabular}{cc}
\hline Estatística do Modelo & Valor \\
\hline Parâmetros estimados & 66 \\
Observações & 2.149 \\
$L L\left(\beta^{\prime}=0\right)$ & $-2.979,15$ \\
$L L\left(\beta^{\prime}=\hat{\beta}\right)$ & $-1.423,68$ \\
$\rho$ & 0,5000 \\
\hline
\end{tabular}

${ }^{59} U_{H W H}=0$ 
Tabela 6.18 - Estimativa do modelo de escolha do padrão de viagens.

\begin{tabular}{|c|c|c|c|c|c|c|c|c|}
\hline \multicolumn{2}{|l|}{ Variáveis } & \multirow{2}{*}{$\begin{array}{c}\mathrm{HWH} \\
0\end{array}$} & \multicolumn{2}{|c|}{$\mathrm{H}+\mathrm{W}+\mathrm{H}$} & \multicolumn{2}{|c|}{ HWHWH } & \multicolumn{2}{|c|}{$\mathrm{H}+\mathrm{W}+\mathrm{H}+\mathrm{W}+\mathrm{H}$} \\
\hline 1. Constante & & & $-2,60$ & $(-8,80)$ & $-2,86$ & $(-11,04)$ & $-2,68$ & $(-10,06)$ \\
\hline $\begin{array}{l}\text { 2. Duração da Atividade Trabalho (acima de } 8 \\
\text { horas) }\end{array}$ & Até 8 horas & 0 & 0,29 & $(2,63)$ & $-0,06$ & $(-0,68)^{*}$ & 0,40 & $(4,53)$ \\
\hline \multirow{5}{*}{$\begin{array}{l}\text { 3. Combinação Modo e } \\
\text { Acessibilidade (Ônibus e } \\
\text { até } 40 \mathrm{~min} \text { ) }\end{array}$} & Até $20 \mathrm{~min}$ & 0 & $-0,56$ & $(-1,50)^{*}$ & 0,98 & $(4,82)$ & 0,73 & $(3.15)$ \\
\hline & Acima de $20 \mathrm{~min}$ & 0 & $-0,17$ & $(-0,42)^{*}$ & $-0,21$ & $(-0,68)^{*}$ & $-0,33$ & $(-0.89)^{*}$ \\
\hline & Até $25 \mathrm{~min}$ & 0 & 0,30 & $(1,32)^{*}$ & 0,84 & $(5,20)$ & 0,73 & $(4.14)$ \\
\hline & Acima de $25 \mathrm{~min}$ & 0 & 0,19 & $(0,54)^{*}$ & 0,03 & $(0,13)^{*}$ & 0,07 & $(0.22)^{*}$ \\
\hline & Acima de $40 \mathrm{~min}$ & 0 & $-0,10$ & $(-0,34)^{*}$ & $-1,04$ & $(-2,80)$ & $-0,79$ & $(-2.47)$ \\
\hline 4. Distância & Acima de $5,44 \mathrm{~km}$ & 0 & 0,19 & $(1,46)^{*}$ & $-0,47$ & $(-3,68)$ & $-0,32$ & $(-2,41)$ \\
\hline 5. Custo por viagem & $\mathrm{RS}$ & 0 & $-0,11$ & $(-0,40)^{*}$ & $-0,08$ & $(-0,41)^{*}$ & 0,29 & $(1,35)^{*}$ \\
\hline \multirow{2}{*}{ 6. Renda Individual } & De $\mathrm{R} \$ 400$ até $\mathrm{R} \$ 800$ & 0 & 0,07 & $(0,44)^{*}$ & $-0,15$ & $(-1,29)^{*}$ & $-0,20$ & $(-1,54)^{*}$ \\
\hline & Acima de R\$ 800 & 0 & $-0,22$ & $(-1,11)^{*}$ & 0,39 & $(3,11)$ & 0,17 & $(1,16)^{*}$ \\
\hline \multirow{2}{*}{ 7. Renda Domiciliar } & Até $\mathrm{R} \$ 1.200$ & 0 & $-0,33$ & $(-1,81)^{*}$ & 0,02 & $(0,14)^{*}$ & 0,01 & $(0,04)^{*}$ \\
\hline & Acima de $\mathrm{R} \$ 2.000$ & 0 & $-0,15$ & $(-0,83)^{*}$ & $-0,16$ & $(-1,32)^{*}$ & $-0,07$ & $(-0,55)^{*}$ \\
\hline \multirow{2}{*}{ 8. Posse de Automóvel (1 automóvel) } & Nenhum automóvel & 0 & $-0,38$ & $(-2,07)$ & $-0,25$ & $(-1,88)^{*}$ & $-0,37$ & $(-2,52)$ \\
\hline & Acima de 1 automóvel & 0 & 0,14 & $(0,64)^{*}$ & 0,32 & $(2,29)$ & 0,35 & $(2,22)$ \\
\hline 9. Criança que viaja no domicílio & Sim & 0 & 0,13 & $(0,80)^{*}$ & 0,01 & $(0,11)^{*}$ & $-0,01$ & $(-0,03)^{*}$ \\
\hline $\begin{array}{l}\text { 10. Número de Pessoas no Domícilio Acima de } 4 \\
\text { pessoas }\end{array}$ & Sim & 0 & 0,01 & $(0,02)^{*}$ & 0,03 & $(0,33)^{*}$ & 0,16 & $(1,71)^{*}$ \\
\hline 11. Casa Alugada & Sim & 0 & 0,04 & $(0,31)^{*}$ & $-0,18$ & $(-1,84)^{*}$ & 0,06 & $(0,64)^{*}$ \\
\hline \multirow[t]{2}{*}{ 12. Setor de Atividade Informal } & Sim & 0 & 0,16 & $(1,27)^{*}$ & $-0,29$ & $(-2,51)$ & 0,24 & $(2,44)$ \\
\hline & Côjuge & 0 & $-0,26$ & $(-1,21)^{*}$ & $-0,14$ & $(-0,82)^{*}$ & $-0,60$ & $(-2,91)$ \\
\hline \multirow[t]{2}{*}{ 13. Situação Familiar (Chefe) } & Filho & 0 & 0,30 & $(1,66)^{*}$ & 0,27 & $(1,84)^{*}$ & 0,73 & $(5,01)$ \\
\hline & Outros & 0 & 0,45 & $(1,90)^{*}$ & $-0,07$ & $(-0,31)^{*}$ & 0,15 & $(0,64)^{*}$ \\
\hline
\end{tabular}


Como já mencionado, não há limites fixados para se afirmar qual índice de razão da verossimilhança $(\rho)$ é suficiente para determinar o desempenho do modelo de escolha discreta, no entanto, com o propósito de situar o valor obtido para o índice é apresentado na Tabela 6.19 alguns valores para este índice reportados na literatura sobre modelos de escolha de padrões de viagens ${ }^{60}$. Ressalta-se que o propósito desta comparação é apenas situar o valor em relação aos valores reportados na literatura.

Tabela 6.19 - Medidas de desempenho de modelos multinomial logit para escolha do modo de transportes.

\begin{tabular}{ccccccc}
\hline Estudo & Cidade & $\begin{array}{c}\text { Parâmetros } \\
\text { estimados }\end{array}$ & Observações & $\boldsymbol{L L}\left(\boldsymbol{\beta}^{\prime}=\mathbf{0}\right)$ & $\boldsymbol{L L}\left(\boldsymbol{\beta}^{\prime}=\widehat{\boldsymbol{\beta}}\right)$ & $\boldsymbol{\rho}$ \\
\hline $\begin{array}{c}\text { Bowman } \\
(1995)\end{array}$ & Boston & 34 & 1.901 & -7.740 & -3733 & 0,514 \\
$\begin{array}{c}\text { Bowman } \\
(1995)\end{array}$ & Boston & 34 & 1.929 & -9.126 & -4641 & 0,489 \\
$\begin{array}{c}\text { Bowman } \\
(1998)\end{array}$ & Portland & 276 & 6.475 & -39.241 & -24.033 & 0,3876 \\
\hline
\end{tabular}

${ }^{1}$ Cadeias de viagens com trabalho; ${ }^{2}$ Cadeias de viagens exceto trabalho

Confrontando a medida de desempenho do modelo de escolha modal obtido com os valores da Tabela 6.19, observa-se que a medida de desempenho do modelo situa-se na dentro da faixa dos valores encontrado na literatura.

Com relação ao modelo, foram estimados 63 parâmetros associados às variáveis independentes e 3 associados às constantes específicas (ASC). Todos os coeficientes estimados são em sinal esperado. Há vários parâmetros calibrados que não são significantes para o nível de $5 \%$, provavelmente em função da baixa amostragem dos padrões para estas variáveis. Entretanto, estes parâmetros insignificantes foram mantidos no modelo pela sua importância na análise da segmentação da demanda.

Todas as ASC são negativas, e a análise do efeito das variáveis independentes quando os parâmetros assumem o valor de zero sobre a utilidade é uma propensão de $84 \%$ para o padrão “HWH”. Pelos dados da Tabela 5.30 a proporção do modo a pé é de $78 \%$.

Como o modelo foi especificado em função da alternativa dominante, a tendência é que o efeito do parâmetro zero sobre as variáveis represente o efeito da alternativa dominante no banco de dados, diferente da especificação apresentada no modelo de escolha modal.

\footnotetext{
${ }^{60}$ Considerando aplicação do modelo logit (multinomial e o hierárquico) na escolha do padrão de viagens.
} 
O comportamento da variável duração da atividade sugere que indivíduos com carga horária diária inferior a 8 horas tem tendência a incorporar mais atividades aos padrões de viagens do que indivíduos sujeitos a mais de 8 horas diárias de trabalho. Este comportamento é coerente segundo a teoria sobre programação diária de atividades. Após alocar a duração das atividades primárias, o indivíduo tentará alocar, para o tempo disponível (descontado o tempo de viagens para as atividades compulsórias), outras atividades na sua grade de programação.

A distância de viagem reflete restrições espaciais para participação em outras atividades. Quanto maior é a distância para realização da atividade primária trabalho, a tendência é um aumento da restrição espacial e temporal para engajamento em outras atividades.

$\mathrm{O}$ sinal positivo do custo por viagem para o padrão de viagem " $\mathrm{H}+\mathrm{W}+\mathrm{H}+\mathrm{W}+\mathrm{H}$ ” pode ser interpretado de duas formas: (i) sugere uma redução no custo das viagens para realização de atividades em comparação aos outros padrões e/ou engajamento em atividades que geram viagens por modos não motorizados (sem custo), e (ii) para realizar este tipo de padrão os indivíduos terão que aumentar o custo da viagem, ou migrarem do modo a pé, ou ônibus para automóvel.

Em relação à condição econômica dos indivíduos, os valores dos parâmetros da renda individual sugerem que para as classes com rendimento até 400 reais, uma propensão dos indivíduos desta classe para o padrão "HWH"; para valores de 400 a 800 reais, uma propensão ao padrão " $\mathrm{H}+\mathrm{W}+\mathrm{H}$ " e para valores acima de 800 reais, uma propensão dos padrões com retorno ao domicilio durante o dia.

Estas relações estão coerentes com os valores de taxas de viagens apresentados na Tabela 5.12: indivíduos de menor poder aquisitivo tendem a realizar um menor número de viagens, em comparação aos indivíduos com maior poder aquisitivo. Uma análise detalhada do efeito da renda, pode ser realizada pelo efeito combinado da renda individual associado à renda domiciliar, conforme apresentado na Tabela 6.20.

Analisando os valores das funções de utilidade apresentados na Tabela 6.20, observa-se uma propensão dos indivíduos de baixa renda $(I D=1)$ para realização de padrões "HWH"; uma propensão dos indivíduos de renda média (ID = 5) para padrões de viagens com mais atividades, e; uma propensão dos indivíduos de renda alta $($ ID $=9)$ para padrões com retorno ao domicilio durante o dia. 
Tabela 6.20 - Análise dos valores das funções de utilidade para escolha do padrão de viagens para combinações de renda individual e renda domiciliar.

\begin{tabular}{ccccccc}
\hline ID & $\begin{array}{c}\text { Renda } \\
\text { Individual }\end{array}$ & $\begin{array}{c}\text { Renda } \\
\text { Domiciliar }\end{array}$ & HWH & H+W+H & HWHWH & H+W+H+W+H \\
\hline (1) & Até $R \$ 400$ & Até $R \$ 1.200$ & 0 & $-0,39$ & $-0,04$ & $-0,05$ \\
(2) & Até $R \$ 400$ & De $R \$ 1.200$ a $R \$ 2.000$ & 0 & 0,63 & 0,63 & 0,63 \\
(3) & Até $R \$ 400$ & Acima de $R \$ 2.000$ & 0 & $-0,20$ & $-0,21$ & $-0,13$ \\
(4) & De $R \$ 400$ a $R \$ 800$ & Até $R \$ 1.200$ & 0 & $-0,27$ & $-0,13$ & $-0,20$ \\
(5) & De $R \$ 400$ a $R \$ 800$ & De $R \$ 1.200$ a $R \$ 2.000$ & 0 & 0,75 & 0,54 & 0,48 \\
(6) & De $R \$ 400$ a $R \$ 800$ & Acima de $R \$ 2.000$ & 0 & $-0,08$ & $-0,30$ & $-0,28$ \\
(7) & Acima de $R \$ 800$ & Até $R \$ 1.200$ & 0 & $-0,55$ & 0,40 & 0,17 \\
(8) & Acima de $R \$ 800$ & De $R \$ 1.200$ a $R \$ 2.000$ & 0 & 0,47 & 1,07 & 0,85 \\
(9) & Acima de $R \$ 800$ & Acima de $R \$ 2.000$ & 0 & $-0,36$ & 0,23 & 0,10 \\
\hline
\end{tabular}

A decisão de longo prazo de posse de automóvel no domicílio tem impacto positivo na utilidade dos padrões de viagens com um maior número de atividades. A presença de criança no domicilio que realiza viagem, sugere uma propensão para realização de padrões “H+W+H”. Entretanto, não há elementos para afirmar se as atividades adicionadas ao trabalho estão relacionadas a atividades desempenhadas em conjunto com a criança.

Indivíduos que residem em domicílios com mais de 4 pessoas possuem uma tendência em realizar cadeias com um maior número de viagens, e pessoas que moram em casa própria são propensas a realizar o padrão "HWHWH".

Trabalhadores do mercado informal são propensos a realizar cadeias de viagens com um maior número de atividades. Não há informação no banco de dados para distinguir se o emprego das cadeias das viagens destes trabalhadores é o mesmo ou diferentes, o que traria mais elementos para a análise.

Porém, há uma sugestão no banco de dados da jornada diária do emprego informal ser inferior a 8 horas diárias, e dentro da teoria sobre a programação individual das atividades explicaria o engajamento destes indivíduos em outras atividades.

Em relação a situação familiar, se o indivíduo é chefe de família ou cônjuge ele é propenso a escolher o padrão de viagens "HWH", ao passo que se for filho ou desempenhar 
outro papel no domicilio o individuo é propenso a escolher padrões com um maior número de viagens e atividades.

Analisando a acessibilidade, indivíduos por modos não motorizados (a pé e bicicleta) com tempos de viagens até 20 minutos ao trabalho são propensos a realizar padrões com uma maior cadeia de viagens. Quando a faixa de viagem é alterada para 20 minutos (por modo não motorizado) a tendência é realizar o padrão "HWH".

Indivíduos de modo privado (automóvel motorista e passageiro) são propensos a realizar padrões com um maior número de viagens e atividades independente do tempo da viagem até o local do trabalho.

Trabalhadores que utilizam o ônibus para realizarem o deslocamento até o trabalho são propensos, independente da faixa de tempo, a desempenharem padrões de viagens "HWH”.

Os resultados da acessibilidade sugerem que se os indivíduos tiverem ganho de acessibilidade, por exemplo, redução do tempo de viagem (por melhoria de acesso aos locais das atividades), há uma tendência dos indivíduos migrarem para padrões com maior número de viagens e/ou maior número de atividades.

\subsubsection{Modelos 2-N-L e 2-N-A}

\section{Modelo 2-N-L}

Para formação dos conjuntos individuais de alternativas foram considerados os quatro padrões de viagens. Todas as alternativas foram consideradas disponíveis a todos os indivíduos. A hipótese de interferência testada no modelo foi:

- A escolha do padrão de viagens é influenciada pelas características individuais, características do domicílio, participação em atividades e características do sistema de transportes, incluindo a acessibilidade.

Para verificação desta hipótese cada variável independente incluída no modelo foi submetida a um teste de significância para verificar se o parâmetro da variável é diferente de zero. Assim, a hipótese nula verificada pelo modelo foi:

$\mathrm{H}_{0}: \mathrm{B}=0$ 


$$
H_{1}: B \neq 0
$$

Em que $B$ é o parâmetro da variável independente.

$\mathrm{Na}$ especificação do modelo a alternativa "HWH" foi considerada dominante, assumindo o valor zero para a sua utilidade e a função de utilidade empregada é semelhante a Equação 97.

$\mathrm{Na}$ Tabela 6.21 são apresentadas as medidas de desempenho do modelo logit multinomial estimado para o cálculo das probabilidades individuais para escolha padrão de viagens e na Tabela 6.22 são apresentados os valores dos parâmetros das funções de utilidade de cada alternativa com suas estatísticas de significância. Os valores marcados com "*" indicam os parâmetros que não foram significativos ao nível de $5 \%$.

Tabela 6.21 - Estatísticas do modelo de escolha do padrão de viagens: amostra de indivíduos com modo predominante não motorizado.

\begin{tabular}{cc}
\hline Estatística do Modelo & Valor \\
\hline Parâmetros estimados & 45 \\
Observações & 547 \\
$L L\left(\beta^{\prime}=0\right)$ & $-758,303$ \\
$L L\left(\beta^{\prime}=\hat{\beta}\right)$ & $-379,885$ \\
$\rho$ & 0,440 \\
\hline
\end{tabular}


Tabela 6.22 - Estimativa do modelo de escolha do padrão de viagens: amostra de indivíduos com modo predominante não motorizado.

\begin{tabular}{|c|c|c|c|c|c|c|c|c|}
\hline \multicolumn{2}{|l|}{ Variáveis } & \multirow{2}{*}{$\begin{array}{c}\text { HWH } \\
0\end{array}$} & \multicolumn{2}{|c|}{$\mathrm{H}+\mathrm{W}+\mathrm{H}$} & \multicolumn{2}{|c|}{ HWHWH } & \multicolumn{2}{|c|}{$\mathrm{H}+\mathrm{W}+\mathrm{H}+\mathrm{W}+\mathrm{H}$} \\
\hline 1. Constante & & & $-3,43$ & $(5,61)$ & $-1,68$ & $(-5,99)$ & $-2,31$ & $(-5,96)$ \\
\hline $\begin{array}{l}\text { 2. Duração da Atividade Trabalho (acima de } 8 \\
\text { horas) }\end{array}$ & Até 8 horas & 0 & 0,73 & $(2,32)$ & $-0,24$ & $(-1,55)^{*}$ & 0,37 & $(2,20)$ \\
\hline 3. Acessibilidade & Acima de $20 \mathrm{~min}$ & 0 & 0,14 & $(0,65)^{*}$ & $-0,48$ & $(-2,88)$ & $-0,33$ & $(-1,66)^{*}$ \\
\hline & De $R \$ 400$ até $R \$ 800$ & 0 & $-0,70$ & $(-1,47)^{*}$ & $-0,48$ & $(-2,40)$ & $-0,40$ & $(-1,41)^{*}$ \\
\hline \multicolumn{9}{|l|}{ 4. Renda Individual } \\
\hline & Acima de $\mathrm{R} \$ 800$ & 0 & 0,47 & $(0,92)^{*}$ & 0,68 & $(3,13)$ & 0,20 & $(0,59)^{*}$ \\
\hline & Até $\mathrm{R} \$ 1.200$ & 0 & $-0,55$ & $(-0,94)^{*}$ & 0,23 & $(1,17)^{*}$ & 0,09 & $(0,36)^{*}$ \\
\hline \multicolumn{9}{|l|}{ 5. Renda Domiciliar } \\
\hline & Acima de $\mathrm{R} \$ 2.000$ & 0 & $-0,21$ & $(-0,35)^{*}$ & $-0,18$ & $(-0,80)^{*}$ & $-0,15$ & $(-0,55)^{*}$ \\
\hline & Nenhum automóvel & 0 & $-0,30$ & $(-0,67)^{*}$ & $-0,66$ & $(-3,20)$ & $-0,49$ & $(-2,00)$ \\
\hline \multicolumn{9}{|l|}{ 6. Posse de Automóvel (1 automóvel) } \\
\hline & Acima de 1 automóvel & 0 & 0,86 & $(1,43)^{*}$ & 0,70 & $(2,44)$ & 0,69 & $(2,08)$ \\
\hline 7. Criança que viaja no domicílio & Sim & 0 & 0,13 & $(1,68)^{*}$ & 0,24 & $(1,25)^{*}$ & $-0,48$ & $(1,47)^{*}$ \\
\hline $\begin{array}{l}\text { 8. Número de Pessoas no Domícilio Acima de } 4 \\
\text { pessoas }\end{array}$ & Sim & 0 & $-0,43$ & $(-1,05)^{*}$ & $-0,06$ & $(-0,39)^{*}$ & $-0,28$ & $(1,54)^{*}$ \\
\hline \multirow[t]{2}{*}{ 9. Setor de Atividade Informal } & $\operatorname{Sim}$ & 0 & $-0,01$ & $(-0,04)^{*}$ & $-0,33$ & $(-1,89)^{*}$ & 0,29 & $(1,71)^{*}$ \\
\hline & Côjuge & 0 & 0,23 & $(0,43)^{*}$ & 0,30 & $(1,20)^{*}$ & $-0,68$ & $(-1,78)^{*}$ \\
\hline \multirow[t]{2}{*}{ 1/. Situação Familiar (Chefe) } & Filho & 0 & $-0,49$ & $(-0,75)^{*}$ & 0,21 & $(0,83)^{*}$ & 0,59 & $(2,28)$ \\
\hline & Outros & 0 & $-0,17$ & $(-0,20)^{*}$ & $-0,32$ & $(-0,83)^{*}$ & 0,54 & $(1,53)^{*}$ \\
\hline
\end{tabular}


Confrontando a medida de desempenho do modelo de escolha modal obtido com os valores da Tabela 6.19, observa-se que a medida de desempenho do modelo situa-se na dentro da faixa dos valores encontrado na literatura.

Com relação ao modelo, foram estimados 45 parâmetros associados às variáveis independentes e 3 associados as constantes específicas (ASC). Todos os coeficientes estimados são em sinal esperado. Há vários parâmetros calibrados que não são significantes para o nível de $5 \%$, provavelmente em função da baixa amostragem dos padrões para estas variáveis. Entretanto, estes parâmetros insignificantes foram mantidos no modelo pela sua importância na análise da segmentação da demanda.

O comportamento da variável duração da atividade sugere um comportamento semelhante ao encontrado no modelo "1-FULL", que indivíduos com carga horária diária inferior a 8 horas tem tendência a incorporar mais atividades aos padrões de viagens do que indivíduos sujeitos a mais de 8 horas diárias de trabalho.

Uma análise detalhada do efeito da renda, pode ser realizado pelo efeito combinado da renda individual associado a renda domiciliar, conforme apresentado na Tabela 6.23. Analisando os valores das funções de utilidade apresentados nesta tabela, observa-se uma propensão dos indivíduos de baixa renda $(I D=1)$ para realização de padrões "HWH"; uma ligeira propensão dos indivíduos de renda média $(I D=5)$ para padrões de viagens com mais atividades, e; uma propensão dos indivíduos de renda alta $(I D=9)$ para padrões de viagens com mais atividades.

Tabela 6.23 - Análise dos valores das funções de utilidade para escolha do padrão de viagens para combinações de renda individual e renda domiciliar.

\begin{tabular}{ccccccc}
\hline ID & $\begin{array}{c}\text { Renda } \\
\text { Individual }\end{array}$ & $\begin{array}{c}\text { Renda } \\
\text { Domiciliar }\end{array}$ & HWH & H+W+H & HWHWH & H+W+H+W+H \\
\hline (1) & Até $R \$ 400$ & Até $R \$ 1.200$ & 0 & $-0,32$ & $-0,03$ & 0,29 \\
(5) & De R\$400 a R\$800 & De R\$1.200 a R\$2.000 & 0 & 0,06 & $-0,53$ & $-0,34$ \\
(9) & Acima de $R \$ 800$ & Acima de $R \$ 2.000$ & 0 & 0,36 & 0,23 & 0,10 \\
\hline
\end{tabular}

A posse de automóvel neste modelo é interpretada como uma variável que pode expressar o poder aquisitivo do domicílio. A interpretação dos parâmetros sugere que indivíduos em domicílios com mais de um automóvel são propensos a realizar padrões com um maior número de viagens. 
A presença de criança no domicílio que realiza viagem, sugere uma propensão para realização de padrões “HWHWH”. Entretanto, não há elementos para afirmar se o desejo do retorno ao domicilio é envolvido com a presença da criança.

Indivíduos que residem em domicílios com mais de 4 pessoas possuem uma tendência em realizarem cadeias com menor número de viagens a pé. Trabalhadores do mercado informal são propensos a realizarem cadeias de viagens por modo não motorizado com um maior número de atividades (provavelmente os locais das atividades são próximos). Não há informação no banco de dados para distinguir se o emprego das cadeias das viagens destes trabalhadores é o mesmo ou diferente, o que traria mais elementos para a análise.

Em relação a situação familiar, se o indivíduo é chefe de família ele é propenso a escolher o padrão de viagens " $\mathrm{H}+\mathrm{W}+\mathrm{H}$ ", ao passo que se for filho ou desempenhar outro papel no domicílio o individuo o indivíduo é propenso a escolher padrões com um maior número de viagens e atividades.

Analisando a acessibilidade, indivíduos com acesso as oportunidades com tempo de viagem até 20 minutos, são propensos a realizar padrões com um maior número de viagens e atividades (“HWHWH” e "H+W+H+W+H”).

Ao reduzir à acessibilidade do indivíduo às oportunidades, aumentando o tempo de viagem por modo não motorizado (mudança do tempo de viagem às oportunidades de trabalho para valores superiores a $20 \mathrm{~min}$ ) a propensão dos padrões passa a cadeias com menor número de viagens.

\section{Modelo 2-N-A}

Para a aplicação do minerador de dados com o modelo de árvore de decisão ao banco de dados foi adotado um desvio de 0,15 e os critérios de 25 e 50 para o número mínimo de observações antes da divisão e o número mínimo de observações nas folhas. Estes critérios foram adotados como tentativa em se obter um modelo que expresse as principais relações entre as variáveis.

Foi adotado como variável independente os quatro tipos de padrões de viagens encadeadas apresentados na Tabela 4.6 ("HWH", "H+W+H", "HWHWH", e "H+W+H+W+H") e como variáveis dependentes as características socioeconômicas dos indivíduos e dos domicílios (Tabela 4.3), participação em atividades (Tabela 4.4) e características do sistema de transportes (Tabela 4.5). 
Na mineração dos dados o modelo de árvore selecionou as variáveis "Acessibilidade", "Trabalho Informal", "Posse de Automóvel" e "Renda Domiciliar". 0 resultado do processamento é uma árvore com a divisão dos indivíduos em 10 grupos (folhas) distintos e as probabilidades de ocorrências dos 4 padrões de viagens apresentados graficamente, conforme a Figura 6.2. 


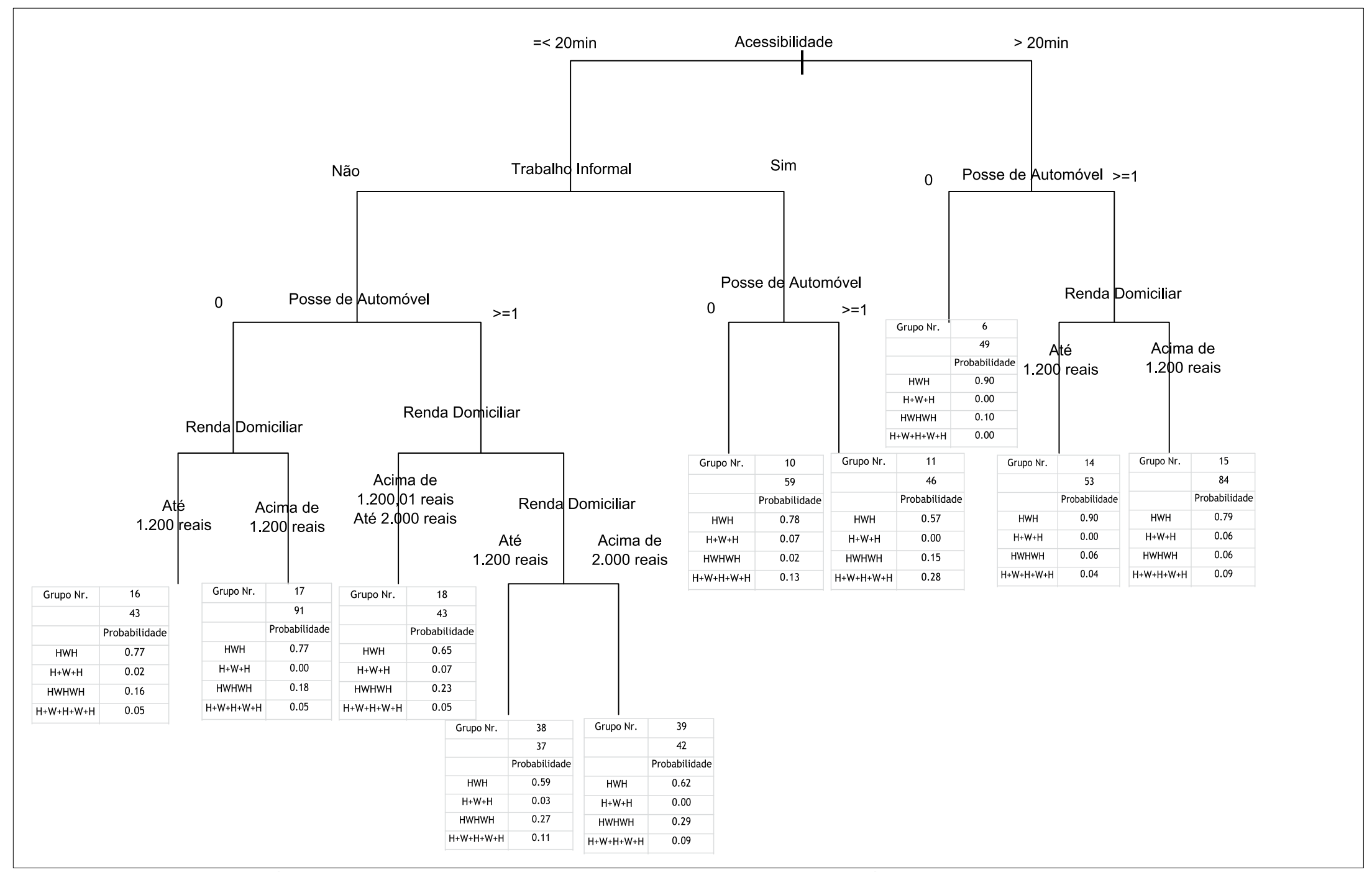

Figura 6.2 - Modelo de árvore de decisão para o conjunto de dados: amostra de indivíduos com modo predominante não motorizado. 
Para análise da influência das variáveis nas escolhas dos padrões de viagens realizados pelos indivíduos com modo predominante não motorizado, é observada a construção da hierarquia da árvore. A importância de cada uma das variáveis é explicada quando se analisa a construção da árvore (ramo a ramo).

Assim na primeira divisão da árvore ilustrada na Figura 6.2, a primeira variável considerada foi a acessibilidade segregando a árvore em dois ramos: (1) acessibilidade inferior a 20 minutos; e (2) acessibilidade superior a 20 minutos. Ao escolher a acessibilidade na primeira divisão binária, a árvore expressa a importância desta variável nas escolhas dos padrões de viagens.

Nos modelos 1-FULL e 2-N-L já havia sido delineado a influência da acessibilidade pelo modo de transportes não motorizado nas escolhas dos padrões de viagens, com significância estatística para os padrões com maior número de viagens e atividades. 0 resultado do modelo reforça a noção da influência da acessibilidade na escolha dos padrões de viagens.

Observado as folhas $16,17,18,38$ e 39 , e a probabilidade de ocorrência dos padrões em cada folha, verifica-se que nestas folhas (que corresponde aos trabalhadores do mercado formal com acessibilidade até 20 minutos) há valores de probabilidades do padrão "HWH" de 0,77 (folhas 16 e 17) e 0,59-0,65 (folhas 18, 38 e 39) e de padrões com mais viagens de 0,23 (folhas 16 e 17) e 0,35-0,41 (folhas 18,38 e 39).

Nas folhas 10 e 11 observam-se valores de probabilidade para o padrão "HWH" de 0,78 e 0,57 , respectivamente, e de padrões com mais viagens de 0,22 (folha 10) e 0,43 (folha 11).

As distribuições das probabilidades dos padrões de viagens pela renda domiciliar sugere que esta variável não exerce influência significativa nas escolhas dos padrões, entretanto, o comportamento das distribuições em relação a posse de automóvel sugere que esta variável (que neste modelo é interpretado como uma variável que pode expressar o poder aquisitivo do domicilio) exerce influência relevante.

Por exemplo, na folha 11, para indivíduos com acessibilidade até 20 minutos, trabalhadores informais e com posse de automóvel no domicilio superior a um, tem um crescimento de 21 p.p na probabilidade de padrões com um maior número de viagens do que os indivíduos sem posse de automóvel (folha 10) 
Pelo ramo 1, indivíduos residentes em domicílios com mais de um automóvel, são mais propensos a realizar padrões de viagens com maior número de viagens e atividades em comparação aos indivíduos residentes em domicílios sem posse de automóvel. No ramo 2, que corresponde aos indivíduos com acessibilidade acima de 20 minutos, apesar da dificuldade de acesso, os indivíduos são propensos a escolherem padrões com maior número de viagens e atividades do que indivíduos sem posse de automóvel no domicilio.

Ao analisar as folhas com agrupamentos baseados na posse de automóvel observa-se a influência da acessibilidade. Na folha 10, indivíduos com acessibilidade até 20 minutos e sem posse de automóvel, a propensão para padrões com um maior número de viagens é de 0,22; ao passo que para os indivíduos com acessibilidade acima de 20 minutos e sem posse de automóvel, a propensão esta propensão é reduzida em 10 p.p.

O efeito da acessibilidade também é percebido na análise das folhas 38 e 14. Na foIha 38, indivíduos com acessibilidade até 20 minutos, com posse de automóvel no domicilio superior a um e renda domiciliar até 1.200 reais, possuem uma propensão de 0,41 para padrões com maior número de viagens. Na folha 14, indivíduos com acessibilidade acima de 20 minutos, com posse de automóvel no domicilio superior a um e renda domiciliar até 1.200 reais possuem a propensão para os padrões com maior número de viagens reduzido em 31 p.p.

\subsubsection{Modelos 3-C-L e 3-C-A}

\section{Modelo 3-C-L}

Para formação dos conjuntos individuais de alternativas foram considerados os quatro padrões de viagens. Todas as alternativas foram consideradas disponíveis a todos os indivíduos. A hipótese de interferência testada no modelo foi:

- A escolha do padrão de viagens é influenciada pelas características individuais, características do domicílio, participação em atividades e características do sistema de transportes, incluindo a acessibilidade.

Para verificação desta hipótese cada variável independente incluída no modelo foi submetida a um teste de significância para verificar se o parâmetro da variável é diferente de zero. Assim, a hipótese nula verificada pelo modelo foi: 


$$
\begin{aligned}
& H_{0}: B=0 \\
& H_{1}: B \neq 0
\end{aligned}
$$

Em que $B$ é o parâmetro da variável independente.

$\mathrm{Na}$ especificação do modelo a alternativa "HWH" foi considerada dominante, assumindo o valor zero para a sua utilidade e a função de utilidade empregada é semelhante a Equação 97.

Na Tabela 6.23 são apresentadas as medidas de desempenho do modelo logit multinomial estimado para o cálculo das probabilidades individuais para escolha padrão de viagens e na Tabela 6.23 são apresentados os valores dos parâmetros das funções de utilidade de cada alternativa com suas estatísticas de significância. Os valores marcados com "*" indicam os parâmetros que não foram significativos ao nível de $5 \%$.

Tabela 6.23 - Estatísticas do modelo de escolha do padrão de viagens: como modo predominante coletivo.

\begin{tabular}{cc}
\hline Estatística do Modelo & Valor \\
\hline Parâmetros estimados & 45 \\
Observações & 891 \\
$L L\left(\beta^{\prime}=0\right)$ & -1.235 .188 \\
$L L\left(\beta^{\prime}=\hat{\beta}\right)$ & -388.036 \\
$\rho$ & 0,649 \\
\hline
\end{tabular}


Tabela 6.24 - Estimativa do modelo de escolha do padrão de viagens: amostra de indivíduos com modo predominante coletivo.

\begin{tabular}{|c|c|c|c|c|c|c|c|c|}
\hline \multicolumn{2}{|l|}{ Variáveis } & \multirow{2}{*}{$\begin{array}{c}\text { HWH } \\
0\end{array}$} & \multicolumn{2}{|c|}{$\mathrm{H}+\mathrm{W}+\mathrm{H}$} & \multicolumn{2}{|c|}{ HWHWH } & \multicolumn{2}{|c|}{$\mathrm{H}+\mathrm{W}+\mathrm{H}+\mathrm{W}+\mathrm{H}$} \\
\hline 1. Constante & & & 3,05 & $(-8,15)$ & $-4,59$ & $(6,47)$ & $-3,24$ & $(-8,14)$ \\
\hline $\begin{array}{l}\text { 2. Duração da Atividade Trabalho (acima de } 8 \\
\text { horas) }\end{array}$ & Até 8 horas & 0 & 0,18 & $(1,10)^{*}$ & 0,38 & $(1,80)^{*}$ & 0,75 & $(3,81)$ \\
\hline 3. Acessibilidade & Acima de $40 \mathrm{~min}$ & 0 & $-0,24$ & $(-1,38)^{*}$ & $-0,13$ & $(-0,53)^{*}$ & $-0,29$ & $(-1,31)^{*}$ \\
\hline \multirow[t]{2}{*}{ 4. Distância } & Acima de $5,44 \mathrm{~km}$ & 0 & 0,34 & $(2,09)$ & $-0,25$ & $(-1,05)^{*}$ & $-0,27$ & $(-1,35)^{*}$ \\
\hline & De $R \$ 400$ até $R \$ 800$ & 0 & 0,37 & $(1,34)^{*}$ & 0,21 & $(0,72)^{*}$ & $-0,02$ & $(-0,08)^{*}$ \\
\hline \multicolumn{9}{|l|}{ 5. Renda Individual } \\
\hline & Acima de R\$ 800 & 0 & $-0,70$ & $(-1,61)^{*}$ & 0,14 & $(0,35)^{*}$ & 0,00 & $(0,00)^{*}$ \\
\hline & Até $R \$ 1.200$ & 0 & $-0,32$ & $(-1,16)^{*}$ & $-0,33$ & $(-0,89)^{*}$ & 0,03 & $(0,09)^{*}$ \\
\hline \multicolumn{9}{|l|}{ 6. Renda Domiciliar } \\
\hline & Acima de $\mathrm{R} \$ 2.000$ & 0 & $-0,34$ & $(-1,31)^{*}$ & 0,17 & $(0,54)^{*}$ & $-0,09$ & $(0,31)^{*}$ \\
\hline & Nenhum automóvel & 0 & $-0,44$ & $(-1,78)^{*}$ & 0,44 & $(1,06)^{*}$ & $-0,28$ & $(0,94)^{*}$ \\
\hline \multicolumn{9}{|l|}{ 7. Posse de Automóvel (1 automóvel) } \\
\hline & Acima de 1 automóvel & 0 & 0,30 & $(0,84)^{*}$ & $-0,37$ & $(-0,53)^{*}$ & 0,04 & $(0,08)^{*}$ \\
\hline 8. Criança que viaja no domicílio & Sim & 0 & $-0,06$ & $(-0,21)^{*}$ & $-0,39$ & $(-0,74)^{*}$ & 0,28 & $(0,96)^{*}$ \\
\hline \multirow[t]{2}{*}{ 9. Setor de Atividade Informal } & Sim & 0 & 0,25 & $(1,41)^{*}$ & $-0,26$ & $(-0,81)^{*}$ & 0,26 & $(1,30)^{*}$ \\
\hline & Côjuge & 0 & $-0,13$ & $(-0,41)^{*}$ & $-1,36$ & $(-1,72)^{*}$ & $-0,30$ & $(-0,77)^{*}$ \\
\hline \multirow[t]{2}{*}{ 10. Situação Familiar (Chefe) } & Filho & 0 & 0,63 & $(2,56)$ & 0,84 & $(2,07)$ & 1,18 & $(3,83)$ \\
\hline & Outros & 0 & 0,91 & $(2,87)$ & 0,24 & $(0,38)^{*}$ & $-0,17$ & $(-0,29)^{*}$ \\
\hline
\end{tabular}


Confrontando a medida de desempenho do modelo de escolha modal obtido com os valores da Tabela 6.19, observa-se que a medida de desempenho do modelo situa-se acima da faixa dos valores encontrado na literatura.

Com relação ao modelo, foram estimados 45 parâmetros associados às variáveis independentes e 3 associados as constantes específicas (ASC). Todos os coeficientes estimados são em sinal esperado. Há vários parâmetros calibrados que não são significantes para o nível de $5 \%$, provavelmente em função da baixa amostragem dos padrões para estas variáveis. Entretanto, estes parâmetros insignificantes foram mantidos no modelo pela sua importância na análise da segmentação da demanda.

O comportamento da variável duração da atividade sugere que indivíduos com carga horária diária inferior a 8 horas tem tendência a incorporar mais atividades aos padrões de viagens do que indivíduos sujeitos a mais de 8 horas diárias de trabalho e são mais propensos em comparação aos indivíduos que utilizam o modo não motorizado como predominante no padrão de viagens.

A distância de viagem reflete restrições espaciais para o retorno ao domicilio entre a realização de atividades. Quanto maior é a distância para realização da atividade primária trabalho, a tendência é um aumento da restrição espacial e temporal para engajamento em outras atividades.

Uma análise do efeito da renda é apresentado na Tabela 6.25. Analisando os valores das funções de utilidade apresentados nesta tabela, observa-se uma propensão dos indivíduos de baixa renda (ID = 1) para não realizarem padrões "HWHWH"; uma propensão dos indivíduos de renda média (ID = 5) para padrões de viagens com mais atividades, e; uma propensão dos indivíduos de renda alta $(I D=9)$ para padrões para padrões de viagens "HWHWH".

Tabela 6.25 - Análise dos valores das funções de utilidade para escolha do padrão de viagens para combinações de renda individual e renda domiciliar.

\begin{tabular}{ccccccc}
\hline ID & $\begin{array}{c}\text { Renda } \\
\text { Individual }\end{array}$ & $\begin{array}{c}\text { Renda } \\
\text { Domiciliar }\end{array}$ & HWH & H+W+H & HWHWH & H+W+H+W+H \\
\hline (1) & Até $R \$ 400$ & Até $R \$ 1.200$ & 0 & 0,01 & $-0,68$ & 0,05 \\
(5) & De $R \$ 400$ a $R \$ 800$ & De $R \$ 1.200$ a R\$2.000 & 0 & 1,03 & 0,37 & 0,04 \\
(9) & Acima de $R \$ 800$ & Acima de $R \$ 2.000$ & 0 & $-1,04$ & 0,31 & $-0,09$ \\
\hline
\end{tabular}


A posse de automóvel neste modelo é interpretada como uma variável que pode expressar o poder aquisitivo do domicílio. A interpretação dos parâmetros sugere que indivíduos em domicílios com mais de um automóvel são propensos a realizarem padrões com um maior número de viagens.

A presença de criança no domicilio que realiza viagem sugere uma propensão para realização de padrões “ $\mathrm{H}+\mathrm{W}+\mathrm{H}+\mathrm{W}+\mathrm{H}$ ”. Entretanto, não há elementos para afirmar se as viagens são realizadas para realização de atividades na companhia da criança.

Trabalhadores do mercado informal são propensos a realizar cadeias de viagens por modo coletivo com um maior número de atividades. Não há informação no banco de dados para distinguir se o emprego das cadeias das viagens destes trabalhadores é o mesmo ou diferentes, o que traria mais elementos para a análise.

Em relação a situação familiar, se o indivíduo é chefe de família ele é propenso a escolher o padrão de viagens "HWH", ao passo que se for filho ou desempenhar outro papel no domicilio o individuo o indivíduo é propenso a escolher padrões com um maior número de viagens e atividades.

Analisando a acessibilidade, indivíduos com acesso às oportunidades com tempo de viagem até 40 minutos são propensos a realizar padrões com um maior número de viagens e atividades ("HWHWH" e "H+W+H+W+H”).

Ao reduzir a acessibilidade do indivíduo às oportunidades, aumentando o tempo de viagem pelo modo coletivo (mudança do tempo de viagem às oportunidades de trabalho para valores superiores a $40 \mathrm{~min}$ ) a propensão dos padrões passa a cadeias com menor número de viagens.

\section{Modelo 3-C-A}

Para a aplicação do minerador de dados com o modelo de árvore de decisão ao banco de dados foi adotado um desvio de 0,15 e os critérios de 25 e 50 para o número mínimo de observações antes da divisão e o número mínimo de observações nas folhas.

Foi adotado como variável independente os quatro tipos de padrões de viagens encadeadas, apresentados na Tabela 4.6 ("HWH", "H+W+H", "HWHWH", e "H+W+H+W+H") e como variáveis dependentes as características socioeconômicas dos indivíduos e dos domi- 
cílios (Tabela 4.3), participação em atividades (Tabela 4.4) e características do sistema de transportes (Tabela 4.5).

Na mineração dos dados o modelo de árvore selecionou as variáveis "Distância", "Posse de Automóvel”, “Acessibilidade” e "Condição de Moradia”. O resultado do processamento é uma árvore com a divisão dos indivíduos em 12 grupos (folhas) distintos e as probabilidades de ocorrências dos 4 padrões de viagens apresentados graficamente, conforme a Figura 6.3. 


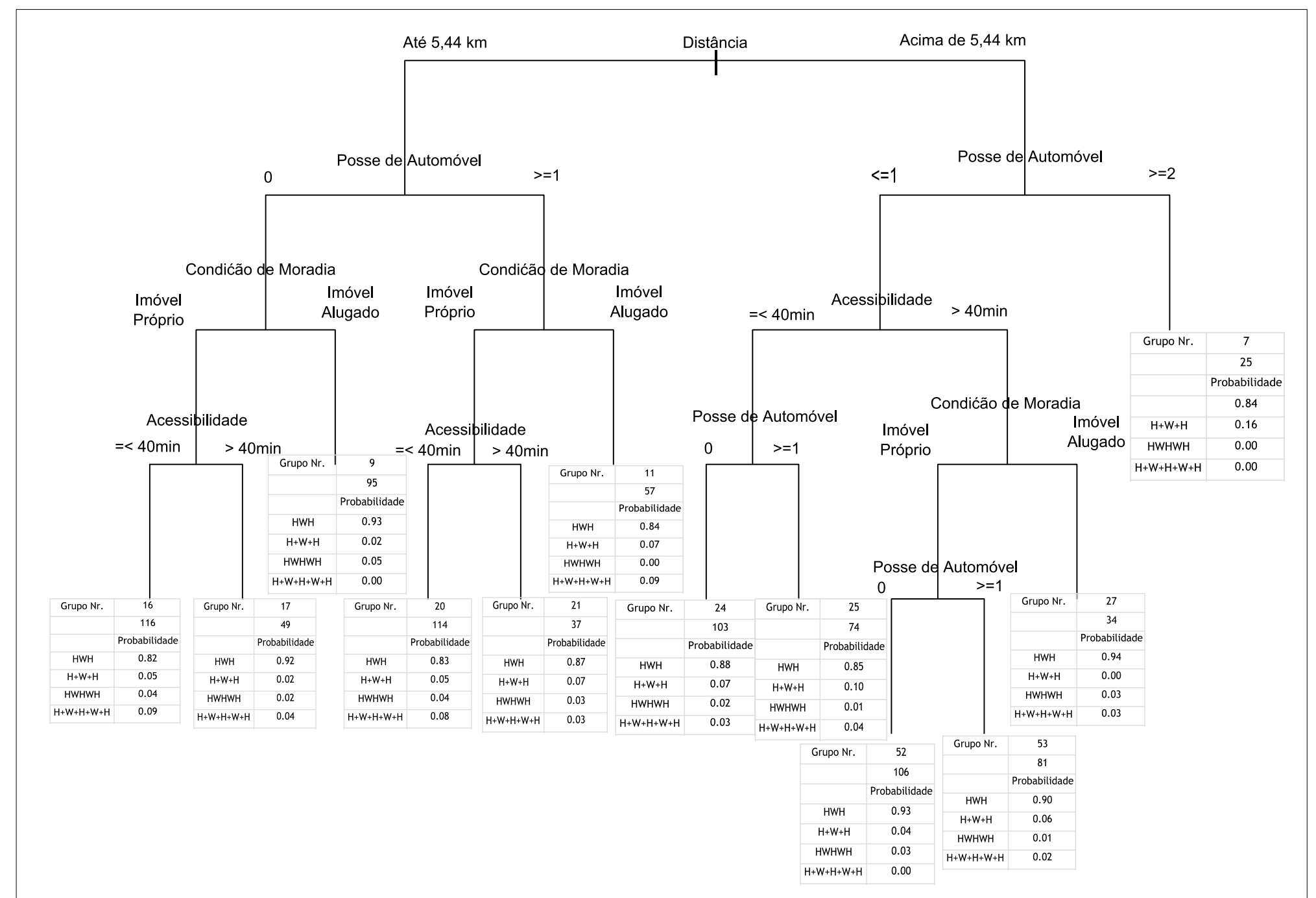

Figura 6.3 - Modelo de árvore de decisão para o conjunto de dados: amostra de indivíduos com modo predominante coletivo. 
Na primeira divisão da árvore ilustrada na Figura 6.3, a primeira variável considerada foi a distância pela rede viária, segregando a árvore em dois ramos: (1) etapas de viagens de até 5,44 km (viagens curtas); e (2) etapas de viagens acima de 5,44 km (viagens longas).

Ao selecionar a distância pela rede viária na primeira divisão binária, a árvore expressa a importância desta variável no contexto das escolhas dos padrões de viagens. Ressalta-se que a distância é uma medida comumente utilizada para representar a acessibilidade, como foi exposto no Capítulo 2.

Analisando a hierarquia da árvore, especificamente a influência da acessibilidade na classificação dos dados, a acessibilidade é utilizada como variável para segmentação em ambos os ramos. No ramo 1 ela aparece no quarto nível e no ramo 2 no terceiro nível.

No ramo 1 (etapas curtas de viagem) a acessibilidade é considerada para divisão binária, após variáveis que expressam o poder aquisitivo dos indivíduos (posse de automóvel e condição de moradia). Nas folhas 16/17 (indivíduos com etapas curtas de viagens, sem posse de automóvel no domicílio e moradia própria) observa-se a influência da acessibilidade: indivíduos com acesso às oportunidades até 40 minutos tem uma propensão 10 p.p maior para realização de padrões com maior número de viagens e atividades, que comparados aos indivíduos com acessibilidade às oportunidades acima de 40 minutos.

Nas folhas 20/21 (indivíduos com etapas curtas de viagens, com posse de automóvel no domicilio e moradia própria) há influência da acessibilidade, mas com menor intensidade nas escolhas dos padrões em comparação as folhas 16/17. A diferença na distribuição das escolhas dos padrões é de 5 p.p.

Analisando o ramo 2 (etapas longas de viagens), nas folhas 24/52 (sem posse de automóvel no domicilio) e nas folhas $25 / 53$ (com posse de automóvel no domicílio) indivíduos com acesso as oportunidades até 40 minutos tem uma propensão 5 p.p maior para realização de padrões com maior número de viagens e atividades, que comparados aos indivíduos com acessibilidade às oportunidades acima de 40 minutos. 


\subsubsection{Modelos 4-P-L e 4-P-A}

Para formação dos conjuntos individuais de alternativas foram considerados os quatro padrões de viagens. Todas as alternativas foram consideradas disponíveis a todos os indivíduos. A hipótese de interferência testada no modelo foi:

- A escolha do padrão de viagens é influenciada pelas características individuais, características do domicílio, participação em atividades e características do sistema de transportes, incluindo a acessibilidade.

Para verificação desta hipótese cada variável independente incluída no modelo foi submetida a um teste de significância para verificar se o parâmetro da variável é diferente de zero. Assim, a hipótese nula verificada pelo modelo foi:

$$
\begin{aligned}
& H_{0}: B=0 \\
& H_{1}: B \neq 0
\end{aligned}
$$

Em que B é o parâmetro da variável independente.

$\mathrm{Na}$ especificação do modelo a alternativa "HWH" foi considerada dominante, assumindo o valor zero para a sua utilidade e a função de utilidade empregada é semelhante a Equação 97.

Na Tabela 6.25 são apresentadas as medidas de desempenho do modelo logit multinomial estimado para o cálculo das probabilidades individuais para escolha padrão de viagens e na Tabela 6.26 são apresentados os valores dos parâmetros das funções de utilidade de cada alternativa com suas estatísticas de significância. Os valores marcados com "*" indicam os parâmetros que não foram significativos ao nível de $5 \%$.

Tabela 6.25 - Estatísticas do modelo de escolha do padrão de viagens: amostra de indivíduos com modo predominante privado.

\begin{tabular}{cc}
\hline Estatística do Modelo & Valor \\
\hline Parâmetros estimados & 45 \\
Observações & 711 \\
$L L\left(\beta^{\prime}=0\right)$ & $-985,655$ \\
$L L\left(\beta^{\prime}=\hat{\beta}\right)$ & $-610,598$ \\
$\rho$ & 0,335 \\
\hline
\end{tabular}


Tabela 6.26 - Estimativa do modelo de escolha do padrão de viagens: amostra de indivíduos com modo predominante privado.

\begin{tabular}{|c|c|c|c|c|c|c|c|c|}
\hline \multicolumn{2}{|l|}{ Variáveis } & \multirow{2}{*}{$\begin{array}{c}\text { HWH } \\
0\end{array}$} & \multicolumn{2}{|c|}{$\mathrm{H}+\mathrm{W}+\mathrm{H}$} & \multicolumn{2}{|c|}{ HWHWH } & \multicolumn{2}{|c|}{$\mathrm{H}+\mathrm{W}+\mathrm{H}+\mathrm{W}+\mathrm{H}$} \\
\hline 1. Constante & & & $-2,95$ & $(-6,70)$ & $-2,42$ & $(-8,02)$ & $-1,96$ & $(6,80)$ \\
\hline $\begin{array}{l}\text { 2. Duração da Atividade Trabalho (acima de } 8 \\
\text { horas) }\end{array}$ & Até 8 horas & 0 & 0,32 & $(1,65)^{*}$ & $-0,11$ & $(-0,91)^{*}$ & 0,28 & $(2,15)$ \\
\hline 3. Acessibilidade & Acima de $25 \mathrm{~min}$ & 0 & $-0,13$ & $(-0,54)^{*}$ & $-0,35$ & $(-2,10)$ & $-0,26$ & $(-1,46)^{*}$ \\
\hline 4. Distância & Acima de $5,44 \mathrm{~km}$ & 0 & $-0,03$ & $(-0,12)^{*}$ & $-0,65$ & $(-4,13)$ & $-0,25$ & $(-1,62)^{*}$ \\
\hline & De $R \$ 400$ até $R \$ 800$ & 0 & 0,29 & $(1,07)^{*}$ & $-0,14$ & $(-0,74)^{*}$ & $-0,08$ & $(-0,41)^{*}$ \\
\hline \multicolumn{9}{|l|}{ 5. Renda Individual } \\
\hline & Acima de $\mathrm{R} \$ 800$ & 0 & $-0,08$ & $(-0,26)^{*}$ & 0,30 & $(1,75)^{*}$ & 0,22 & $(1,14)^{*}$ \\
\hline & Até $R \$ 1.200$ & 0 & 0,00 & $(0,00)^{*}$ & $-0,05$ & $(-0,30)^{*}$ & 0,03 & $(0,17)^{*}$ \\
\hline \multicolumn{9}{|l|}{ 6. Renda Domiciliar } \\
\hline & Acima de $\mathrm{R} \$ 2.000$ & 0 & 0,00 & $(0,00)^{*}$ & $-0,22$ & $(-1,33)^{*}$ & $-0,07$ & $(-0,04)^{*}$ \\
\hline \multirow{3}{*}{ 7. Posse de Automóvel (1 automóvel) } & Nenhum automóvel & 0 & $-0,68$ & $(-1,31)^{*}$ & $-0,22$ & $(-0,95)^{*}$ & $-0,36$ & $(-1,29)^{*}$ \\
\hline & & & & & & & & \\
\hline & Acima de 1 automóvel & 0 & 0,04 & $(0,09)^{*}$ & 0,36 & $(2,01)$ & 0,38 & $(1,83)^{*}$ \\
\hline 8. Criança que viaja no domicílio & $\operatorname{Sim}$ & 0 & 0,04 & $(0,17)^{*}$ & $-0,04$ & $(-0,19)^{*}$ & 0,20 & $(1,05)^{*}$ \\
\hline \multirow[t]{2}{*}{ 10. Setor de Atividade Informal } & $\operatorname{Sim}$ & 0 & 0,18 & $(0,73)^{*}$ & $-0,25$ & $(-1,38)^{*}$ & 0,28 & $(1,73)^{*}$ \\
\hline & Côjuge & 0 & $-0,52$ & $(-1,16)^{*}$ & $-0,30$ & $(-1,11)^{*}$ & $-0,67$ & $(-2,02)$ \\
\hline \multirow[t]{2}{*}{ 11. Situação Familiar (Chefe) } & Filho & 0 & 0,19 & $(0,51)^{*}$ & 0,16 & $(0,70)^{*}$ & 0,68 & $(2,78)$ \\
\hline & Outros & 0 & 0,46 & $(0,92)^{*}$ & 0,14 & $(0,39)^{*}$ & 0,03 & $(0,07)^{*}$ \\
\hline
\end{tabular}


Confrontando a medida de desempenho do modelo de escolha modal obtido com os valores da Tabela 6.19, observa-se que a medida de desempenho do modelo situa-se próximo da faixa dos valores encontrado na literatura.

Com relação ao modelo, foram estimados 45 parâmetros associados às variáveis independentes e 3 associados as constantes específicas (ASC). Todos os coeficientes estimados são em sinal esperado. Há vários parâmetros calibrados que não são significantes para o nível de $5 \%$, provavelmente em função da baixa amostragem dos padrões para estas variáveis. Entretanto, estes parâmetros insignificantes foram mantidos no modelo pela sua importância na análise da segmentação da demanda.

O comportamento da variável duração da atividade sugere que indivíduos com carga horária diária inferior a 8 horas tem tendência a incorporar mais atividades aos padrões de viagens do que indivíduos sujeitos a mais de 8 horas diárias de trabalho (exceto o padrão “HWHWH”). A distância de viagem reflete restrições espaciais para escolha dos padrões com maior número de viagens e atividades.

Uma análise do efeito da renda é apresentado na Tabela 6.27. Analisando os valores das funções de utilidade apresentados nesta tabela observa-se uma propensão dos indivíduos de baixa renda (ID = 1) para realizarem padrões "HWH"; uma propensão dos indivíduos de renda média (ID = 5) para padrões de viagens " $\mathrm{H}+\mathrm{W}+\mathrm{H}$ " e "HWHWH", e; uma propensão dos indivíduos de renda alta $(I D=9)$ para padrões para padrões de viagens “H+W+H+W+H".

Tabela 6.27 - Análise dos valores das funções de utilidade para escolha do padrão de viagens para combinações de renda individual e renda domiciliar.

\begin{tabular}{ccccccc}
\hline ID & $\begin{array}{c}\text { Renda } \\
\text { Individual }\end{array}$ & $\begin{array}{c}\text { Renda } \\
\text { Domiciliar }\end{array}$ & HWH & H+W+H & HWHWH & H+W+H+W+H \\
\hline (1) & Até $R \$ 400$ & Até $R \$ 1.200$ & 0 & $-0,21$ & $-0,21$ & $-0,10$ \\
(5) & De $R \$ 400$ a R\$800 & De R\$1.200 a R\$2.000 & 0 & 0,29 & 0,13 & $-0,04$ \\
(9) & Acima de $R \$ 800$ & Acima de $R \$ 2.000$ & 0 & $-0,08$ & $-0,08$ & 0,15 \\
\hline
\end{tabular}

A posse de automóvel neste modelo é interpretada como uma variável de mobilidade. A interpretação dos parâmetros sugere que indivíduos em domicílios com mais de um automóvel são propensos a realizar padrões com um maior número de viagens. 
A presença de criança no domicílio que realiza viagem, sugere uma propensão para realização de padrões “ $\mathrm{H}+\mathrm{W}+\mathrm{H}+\mathrm{W}+\mathrm{H}$ ”. Entretanto, não há elementos para afirmar se as viagens são realizadas para realização de atividades na companhia da criança.

Trabalhadores do mercado informal são propensos a realizar cadeias de viagens por com um maior número de atividades. Não há informação no banco de dados para distinguir se o emprego das cadeias das viagens destes trabalhadores é o mesmo ou diferente, o que traria mais elementos para a análise.

Em relação a situação familiar, se o indivíduo é chefe de família ele é propenso a escolher o padrão de viagens "HWH", ao passo que se for filho ou desempenhar outro papel no domicilio o individuo o indivíduo é propenso a escolher padrões com um maior número de viagens e atividades.

Analisando a acessibilidade, indivíduos com acesso às oportunidades com tempo de viagem até 25 minutos, são propensos a realizar padrões com um maior número de viagens e atividades (“HWHWH” e “H+W+H+W+H”).

Ao reduzir à acessibilidade do indivíduo às oportunidades, aumentando o tempo de viagem pelo modo coletivo (mudança do tempo de viagem às oportunidades de trabalho para valores superiores a $25 \mathrm{~min}$ ) a propensão dos padrões passa a cadeias com menor número de viagens. 


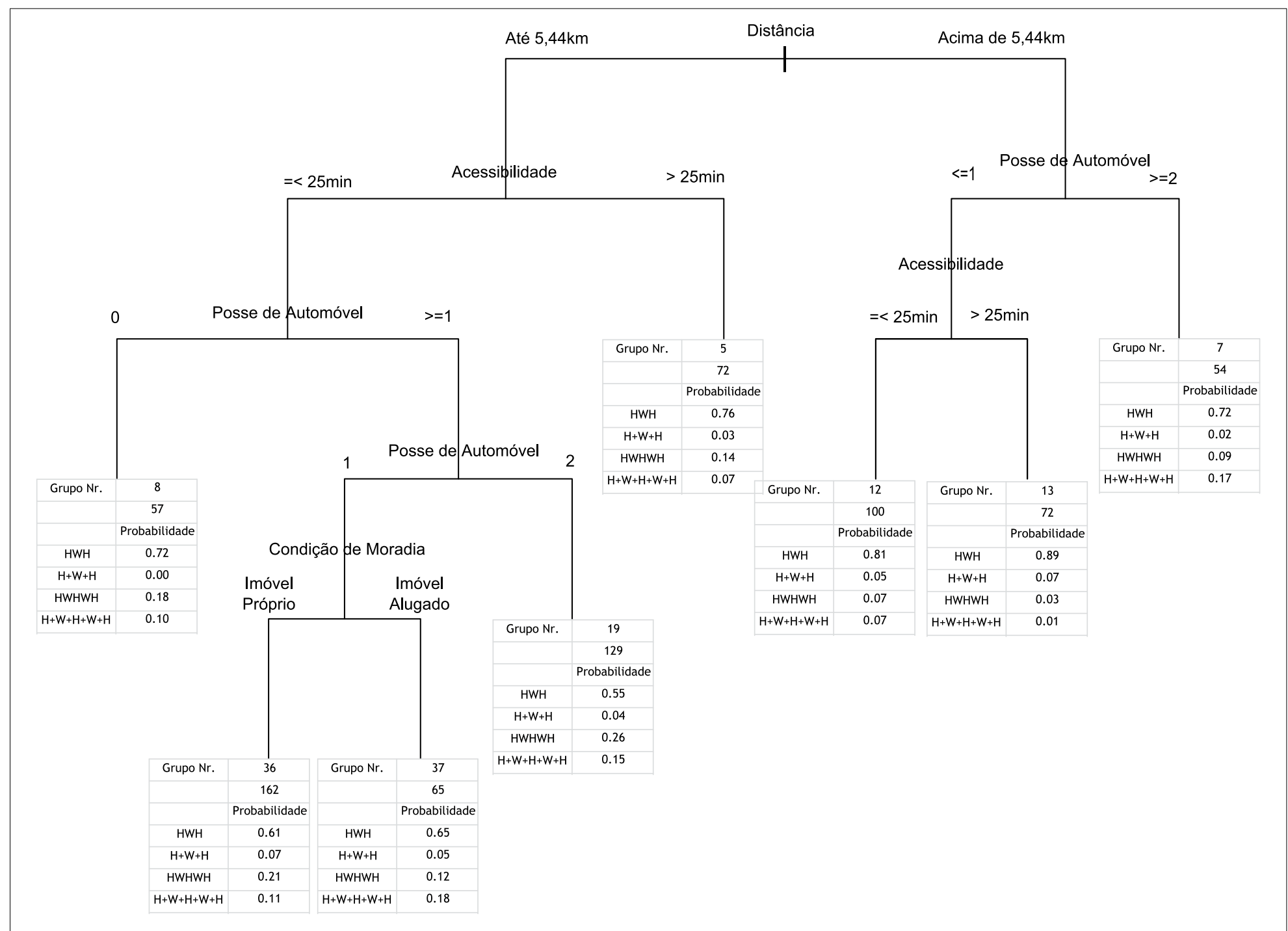

Figura 6.4 - Modelo de árvore de decisão para o conjunto de dados: amostra de indivíduos com modo predominante privado. 
Na primeira divisão da árvore ilustrada na Figura 6.4, a primeira variável considerada foi a distância pela rede viária, segregando a árvore em dois ramos: (1) etapas de viagens de até 5,44 km (viagens curtas); e (2) etapas de viagens acima de 5,44 km (viagens longas). Ao selecionar a distância pela rede viária na primeira divisão binária, a árvore expressa a importância desta variável no contexto das escolhas dos padrões de viagens.

Analisando a hierarquia da árvore, especificamente a influência da acessibilidade na classificação dos dados, a acessibilidade é utilizada como variável para segmentação em ambos os ramos. No ramo 1 ela aparece no primeiro nível e no ramo 2 no segundo nível.

No ramo 1 (etapas curtas de viagem) a acessibilidade é considerada para divisão binária, após a distância. Nas folhas $58+36+37+19 / 72$ que representam os indivíduos com etapas curtas de viagens observa-se a influência da acessibilidade: indivíduos com acesso as oportunidades até 25 minutos tem uma propensão até 21 p.p maior para realização de padrões com maior número de viagens e atividades, se comparados aos indivíduos com acessibilidade às oportunidades acima de 25 minutos.

Dentro do agrupamento baseado em etapas curtas de viagem e acessibilidade as oportunidades de até 25 minutos (folhas 58, 36, 37 e19) há variação na distribuição das probabilidades das escolhas dos padrões em função da posse de automóvel no domicilio. Neste ramo, para indivíduos sem posse de automóvel no domicilio (folha 8) a propensão para escolha de padrões com maior número de viagens e atividades é até 11 p.p menor se comparado a indivíduos com um automóvel no domicilio (folha 36) e 17 p.p menor que comparado a indivíduos com mais de um automóvel no domicilio (folha 72).

A classificação obtida pela árvore sugere que o aumento da posse do automóvel no domicilio induz a um aumento na propensão individual para escolha dos padrões com maior número de viagens.

No ramo 2 (etapas longas de viagem) a acessibilidade é considerada para divisão binária, após a distância e posse de automóvel. Nas folhas $12 / 13$ observa-se a influência da acessibilidade: indivíduos com acesso as oportunidades até 25 minutos tem uma propensão 8 p.p maior para realização de padrões com maior número de viagens e atividades, se comparados aos indivíduos com acessibilidade às oportunidades acima de 25 minutos. 


\subsection{Verificação da Hipótese Nula do Projeto}

A partir dos resultados encontrados em cada etapa do processo de modelagem e com a atenção da análise voltada para o delineamento da influência da acessibilidade no comportamento individual, são reunidos indícios para elaboração da conclusão da rejeição ou não rejeição da hipótese nula do projeto:

Acessibilidade a oportunidades influencia o comportamento dos padrões de viagens encadeadas desempenhados pelos indivíduos.

A verificação foi realizada em três etapas: significância da variável medida de acessibilidade nos modelos; verificação do desempenho dos modelos, e; verificação das relações encontradas nos modelos, conforme apresentado no quadro da Tabela 6.28.

Tabela 6.28 - Análise da hipótese nula nas etapas de modelagem do comportamento individual relacionado as escolhas de transportes.

\begin{tabular}{lccc} 
Etapas de Verificação & $\begin{array}{c}\text { Modelo de Escolha } \\
\text { Modal }\end{array}$ & $\begin{array}{c}\text { Modelo de Escolha } \\
\text { do Destino }\end{array}$ & $\begin{array}{c}\text { Modelo de Escolha do } \\
\text { Padrão de Viagens }\end{array}$ \\
\hline $\begin{array}{c}\text { Significância da variável } \\
\text { medida de acessibilidade } \\
\text { nos modelos }\end{array}$ & 1 & 1 & 1 \\
$\begin{array}{c}\text { Verificação do desempe- } \\
\text { nho dos modelos }\end{array}$ & 1 & 1 & 1 \\
$\begin{array}{c}\text { Verificação das relações } \\
\text { encontradas nos modelos }\end{array}$ & 1 & 1 & 1 \\
\hline
\end{tabular}

(-1) Rejeita-se a hipótese; (0) - Parcialmente, não há elementos para rejeitar a hipótese; (1) - Não há elementos suficientes para rejeitar a hipótese.

Sobre a significância da variável medida de acessibilidade no modelo de escolha de padrão de viagens, ressalta-se que foram encontrados valores significantes para a acessibilidade (com valores elevados para a estatística $t$ ), e que os todos os parâmetros (significantes e insignificantes) demonstraram coerência nas relações encontradas.

Se todos os valores da variável acessibilidade fossem insignificantes no modelo de escolha do padrão de viagens, a hipótese seria rejeitada, entretanto, como houve valores significativos em meio a valores insignificativos adota-se o termo "parcialmente" para não rejeitar a hipótese. Acredita-se que a insignificância de alguns parâmetros foi ocasionada devido à baixa amostragem para extração da relação da acessibilidade com os padrões de 
viagens. No Capítulo 7 é apresentado uma alternativa para este tipo de problema que ocorre durante o processo de modelagem.

Conclusão: Pela verificação realizada não há elementos para rejeitar a hipótese nula. 


\section{Capítulo 7}

\section{Considerações Finais}

\subsection{Considerações}

Juntamente com os trabalhos de Ichikawa (2002), Pitombo (2003), Souza (2004), Aguiar (2005), Silva (2006) e Pitombo (2007) esta pesquisa faz parte de uma das linhas de pesquisa da Escola de Engenharia de São Carlos (EESC) da Universidade de São Paulo (USP) que propõe a abordagem de atividades para o estudo do comportamento de viagens urbanas com a utilização da técnica de mineração de dados com o modelo de árvore de decisão.

Ichikawa (2002) demonstrou a aplicabilidade do minerador de dados para obter relações entre padrões de viagens encadeadas e as características socioeconômicas dos viajantes urbanos, utilizando dados da Região Metropolitana de São Paulo coletados na Pesquisa de Origem-Destino de 1987.

Pitombo (2003) estudou a relação entre variáveis socioeconômicas e padrões de viagens encadeadas, aplicando a técnica de mineração nos dados da Pesquisa Origem-Destino de 1987 da Região Metropolitana de São Paulo. Nesta pesquisa foi concluído que há relação entre as variáveis analisadas e os padrões de encadeamento de viagens, indicando que o minerador de dados pode ter um papel importante na análise do comportamento relacionado às viagens. 
Souza (2004) identificou que o comportamento de viajantes urbanos sofre influência de políticas urbanas, características socioeconômicas e espaciais ao comparar os resultados da extração de padrões de bases de informações utilizando a mineração de dados da Pesquisa Origem-Destino de 1997 de Bauru da Pesquisa de Entrevistas Domiciliares de 2000 da Região Metropolitana de Belém e da Pesquisa Origem-Destino de 1997 da Região Metropolitana de São Paulo.

Em Aguiar (2005) foi proposta a possibilidade de reduzir a quantidade de indivíduos na amostra de Pesquisa de Entrevistas Domiciliares, através da mineração de dados utilizando a base de informações da Região Metropolitana de Belém.

Silva (2006) demonstrou a aplicabilidade da árvore de decisão como ferramenta para previsão dos padrões de viagens encadeadas, utilizando dados da Pesquisa OrigemDestino de 1987 e 1997 da Região Metropolitana de São Paulo.

Pitombo (2007) analisou a influência de variáveis socioeconômicas, participação em atividades e uso do solo nos padrões de viagens encadeadas, utilizando a técnica de mineração e de análise de agrupamento aos dados da Pesquisa Origem-Destino de 1987 da Região Metropolitana de São Paulo.

A proposta deste trabalho, inserida à esta linha de pesquisa, foi analisar características do sistema de transportes, expressa através da acessibilidade às oportunidades, ao conjunto de variáveis socioeconomicas e de uso do solo para a melhor compreensão da formação dos padrões de viagens encadeadas.

Para análise da influência da acessibilidade no comportamento individual relacionado as escolhas de transportes, foi formulado um problema que se caracterizou como o problema central da tese:

- Como a acessibilidade a oportunidades influencia o comportamento relacionado às viagens encadeadas?

Para responder a este problema formulou-se a hipótese nula que foi submetida a um teste de verificação para confirmá-la ou refutá-la:

- Acessibilidade a oportunidades influencia o comportamento dos padrões de viagens encadeadas desempenhados pelos indivíduos. 


\subsection{Resultados Alcançados}

A hipótese formulada foi submetida a um teste de verificação delineada no Capítulo 4 deste trabalho. Para realização do experimento foram utilizados os dados disponíveis na Pesquisa Origem-Destino de Uberlândia para o ano de 2002. Após a realização do teste, a hipótese não foi rejeitada.

\subsection{Considerações sobre o Método Adotado}

Neste trabalho foi elaborado um corpo conceitual para análise da influência da acessibilidade, medida através do tempo de viagem, no comportamento individual relacionado as escolhas de transportes.

Foram propostos modelos para representação do comportamento individual em três níveis de decisão da programação diária de atividades: modo de viagem; destino da atividade primária, e; padrão de viagens, para analise da influência da acessibilidade no comportamento individual relacionado as escolhas de transportes.

Pelo método adotado, para cada nível de decisão da programação diária de atividades em que foi aplicada uma técnica de modelagem para representação do comportamento individual, foi formulada uma hipótese auxiliar, relacionada a hipótese nula do projeto, para interação das variáveis independentes (incluindo a acessibilidade) na variável dependente. Adicionalmente, para análise dos padrões de viagens foram elaborados modelos baseados em regras para investigar a dependência entre variáveis incluídas na modelagem.

Os modelos obtidos foram avaliados através de medidas de desempenhos e cada hipótese auxiliar foi submetida a um teste de verificação por meio da estatística de significância dos parâmetros estimados. A consistência das relações encontradas entre as variáveis dependentes e independentes foi, também, analisada.

A partir dos resultados encontrados em cada etapa do processo de modelagem e com a atenção da análise voltada para o delineamento da influência da acessibilidade no comportamento individual, foram reunidos indícios para elaboração da conclusão da rejeição ou não rejeição da hipótese nula do projeto (acessibilidade a oportunidades influencia o comportamento dos padrões de viagens encadeadas desempenhados pelos indivíduos) que é apresentada ao final deste capítulo. 
O método desenvolvido, e o processo de modelagem obtiveram resultados satisfatórios, contudo, durante o processo de modelagem com aplicação de modelos de escolha discreta para segmentação da demanda foram obtidos valores de significância estatística abaixo do esperado para um nível de $5 \%$. Acredita-se que a insignificância de alguns parâmetros foi ocasionada devido à baixa amostragem para extração da relação da acessibilidade com os padrões de viagens. Este problema foi discutido em Bowman (1998) que sugere a utilização de um conjunto de dados formado por Pesquisas de Preferência Revelada e Declarada para melhoria da significância estatística de variáveis na segmentação da demanda.

\subsection{Caráter Científico do Trabalho}

Este trabalho é de caráter científico na medida em que documenta, de modo público e controlável, toda a experiência da pesquisa e permite que outros pesquisadores repitam a pesquisa, quer para replicar os experimentos, quer para constatar que os resultados aqui encontrados foram de natureza casual e que não se deveram à intenção do autor, mas a outros fatores que não foram considerados.

\subsection{Recomendações a Trabalhos Futuros}

Recomenda-se aos trabalhos futuros nesta linha de pesquisa:

- Análise da acessibilidade em outros níveis da programação diária de atividades;

- Análise mais aprofundada do estudo da competição pelas oportunidades;

- Análise segmentada da influência da acessibilidade para escolha das atividades, não apenas a atividade trabalho;

- Diferenciação das oportunidades de trabalho na análise das escolhas individuais;

- A utilização de outros modelos nas etapas de representação do comportamento individual relacionado às escolhas de transportes, por exemplo, logit hierárquico para segmentação da demanda e modelo gravitacional de oportunidades intervenientes;

- Consideração dos indivíduos que realizam mais de quatro viagens e que não possuem origem da viagem no domicilio; 
- Incorporar ao padrão de viagem encadeada atributos como duração e custo da viagem;

- Na elaboração do cenário para modelagem considerar as restrições de tempo e espaço, e;

- Considerar estudos da área de ciências humanas a trabalhos de análise de comportamento do indivíduo e sua relação com a demanda por transportes. 


\section{Referências}

ADAMOWICZ, W. L.; LOUVIERE J.; WILLIAMS, M. Combining Stated and Revealed Preference Methods for Valuing Environmental Amenities. Journal of Environmental Economics and Management, vol. 26, p. 271-292, 1994.

AGUIAR, M. F. M. Possibilidade de redução no tamanho da amostra de pesquisas de entrevistas domiciliares para planejamento de entrevistas domiciliares para planejamento de transportes. 2005. 180 p. Dissertação (Mestrado) - Escola de Engenharia de São Carlos, Universidade de São Paulo, São Carlos, 2005.

AKINYEMI E. O. Understanding urban mobility and accessibility for transportation engineering purposes. In: WORD CONFERENCE ON TRANSPORTATION RESEARCH, $8^{\text {th }}, 1998$, Antwep. Proceedings... Antwerp: [?], 1998.

ALGERS, S.; DALY, A.; KJELLMAN, P.; WIDLERT, S. Stockholm model system (SIMS): Application. In: WORD CONFERENCE ON TRANSPORTATION RESEARCH, $7^{\text {th }}, 1995$, Sydney. Proceedings... Sydney: The University of New South Wales, 1995.

ALMEIDA L. M. V. Desenvolvimento de uma metodologia para análise locacional de sistemas educacionais usando modelos de interação espacial e indicadores de acessibilidade. 1999. 135 p. Tese (Doutorado) - Universidade Federal de Santa Catarina, Florianópolis, 1999.

ARENTZE, T. A; ETTEMA, D. F; TIMMERMANS, H. J. P. Incorporating time and income constraints in dynamic agent-based models of activity generation and time use: approach and illustration. Transportation Research Part C, vol. 18, n. 1, p. 71-83, 2010.

ARENTZE, T. A.; HOFMAN, F.; van MOURIK, H.; TIMMERMANS, H. J. P. Albatross: multiagent rule based model of activity pattern decisions. Transportation Research Record, $\mathrm{n}$. 1706, p. 136-144, 2000.

ARENTZE, T. A.; TIMMERMANS, H. J. P. A learning-based transportation oriented simulation system. Transportation Research Part B, vol. 38, n. 7, p. 613-633, 2004.

ARENTZE, T. A.; TIMMERMANS, H. J. P. Parametric action decision trees: Incorporating continuous attribute variables into rule-based models of discrete choice. Transportation Research Part B, vol. 41, n. 7, p. 772-783, 2007.

ARENTZE, T. A.; TIMMERMANS, H. J. P. A Need-Based Model of Multi-Day, Multi-Person Activity Generation. Transportation Research. Part B: Methodological, vol. 43, n. 2, p. 251265, 2009.

ARRUDA, J. B. F. Evaluation of urban transport projects in developing countries: an accessibility approach. 1995. 267 p. Tese (PhD) - University of Leeds, Leeds, 1995.

AULETE, F. J. C.; VALENTE, A. L. S Dicionário contemporâneo da língua portuguesa Caldas Aulete. 2001. CD-ROM. 
AVV NVVP beleidsopties verkend. Deel I: Personenvervoer. Dell II: Goederenvervoer. Rotterdam: Adviesdienst Verleer en Vervoer, 2000.

AXHAUSEN, K. W. The data needs of activity scheduling models. In: INTERNATIONAL CONFERENCE ON ACTIVITY-BASED APPROACHES: ACTIVITY SCHEDULING AND THE ANALYSIS OF TRAVEL PATTERNS, 1995, Eindhoven. Proceedings... Disponível em: http://bit.ly/zixRXf. Último Acesso em: 21 de Janeiro de 2012.

AXHAUSEN, K. W. Presenting and preserving travel data. In: TRANSPORT SURVEYS: RAISING THE STANDARD. 1997, Grainau. Working Papers... Grainau: Transportation Research Record, Transportation Research Circular E-C008, 2000. Disponível em: http://bit.ly/wPuw19. Último acesso em 21 de Janeiro de 2012.

AXHAUSEN, K. W. The limits to travel: How far will you go? Transport Reviews, vol. 30, n. 2, p. 271-273. 2010.

AXHAUSEN, K. W.; GÄRLING, T. Activity based approaches to travel analysis: conceptual frameworks, models and research problems. Transport Reviews, vol. 12, n. 4, p. 323-341, 1992.

BADOE, D.; MILLER, E. Transportation-land use interaction: empirical findings in North America, and their implications for modeling. Transportation Research Part D, vol. 5, $\mathrm{n}$. 4, p. 235-263, 2000.

BANISTER, D. Transport Planning. $2^{\text {nd }}$ ed. London: Taylor \& Franccis, 2000. 317 p.

BANISTER, D.; BROWNE, M.; GIVONI, M. Transport Reviews - The 30th anniversary of the journal. Transport Reviews, vol. 30, n. 1, p. 1-10, 2010.

BATES J. History of Demand Modeling. In: HENSHER,D. A.; BUTTON, K. J. (Ed.). Handbook of Transport Modelling. $2^{\text {nd }}$ ed. London: Elsevier, 2008. p. 11-34.

BATES J.; GUNN, H.; ROBERTS, M. A model of household car ownership: part 1. Traffic Engineering Control, vol. 19, n.1, p. 486-491, 1978.

BEAUD, M. Arte da tese: como redigir uma tese de mestrado ou de doutorado, uma monografia ou qualquer outro trabalho universitário. Tradução: Glória de Carvalho Lins - Rio de Janeiro: Betrand Brasil, 1996.

BECK, M.; GYRD-HANSEN, D. Effects coding in discrete choice experiments. Health Economics, vol. 14, n.10, p.1079-1083, 2005

BECKER, G. S. A Theory of the allocation of time. Economic Journal, vol. 75, n. 299, p. 493-517, 1965.

BEKHOR, S.; PRASHER, J. N. GEV-based destination choice models that account for unobserved similarities among alternatives. Transportation Research Part B, vol. 42, n.3, p.243-262, 2008.

BELL, J. B. Application of classification tree to the habitat preference of upland birds. Journal of Applied Statistics, vol. 23, n. 2-3, p. 349-359, 1996. 
BEN-AKIVA M.; LERMAN, S. Disaggregate travel and mobility-choice models and measuring of accessibility. In: HENSHER,D. A.; STOPHER,P. R. (Ed.). Behavioural travel modeling. London: Croom Helm, 1978. p. 654-679.

BEN-AKIVA, M.; LERMAN, S. Discrete choice analysis: theory and application to travel demand. $2^{\text {nd }}$ ed. Cambridge: The Mit Press, 1985. 390 p.

BERNARDIN, V.L.; KOPPELMAN F.; BOYCE, D. Enhanced destination choice models incorporating agglomeration related to trip chaining while controlling for spatial competition. Transportation Research Record, n. 2131, p. 243-151, 2009.

BHAT, C. R.; GOVINDARAJAN, A.; PULUGURTA, V. Disaggregate attraction-end choice modeling. Transportation Research Record, n. 1645, p. 60-68, 1998.

BHAT, C. R.; KOPPELMAN, F. S. A Retrospective and Prospective Survey of Time-Use Research. Transportation, vol. 26, n. 2, p. 119-139, 1999.

BHAT, C.R.; KOPPELMAN, F.S. Activity-based travel demand analysis: history, results and future directions. In: ANNUAL MEETING OF TRANSPORTATION RESEARCH BOARD, $79^{\text {th }}, 2000$, Washington, D.C. Proceedings... Washington: Transportation Research Board, 2000. 2 CDROM.

BHAT, C. R.; PENDYALA, R. M.; SRINIVASAN, N. Data for Understanding Our Nation's Travel. In: NATIONAL HOUSEHOLD TRAVEL SURVEY CONFERENCE, 2004, Washington. Working Papers... Washington: Transportation Research Record, Transportation Research Circular EC071, 2005. Disponível em: http://bit.ly/yKDNOJ. Último acesso em 21 de Janeiro de 2012.

BIERLAIRE, M. Estimation of discrete choice models with BIOGEME 1.8. Manual. Lausanne: Ėcole Polytechnique Féderale de Lausanne. 2009, 111 p.

BLACK J. Public inconvenience: access and travel in seven Sydney suburbs. Sydney: Australian National University, 1977.

BOWMAN, J. L. Activity based travel demand model system with daily activity schedules. 1995. 94 p. Thesis (Master) - Massachusetts Institute of Technology, Boston, 1995.

BOWMAN, J. L. The day activity schedule approach to travel demand analysis. 1998. 172 p. Dissertation (PhD) - Massachusetts Institute of Technology, Boston, 1998.

BOWMAN, J. L.: BEN-AKIVA, M. E. Activity based travel forecasting. In: ACTIVITY-BASED TRAVEL FORECASTING CONFERENCE, 1996, New Orleans. Summary, Recommendations and Compendium of Papers... New Orleans: USDOT report \#DOT-T-97-17, 1997. 32p.

BOWMAN, J. L.; BEN-AKIVA, M. E. Activity-based disaggregate travel demand model system with activity schedules. Transportation Research Part A, vol. 35, n. 1, p. 1-28, 2001.

BRADLEY, M. A.; BOWMAN, J. L. A system of activity-based models for Portland, Oregon. Washington: USDOT report number DOT-T-99-02 - Travel Model Improvement Program of the USDOT and EPA, 1998. 
BRADLEY, M.; VOVSHA, P. A model for joint choice of daily activity pattern types of household members. In: TRANSPORTATION RESEARCH BOARD ANNUAL MEETING, 84 ${ }^{\text {TH }}, 2005$, Washington. Proceedings... Washington: Transportation Research Board, 2005. DVD-ROM.

BRASIL. Ministério do Trabalho e Emprego. RAIS - Relação Anual de Informações Sociais 2002. Elaboração de estatísticas do trabalho. 2002.

BRÖCKER, J. Partial equilibrium theory of interregional trade and the gravity model. Papers of the Regional Science Association, vol. 66, n.1, p. 7-18, 1989.

BRUTON, M.J. Introdução ao planejamento dos transportes. Tradução por João F.F. Arruda et al. Rio de Janeiro: Interciência/São Paulo, EDUSP, 1979.

BULIUNG, R.; ROORDA, M. J.; REMMEL, T. K. Exploring spatial variety in patterns of activity-travel behaviour: initial results from the toronto travel-activity panel survey (TTAPS). Transportation, vol. 35, n. 6, p. 697-722, 2008.

BURNS, L. D.; GOLOB, T. F. The role of accessibility in basic transportation choice behavior. Transportation, vol. 5, n. 2, p. 175-198, 1976.

CATANESE A. J. Home and workplace separation in four urban areas. Journal of American Institute of Planners, vol. 37, n. 5, p. 331-337, 1971.

CHAPIN, F.S. Human activity patterns in the city: things people do in time and space. New York: John Wiley \& Sons, 1974. 296 p.

CIRILLO, C.; AXHAUSEN, K. W. Mode choice of complex tours. In: EUROPEAN TRANSPORT CONFERENCE, 1995, Cambridge. Proceedings... Disponível em: http://bit.ly/xL4Gwy. Último Acesso em: 21 de Janeiro de 2012.

COOLS, M.; MOONS, E.; WETS, G. Assessing the impact of weather on traffic intensity. Weather, Climate, and Society, vol. 2, n. 2, p. 60-68, 2010.

CULLEN, I.; GODSON, V. Urban networks: the structure of activity patters. London: Pergamon Press, 1975. $93 \mathrm{p}$.

CURTIS, C.; SCHEURER, J. Planning for sustainable accessibility: developing tools to aid discussion and decision-making. Progress in Planning, vol. 74, n. 2, p. 53-106, 2010.

DARGAY J. The effect of income on car ownership: evidence of asymmetry. Transportation Research Part A, vol. 35, n. 9, p. 807-821, 1971.

DAVIDSON, K.B. Accessibility and isolation in transportation network evaluation. In: WORD CONFERENCE ON TRANSPORTATION RESEARCH, $7^{\text {th }}, 1995$, Sydnei, Australia. Proceedings... Sydney: The University of New South Wales, 1995.

DAVIDSON, W.; DONNELLY, R.; VOVSHA, P.; FREEDMAN, J.; RUEGG, S.; HICKS, J.; CASTIGLIONE, J.; PICADO, R. Transportation Research Part A, vol. 41, n. 5, p. 464 - 488, 2007.

DETR Transport 2010: the background analysis. Department of the Environment. London, 2000. 
DOHERTY, S. T. Interactive methods for activity scheduling processes. In: Goulias, K. G. (Ed.). Transportation systems planning: methods and applications. Boca Raton: CRC Press, 2002. p. 7.1-7.25

DONG, X.; BEN-AKIVA, M.E.; BOWMAN, J.L.; WALKER, J. Moving from trip-based to activitybased measures of accessibility. Transportation Research Part A, vol. 40, n. 2, p. 163 180, 2006.

DOUBLEDAY, C. The effects of differing levels of spatial mobility: a discussion. Transactions of the Martin Centre for Architectural and Urban Studies, vol. 1, p. 95-112, 1979.

DUNPHY, R. T. Transit accessibility as a determinant of automobile ownership. Highway Research Record, n. 472, p. 63-71, 1973.

ELLAWAY A.; MACINTTYRE, S.; HISCOCK, R.; KEARNS, A. In the driving seat: psychosocial benefits from private motor vehicle transport compared to public transport. Transportation Research Part F, vol. 6, n. 2, p. 217-231, 2003.

ETTEMA, D. Activity-based travel demand modeling. 1996. 280 p. Dissertation (PhD) Technische Universiteit Eindhoven, Eindhoven, The Netherlands, 1996.

ETTEMA, D. F.; SCHWANEN, T.; TIMMERMANS, H. J. P. The effect of locational mobility and socio-demographic factors on task and time allocation in households. Transportation, vol. 34, n. 1, p. 89-105, 2007.

ETTEMA, D.; TIMMERMANS, H. Space-time accessibility under conditions of uncertain travel times: theory and numerical simulations. Geographical Analysis, vol. 39, n. 2, p. 217-240, 2007.

FARRINGTON, J. H. The new narrative of accessibility: its potential contribution to discourses in (transport) geography. Journal of Transport Geography, vol. 15, n. 5, p. 319330, 2007.

FERDOUS, N.; PINJARI A. R.; BHAT C. R.; PENDYALA, R. M. A comprehensive analysis of household transportation expenditures relative to other goods and services: an application to United States consumer expenditure data. Transportation, vol. 37, n. 3, p. 363-390, 2010.

FORTHERINGHAM, A. S. A new set of spatial interaction models: the theory of competing destinations. Environment and Planning A, vol. 15, n. 1, p. 15-36, 1983.

FROST, M.; SPENCE, N. Work travel responses to changing workplaces and changing residences. In: BROTCHIE, J.; BATTY, M.; BLAKELY, E.; HALL, P.; NEWTON, P. (Eds) Cities in Competition. Productive and Sustainable Cities for the 21st Century. Melbourne: Longman Australia, 1995. p. 359-381.

GAHEGAN, M. The case for inductive and visual techniques in the analysis of spatial data. Geographical Systems, vol. 7, n. 2, p. 77-83, 2000.

GÄRLING, T.; GILHOLM, R.; GÄRLING, A. Reintroducing attitude theory in travel behavior research: the validity of an interactive interview procedure to predict car use. Transportation, vol. 25, n. 2, 129-146, 1998. 
GEURS, K. T.; ECK, G. Accessibility measures: review and applications. RIVM report 408505 006. Amsterdan: National Institute of Public Health and the Environmente, 2001, 265 p.

GEURS, K. T.; WEE, B. Accessibility evaluation of land-use and transport strategies: review and research directions. Journal of Transport Geography, vol. 12, n. 2, p. 127-140, 2004.

GLIEBE, J. P.; KOPPELMAN, F. S. Modeling household activity-travel Interactions as parallel constrained choices. Transportation, vol. 32, n. 5, p. 449-471, 2005.

GOLLEDGE, R. Building on the Down Under experience. In: King, L. J. (Ed.). North American Explorations: Ten Memoirs of Geographers from Down Under. Victoria, BC: Trafford Publishing, 2007. p. 18- 35.

GOLLEDGE, R. G.; GÄRLING, T. Cognitive maps and urban travel. In: HENSHER, D.; BUTTON, K.; HAYNES, K.; STOPHER, P. (Ed.). Handbook of Transport Geography and Spatial Systems. Amsterdam: Elsevier, 2004. p. 501-512.

GOODWIN, P. B. A review of new demand elasticities with special reference to short and long run effects of prices changes. Journal of Transport Economics and Policy, vol. 26, $\mathrm{n}$. 2 , p. 155-169, 1992.

GUO, J. Y; BHAT, C. R. Population synthesis for microsimulating travel behavior. Transportation Research Record, n. 2014, p. 92-101, 2007.

HÄGERSTRAND, T. What about people in regional science? Papers of the Regional Science Association, n. 23, p. 7-23, 1970.

HAIR, J.F.; TATHAM, R. L.; ANDERSON, R. E.; BLACK, W. Multivariate Data Analysis. $5^{\text {th }}$ ed. New Jersey: Prentice-Hall, 1998, 730p.

HANNES, E.; JANSSENS, D.; Wets, G. Destination Choice in Daily Activity Travel: Mental Map's Repertoire. Transportation Research Record, n. 2054, p. 20-27, 2008.

HANNES, E.; JANSSENS, D.; Wets, G. Does space matter? Travel mode scripts in daily activity travel. Environment and Behavior, vol. 41, n. 1, p. 75-100, 2009.

HANSEN, E. How accessibility shapes land use. Journal of the American Institute of Planners, vol. 25, n. 2, p. 73-76, 1959.

HAYES-ROTH, B.; HAYES-ROTH, F. A cognitive model of planning. Cognitive Science, vol. 3, n. 4 p. 275-310, 1979.

HENSHER, D. A.; ROSE, J. M.; GREENE, W. H. Applied choice analysis: a primer. Cambridge: Cambridge University Express, 2005. 717p.

HESS, S.; BIERLAIRE, M.; POLAK, J. W. Estimation of values of travel-time savings using mixed logit models. Transportation Research Part A, vol. 39 n. 3, p.221-236, 2005.

HILLMAN, M. E.; WHALLEY, A. Fair play for all: a study of access to sport and informal recreation. London: PEP Broadsheet 571, Political and Economic Planning, London, 1977. 
HSU, C-I.; HSIEH, Y-P. Travel and activity choices based on an individual accessibility model. Papers in Regional Science, vol. 83, p. 387-406, 2004.

ICHIKAWA, S. M. Aplicação de minerador de dados na obtenção de relações entre padrões de encadeamento de viagens codificados e características sócio-econômicas. 2002. 136 p. Dissertação (Mestrado) - Escola de Engenharia de São Carlos, Universidade de São Paulo, São Carlos, 2002.

ICHIKAWA, S.M; PITOMBO, C.S.; KAWAMOTO, E. Aplicação de Minerador de Dados na Obtenção de Relações entre Padrões de Viagens Encadeadas e Características Sócioeconômicas. In: PANORAMA NACIONAL DE PESQUISA EM TRANSPORTES 2002, XVI ANPET, 2002, Natal. Anais... Natal: Associação Nacional de Ensino e Pesquisa em Transportes v.2, p.175-186.

INGRAN, D. R. The concept of accessibility: a search for an operational form. Regional Studies. vol. 5, n. 2, p.101-107, 1971.

INSTITUTO BRASILEIRO DE GEOGRAFIA E ESTATÍSTICA - IBGE. Censo 2010 - Recenseamento Populacional. Apresenta informações sobre o recenseamento da população de Uberlândia do ano 2010, Rio de Janeiro, 2010.

JANUÁRIO, M. H.; CAMPOS, V. B. G. Determinação de níveis de acessibilidade do transporte público. In: CONGRESSO LATINOAMERICANO DE TRANSPORTE PUBLICO Y URBAO, VIII, 1996, Rio de Janeiro. Anais... 1996, Rio de Janeiro: ANTP. Disquetes

JARA-DÍAZ, S. Transport economic theory. London: Elsevier, 2007. 140p.

JONES, S. R. Accessibility measures: a literature review. Washington: Transport and Road Research Laboratory, Department of the Environment, Department of Transport, Laboratory Report 967, 1981.

JONES, P.; CLARKE, M.; DIX, M. Understanding travel behavior. Aldershot: Gower, 1983.

JONES, P.; KOPPELMAN F.; ORFUEIL, J.P. Activity analysis: State-of-the-art and future directions. In: JONES, P. (Ed.) Developments in Dynamic and Activity-Based Approaches to Travel Analysis, Aldershot: Gower Publishing, 1990. p. 34-55.

KANAFANI, A. Transportation Demand Analysis. New York: McGraw-Hill, 1983. 320 p.

KATO, H.; MATSUMOTO, M. Intra-household interaction in a nuclear family: a utilitymaximizing approach. Transportation Research Part B, vol. 43, n. 2, p.191-203, 2009.

KITAMURA, R. A sequential, history dependent approach to trip-chaining behavior. Transportation Research Record, n. 944, p. 22-38, 1984.

KITAMURA, R. Applications of models of activity behavior for activity based demand forecasting. In: ACTIVITY BASED TRAVEL FORECASTING CONFERENCE, 1996. Summary, Recommendations, and Compendium of Papers... Washington: US-DOT-EPA-DE, 1997. p. 119-150.

KITAMURA, R. Transportation research. Encyclopedia of Social Measurement. vol. 3, p. 869-874, 2004. 
KITAMURA, R.; MOHAMAD, J. Rapid motorization in Asian cities: urban transport infrastructure, spatial development and travel behavior. Transportation, vol. 36, n. 3, p. 269-274, 2009.

KITAMURA, R.; MOKHTARIAN P. L; LAIDET, L. A micro-analysis of land use and travel in five neighborhoods in the San Francisco bay area. Transportation, vol. 24, n. 2, p. 125-158, 1997.

KNIGHT, R. L.; TRYGG, L. L. Evidence of land use impacts of rapid transit systems. Transportation, vol. 6, n. 3, p. 231-247, 1977.

KOENIG, J. C. Accessibility and individual behaviour. In: PTRC Annual Meeting, 1978. Proceedings... London: PTRC, 1978.

KRYGSMAN, S.; ARENTZE, T. A.; TIMMERMANS, H. J. P. Capturing tour mode and activity choice interdependencies: A co-evolutionary logit modelling approach. Transportation Research Part A, vol. 41. n. 10. 913-933, 2007.

KÜHLKAMP, N. Modelo de oportunidades intervenientes de distribuição de viagens, com ponderação das posições espaciais relativas das oportunidades. 2003. 197 p. Tese (Doutorado) - Universidade Federal de Santa Catarina, Florianópolis, 2003.

KUIPERS B. J. Modeling spatial knowledge. Cognitive Science, vol. 2, p. 129-153, 1978.

KUPPAM, A. R; PENDYALA, R. M. A Structural Equations Analysis of Commuter Activity and Travel Patterns. Transportation, vol. 28, n. 1, p. 33-54, 2001.

KWAN , M-P Space time and integral measures of individual accessibility: a comparative analysis using a point-based framework. Geographical Analysis, vol. 30, n. 3, p. 191-216, 1998.

KWAN, M-P.; MURRAY, A. T.; O'KELLY, M.; TIERFELSDORF, M. Recent advances in accessibility research: representation, methodology and applications. Journal of Geographical Systems, vol. 5, n. 1, p. 129-138, 2003.

KWAN, M-P.; WEBER, J. Scale and accessibility: implications for the analysis of land-use travel interaction. Applied Geography, vol 28, n. 2, p. 110-123, 2008.

LEE M. S; GOULIAS, K. G. Accessibility indicators for transportation planning using GIS. In: TRANSPORTATION RESEARCH BOARD ANNUAL MEETING, 76 ${ }^{\mathrm{TH}}$, 1997, Washington. Proceedings... Washington: Transportation Research Board, 1997. 2 CD-ROM.

LENNTORP, B. Paths in space-time environments: a time-geographic study of movement possibilities of individuals. Lund: University of Lund, 1976.

LEENTORP, B. A time-geographic simulation model of individual activity programmes. In: CARLSTEIN, T.; PARKES, D.; THRIFT, N. (Ed.). Human activity and time geography. London: Edward Arnold, 1978. p. 162-168.

LOUVIERE, J. J.; HENSHER, D. A.; SWAIT, J. D. Stated Choice Methods and Analysis. Cambridge: Cambridge University Press, 2000. 
Referências

MAGALHÃES, M.T.Q.; TEIXEIRA, G.L.; YAMASHITA, Y. Indicadores de cobertura espacial para diagnóstico da dotação de estrutura de circulação rodoviária brasileira, In: PANORAMA NACIONAL DE PESQUISA EM TRANSPORTES 2004, XVII ANPET, 2004, Florianópolis Anais... Florianópolis: Associação Nacional de Ensino e Pesquisa em Transportes, 2004, vol. 2, p. 880-891

MALHOTRA, N. K. Pesquisa de Marketing: uma orientação aplicada. Porto Alegre: Editora Bookman, 2001.

MARK, T. L.; SWAIT, J. Using stated preference and revealed preference modeling to evaluate prescribing decisions. Health Economics, vol. 13, n. 6, p. 563-573, 2004.

MATTSON, L. G.; WEIBULL, J. Competition and accessibility on a regional labour market. Regional Science and Urban Economics, vol. 11, n. 4, p. 471-497, 1981.

MCFADDEN, D. Conditional logit analysis of qualitative choice behavior. In: ZAREMBKA, P. Frontiers in econometrics. New York: Academic Press, 1973. p. 105-142.

MCFADDEN, D. Modelling the choice of residential location. In: KARLQUIST, A.; LUNDQUIST, L.; SNICKARS; WEIBULL; J. Spatial Interaction Theory and Planning Models. Amsterdam: North Holland, 1977.

MCFADDEN, D. Disaggregate behavioural travel demand's RUM side: a 30-year retrospective. In: HENSHER, D. A. Travel behaviour research. The leading edge. Amsterdam: Pergamon, 2001. p. 17-63.

MCFADDEN, D.; TRAIN, K. Mixed MNL models for discrete response. Journal of applied econometris, vol. 15, n. 5, p. 447-470, 2000.

MCNALLY, M. G.; RINDT, C. R. The activity based approach, Irvine. UCI-ITS-AS-WP-07-1. Irvine: Institute of Transportations Studies da University of California, 2008.

MEISTER, K.; FRICK, M.; AXHAUSEN, K. W. Generating daily activity schedules for households using genetic algorithms. In: Swiss Transport Research Conference, $5^{\text {th }}, 2005$. Proceedings... Ascona: IVT-ETH, 2005. Disponível em http://bit.ly/xO5UZe. Último acesso em: 21 de Janeiro de 2012.

MILLER, H. J. A measurement theory for time geography. Geographical analysis, vol. 37, n. 1, p. 17-45, 1995.

MILLER, H. J. Measuring space-time accessibility benefits within transportation networks: basic theory and computation procedures. Geographical analysis, vol. 31, n. 2, p. 187-212, 1999.

MOKHTARIAN, P. L.; SALOMON I. How derived is the demand for travel? Some conceptual and measurement considerations. Transportation Research Part A, vol. 35, n. 8, p. 695719, 2001.

MOONS, E.; WETS, G.; AERTS, M.; ARENTZE, T. A; TIMMERMANS, H. J. P. The impact of simplification in a sequential rule-based model of activity-scheduling behavior. Environment and Planning A, vol. 37, n. 3. p. 551-568, 2005. 
NAESS, P. Accessibility, activity participation and location of activities: exploring the links between residential location and travel behaviour. Urban Studies, vol. 43, n. 3, p. 627652, 2006.

NEUBURGER, $\mathrm{H}$. User benefits in the evaluation of transport and land-use plans. Journal of Transport Economics and Policy. vol. 5, n. 1, p.52-75, 1971.

NIERMEIER, D. A Accessibility: an evaluation using consumer welfare. Transportation, vol. 24, n. 4, p. 377-396, 1997.

O'KEEFE, J.; NADEL, L. The hippocampus as a cognitive map. London: Oxford University Press, 1978. 570p.

ORGANISATION FOR ECONOMIC CO-OPERATION AND DEVELOPMENT Transport requirements for urban communities: planning for personal travel. Working Document of the Road Research Programme Research Group T11, 1977.

ORTÚZAR, J.D.; WILLUMSEN, L.G. Modeling Transport. $3^{\text {rd }}$ ed. London: John Wiley \& Sons, 2001. 439p.

OWENS, S. From "predict and provide" to "predict and prevent"?: pricing and planning in transport policy. Transport Policy, vol. 2, n. 1, p. 43-49, 1995

PALMA, A.; PICARD, N.; WADDEL, P. Discrete choice models with capacity constraints: an empirical analysis of the housing market of the greater Paris region. Journal of Urban Economics, vol. 62, n. 2, p. 204-230, 2007.

PANT, P. D.; BULLEN, A. G. R. Urban activities, travel, and time: relationships from national time-use survey, Transportation Research Record, n. 750, p.1-6, 1982.

PAS, E. I. Recent Advances in Activity-Based Travel Demand Modeling. In: Activity-Based Travel Forecasting Conference, Arlington, 1996. Summary, Recommendations and Compendium of Papers... [?]: [?], 1997. Disponível em http://bit.ly/xBlHfW. Último Acesso em 20 de Janeiro de 2012.

PFEIFFER, L. M.; STRAMBI, O. Análise e modelagem da evolução temporal da posse de autos na Região Metropolitana de São Paulo. Transportes, v. 13, p. 21-29, 2005.

PINDYCK, R. S.; RUBINFELD, D. L. Econometrics models and economic forecasts. $4^{\text {th }}$ ed. London: McGraw-Hill, 1998. 634p.

PITOMBO, C. S. Estudos de relações entre variáveis socioeconômicas, de uso do solo, participação em atividades e padrões de viagens encadeadas urbanas. 2007. 285 p. Tese (Doutorado) - Escola de Engenharia de São Carlos, Universidade de São Paulo, São Carlos, 2007

PITOMBO, C.S.; KAWAMOTO, E. Aplicação de técnicas de análises multivariadas de dados em um estudo exploratório da influência do uso do solo nas escolhas de padrões de encadeamento de viagens. In: PANORAMA NACIONAL DE PESQUISA EM TRANSPORTES 2005, XIX ANPET, 2005, Recife. Anais... Recife: Associação Nacional de Ensino e Pesquisa em Transportes, v.1, p.399-412.

PITOMBO, C.S.; SOUSA, P.B.; KAWAMOTO, E. A influência de mudanças contextuais nos 
padrões de encadeamento de viagens urbanas. In: PANORAMA NACIONAL DE PESQUISA EM TRANSPORTES 2004, XVIII ANPET, Florianópolis. Anais... Florianópolis: Associação Nacional de Ensino e Pesquisa em Transportes v.1, p.687-698.

PITOMBO, C. S. Análise do comportamento subjacente ao encadeamento de viagens através do uso de minerador de dados. 2003. 149 p. Dissertação (Mestrado) - Escola de Engenharia de São Carlos, Universidade de São Paulo, São Carlos, 2003.

PITOMBO, C. S.; KAWAMOTO, E.; QUINTANILHA, J. A. Investigação da influência do uso do solo e das características socioeconômicas na sequência de deslocamentos dos industriários na Região Metropolitana de São Paulo. In: PANORAMA NACIONAL DE PESQUISA EM TRANSPORTES 2006, XX ANPET, 2006, Brasília. Anais... Brasília: Associação Nacional de Ensino e Pesquisa em Transportes v.1, p. 541-552.

QUINLAN, J. R. Learning efficient classification procedures and their application to chess end-games. In: MICHALSKI, R. S.; CARBONELL, J. G.; MITCHELL, T. M. Machine Learning: An Artificial Intelligence Approach. [New York]: Morgan Kaufmann Publishers, Inc., 1983. p. $463-482$.

RAIA JR, A. A. Acessibilidade e mobilidade na estimativa de um índice de potencial de viagens utilizando Redes Neurais Artificiais e Sistemas de Informações Geográficas. 2000. 217 p. Tese (Doutorado) - Escola de Engenharia de São Carlos, Universidade de São Paulo, São Carlos, 2000.

RAIA JR., A. A.; SILVA, A.N.R.; BRONDINO, N. C. M Comparação entre medidas de acessibilidade para aplicação em cidades brasileiras de médio porte. In: PANORAMA NACIONAL DE PESQUISA EM TRANSPORTES 1997, VII ANPET, 1997, Rio de Janeiro. Anais... Rio de Janeiro: Associação Nacional de Ensino e Pesquisa em Transportes, 1997, p. 541-552.

RECKER, W. W.; CHEN, C.; MCNALLY, M. G. Measuring the impact of efficient household travel decision on potential travel time savings and accessibility gains. Transportation Research Part A, vol. 35, n. 4, p. 339-369, 2001.

RECKER, W. W.; MCNALLY, M. G.; ROOT, G. S. A model of complex travel behavior: part II an operation model. Transportation Research Part A, vol. 4, n. 20, p. 319-330, 1986a.

RECKER, W. W.; MCNALLY, M. G.; ROOT, G. S. A model of complex travel behavior: part I theoretical development. Transportation Research Part A, vol. 4, n. 20, p. 307-318, 1986b.

RIBEIRO, R.; CUNHA, S.; BORGES, M. M. C. O mercado de trabalho na cidade de Uberlândia. In: Seminário sobre a Economia Mineira, X, 2002, Belo Horizonte. Anais... Disponível em http: / /bit.ly/AuZf8u. Último acesso em 20 de Janeiro de 2012.

RIETVELD, P. (2002). Rounding of arrival and departure times in travel surveys: an interpretation in terms of scheduled activities. Journal of Transportation and Statistics, vol. 5, n. 1, p. 71-81, 2002.

ROORDA, M. J.; CARRASCO, J. A.; MILLER, E. J. (2009) A joint model of vehicle transactions, activity scheduling, and mode choice. Transportation Research Part B, vol. 43, n. 2, p. 217-229, 2009. 
ROORDA, M. J.; RUIZ, T. Long and Short-term Dynamics in Activity Scheduling: A Structural Equations Approach. Transportation Research Part A, vol 42, n. 3, p. 545-562, 2008.

ROSEN, D.; SHANKAR, V. N.; ULFARSSON, G. F. The relationship of shopping activity duration and travel time with planning-level network and socio-economic factors. Transportation Research Record, n. 1894, p. 160-169, 2004.

ROUWENDAL, J.; POMMER, J. An indirect utility model of multiple car ownership and use. Working Paper 04-085/3, Tinbergen: Tinbergen Institute, 2004.

RUITER, E. R. Toward a better understanding of intervening opportunities model. Transportation Research, vol. 1, n. 1, p. 47-56, 1967.

SCHNEIDER, M. Gravity models and trip distribution theory. Papers and Proceedings on the Regional Science Association, vol. 5, p. 51-56, 1959.

SCHÖNFELDER, S.; AXHAUSEN, K. W. Urban Rhythms and Travel Behaviour: Spatial and temporal phenomena of daily travel. Farnham: Ashgate, 2010. 248 p.

SHEN, Q. Location characteristics of inner-city neighborhoods and employment accessibility of low-wage workers. Environment and Planning B, vol. 25, n. 3 p. 345-365, 1998.

SHINDLER, R.; FERRARI, M. G. Auto ownership as affected by transportation System alternatives. Traffic Engineering, vol. 38, n.1, p. 24-28, 1967.

SILVA, M. A. (2006) Verificação da aplicabilidade da técnica de mineração de dados na previsão da demanda por transporte de passageiros urbanos usando dados da Região Metropolitana de São Paulo. 2006. 176 p. Dissertação (Mestrado) - Escola de Engenharia de São Carlos, Universidade de São Paulo, São Carlos, 2006.

SILVA, M.A ; KAWAMOTO, Eiji . Aplicação da técnica de mineração de dados na previsão da demanda por passageiros urbanos. In: PANORAMA NACIONAL DE PESQUISA EM TRANSPORTES 2006, XX ANPET, 2006, Brasília. Anais... Brasília: Associação Nacional de Ensino e Pesquisa em Transportes v.1, p. 528-540.

SIMON, H. A. Models of Bounded Rationality, volume 1: Economic Analysis and Public Policy. $1^{\text {st }}$ ed. Cambridge: MIT Press Books, 1984.

SOHN, K.; YUN, J. Separation of car-dependent commuters from normal-choice riders in mode-choice analysis. Transportation, vol. 36, n. 4, p. 423-436, 2009.

SOUZA, P. B. Análise comparativa do encadeamento de viagens através de três áreas urbanas. 2004. 130 p. Dissertação (Mestrado) - Escola de Engenharia de São Carlos, Universidade de São Paulo, São Carlos, 2004.

SRINIVASAN, K. K; ATHURU, S. R. Analysis of whithin-household effects and between household differences in maintenance activity allocation. Transportation, v. 32, n. 5, p.495-521, 2005.

SRINIVASAN, S.; BHAT, C. R. Modeling household interactions in daily in-home an out-ofhome maintenance activity participation. Transportation, vol 32, n. 5, p.523-544, 2005. 
STEED, J. L.; BHAT, C. R. On modeling departure time choiuce for home-based social/recreational and shopping trips. Transportation Research Record, n. 1706, p. 152159, 2000.

STEGMAN, M.A. Accessibility models and residential location. Journal of the American Institute of Planners, v.35, n. 1, p. 22-29, 1969.

STOUFFER, S. A Intervening opportunities and competing migrants. Journal of Regional Science, vol. 2, n. 1, p. 845-867, 1960.

STOUPHER, S. A Intervening opportunities: a theory relating mobility and distance. American Sociological Review, vol. 5, n. 5, p. 845-867, 1940.

SWAIT, J.; BEN-AKIVA, M. Empirical test of a constrained choice discrete model: mode choice in São Paulo. Transportation Research Part B, vol. 21, n. 2, p. 103-115, 1987.

THILL, J.; KIM, M. Trip making, induced travel demand, and accessibility. Journal of Geographical Systems, vol. 7, n. 2, p. 229-248, 2005.

THILL, J.; WHEELER, A. Tree induction of spatial choice behavior. Transportation Research Record, n. 1719, p. 250-258, 2000.

THOMAS, R. S. An interpretation of the journey to work on Merseyside using entropymaximizing methods. Environment and Planning A, vol. 9, n. 7, p. 817-834, 1977.

TRAIN, K. A structured logit model of auto ownership and mode choice. The review of Economics Studies, vol. 47, n. 2, p. 357-370, 1980.

TRAIN, K. Qualitative choice analysis: theory, econometrics, and application to automobile demand. Cambridge: MIT Press, 1990.

TRAIN, K. Discrete choice methods with simulation. $2^{\text {nd }}$ ed. Cambridge: Cambridge University, 2009. $342 \mathrm{p}$.

TRAIN, K.; MCFADDEN, D. The goods/leisure trade-off and disaggregate work trip mode choice models. Transportation Research, vol. 12, p. 349-353, 1978.

TVERSKI, A. Elimination by aspects: a theory of choice. Pychological Review, vol. 79, n. 3, p. 281-299, 1972.

UNIVERSIDADE FEDERAL DE UBERLÂNDIA - UFU. Pesquisa Origem-Destino de Uberlândia, 2002.

ULYSSÉA NETO, I. The development and testing of a non-recursive aggregate passenger travel demand modeling approach. 1988. Dissertation (PhD) - Bristol University, 1988.

VAN DE BILT, K.-A. Desenvolvimento e validação de um procedimento de projeção desagregada a um modelo de geração de viagens baseado em análise de segmentação. 2002. 164 p. Tese (Doutorado) - Escola Politécnica, Universidade de São Paulo, São Paulo, 2002. 
VICKERMAN, R. Accessibility, attraction, and potential: a review of some concepts and their use in determining mobility. Environment and Planning A, vol. 6, n. 6, p. 675-691, 1974.

VOVSHA, P.; CHIAO, K-A. Development of New York Metropolitan Transportation Council Tour-Based Model. In: BHAT, C. R. et al. Transportation Research Board Conference Proceedings. Washington: Transporation Research Board, 2008. n. 2, vol. 42, p. 21-23.

VOVSHA P.; BRADLEY, M. Hybrid Discrete Choice Departure-Time and Duration Model. Transportation Research Record, n. 1894, p. 46-56, 2004.

WEE, B. Land use and transport: research and policy challenges. Journal of Transport Geography, v. 10, n. 4, p. 259-271, 2002.

WEE, B.; HAGOORT, M. J.; ANNEMA, J. A. Accessibility measures with competition. Journal of Transport Geography, vol. 9, n. 3, p. 199-208, 2001.

WEIBULL, J. W. An axiomatic approach to the measurement of accessibility. Regional Science and Urban Economics, vol. 6, p. 357-379, 1976.

WEIBULL, J. W. On the numerical measurement of accessibility. Environment and Planning A, vol.30, n. 12, p. 53-67, 1980.

WEISBROD, G. E.; LERMAN, S. R.; BEN-AKIVA, M. Trade-offs in residential location decisions: transportation versus other factors. Transport Policy and Decision Making, vol. 1, n. 1, p. 13-26, 1980.

WESTON, L.; HANDY, S. Mental Maps. In: HENSHER, D. A.; BUTTON, K. J.; HAYNES, K. J.; STOPHER, P. R. (Ed.). Handbook of Transport Geography and Spatial Systems. Bingley: Emerald Group Publishing, 2004. p. 533-545.

WESTPHAL, C.; BLAXTON, T. Data mining solutions: methods and tools for solving realword problems. New York: John Wiley \& Sons, 1998. 617 p.

WETS, G.; VANHOOF, K; ARENTZE, T. A.; TIMMERMANS, H. J. P. Identifying decision structures underlying activity patterns : an exploration of data mining algorithms. Transportation Research Record, n. 1718. p. 1-9, 2000.

WILLIAMS, H. C. W. L. On the formation of travel demand models and economic evaluation measures of user benefit. Environment and Planning A, vol. 9, n. 3, p. 285-344, 1976.

WILSON, A. G. A statistical theory of spatial distribution models. Transportation Research, vol. 1, p. 253-269, 1967.

XIE, C.; LU, J.; PARKANY, E. Work travel mode choice modeling using data mining: decision tree and neural networks. In: TRANSPORTATION RESEARCH BOARD ANNUAL MEETING, $82^{\text {nd }}$, 2003, Washington. Proceedings... Washington: Transportation Research Board. DVD-ROM.

YAMAMOTO, T.; KITAMURA, R.; FUJII, J. Driver's route choice behavior: analysis by data mining algorithms, Transportation Research Record, n. 1807, p. 59-66, 2002. 